\title{
Investigating diversity, evolution, development and physiology of red algal parasites from New Zealand
}

\author{
BY \\ MAREN PREUSS

\begin{abstract}
A thesis
submitted to Victoria University of Wellington

in fulfilment of the requirements for the degree of

Doctor of Philosophy
\end{abstract}

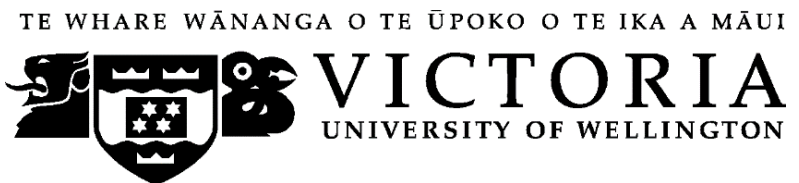

Victoria University of Wellington

Te Whare Wānanga o te Ūpoko o te Ika a Māui (2018) 
This thesis was conducted under the supervision of

Associate Professor Joe Zuccarello (Primary Supervisor)

Victoria University of Wellington,

Wellington, New Zealand

and

Professor Wendy Nelson (Secondary Supervisor)

National Institute of Atmospheric Research,

Wellington, New Zealand

and

University of Auckland,

Auckland, New Zealand 


\section{Abstract}

Red algal parasites have evolved independently over a 100 times and grow only on other red algal hosts. Most parasites are closely related to their host based on the similarity of their reproductive structures. Secondary pit connections between red algal parasites and their hosts are used to transfer parasite organelles and nuclei into host cells. Morphological and physiological changes in infected host cells have been observed in some species. Parasite mitochondrial genomes are similar in size and gene content to free-living red algae whereas parasite plastids are highly reduced. Overall, red algal parasites are poorly studied and thus the aim of this study was to increase the general knowledge of parasitic taxa with respect to their diversity, evolutionary origin, development, physiology, and organelle evolution. Investigation of the primary literature showed that most species descriptions of red algal parasites were poor and did not meet the criteria for defining a parasitic relationship. This literature study also revealed a lack of knowledge of many key parasitic processes including early parasite development, host cell "control", and parasite origin. Many of these poorly studied research areas were addressed in this thesis. Phylogenetic analyses, using a range of markers from all three genomes (cpDNA: $r b c \mathrm{~L}$, nDNA: actin, LSU rRNA; mtDNA: cox1), showed different patterns of phylogenetic relationships for the four new red algal parasites and their hosts. The parasites Phycodrys novae-zelandiophila sp. nov. and Vertebrata aterrimophila sp. nov. closest relative is its host species. Cladhymenia oblongifoliophila sp. nov. closest relative is its host species based on nuclear and mitochondrial markers whereas the plastid markers group the parasite with Cladhymenia lyallii, suggesting that the parasite plastid was acquired when previously parasitizing C. lyallii. Judithia parasitica sp. nov. grows on two Blastophyllis species but the parasites' closest relative is the non-host species Judithia delicatissima. Developmental studies of the parasite Vertebrata aterrimophila, showed a unique developmental structure (“trunk-like" cell) not known in other parasites, plus localised infection 
and few changes in infected host cells. High-throughput-sequencing revealed mitochondrial genomes of similar size, gene content and order in the parasite Pterocladiophila hemisphaerica to its host Pterocladia lucida, and a reduced non-photosynthetic plastid in the parasite. Mitochondrial (mt) and plastid (cp) genome phylogenies placed Pterocladiophila hemisphaerica on long branches, either as sister to Ceramiales (mt) or Gracilariales (cp). Further analyses, filtering non-elevated plastid genes grouped the parasite neither with the Gracilariales (mt) or Gelidiales (cp) on shorter branches but without support. Nuclear phylogeny grouped $P$. hemisphaerica as sister to the Gelidiales and other red algal orders and was the only phylogenetic relationship with support. Investigations of photosystem II capacity using PAM fluorometry, and quantifying chlorophyll $a$ content in three pigmented parasites, showed different host nutrient dependencies. Rhodophyllis parasitica and Vertebrata aterrimophila are not able to photosynthesize and are fully dependent on host nutrients. Pterocladiophila hemisphaerica is able to photosynthesize independently, even though it has a reduced non-photosynthetic plastid genome, and therefore is only partially dependent on its host. This study advances our current understanding of red algal parasites and highlights many possibilities for future research including genome evolution and understanding parasite diversity. 


\section{Acknowledgements}

This PhD thesis would not have been possible without the endless support of my supervisor Joe Zuccarello. I will forever be grateful for the opportunity to do my $\mathrm{PhD}$ in your lab. Thanks for taking the time to read my chapters/manuscripts, listening to my presentations and going on fieldtrips and conferences with me etc. Thanks Joe! You have been an amazing supervisor!

Another major thanks to my partner Sven Sondhauss. Thanks for all your emotional and financial support. Thanks for always taking care of me when I was sick. I would have never been able to do my $\mathrm{PhD}$ without you. Thank you so much for everything. You are the best and I love you!

I would also like to thank my secondary supervisor Wendy Nelson for agreeing to supervise my thesis and for always taking the time to support my research, read drafts and go collecting with me. Further thanks go to all the Phycologists in Wellington for all the social gatherings and meetings. It has been a great help and inspiration seeing other scientists balance science and free time.

Thanks so much to my family and friends around the world who have supported me constantly during my PhD thesis. Firstly, I would like to thank the hardworking people in KK416 (past and present "now TTR"). Especially, Cong, Kim and Pop! Another thanks to Andrea, Balam, Catherine and Shalen. There have been so many great moments and sometimes tough times during the last three and a half years and I am happy that you could take this journey with me. Thanks to Anna Millek for all the skype talks and messages. Thanks to my godchild Hinemoana, you enriched my life and it is a blessing seeing you grow up. Ein grosser Dank auch an Gerlinde + Eckard Knaup und Frauke + Stefan Sondhauss. I love you heaps guys!

Chapter 2: I thank E. K. Ganesan, Yuki Masuda, Narongrit Muangmai, Reinhard Schnetter, Marc Verlaque, and Michael Wynne for publications. I thank two anonymous reviewers and Matt Dring for helpful comments on the manuscript.

Chapter 3: This research was supported by a student grant from the Wellington Botanical Society and the Hansjörg Eichler Research Fund from the Australasian Systematic Botany Society. I thank Wendy Nelson for samples and support, Roberta D'Archino (NIWA, Wellington, NZ) for samples and training for hand sectioning and Caoimhghin Ó Maolagáin 
(NIWA, Wellington, NZ) for technical support and the Te Papa museum for access to their herbarium.

Chapter 4: Thanks to Wendy Nelson and Roberta D'Archino for access to their microscope facility, Te Papa for access to their herbarium and Andrea Glockner-Fagetti for collection support.

Chapter 5: I thank Dan Crossett and Andrea Glockner-Fagetti for diving support. I also thank Chiela Cremen and Chris Jackson for technical support.

Chapter 6: Thanks to Ken Ryan for comments on the manuscript and technical support for the experiments. I thank Dan Crossett and Andrea Glockner-Fagetti for scuba diving support and Lisa Woods for statistical consulting.

Awards: Thanks to the Australasian Society of Phycology and Aquatic Botany (ASPAB) for selecting my presentation at the ASPAB conference in Hobart, Australia (2015) as the best Macrophyte talk. I thank Victoria University of Wellington for awarding me $3^{\text {rd }}$ place in the SBS Best Student Publication Awards in 2017 for "Red algal parasites: a synopsis of described species, their hosts, distinguishing characters and areas for continued research" (Chapter 2).

Conference funding: I would like to also thank the International Phycological Society (IPC) for the P.C. Silva grant and the Australian Society for Phycology and Aquatic Botany (ASPAB) for supporting my attendance at the ASPAB conferences in Hobart (2015) and Warrambool (2016). Another thanks goes to Victoria University of Wellington for the Faculty Strategic Research Grant partial covering my travel costs to the International Phycological Congress in Szczecin, Poland (2017).

Laboratory visit: Many thanks to Heroen Verbruggen and his lab for welcoming me warmly during a short laboratory visit in Melbourne and sharing their genomic knowledge with me.

General help: Thanks to numerous people, who supported my research as dive and fieldtrip buddies as well as emergency and shore contacts. Thanks to Chris Thorn for always lending a helpful hand.

General funding: I thank Victoria University of Wellington for the Victoria Doctoral Fees Scholarship, Victoria Hardship Fund Equity Grants and Victoria Doctoral Submission Scholarship.

Examiners: I would like to thank my $\mathrm{PhD}$ examiners for reading my $\mathrm{PhD}$ thesis and all the helpful comments. 


\section{Thesis declaration}

I hereby declare that this thesis is my own work and that all sources quoted, paraphrased or otherwise referred to, have been acknowledged in the references at the end of this document. To the best of my knowledge, this thesis neither contains material previously published or written by another person, nor material which to a substantial extent has been accepted for the award of any other degree or diploma of the university or other institutes of higher learning, except where due to the acknowledgement is has been made clear in the text. 
Table of Contents

Abstract

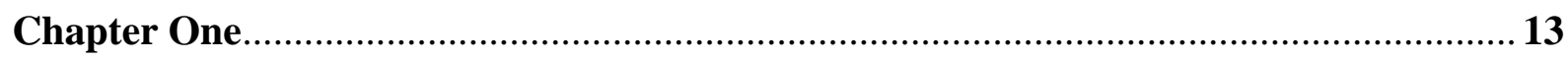

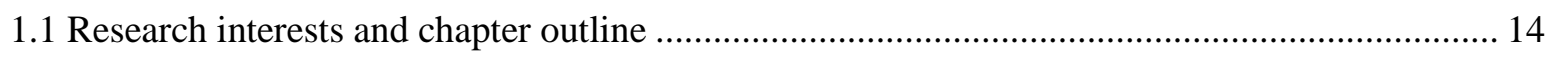

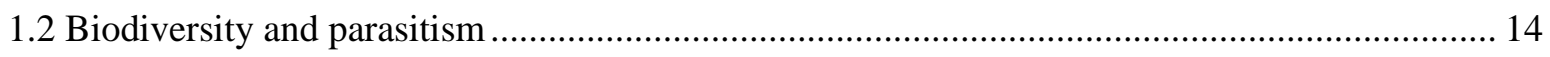

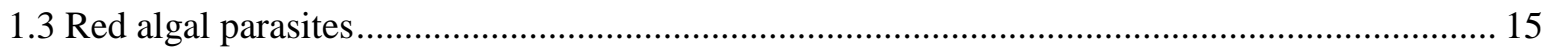

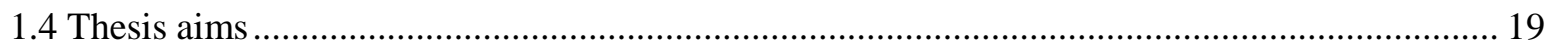

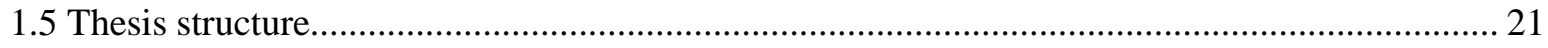

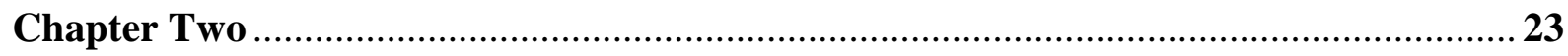

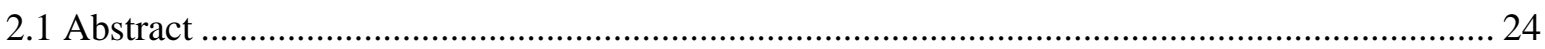

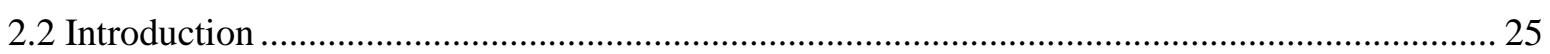

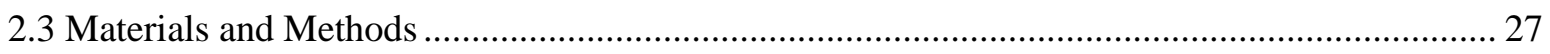

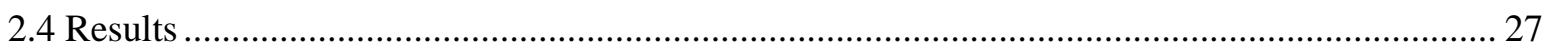

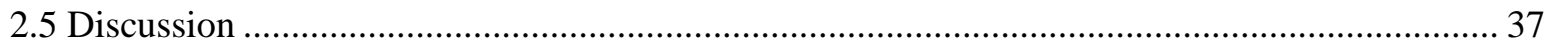

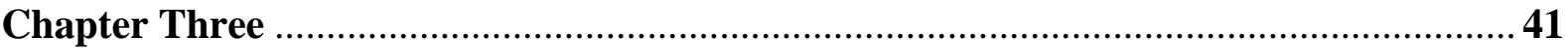

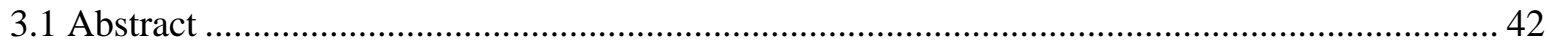

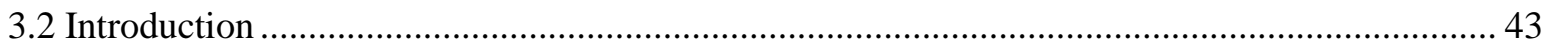

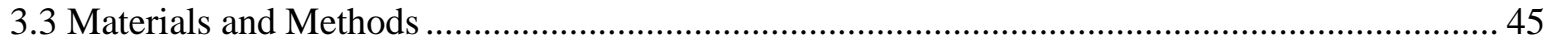

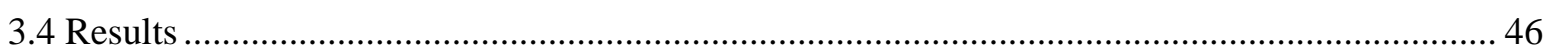

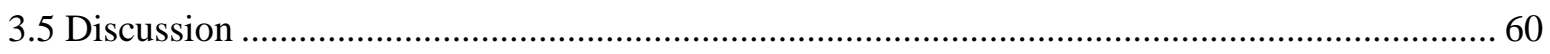

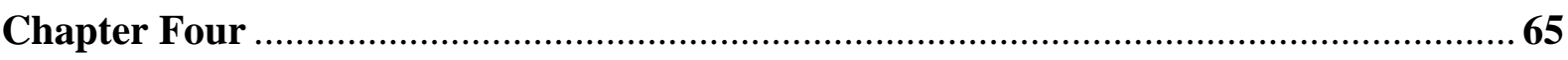

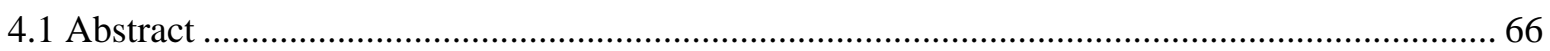

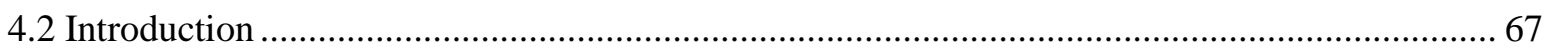

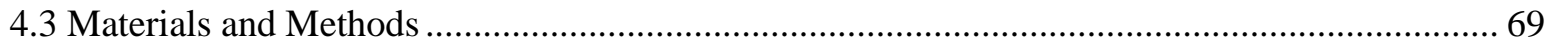

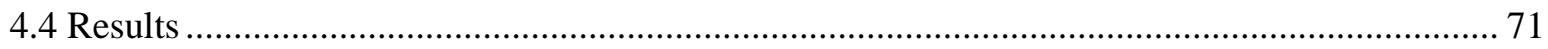

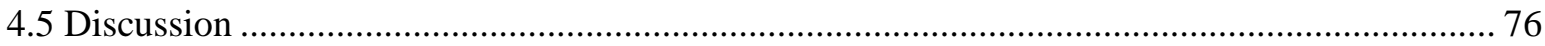


Chapter Five

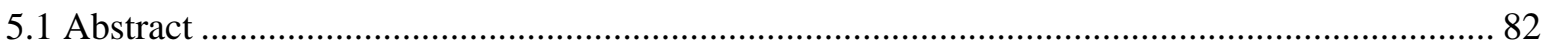

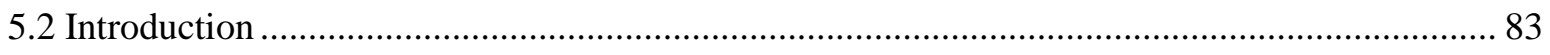

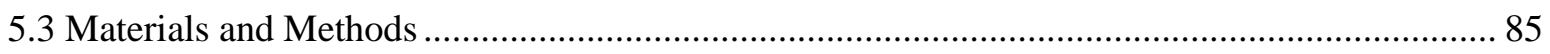

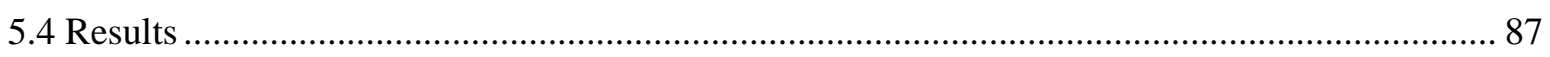

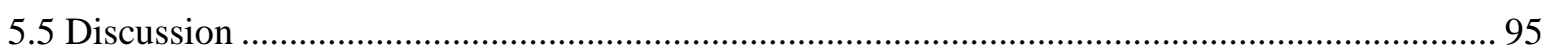

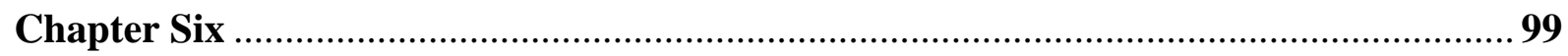

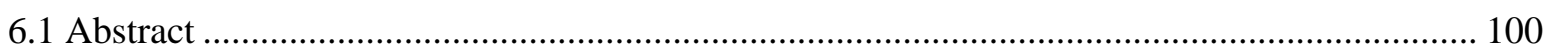

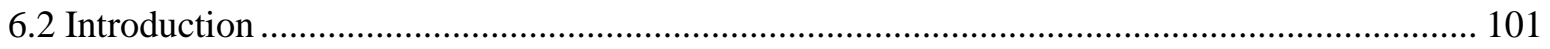

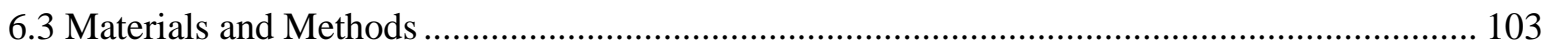

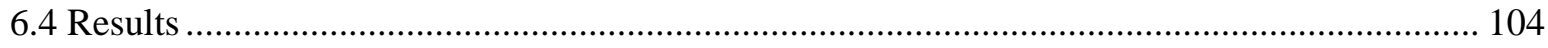

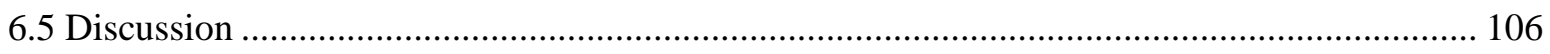

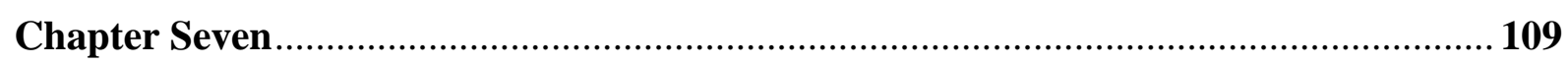

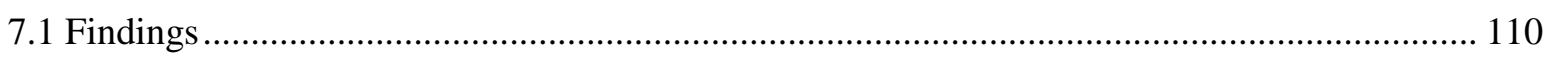

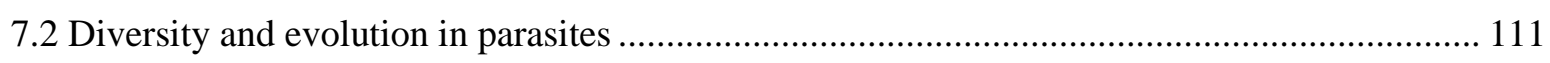

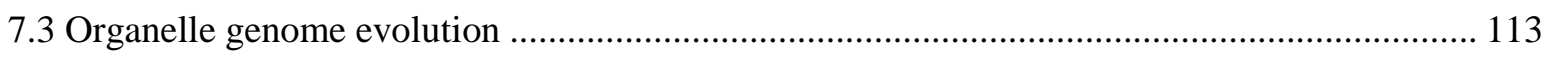

7.4 Is there enough evidence to label red algal parasites as parasites? ............................................ 114

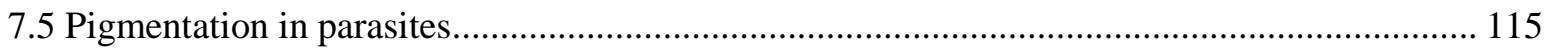

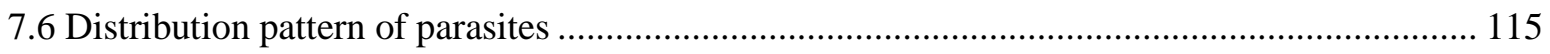

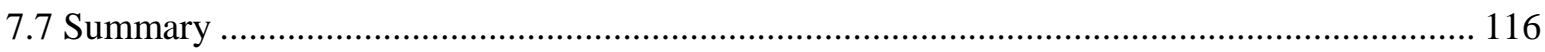

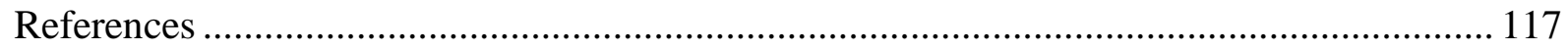

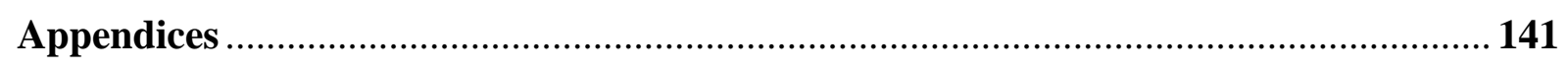

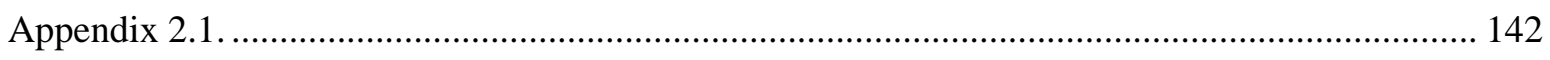

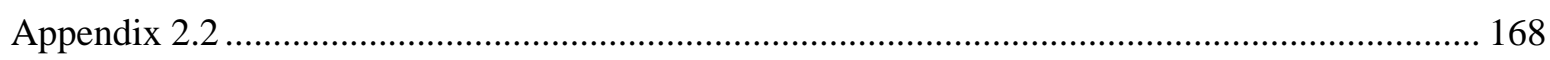

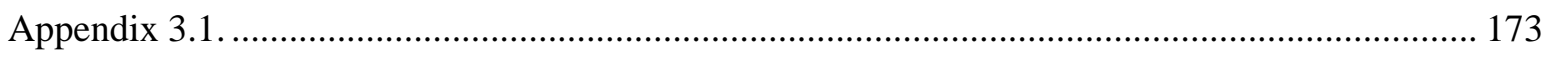

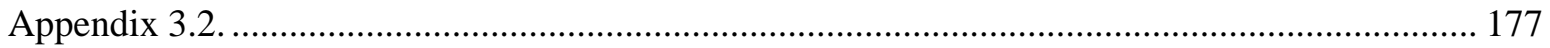

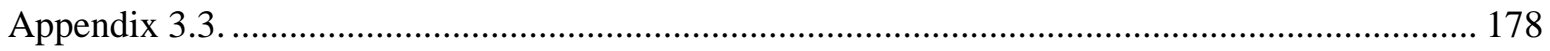

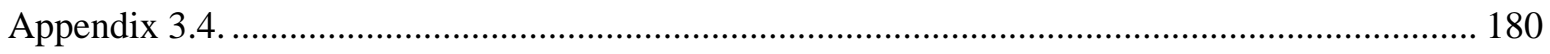

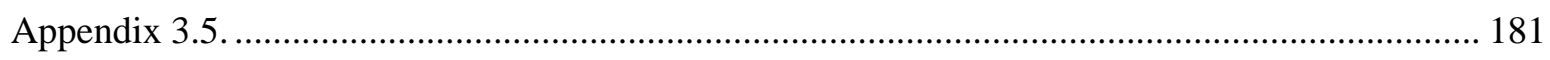

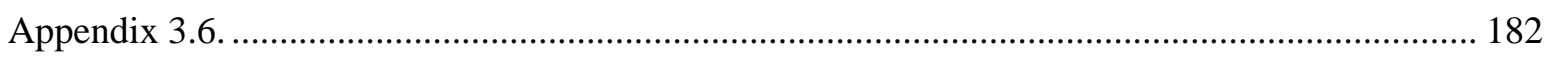

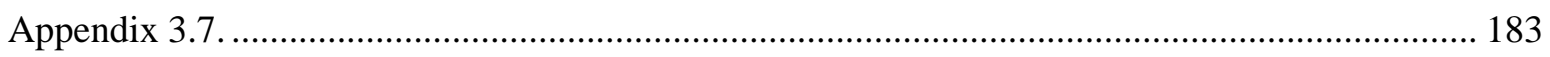

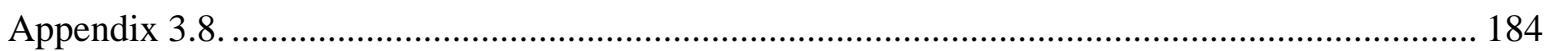

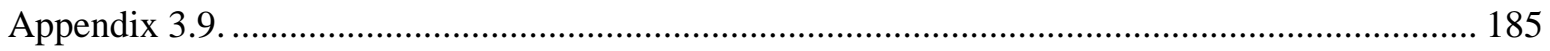

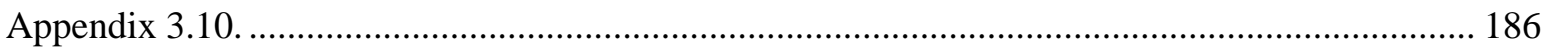

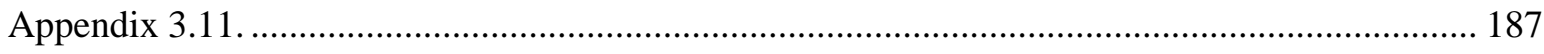




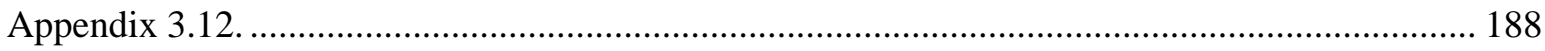

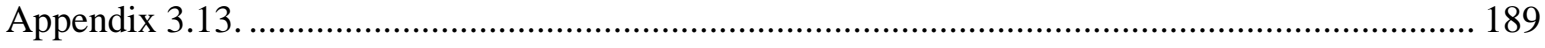

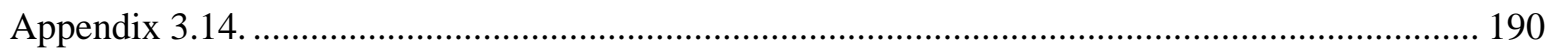

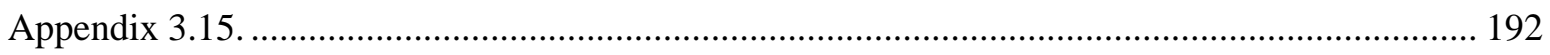

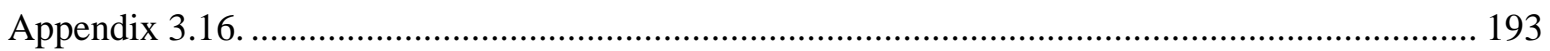

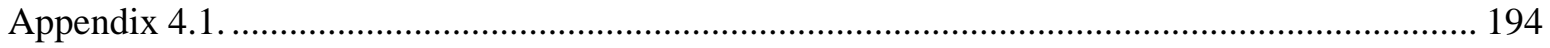

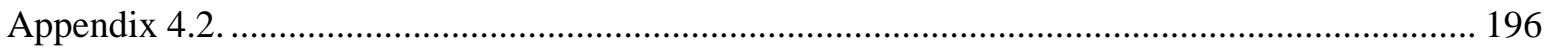

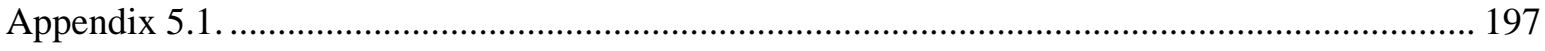

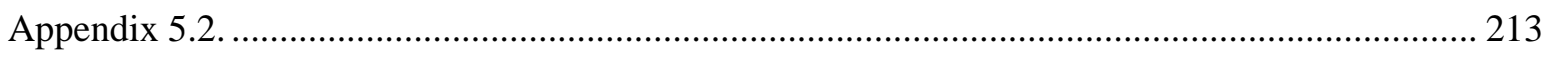

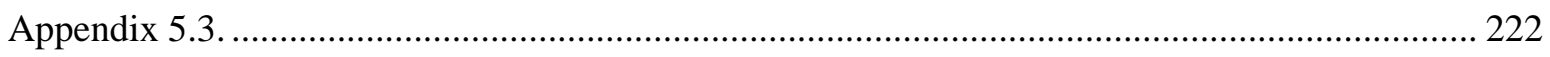

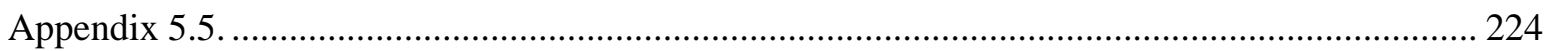

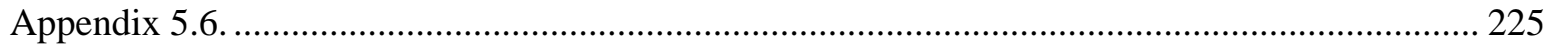

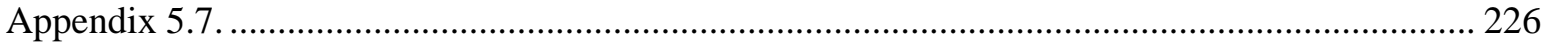

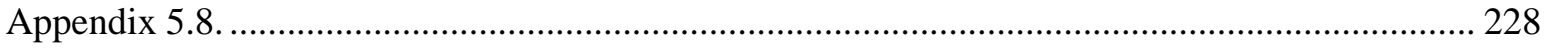

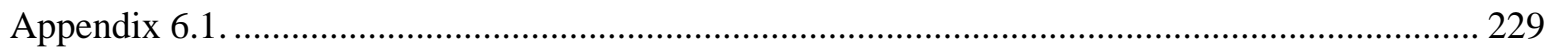


Chapter One

General Introduction 


\subsection{Research interests and chapter outline}

Parasitism is the most successful lifestyle on earth but our understanding of many key processes are still poorly understood or based on only a few selected taxa. The aim of this $\mathrm{PhD}$ thesis is to increase our general knowledge of parasitic taxa in regards to their diversity, evolutionary origin, development, physiology, and organelle evolution.

This general introduction chapter is divided into two parts: biodiversity and parasitism, and red algal parasites. The first part is an introduction to biodiversity and parasitism by defining diversity and symbiotic relationships and highlighting evolutionary trends. The second part provides a brief summary about parasitic red algae. This section is rather short as the second chapter is a literature review on all described red algal parasites and covers this topic more extensively.

\subsection{Biodiversity and parasitism}

Biodiversity describes the entirety of diversity at all biotic levels, from genetic variation to ecosystem function (Purvis \& Hector 2000), and species are central to most measures of diversity. The complexity of species definitions challenges our ability to determine how many species are present (Agapow et al. 2004). There are many different species concepts; species may be defined by their sexual incompatibility (biological species concept), difference in niches (ecological species concept), and/or levels of genetic distinctness (phylogenetic species concept) (Hausdorf 2011). In algae, the morphological species concept is either the most dominant, or is used in combination with the phylogenetic species concept (Guiry 2012). It is important to understand biodiversity to fully appreciate important biological questions such as speciation, ecosystem function, interaction of species (competition, symbiosis, predator-prey), ecological importance (productivity, food webs) and economic importance for humans. 
Symbiosis can lead to diversification of species and was first described as an intimate living together of dissimilar organisms (de Bary 1879) and can be further classified into: 1) commensalism: one organism benefits from the interaction and the other organism neither benefits nor gets harmed, 2) mutualism: both organisms benefit, and 3) parasitism: one organism benefits while harming the other organism (de Bary 1879). Symbiotic relationships can change over time (Neuhauser \& Fargione 2004) or cannot be strictly determined as one of these three symbiotic relationships (Roossinck 2011). Nevertheless, parasitism is the most common lifestyle of organisms (Dobson et al. 2008) and has evolved independently over 223 times in animals (Weinstein \& Kuris 2006). Parasitic species can be found in all eukaryotes, such as apicomplexans (Leander 2005), fungi (Quandt et al. 2015), oomycetes (Li et al. 2010), plants (Westwood et al. 2010) and red algae (Goff 1982). Parasites can influence the ecology, behaviour and evolution of free-living organisms (Poulin 1995; Hudson et al. 1998) and biodiversity (Karvonen \& Seehausen 2012).

Parasites can share similar evolutionary trends with other parasites. Many parasites share phenotypic changes, i.e. reduced morphology (Keeling \& Fast 2002) and complex sensory structures (Poulin 2011). Another common trend concerns changes in functions, for example reduction or loss of metabolic pathways (Revill et al. 2005; Müller et al. 2012) and genomic changes (reduction and compaction of genomes, Keeling 2004; Slamovits et al. 2004; Keeling et al. 2010). The interpretation of these evolutionary trends should be treated with caution because there are always exceptions and many parasitic taxa have yet to be studied.

\subsection{Red algal parasites}

Red algal parasites only grow on other red algae and have evolved over 100 times (Goff 1982; Salomaki \& Lane 2014). Currently used characters to describe these parasites are: 1) reduction in size; 2) reduction in pigmentation; 3) presence of both gametophytes and sporophytes on the host, and 4) connection between parasite and host cell (via formation of secondary pit connections) (Wynne \& Scott 1989). Most of those characters have been used to clarify the nature of structures such as galls and exclude misidentifications (i.e., epiphytes). The formation of secondary pit connections between parasite and host is the most important character for distinguishing these organisms as parasites (Goff \& Coleman 1985). 
Red algal parasites were initially grouped into "adelphoparasites" or "alloparasites" (Feldmann \& Feldmann 1951). Eighty percent of red algal parasites were defined to be "adelphoparasites" or taxonomically closely related to their hosts, and parasites with a distant relationship to their hosts were described as "alloparasites" (Goff 1982). These two terms are still commonly used (Vérges et al. 2005; Kim \& Cho 2010; Salomaki et al. 2015) but they are quite controversial because there seems to be a continuum between closely to distantly related parasite-host combinations (Zuccarello et al. 2004; Preuss \& Zuccarello 2014).

Phylogenetic analyses are an essential tool to address questions about parasite origins, host switching and phylogenetic relationships. The patterns of host-parasite relationships can be quite complex. Some red algal parasites appear to have evolved from and continue to infect the same host species (e.g., Gardneriella tuberifera Kylin). Other parasites evolved from and infect one host but have also switched to a secondary host (e.g., Faucheocolax attenuata Setch.). While yet other parasites evolved on one host species, switched to a secondary closely related host and are not found on the original host (e.g., Plocamiocolax pulvinata Setch.) (Goff et al. 1996). The evolutionary relationships of red algal parasites to their hosts can range from closely related to distantly related but phylogenetic data are still quite limited on red algal parasites and further intensive studies are needed to address questions on their evolution pattern and complex organelle history.

Red algal parasites have unusual organelle relationships to their hosts. The mitochondria and nuclei of host and parasite can be either quite similar (Preuss \& Zuccarello 2014) or quite different (Goff \& Coleman 1995). Similar gene sequences would lead to the assumption that the parasite evolved from its host recently, whereas different gene sequences would indicate that the parasite retained its own mitochondria and nuclei and either evolved long ago or evolved from distantly related species and then switched to its secondary and current host. The plastid, on the other hand, is usually identical in most host and parasite combinations and this pattern suggests that the parasite has acquired and retained the plastid of its host (Goff \& Coleman 1995). There are exceptions where a parasite has its own plastid genome (Salomaki et al. 2015). Phylogenetic studies using genes from all three genomes ( $\operatorname{cox} 1$, ITS $r b c \mathrm{~L})$ compared parasites, Gracilaria babae (H.Yamam.) P.K.Ng, P.E.Lim et Phang, growing on host species in different genera (Gracilaria and Hydropuntia). All parasites genes were almost identical to the host Gracilaria salicornia (C.Agardh) E.Y.Dawson, even when growing on Hydropuntia (Ng et al. 2014). This close relationship between the parasite and G. salicornia 
would indicate that the parasite evolved from a recent common ancestor of G. salicornia and did not capture the host plastid when growing on a Hydropuntia species.

Red algal parasites have a unique development. Usually germinating parasite spores produce an infection peg (Goff \& Coleman 1984) which fuses either by connecting directly with an epidermal host cell after penetrating the host cuticle or first growing between host cells separately and then connecting to subepidermal host cells (Goff \& Zuccarello 1994; Zuccarello $\&$ West 1994a). The fusion of parasite and host cells establishes a structural linkage, called a secondary pit connection (Goff \& Coleman 1985) and this is an essential connection for early parasite development (Zuccarello et al. 2004) and organelle transfer, i.e. nuclei, to the host cell (Goff \& Coleman 1995).

This organelle transfer is another unique process in red algal parasites and can give the parasite control over the host cell (host cell 'transformation') (Goff \& Coleman 1987). Transformed host cells undergo unusual developmental processes (Goff \& Coleman 1995). Only a few developmental studies have been conducted on red algal parasites (e.g., Nonomura 1979; Goff \& Coleman 1987; Zuccarello \& West 1994a) and further research is needed to understand different infection mechanisms and investigate differences in parasite infection and host cell transformation.

The understanding of parasite genome evolution improved with the use of Next-Generation Sequencing. Assembled whole genome data can be used to study genome size: if there is reduction (Jackson 2015) and compaction (Corradi et al. 2007); genetic changes, for example gene loss (Keeling \& Slamovits 2005) and gene order (Corradi et al. 2007) and functional changes, such as loss of photosynthesis genes (Wicke et al. 2013). Red algal parasites are good model organisms to study parasite evolution as they have a close relationship to their hosts and have evolved independently multiple times. The genomic comparison of parasites with their closest relatives could unravel the changes an organism has to undergo to become parasitic (Hancock et al. 2010). Investigations of more examples of parasitic taxa are needed to explore these questions. 
Genomic data of red algal parasites are limited to two mitochondrial genomes (Hancock et al. 2010) and one plastid genome (Salomaki et al. 2015). The mitochondrial genome of the red algal parasites Gracilariophila oryzoides Setch. et H.L.Wilson is reduced (mainly due to one deletion of a large intergenic spacer) but is not smaller in comparison with other red algal species (Hancock et al. 2010). The plastid genome of the parasite Choreocolax polysiphoniae Reinsch has lost photosynthesis genes (Salomaki et al. 2015).

Pigmentation in plants is associated with photosynthesis and whether or not red algal parasites can independently photosynthesize is a result of complex interactions between organelles and their genes/protein products. Both nuclear- and plastid-encoded genes are used for photosynthesis (Race 1999), and to function, signalling pathways between organelles and photosynthetic gene expression have to operate correctly (Queval \& Foyer 2012). Loss of photosynthesis is often associated with loss of photosynthetic genes in plastid genomes (Suzuki et al. 2018). This loss of functionality can be explained by conflict between different genomes (for example, between nuclear and mitochondrial genomes) (Werren 2011) and is also known as intra-individual conflict. Further studies are needed to reveal if intra-individual/cell genome conflict occurs in red algal parasites.

The level of host dependency of red algal parasites is mostly unknown. The range of pigmentation in red algal parasites varies from unpigmented (Zuccarello \& West 1994a; Salomaki et al. 2015) to pigmented (Maggs \& Hommersand 1993; Wynne 2013; Preuss \& Zuccarello 2014). Some parasites show variation in pigmentation depending on their host species (Goff et al. 1997) and other parasites undergo a juvenile non-pigmented stage followed by a mature pigmented stage (Nonomura \& West 1981). In at least a few examples, parasites have been shown to receive photosynthetic products from their host (Evan et al. 1973; Goff 1979; Kremer 1983) but without further studies of pigmented parasites, questions about their level of host dependency remain. 


\subsection{Thesis aims}

The aims of my PhD research were to increase our general knowledge of red algal parasites in regard to their diversity, evolutionary origin, development, physiology, and organelle evolution. Specific research questions were separately addressed in each research chapter.

i. Red algal parasites: a synopsis of described species, their hosts, distinguishing characters and areas for continued research (Chapter 2). The following questions were addressed:

- What is the current understanding of the diversity of red algal parasites?

- Do existing descriptions meet the criteria for defining these organisms as parasites?

ii. Three new red algal parasites from New Zealand: Cladhymenia oblongifoliophila sp. nov. (Rhodomelaceae), Phycodrys novae-zelandiophila sp. nov. (Delesseriaceae) and Judithia parasitica sp. nov. (Kallymeniaceae) (Chapter 3)

- What are morphological feature of the parasite?

- What is the phylogenetic relationship of the parasite to its host?

- In which genus should the parasite be placed?

iii. Development of the red algal parasite Vertebrata aterrimophila sp. nov. (Rhodomelaceae, Ceramiales) from New Zealand (Chapter 4)

- How does the development in the parasite Vertebrata aterrimophila compare with other known red algal parasites?

- What impacts does the parasite have on infected host cells?

- What is the phylogenetic relationship of the parasite Vertebrata aterrimophila to its host? 
iv. High mutation rates in a non-photosynthetic plastid hides phylogenetic relationships in the red algal parasite Pterocladiophila hemisphaerica (Gelidiales) (Chapter 5)

- Does Pterocladiophila hemisphaerica have a highly reduced plastid genome?

- What is the phylogenetic relationship of Pterocladiophila hemisphaerica and its hosts Pterocladia lucida?

- Is the current taxonomic position of Pterocladiophila hemisphaerica in the order Gracilariales correct?

v. Comparative studies of photosynthetic capacity in three pigmented red algal parasites using PAM fluorometry and chlorophyll $a$ concentration (Chapter 6)

- Can pigmented parasites photosynthesize independently? 


\subsection{Thesis structure}

This $\mathrm{PhD}$ thesis was written in five individual research chapters (2-6), some of which are published or submitted to peer review journals. All published chapters are similar to the publications, and there is some repetition between chapters. All references and all supplementary materials were combined in a single reference list and appendices at the end of this thesis.

Chapter 2 has been published: Preuss, M., Nelson, W. A. \& Zuccarello G.C. 2017. Red algal parasites: a synopsis of described species, their hosts, distinguishing characters and areas for continued research. Botanica Marina. 60:13-25.

Author contributions: I conceived the idea, collect the literature, analyzed the data, wrote the manuscript and submitted it for publication. W. A. Nelson provided some literature and commented on the manuscript. G.C. Zuccarello helped with revisions on the manuscript and strengthening of the main arguments.

Chapter 3 has been published: Preuss, M. \& Zuccarello G.C. 2018. Three new red algal parasites from New Zealand: Cladhymenia oblongifoliaphila sp. nov. (Rhodomelaceae), Phycodrys novae-zelandiaephila sp. nov. (Delesseriaceae) and Judithia parasitica sp. nov. (Kallymeniaceae). Phycologia. 57:9-19.

Author contributions: I collected the samples, analyzed the data and wrote the manuscript. G.C. Zuccarello helped collect some of the samples and helped to improve the manuscript significantly with his comments.

Chapter 4 has been accepted to the European Journal of Phycology: Preuss, M. \& Zuccarello G.C. Development of the red algal parasites Vertebrata aterrimophila sp. nov (Rhodomelaceae, Ceramiales) from New Zealand.

Author contributions: I collected the samples, collected and analyzed the data and wrote the manuscript. G.C. Zuccarello helped to define the research ideas and improved the manuscript with critical comments. 
Chapter 5 is in preparation to be submitted: Preuss, M., Verbruggen, H. \& Zuccarello G.C. High mutation rates in a non-photosynthetic plastid hides phylogenetic relationships in the red algal parasite Pterocladiophila hemisphaerica.

Author contributions: I collected the samples and analyzed the majority of the data and wrote the manuscript. H. Verbruggen analyzed the plastid data sets and improved the manuscript with helpful comments. G.C. Zuccarello helped significantly to improve the manuscript and clarify the research ideas.

Chapter 6 has been accepted to Phycological Research: Preuss, M. \& Zuccarello G.C. Comparative studies of photosynthetic capacity in three pigmented red algal parasites using chlorophyll $a$ concentrations and PAM fluorometry.

Author contributions: I collected the samples, designed the experiments, analyzed the data and wrote the manuscript. G.C. Zuccarello helped to define the research ideas and made many useful suggestions to improve the manuscript. 


\section{Chapter Two}

Red algal parasites: a synopsis of described species, their hosts, distinguishing characters and areas for continued research 


\subsection{Abstract}

Red algal parasites are diverse organisms that are unusual due to the fact that many are closely related to their hosts. Parasitism has developed many times within different red algal groups, but the full extent of parasite biodiversity is unknown, as parasites are easily overlooked due to their small size and often low abundance. Additionally, the literature on red algal parasites is dispersed and has not been compiled in over 30 years. Although criteria have been proposed to define what constitutes a red algal parasite, many parasites are poorly described, and the cellular interactions with their host are poorly known. A few studies have demonstrated that parasites transfer organelles to host cells, which can alter the physiology of the host to the benefit of the parasite. Here, we apply a set of defining criteria for parasites to a compiled list of all described red algal parasites. Our results highlight the lack of knowledge of many key parasitic processes including early parasite development, host cell "control”, and parasite origin. Until the biology of more parasites is studied, generalisations on the processes of parasitism in red algae may be premature. We hope this synopsis will stimulate research into this fascinating group.

Key words: Biodiversity, Development, Host switching, Parasitism, Taxonomy 


\subsection{Introduction}

Parasitism is defined as a relationship that is beneficial for the parasite but harms the host and is a common lifestyle in organisms. Approximately $40 \%$ of all known species across all phyla are parasitic and the actual number of parasites is thought to be higher than the number of freeliving organisms (Dobson et al. 2008). The parasitic lifestyle occurs in a wide range of organisms such as fish (Le Roux \& Avenant-Oldewage 2010), flatworms (Cribb et al. 2002), fungi (Quandt et al. 2015), plants (Westwood et al. 2010), 'protozoa' (Keeling \& Rayner 2015) and algae (Blouin \& Lane 2012; 2016). The importance parasites have for the ecology, behaviour and evolution of free-living organisms (e.g., Poulin 1995; Hudson et al. 1998) and biodiversity (e.g., Karvonen \& Seehausen 2012) are well documented.

Red algal parasites are common on other red algae (Goff 1982) and are known from eight orders: Ceramiales, Corallinales, Gigartinales, Gracilariales, Halymeniales, Palmariales, Plocamiales, Rhodymeniales (Salomaki \& Lane 2014; Blouin \& Lane 2016). The majority of red algal parasites are taxonomically closely related to their hosts (designated as 'adelphoparasites'), while a lesser number are more distantly related to their hosts (designated 'alloparasites'; Goff 1982). While this dichotomy has been used in the past, there appears to be a continuum from closely related to more distantly related parasite-host combinations (Zuccarello et al. 2004, Blouin \& Lane 2012). However, only a few red algal parasites have been investigated phylogenetically.

Red algal parasites are unique in that they transfer organelles (e.g., nuclei, mitochondria, plastids) into host cells, via host-parasite cell fusion by secondary pit connection formation (Goff \& Coleman 1985; Salomaki et al. 2015) and thereby 'control' host cells for their benefit. A recent study showed that in one parasite these heterokaryotic cells not only contain the host plastid but also retain their own plastid ("ghost plastid") (Salomaki et al. 2015). The process of parasite-host cell fusion is unique to red algal parasite-host interactions, and has led to speculation as to their origin and how complete the 'control' is (Blouin \& Lane 2012). The outcome of parasite organelles being transferred to host cells and the details of parasite development have been studied in very few parasites. However, the establishment of secondary pit connections appears to be essential for parasite development, and host resistance can occur as a response to incompatibility in parasite-host cell fusion (Zuccarello \& West 1994a; b; c). 
The descriptions of red algal parasites have been problematic for decades, in part because of the size of the parasite thallus and the infrequency with which they have been collected. Some described parasites have later been shown to be misidentifications of small red algal epiphytes, or bacterial infections, or even parts of the host thallus (Table 2.1). Given these problems, Setchell (1918) attempted to develop a set of characters to be used to characterise red algal parasites and to distinguish them from epiphytes and host outgrowths. This set of characters was: 1) penetration beyond the superficial layer of the host; 2) reduction in size of the thallus, and 3) loss of colour. These characters were later reviewed and modified by Wynne \& Scott (1989) to: 1) reduction in size; 2) reduction in pigmentation; 3) formation of secondary pit connections between parasite and host cells, and 4) presence of both gametophytes and sporophytes on the same host stage. Most of these criteria if taken alone would not be sufficient to confirm that a red algal species was a parasite. For example, some parasites are pigmented during certain stages of their life cycle (Nonomura 1979; Goff \& Coleman 1995).

Much of the current knowledge of red algal parasite species diversity is based on old lists and general statements. Setchell (1918) created the first list of described red algal parasites, and further lists followed (Evans et al. 1978; Goff 1982), while subsequent reviews have focused on general knowledge of red algal parasite biology (Blouin \& Lane 2012; 2016; Salomaki \& Lane 2014). The percentage of parasitic red algal genera has been estimated at $15 \%$ of all red algal genera by Goff (1982) or $8 \%$ of all florideophyte genera by Blouin \& Lane (2012). The estimated number of red algal parasite species has more than doubled since Setchell's (1918) initial list of about 50 species to over a 100 species (Goff 1982; Salomaki \& Lane 2014), 116 species (Blouin \& Lane 2012) or 121 species (Blouin \& Lane 2016).

The aim of this study was to create a comprehensive list of red algal parasite species, with associated primary literature, as such a list has not been produced for over 30 years. This paper 1) summarises the current understanding of the diversity of red algal parasites, and, 2) provides an analysis of whether existing descriptions meet the criteria for defining parasites. This synopsis highlights the lack of documentation available for many parasite species, as well as the scarcity of data about many key parasite characters and processes (i.e. host cell 'control', parasite origin), which may alter our notions of parasite biology, and suggest areas for future targeted research. 


\subsection{Materials and Methods}

This list of red algal parasite species was created by examining recent literature and classifications, reviewing red algal classification for parasitic genera and consulting AlgaeBase (Schneider \& Wynne 2007; Wynne \& Schneider 2010; Schneider \& Wynne 2013; Guiry \& Guiry 2016). Over 200 papers in ten different languages were located, and the species were categorised, and tabulating criteria (i.e. level of pigmentation, reduced thallus, presence of secondary pit connections, penetration of host tissue, and descriptions of all life cycle stages) were used in defining red algal parasites. The number of these criteria that were met was then used to rank (e.g., all criteria met; only one criterion met) whether there are sufficient data on the described organism to meet the definition of a red algal parasite.

\subsection{Results}

Our list contains 120 species and two invalidly described species (Appendix 2.1, Fig. 2.1). Appendix 2.1 combines all available information on red algal parasite species and is organised in systematic order based on the presumed taxonomy of the parasite species. The entries include general information such as host species, year of description, type locality (based on primary literature), and distribution, and whether the criteria used to determine parasitic status (Goff 1982; Wynne \& Scott 1989) were described. Recognized parasites are listed alphabetically in Table 2.2.

Many red algal parasites were described by Setchell $(1914 ; 1923)$ and Pocock $(1953 ; 1956)$. Based on the dates listed in Table 2.2, approximately $15 \%$ of all red algal parasites were described in the $19^{\text {th }}$ century, $80 \%$ in the $20^{\text {th }}$ century and $5 \%$ in the $21^{\text {st }}$ century.

Red algal parasites are found in a number of families within the Florideophyceae. Parasitic genera are often small containing 1-4 species. The Pterocladiophilaceae is the only family containing solely parasitic genera (Gelidiocolax, Holmsella and Pterocladiophila). 


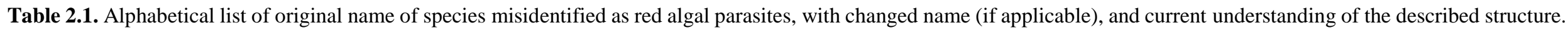

\begin{tabular}{|c|c|c|c|}
\hline Original name of species & Changed name & Current understanding & Reference \\
\hline Actinococcus aggregatus F.Schmitz & Gymnogongrus griffithsiae (Turner) Mart. & Nemathecium & Gregory 1930 \\
\hline Actinococcus chiton M.Howe & $\begin{array}{l}\text { Fredericqia chiton (M.Howe) Maggs, LeGall, } \\
\text { Mineur, Provan et G.W.Saunders }\end{array}$ & Nemathecium & McCandless \& Vollmer 1984 \\
\hline Actinococcus latior F.Schmitz & Gymnogongrus dilatatus (Turner) J.Agardh & Tetrasporangial outgrowth & Silva et al. 1996 \\
\hline Actinococcus peltaeformis F.Schmitz & Gymnogongrus crenulatus (Turner) J.Agardh & Nemathecium & McCandless \& Vollmer 1984 \\
\hline Actinococcus subcutaneus (Lyngb.) Rosenv. & $\begin{array}{l}\text { Coccotylus trunacates (Pall.) M.J.Wynne et } \\
\text { J.N.Heine }\end{array}$ & Carpotetrasporangial outgrowth & Dixon \& Irvine 1995 \\
\hline Callilithophytum parcum (Setch. et Foslie) & - & Epiphyte & Adey et al. 2015 \\
\hline \multicolumn{4}{|l|}{$\begin{array}{l}\text { P.W.Gabrielson, W.H.Adey, G.P.Johnson et } \\
\text { Hernández-Kantún }\end{array}$} \\
\hline Catenellocolax leeuwenii Weber Bosse & - & Fungal infection & Zuccarello 2008 \\
\hline Choreocolax cystoclonii Kylin & - & Bacterial infection & Dixon \& Irvine 1995 \\
\hline Choreocolax delesseriae Reinsch & $\begin{array}{l}\text { Neuroglossum delesseriae (Reinsch) } \\
\text { M.J.Wynne }\end{array}$ & $\begin{array}{l}\text { Early stages in lateral branch } \\
\text { formation }\end{array}$ & Wynne 2013 \\
\hline Colacolepsis decipiens F.Schmitz & Phyllophora herediae (Clem.-Munoz) J.Agardh & Nemathecium & Goff 1982 \\
\hline Colacolepis incrustans F.Schmitz & Phyllophora crispa (W.E.Hudson) P.S.Dixon & Cystocarpic outgrowth & Dixon \& Irvine 1995 \\
\hline Entocolax rhodymeniae Reinsch & - & Fungal infection & Edelstein 1972 \\
\hline Erythrocystis saccata (J.Agardh) P.C.Silva & - & Epiphyte & Melchionna \& De Masi 1977 \\
\hline $\begin{array}{l}\text { Fosliella paschalis (Me.Lemoine) Setch. et } \\
\text { N.L.Gardner }\end{array}$ & - & Epiphyte & Setchell \& Gardner 1930 \\
\hline Lobocolax deformans M.Howe & - & Bacterial infection & $\begin{array}{l}\text { McBride } \text { et al. 1974; Ashen \& } \\
\text { Goff } 1998\end{array}$ \\
\hline
\end{tabular}




\begin{tabular}{|c|c|c|c|}
\hline Loranthophycus californicus (E.Y.Dawson) & Loranthophycus californicus E.Y.Dawson & Tetrasporophytic outgrowth & Dawson 1945; Goff 1982; \\
\hline E.Y.Dawson ${ }^{1}$ & & & Wynne 2013 \\
\hline Neopolyporolithon reclinatum (Foslie) W.H.Adey & - & Epiphyte & Adey et al. 2015 \\
\hline \multicolumn{4}{|l|}{ et G.P.Johansen } \\
\hline Phaeocolax kajimurae Hollenb. & - & Epiphyte & Apt $1984 \mathrm{a}$ \\
\hline Pleurostichidium falkenbergii Heydr. & - & Epiphyte & Phillips 2000 \\
\hline Rhodymeniocolax austrina & Halopeltis austrina (Womersley) G.W.Saunders & Epiphyte & Saunders \& McDonald 2010 \\
\hline Sterrocolax decipiens F.Schmitz & Ahnfeltia plicata (W.E.Hudson) Fr. & Gametangial outgrowth & Dixon \& Irvine 1995 \\
\hline
\end{tabular}

${ }^{1}$ described as an outgrowth on Holmesia californica (Dawson) Dawson 
Approximately $60 \%$ of red algal parasites are known from only one host species, $30 \%$ have been reported on two or three host species, and only 10\% on more than three host species (Fig 2.1). Four genera, Gracilaria (Gracilariaceae), Gelidium (Gelidiaceae), Laurencia and Polysiphonia (Rhodomelaceae), are the most common hosts of red algal parasites (Appendix 2.1). Surprisingly, approximately $54 \%$ of the parasites found on two or more hosts have host species from different genera (Appendix 2.1). For example, Choreocolax polysiphoniae Reinsch has been reported from Cystoclonium purpureum (W.E.Hudson) Batters, Neosiphonia confusa (Hollenb.) J.N.Norris, and Vertebrata lanosa (L.)T.R.Chr.

Table 2.2. Alphabetical list of red algal parasites, year of publication, and family to which they belong. For species authorities, refer to Appendix 2.1.

\begin{tabular}{|c|c|c|c|}
\hline Parasite & Year & Family & Reference \\
\hline Aiolocolax pulchella & 1956 & Rhodomelaceae & [1] \\
\hline Antarctocolax lambii & 1953 & Rhodomelaceae & [2] \\
\hline Apoglossocolax pusilla & 1993 & Delesseriaceae & [3] \\
\hline Asterocolax denticulatus & 1934 & Delesseriaceae & {$[4,5]$} \\
\hline Asterocolax erythroglossi & 1951 & Delesseriaceae & [5] \\
\hline Asterocolax gardneri & 1923 & Delesseriaceae & {$[5,6]$} \\
\hline Asterocolax hypophyllophilus & 1970 & Delesseriaceae & [7] \\
\hline Benzaitenia yenoshimensis & 1913 & Rhodomelaceae & [8] \\
\hline Bostrychiocolax australis & 1994 & Rhodomelaceae & [9] \\
\hline Callocolax acicularis & 1992 & Kallymeniaceae & [10] \\
\hline Callocolax fungiformis & 1925 & Kallymeniaceae & {$[11]$} \\
\hline Callocolax japonica & - & Kallymeniaceae & [12] \\
\hline Callocolax neglectus & 1895 & Kallymeniaceae & {$[13]$} \\
\hline Centrocerocolax ubatubensis & 1965 & Ceramiaceae & {$[14]$} \\
\hline Chamaethamnion pocockiae & 1988 & Rhodomelaceae & {$[15]$} \\
\hline Chamaethamnion schizandra & 1897 & Rhodomelaceae & {$[16]$} \\
\hline Champiocolax lobatus & 1996 & Champiaceae & {$[17]$} \\
\hline Champiocolax sarae & 1985 & Champiaceae & {$[18]$} \\
\hline Choreocolax americanus & 1875 & Rhodomelaceae & {$[19]$} \\
\hline Choreocolax destructor & 1875 & Rhodomelaceae & {$[19]$} \\
\hline Choreocolax polysiphoniae & 1875 & Rhodomelaceae & {$[19]$} \\
\hline Choreocolax rabenhorstii & 1875 & Rhodomelaceae & {$[19]$} \\
\hline Choreocolax rhodymeniae & 1888 & Rhodomelaceae & {$[20]$} \\
\hline Choreocolax tumidus & 1875 & Rhodomelaceae & [19] \\
\hline Choreonema thuretii & 1889 & Hapalidiaceaeae & [21] \\
\hline Coccotylus hartzii & 1898 & Phyllophoraceae & {$[22,23]$} \\
\hline
\end{tabular}




\begin{tabular}{|c|c|c|c|}
\hline Colacodasya australica & 1998 & Dasyaceae & [17] \\
\hline Colacodasya californica & 1970 & Dasyaceae & [24] \\
\hline Colacodasya inconspicua & 1888 & Dasyaceae & {$[8,20]$} \\
\hline Colacopsis lophurellae & 1919 & Rhodomelaceae & [25] \\
\hline Colacopsis pulvinata & 1897 & Rhodomelaceae & [8] \\
\hline Colacopsis smitheniae & 1988 & Rhodomelaceae & {$[15]$} \\
\hline Colacopsis velutina & 1953 & Rhodomelaceae & {$[15,26]$} \\
\hline Dawsoniocolax bostrychiae & 1967 & Rhodomelaceae & [27] \\
\hline Dipterocolax fernandezianus & 1977 & Rhodomelaceae & [28] \\
\hline Episporium centroceratis & 1885 & Ceramiaceae & [21] \\
\hline Epulo multipedes & 2004 & Hapalidiaceaeae & [29] \\
\hline Ezo epiyessoense & 1974 & Corallinaceae & [30] \\
\hline Faucheocolax attenuata & 1923 & Faucheaceae & [6] \\
\hline Gardneriella tuberifera & 1941 & Solieriaceae & [8] \\
\hline Gelidiocolax christianae & 1963 & Pterocladiophilaceae & [31] \\
\hline Gelidiocolax deformans & 1982 & Pterocladiophilaceae & [32] \\
\hline Gelidiocolax desikacharyi & 1970 & Pterocladiophilaceae & [33] \\
\hline Gelidiocolax lyndae & 1988 & Pterocladiophilaceae & {$[15]$} \\
\hline Gelidiocolax mammillatus & 1959 & Pterocladiophilaceae & [34] \\
\hline Gelidiocolax margaritoides & 1953 & Pterocladiophilaceae & {$[34,35]$} \\
\hline Gelidiocolax microsphaericus & 1927 & Pterocladiophilaceae & [8] \\
\hline Gelidiocolax pustulatus & 1984 & Pterocladiophilaceae & [36] \\
\hline Gelidiocolax suhriae & 1953 & Pterocladiophilaceae & {$[34,35]$} \\
\hline Gelidiocolax verruculatus & - & Pterocladiophilaceae & [37] \\
\hline Gloiocolax novae-zelandiae & 1957 & Faucheaceae & [38] \\
\hline Gonimocolax australis & 1919 & Delesseriaceae & {$[8,25]$} \\
\hline Gonimocolax corymbosus & 1941 & Delesseriaceae & [39] \\
\hline Gonimocolax roscoffensis & 1961 & Delesseriaceae & [40] \\
\hline Gonimophyllum africanum & 1953 & Delesseriaceae & [35] \\
\hline Gonimophyllum buffhamii & 1892 & Delesseriaceae & [41] \\
\hline Gonimophyllum insulare & 1954 & Delesseriaceae & {$[42]$} \\
\hline Gonimophyllum skottsbergii & 1923 & Delesseriaceae & [6] \\
\hline Gracilaria babae & 1986 & Gracilariaceae & {$[43,44]$} \\
\hline Gracilariocolax deformans & 1928 & Incertae sedis & {$[45,46]$} \\
\hline Gracilariocolax henriettae & 1928 & Incertae sedis & [45] \\
\hline Gracilariocolax infidelis & 1928 & Incertae sedis & {$[45,46]$} \\
\hline Gracilariocolax setchellii & 1928 & Incertae sedis & {$[45,46]$} \\
\hline $\begin{array}{l}\text { Gracilariocolax setchellii var. } \\
\text { aggregata }\end{array}$ & 1928 & Incertae sedis & {$[45,46]$} \\
\hline Gracilariocolax sibogae & 1928 & Incertae sedis & {$[45,46]$} \\
\hline Gracilariophila oryzoides & 1910 & Gracilariaceae & {$[47]$} \\
\hline
\end{tabular}




\begin{tabular}{|c|c|c|c|}
\hline Gracilariophila gardneri & 1923 & Gracilariaceae & [6] \\
\hline Grateloupiocolax colombiana & 1983 & Halymeniaceae & [48] \\
\hline Harveyella mirabilis & 1875 & Rhodomelaceae & {$[8,19]$} \\
\hline Holmsella pachyderma & 1875 & Pterocladiophilaceae & [49] \\
\hline Holmsella australis & 1983 & Pterocladiophilaceae & {$[50]$} \\
\hline Hypneocolax stellaris & 1920 & Cystocloniaceae & [51] \\
\hline Hypneocolax stellaris f. orientalis & 1928 & Cystocloniaceae & {$[52]$} \\
\hline Janczewskia gardneri & 1914 & Rhodomelaceae & [53] \\
\hline Janczewskia hawaiiana & 1987 & Rhodomelaceae & [54] \\
\hline Janczewskia lappacea & 1914 & Rhodomelaceae & [53] \\
\hline Janczewskia meridionalis & 1953 & Rhodomelaceae & [35] \\
\hline Janczewskia moriformis & 1914 & Rhodomelaceae & [53] \\
\hline Janczewskia morimotoi & 1947 & Rhodomelaceae & [55] \\
\hline Janczewskia ramiformis & 1978 & Rhodomelaceae & {$[56]$} \\
\hline Janczewskia solmsii & 1914 & Rhodomelaceae & [53] \\
\hline Janczewskia tasmanica & 1897 & Rhodomelaceae & [57] \\
\hline Janczewskia teysmannii & 1923 & Rhodomelaceae & [58] \\
\hline Janczewskia verruciformis & 1877 & Rhodomelaceae & [53] \\
\hline Jantinella sinicola & 1924 & Rhodomelaceae & {$[59,60]$} \\
\hline Jantinella verruciformis & 1911 & Rhodomelaceae & {$[61,62]$} \\
\hline Kintokiocolax aggregato-ceranthus & 1960 & Halymeniaceae & [63] \\
\hline Kvaleya epilaeve & 1971 & Hapalidiaceaeae & [64] \\
\hline Laurenciocolax polysporus & 1964 & Rhodomelaceae & [65] \\
\hline Leachiella pacifica & 1982 & Rhodomelaceae & [66] \\
\hline Levringiella gardneri & 1923 & Rhodomelaceae & {$[6,8]$} \\
\hline Levringiella microscopica & 1941 & Rhodomelaceae & {$[8,67]$} \\
\hline Masakiella bossiellae & 2007 & Corallinaceae & {$[68]$} \\
\hline Meridiocolax bracteata & 1983 & Rhodomelaceae & [50] \\
\hline Meridiocolax narcissus & 1976 & Rhodomelaceae & [69] \\
\hline Meridiocolax polysiphoniae & 1973 & Rhodomelaceae & {$[50,70]$} \\
\hline Microcolax africanus & 1953 & Rhodomelaceae & [35] \\
\hline Microcolax botryocarpa & 1845 & Rhodomelaceae & {$[16,71]$} \\
\hline Neohalosacciocolax aleutica & 1978 & Palmariaceae & [72] \\
\hline Neotenophycus ichthyosteus & 2002 & Rhodomelaceae & [73] \\
\hline Onychocolax polysiphoniae & 1956 & Rhodomelaceae & [1] \\
\hline Phitycolax inconspicua & 1989 & Delesseriaceae & [74] \\
\hline Plocamiocolax pulvinata & 1923 & Plocamiaceae & [6] \\
\hline Plocamiocolax papenfussianus & 1953 & Plocamiaceae & [35] \\
\hline Polycoryne compacta & 1963 & Delesseriaceae & [75] \\
\hline Polycoryne radiata & 1919 & Delesseriaceae & [25] \\
\hline Pterocladiophila hemisphaerica & 1959 & Pterocladiophilaceae & [34] \\
\hline
\end{tabular}




\begin{tabular}{llcl}
\hline Rhodophyllis parasitica & 2014 & Cystocloniaceae & {$[76]$} \\
Rhodophysema kjellmanii & 1959 & Palmariaceae & {$[77,78]$} \\
Rhodymeniocolax botryoideus & 1923 & Rhodymeniaceae & {$[6]$} \\
Rhodymeniocolax mediterraneus & 2005 & Rhodymeniaceae & {$[79]$} \\
Scagelonema parasiticum & 1969 & Incertae sedis & {$[80,81]$} \\
Sorellocolax stellaris & 1996 & Delesseriaceae & {$[82]$} \\
Sporoglossum lophurellae & 1919 & Rhodomelaceae & {$[25]$} \\
Spyridiocolax capixabus & 1966 & Ceramiaceae & {$[83]$} \\
Stromatocarpus parasiticus & 1897 & Rhodomelaceae & {$[16]$} \\
Symphyocolax koreana & 2010 & Rhodomelaceae & {$[84]$} \\
Syringocolax macroblepharis & 1875 & Ceramiaceae & {$[19]$} \\
Tikvahiella candida & 1983 & Solieriaceae & {$[85]$} \\
Trichidium pedicellatum & 1983 & Rhodomelaceae & {$[50]$} \\
Tylocolax microcarpus & 1897 & Rhodomelaceae & {$[16]$} \\
Ululania stellata & 1998 & Rhodomelaceae & {$[86]$}
\end{tabular}

References: [1] Pocock 1956; [2] Skottsberg 1953; [3] Maggs \& Hommersand 1993; [4] Tokida 1934; [5] Wynne 2013; [6] Setchell 1923; [7] Wynne 1970; [8] Kylin 1956; [9] Zuccarello \& West 1994a; [10] Wynne \& Heine 1992; [11] Abbott \& Hollenberg 1992; [12] Goff 1982; [13] Batters 1895; [14] Joly 1966; [15] Norris 1988; [16] Schmitz \& Falkenberg 1897; [17] Womersley 1998; [18] Bula-Meyer 1985; [19] Reinsch 1875; [20] Reinsch 1890; [21] Womersley 1996; [22] Rosenvinge 1931; [23] Le Gall \& Saunders 2010; [24] Hollenberg 1970; [25] Kylin \& Skottsberg 1919; [26] Pocock 1953; [27] Joly \& Yamaguishi-Tomita 1969; [28] Morrill 1977; [29] Townsend \& Huisman 2004; [30] Adey et al. 1974; [31] Feldmann \& Feldmann 1963; [32] Seoane-Camba 1982; [33] Ganesan 1970; [34] Fan \& Papenfuss 1959; [35] Martin \& Pocock 1953; [36] Yoneshigue \& de Oliveira 1984; [37] Ouahi 1993; [38] Sparling 1957; [39] Baardseth 1941; [40] Feldmann \& Feldmann 1961; [41] Batters 1892; [42] Wagner 1954; [43] Yamamoto 1986; [44] Ng et al. 2014; [45] Weber-van Bosse 1928; [46] Gerung \& Yamamoto 2002; [47] Wilson 1990; [48] Schnetter et al. 1983; [49] Fredericq \& Hommersand 1990; [50] Noble \& Kraft 1983; [51] Børgesen 1920; [52] Womersley 1994; [53] Setchell 1914; [54] Apt 1987; [55] Tokida 1947; [56] Chang \& Xia 1978; [57] Womersley 2003; [58] Weber-van Bosse 1923; [59] Setchell \& Gardner 1924; [60] Kylin 1941; [61] McFadden 1911; [62] Morrill 1976b; [63] Tanaka \& Nozawa 1960; [64] Adey \& Sperapani 1971; [65] Zinova 1967; [66] Kugrens 1982; [67] Levring 1941; [68] Guiry \& Selivanova 2007; [69] Morrill 1976c; [70] De Oliveira \& Ugadim 1973; [71] Harvey \& Hooker 1845; [72] Lee \& Kurogi 1978; [73] Kraft \& Abbott 2002; [74] Wynne \& Scott 1989; [75] Zinova 1963; [76] Preuss \& Zuccarello 2014; [77] Edelstein 1972; [78] Saunders \& Clayden 2010; [79] Vergés et al. 2005; [80] Norris \& Wynne 1969 ‘1968‘; [81] Wynne \& Schneider 2010; [82] Yoshida \& Mikami 1996; [83] Joly \& Oliveira 1966; [84] Kim \& Cho 2010; [85] Kraft \& Gabrielson 1983; [86] Apt \& Schlech 1998. 
Classifying red algal parasites according to their pigments (Appendix 2.1) reveals that $38 \%$ are pigmented, 25\% are unpigmented, and 14\% are described as having both unpigmented and pigmented stages, whereas no information is available on pigmentation for the remaining $23 \%$. In most cases it is not possible to determine from the literature if this pigment variation is due to the parasites being on different host species or is a consequence of a developmental stage (i.e. early development, reproductive stage).

\section{Parasite characters by species}

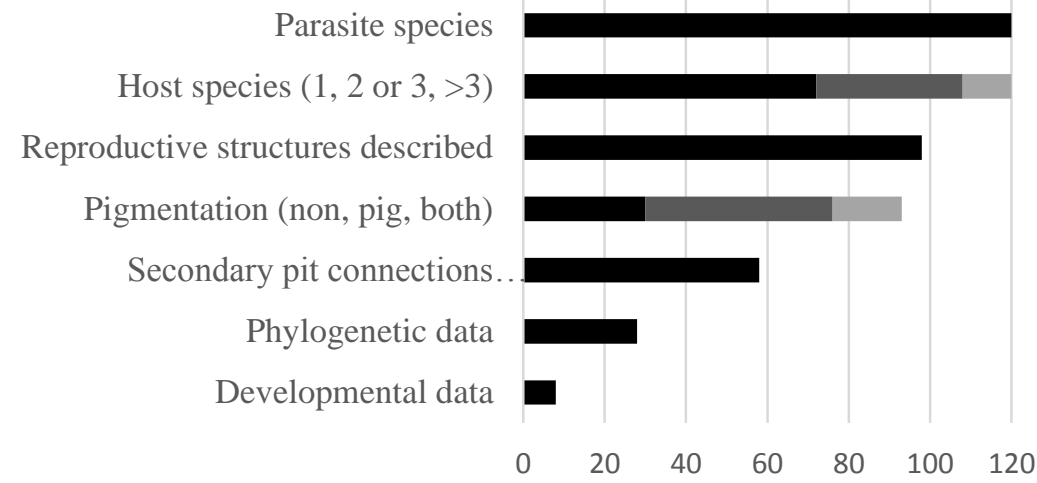

Fig. 2.1. Current knowledge of all 120 red algal parasite species. Host species: number of parasite species which infect one (black bar), two or three (grey bar), or more than three (light grey bar) host species. Reproductive structures described: number of species for which male/female gametophyte and tetrasporophyte described. Pigmentation: none (black), pigmented (grey), both unpigmented and pigmented stages (light grey). Secondary pit connections: number of species for which connections between parasite and host described. Phylogenetic and Developmental data: number of species with any phylogenetic or developmental data.

Based on an estimate of 861 genera of Florideophyceae (Schneider \& Wynne 2007; 2013; Wynne \& Schneider 2010; 2016), slightly over 7\% of genera include parasitic species. Fewer than half of the species (approximately 45\%) fulfil all the criteria used to define red algal parasites (Goff 1982; Wynne \& Scott 1989). Approximately $45 \%$ of all descriptions of parasitic species do not mention secondary pit connections between parasite and host, which is a crucial criterion for establishing parasite status (Goff \& Coleman 1985; Blouin \& Lane 2012). Much of the missing data on secondary pit connections can be explained by the fact that many of these parasitic species were described before 1982, when this unusual developmental process was first highlighted (Goff 1982). A smaller percentage of species descriptions (approximately $10 \%$ ) did not supply information on pigmentation or secondary pit connections, and lacked description of all reproductive structures (Appendix 2.1). 
Table 2.3. List of red algal parasites (and host species) on which phylogenetic analyses have been conducted. $*=$ parasites in which sequences are available from mitochondrial, nuclear and plastid genomes.

\begin{tabular}{|c|c|c|}
\hline Parasite & Host & Reference \\
\hline Aiolocolax pulchella & Polysiphonia caespitosa & Diaz-Tapia \& Bárbara 2013 \\
\hline Asterocolax erythroglossi & Erythroglossum laciniatum & Goff et al. 1997 \\
\hline \multirow[t]{5}{*}{ Asterocolax gardneri } & Anisocladella pacifica & Goff et al. 1997 \\
\hline & Phycodrys isabelliae & Goff et al. 1997 \\
\hline & Phycodrys setchelli & Goff et al. 1997 \\
\hline & Nienburgia andersoniana & Goff et al. 1997 \\
\hline & Polyneura latissima & Goff et al. 1997 \\
\hline Benzaitenia yenoshimensis & Chondria crassicaulis & Kurihara et al. 2010 \\
\hline Bostrychiocolax australis & Bostrychia radicans & $\begin{array}{l}\text { Zuccarello et al. 2004; Zuccarello \& } \\
\text { West } 2006\end{array}$ \\
\hline Choreocolax polysiphoniae & Vertebrata lanosa & $\begin{array}{l}\text { Zuccarello et al. 2004; Salomaki et } \\
\text { al. } 2015\end{array}$ \\
\hline Choreonema thuretii & Jania micrarthrodia & Harvey et al. 2003 \\
\hline Coccotylus hartzii & - & Le Gall \& Saunders 2010 \\
\hline Dawsoniocolax bostrychiae & Bostrychia radicans & Zuccarello et al. 2004 \\
\hline \multirow[t]{2}{*}{ Faucheocolax attenuate } & Gloiocladia laciniata & Goff et al. 1996 \\
\hline & Gloiocladia fryeana & Goff et al. 1996 \\
\hline Gardneriella tuberifera & Sarcodiotheca gaudichaudii & Goff et al. 1996 \\
\hline Gonimophyllum skottsbergii & Cryptopleura crispa & Zuccarello et al. 2004 \\
\hline \multirow[t]{2}{*}{ Gracilaria babae* } & Gracilaria salicornia & $\begin{array}{l}\mathrm{Ng} \text { et al. 2013; } \mathrm{Ng} \text { et al. 2014; } \mathrm{Ng} \text { et } \\
\text { al. } 2015\end{array}$ \\
\hline & Hydropuntia sp. & $\mathrm{Ng}$ et al. 2014 \\
\hline Gracilariophila oryzoides & Gracilariopsis lemaneiformis & $\begin{array}{l}\text { Goff \& Zuccarello 1994; Goff et al. } \\
\text { 1996; Hancock et al. } 2010\end{array}$ \\
\hline \multirow[t]{4}{*}{ Harveyella mirabilis } & Gonimophyllum skottsbergii & Zuccarello et al. 2004 \\
\hline & Odonthalia floccosa & Zuccarello et al. 2004 \\
\hline & Odonthalia washingtoniensis & Zuccarello et al. 2004 \\
\hline & Rhodomela confervoides & Zuccarello et al. 2004 \\
\hline \multirow[t]{2}{*}{ Holmsella pachyderma } & Gracilaria gracilis & Zuccarello et al. 2004 \\
\hline & Gracilariopsis longissima & Zuccarello et al. 2004 \\
\hline Holmsella australis & Gracilaria cliftonii & Zuccarello et al. 2004 \\
\hline Hypneocolax stellaris $f$. orientalis & - & Sherwood et al. 2010 \\
\hline Janczewskia hawaiiana & Laurencia mcdermidiae & Kurihara et al. 2010 \\
\hline Janczewskia morimoto ${ }^{*}$ & Laurencia nipponica & Kurihara et al. 2010 \\
\hline Kintokiocolax aggregato-ceranthus & Grateloupia angusta & Yang \& Kim 2015 \\
\hline Leachiella pacifica & Neosiphonia paniculata & Zuccarello et al. 2004 \\
\hline Plocamiocolax pulvinata & Plocamium cartilagineum & Goff et al. 1996 \\
\hline Rhodophyllis parasitica* & Rhodophyllis membranacea & Preuss \& Zuccarello 2014 \\
\hline
\end{tabular}




\begin{tabular}{lll}
\hline Rhodophysema kjellmanii & - & Clayden \& Saunders 2010 \\
Rhodymeniocolax botryoideus & Rhodymenia pacifica & Goff et al. 1996 \\
Tikvahiella candida & Solieria robusta & Saunders et al. 2004 \\
Ululania stellata & Acanthophora pacifica & Kurihara et al. 2010 \\
& Acanthophora spicifera & Kurihara et al. 2010 \\
\hline
\end{tabular}

The majority of type localities for red algal parasites are in the USA (26), South Africa (13) and Australia (11), and many type localities are on islands. The distribution data available are highly variable, ranging from records of single individuals and their host species to infrequent collections, and thus it is difficult to draw any conclusions about the distribution of most species.

Table 2.4. List of species of red algal parasites in which the parasite's development, parasite-host nuclear transfer and the fate of these parasite nuclei in the host heterokaryotic cell have been documented. Host transformation: + $=$ changes observed in infected host cells, which can include: increased storage products in infected host cells, loss of host plastid fluorescence, host nuclear enlargement, infected host cell division. Parasite nuclear division: $+=$ parasite nuclei known to divide in heterokaryotic host cell; - = parasite nuclei do not divide in heterokaryotic host cell; ? = data not available.

\begin{tabular}{llll}
\hline & $\begin{array}{l}\text { Host } \\
\text { transformation }\end{array}$ & $\begin{array}{l}\text { Parasite nuclear } \\
\text { division }\end{array}$ & Reference \\
\hline Bostrychiocolax australis & + & - & Zuccarello \& West 1994a \\
Leachiella pacifica & + & - & Goff \& Coleman 1985; \\
(as Choreocolax polysiphoniae $)$ & & & Zuccarello et al. 2004 \\
Dawsoniocolax bostrychiae & + & - & Zuccarello \& West 1994a \\
Gardneriella tuberifera & + & + & Goff \& Zuccarello 1994 \\
Gracilariophila oryzoides & + & + & Goff \& Zuccarello 1994 \\
Harveyella mirabilis & + & $?$ & Goff 1976 \\
Janczewskia gardneri & + & + & Goff \& Coleman 1987 \\
Janczewskia morimotoi & + & $?$ & Nonomura 1979 \\
\hline
\end{tabular}


There is limited knowledge of the phylogenetic relationships of red algal parasites. Phylogenetic sequences are available for only $27 \%$ of all red algal parasites (Table 2.3) and, in many cases, all their hosts have not been sequenced. Data from all three genomes (mitochondria, nuclear and plastid) are only available for a small percentage of parasites (2.5\%; Table 2.3).

Only eight red algal parasites have been investigated with reference to host cell transformation, and in only three species are the nuclei known to divide after transfer into the host cell (Table 2.4).

\subsection{Discussion}

Although it has been stated that red algal parasites have evolved independently over a hundred times (Blouin \& Lane 2012), this is based on the current morphological taxonomy rather than on phylogenetic analyses. The origin (i.e. taxonomy) of parasites is complicated by their reduced thalli and consequent lack of diagnostic morphological characters, leading to diversity being underreported (Zuccarello \& West 1994a). The ability of many parasites to switch hosts and infect multiple hosts, and the propensity of phycologists to name parasites based on hosts, further complicate the interpretation of their phylogenetic origin (Goff et al. 1996; 1997), and have led to multiple names for some taxa that are found on multiple hosts (Zuccarello \& West 1994a). An example is Asterocolax gardneri (Setch.) Feldmann et Feldm.-Maz., where phylogenetic results indicate that the species has three independent origins from Phycodrys setchellii Skottsb., Phycodrys isabelliae R.E.Norris et M.J.Wynne and Polyneura latissima (Harv.) Kylin (i.e. a polyphyletic A. gardneri (Goff et al. 1997)). Without further information on their phylogeny or more detailed morphological investigations, the origins of parasites and their true diversity remain to be uncovered. The few phylogenetic studies have revealed parasites that are nested within their host genera, requiring taxonomic changes which may involve parasites losing their distinct generic status to maintain monophyly of the host genus (Ng et al. 2014; Preuss \& Zuccarello 2014). 
Characters used to define the parasitic mode in red algae differ in their utility. Both size and pigmentation are not definitive because small epiphytes do exist, and reproductive structures in some red algae can have lighter pigmentation. The criteria that we feel are most useful are the cell-cell secondary pit connections between parasites and host cells, and finding all life history stages of parasites on the same host plant, which reduces the chance of mistaking host outgrowths as parasites.

Our summary highlights that our understanding of the parasitic process in these unique organisms is based on only a small handful of species that have been studied intensively (e.g., Leachiella pacifica Kugrens). Red algal parasites have been intriguing for scientists since the first reports of nuclear, and organelle, transfer between parasites and hosts (Goff 1982; Goff \& Coleman 1985). This a unique phenomenon in eukaryotic parasitism, although in some nonparasitic florideophyte lineages there is nuclear transfer during carposporophyte development (Kugrens \& Delivopoulos 1985; Delivopoulos \& Diannelidis 1990). Summaries of these processes (early parasite development, host cell 'control') have been presented (Salomaki \& Lane 2014) but generalizations about these processes are based on very few examples, and more data may show that different, and novel, infection mechanisms exist.

The classification of red algal parasites as parasites is rarely discussed but there is evidence that parasites alter hosts and many have detrimental effects on their hosts. This evidence includes: degradative changes in infected host cells include plasmolysis and hypertrophy (Goff 1982), host cell death (Goff 1976), breakdown of host nuclei and plastids (Goff 1982), and reduction in host growth (Apt 1984b). Another negative effect for the host is the loss of cell cycle regulation, shown by rapid division of plastids, nuclei and host cells (Goff 1976; Goff \& Coleman 1985), and the infection spreading to surrounding host cells (Goff \& Coleman 1995). Few studies have analyzed the effects of parasite infection on host fitness, and the results vary from negative effects on the host being either highly localized and minimal (Goff 1982) or appreciable (Martin \& Pocock 1953). In contrast to its effects on the host, it is clear that the parasite depends on the host for nutrients (Evans et al. 1973; Goff 1982), for a habitat due to their host specificity (Goff 1982), and for cell-cell interactions during early development (Zuccarello \& West 1994b; c). The degree of parasitism (i.e. damage to the host) may therefore vary among host species but further investigations are needed for a better understanding of parasite-host relationships. 
We have produced a comprehensive list of described parasites, and characterized the available knowledge about these parasites. It is clear that much information is still lacking. We hope that this list will focus research on poorly studied parasites, and thereby add information about their taxonomy, origins, early development, distribution and effects on host fitness, and will contribute to species discovery. Guiry (2012) estimated that only half of all red algae are described to date. To illustrate this point, many red algal genera and species in New Zealand are continuing to be described (Nelson et al. 2014; Boo et al. 2015; D'Archino et al. 2015; Nelson et al. 2015; D’Archino et al. 2016). Currently, there are ten red algal parasites known from New Zealand. In addition, several undescribed parasitic species have been included in compilations of the flora (Dalen \& Nelson 2013). We hope that molecular studies, especially studies using molecular markers from all three genomes, will be stimulated by this study, and that further work will also investigate host switching and cell-cell relationships between parasites and hosts. The diversity of parasite development has been barely explored, and current hypotheses about developmental processes need to be tested. We hope that this synopsis will aid and inspire further work on these organisms. 


\section{Chapter Three}

Three new red algal parasites from New Zealand: Cladhymenia oblongifoliophila sp. nov. (Rhodomelaceae), Phycodrys novae-zelandiophila sp. nov. (Delesseriacease) and Judithia parasitica sp. nov. (Kallymeniaceae) 


\subsection{Abstract}

There are over 120 species of red algal parasites (Florideophyceae), but they are often overlooked due to their small size and patchy distribution. Red algal parasites have mostly been described as independent genera, but recent phylogenetic studies have shown that parasites are related to free-living relatives, often their hosts, and have been named in these genera to maintain monophyly. We investigated the morphology, distribution and phylogeny, using diverse molecular markers (mitochondrial, nuclear, plastid), of three new red algal parasites in New Zealand. We describe the parasites using morphological and anatomical observations, and estimated their distribution by surveying herbarium vouchers. Analyses of reproductive structures and molecular phylogenies indicate that the closest relative of the parasite Phycodrys novae-zelandiophila sp. nov. is its host, $P$. novae-zelandiae. Based on nuclear and mitochondrial markers, the closest relative of the parasite Cladhymenia oblongifoliophila sp. nov. is its host $C$. oblongifolia, but plastid markers group it with $C$. lyallii, suggesting that this species was a past host and the source of parasite plastids. The parasite Judithia parasitica sp. nov. groups with Judithia delicatissima but infects Blastophyllis spp., suggesting that this parasite evolved as a free-living or parasitic Judithia species and host switching may have occurred. This study adds to our knowledge of New Zealand red algal parasites and highlights contrasting patterns of host-parasite relationships.

Key words: Biodiversity, Ceramiales, Emery's rule, Gigartinales, Monophyletic taxonomy, Parasitism, Plastid capture, Phylogenetics, Rhodophyta, Speciation 


\subsection{Introduction}

Red algal parasites, a poorly studied polyphyletic category with many unique features, are found exclusively on red algal species in eight orders within the Florideophyceae (Blouin \& Lane 2016; Chapter 2). Approximately 120 species have been described world-wide but their diversity is probably severely underestimated due to their small size and patchy distribution (Chapter 2). Four key characters are used to identify red algae as parasitic: 1) reduced size, 2) lack of or reduced pigmentation, 3) formation of secondary pit connection between parasite and host cells, and 4) both gametophytic and sporophytic parasite life stages on the same host stage (Wynne \& Scott 1989). In the past, similarities in reproductive structures were used to indicate a close taxonomic relationship ('adelphoparasites') or more distant relationship ('alloparasites') between parasite and host combinations (Goff 1982), whereas more recent phylogenetic data indicates a continuum of relatedness between hosts and parasites (e.g., Zuccarello et al. 2004; Blouin \& Lane 2012).

The close relationship between most red algal parasites and their hosts led to a hypothesis that these parasites evolved directly from their hosts (Setchell 1918), consistent with the entomological concept known as "Emery's rule" (Emery 1909). Later molecular evidence supported Emery's rule (Goff et al. 1997) but also revealed varied phylogenetic relationships. Several studies showed that some parasites are more closely related to their hosts than the host is to other species in the same genus (Goff et al. 1997; Zuccarello et al. 2004; Preuss \& Zuccarello 2014), while parasites with multiple hosts in different genera (e.g., Harveyella mirabilis (Reinsch) F.Schmitz et Reinke) have undergone host switching (Zuccarello et al. 2004; Kurihara et al. 2010). Previous studies indicated that the plastid was mobile between hosts and parasites with the parasite 'capturing' the host plastid (Goff \& Coleman 1995; Goff et al. 1996), a phenomenon that was not seem with the mitochondria (Goff \& Coleman 1995). This lead to varied relationships between hosts and parasite using plastid sequence data and could be used to indicate parasite origins and host switching. For example, parasites can have similar, occasionally nearly identical, plastid gene sequences to the host (e.g., Rhodophyllis parasitica M.Preuss et Zuccarello; Preuss \& Zuccarello 2014), matching the relationships of the nuclear and mitochondrial markers, indicating a recent evolution from the host species. Parasites can have plastids more closely related to another species of host from the host they are found on (e.g., Gracilaria babae (H.Yamam.) P.K.Ng, P.E.Lim et Phang; Ng et al. 2014), indicating that the parasite acquired its plastids from a previous host. Recent studies have also 
shown that parasites can have a highly reduced plastid genome relative to that of the host (e.g., Choreocolax polysiphoniae Reinsch; Salomaki et al. 2015), possibly indicating a long history of parasitism.

Previously, newly described parasites were grouped into independent parasitic genera (e.g., Kraft \& Abbott 2002; Townsend \& Huisman 2004; Vérges et al. 2005; Kim \& Cho 2010). Several phylogenetic studies have now shown that parasites and hosts are often closely related to each other, using nuclear and mitochondrial markers, and parasites have origins within the host genus, but still distinct parasite generic names were retained (e.g., Goff et al. 1996; Kurihara et al. 2010). Newer studies support a strictly monophyletic scheme reflecting the integration of the parasites into the host genus based on phylogenetic support ( $\mathrm{Ng}$ et al. 2014; Preuss \& Zuccarello 2014).

Of the 120 recognised red algal parasite species, 10 are currently known from New Zealand (Chapter 2). Five species were described from New Zealand and the others were recorded for New Zealand but described from other parts of the world. The five described parasites from New Zealand are: Colacopsis lophurellae Kylin, Gloiocolax novae-zelandiae Sparling, Gonimophyllum insulare F.S.Wagner, Pterocladiophila hemisphaerica K.C.Fan et Papenf., and Rhodophyllis parasitica. The five remaining species are: Callocolax neglectus F.Schmitz et Batters, Choreonema thuretii (Bornet) F.Schmitz, Colacodasya inconspicua (Reinsch) F.Schmitz, Microcolax botryocarpa (Hook.f. et Harv.) F.Schmitz, and Sporoglossum lophurellae Kylin. Molecular data are available only for Rhodophyllis parasitica (Preuss \& Zuccarello 2014).

In this study, we describe three new red algal parasite species from New Zealand: one found on Cladhymenia oblongifolia Hook.f. \& Harv., one on Phycodrys novae-zelandiae Showe M.Lin et W.A.Nelson; and one species found on both Blastophyllis calliblepharoides (J.Agardh) D'Archino et W.A.Nelson and B. hombroniana (Mont.) D'Archino et W.A.Nelson. 


\subsection{Materials and Methods}

Samples were collected mostly as drift around New Zealand (Appendix 3.1). All specimens were pressed as herbarium vouchers, dried in silica gel or fixed in $2 \%$ glutaraldehyde in phosphate buffer $(0.1 \mathrm{M}$, pH 6.8) in $50 \%$ seawater.

For anatomical observations, sections were either embedded in resin following Preuss \& Zuccarello (2014) or hand sectioning with a razor blade. Sections were stained with $1 \%$ acidified aniline blue in either water or 50\% KARO syrup (Englewood Cliffs, New Jersey, USA). Samples were examined using Olympus AX-70 and Olympus BX53 microscopes (Tokyo, Japan) with integrated cameras (Olympus DP-70, Olympus SC100) and images were captured using Olympus cellSens software.

DNA was extracted either using 5\% Chelex following Zuccarello et al. (1999) or following a modified CTAB protocol (Zuccarello \& Lokhorst 2005). Mitochondrial (cox1), nuclear (actin, LSU rDNA, SSU rDNA) and plastid ( $r b c \mathrm{~L})$ markers were used for analysis (Appendix 3.2). PCR conditions for actin amplification were as follows: initial denaturation at $94^{\circ} \mathrm{C}$ for $5 \mathrm{~min}$, followed by 9 cycle of $94^{\circ} \mathrm{C} / 55^{\circ} \mathrm{C} / 72^{\circ} \mathrm{C}$ for 1 min each, followed by 29 cycles of $94^{\circ} \mathrm{C}$ for $30 \mathrm{sec}, 45^{\circ} \mathrm{C}$ and $72^{\circ} \mathrm{C}$ for $1 \mathrm{~min}$ and a final step at $72^{\circ} \mathrm{C}$ for $10 \mathrm{~min}$. PCR conditions for all other genes were carried out with an initial denaturation at $94^{\circ} \mathrm{C}$ for $5 \mathrm{~min}$, followed by 36 cycles of $94^{\circ} \mathrm{C} / 45^{\circ} \mathrm{C} / 72^{\circ} \mathrm{C}$ for $1 \mathrm{~min}$ each and a final step at $72{ }^{\circ} \mathrm{C}$ for $5 \mathrm{~min}$. Successful amplifications were purified using ExoSAP-IT following manufactures instructions (USB product; Affymetrix, Santa Clara, CA, USA) and commercially sequenced (Macrogen Inc., Seoul, Korea).

New sequences were assembled and edited in Geneious 8.0.5 (http://www.geneious.com, Kearse et al. 2012). GenBank sequences were added to the alignments following D'Archino et al. (2017) or using the closest BLAST search hits (Appendix 3.3). MAFFT alignments implemented in Geneious were used and modified by eye. Bayesian inference was performed with MrBayes v.3.2.5 (Ronquist \& Huelsenbeck 2003). Analyses consisted of two independent simultaneous runs of one cold and three incrementally heated chains, and $3 \times 10^{6}$ generations with sampling every 1000 generations. A "burn-in" of $5 \times 10^{5}$ generations was used and 25000 trees were saved to make the consensus tree. RAxML 7.2.8 (Stamatakis 2006) was used to construct maximum-likelihood trees (ML) to show the most likely tree from the data set. 
RAxML was performed using the GTR+gamma model and 500 non-parametric bootstrap replicates (Felsenstein 1985). RAxML and Bayesian inference was performed with all three codons partitioned for $c o x 1$ and $r b c \mathrm{~L}$. Phylogenies of $c o x 1$, LSU and $r b c \mathrm{~L}$ sequences of the parasite growing on Blastophyllis spp., and of cox 1 and LSU sequences of the parasite growing on Cladhymenia sp. were congruent (Appendices 3.4-3.8) and the data sets were concatenated (with partition for LSU and partitioned codons for $\operatorname{cox} 1$ and $r b c \mathrm{~L}$ ) for a more robust phylogeny.

All alignments of the Phycodrys parasite and its host were analyzed for genetic diversity using TCS statistical parsimony networks (Clement et al. 2000) in PopArt 1.7 (http://popart.otago.ac.nz). Phycodrys adamsiae Showe M.Lin et W.A.Nelson was used as comparison of interspecific variation within Phycodrys. Unique sequences were deposited in GenBank (MF319122-MF319182).

Herbarium specimens of Blastophyllis calliblepharoides, B. hombroniana, Cladhymenia oblongifolia and Phycodrys novae-zelandiae at the Museum of New Zealand Te Papa Tongarewa (WELT vouchers) in Wellington were searched for parasites and observed parasites listed.

\subsection{Results}

Three unrecorded parasites were found throughout New Zealand with the exception of the host species Blastophyllis hombroniana (as Callophyllis hombroniana) from which previously a parasite was recorded (Cotton 1907).

\subsubsection{Parasite on Phycodrys novae-zealandiae}

All genetic markers showed the same pattern, and indicated a very close relationship between Phycodrys novae-zelandiae and its parasite.

Partial cox 1 sequences (623 bp) were obtained for six samples of Phycodrys novae-zelandiae and three of its parasite. Genetic distances within P. novae-zelandiae ranged between 0.16$0.64 \%$ (1-4 bp), and between the parasite and host 0.0-1.12\% (0-9 bp) and up to $0.8 \%$ (5 bp) between parasite specimens. Four haplotypes were found: C1-C4. Five hosts and two 
parasites had Haplotype $\mathrm{C} 3$ while $\mathrm{C} 1$ and $\mathrm{C} 2$ were represented in one host specimen each. $\mathrm{C} 4$ was represented in one parasite specimen (Fig. 3.1A).
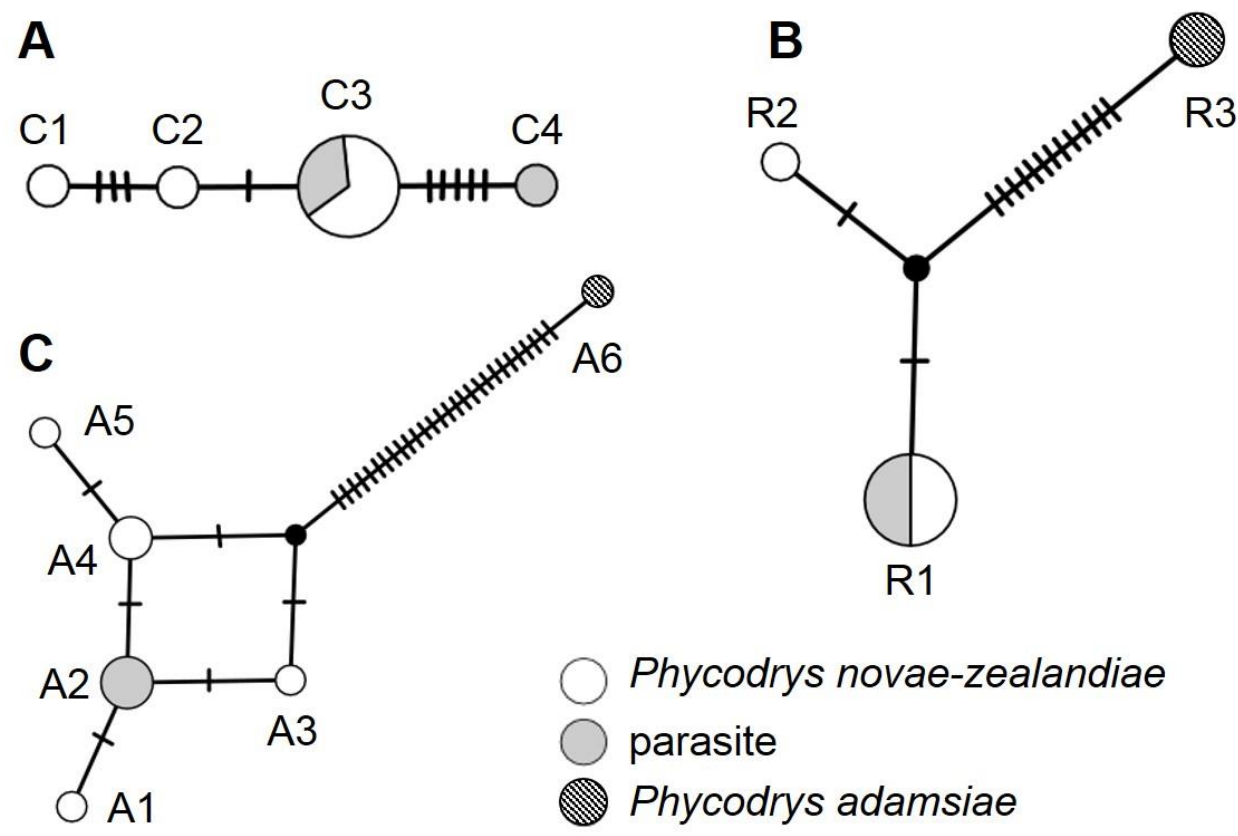

R1

Phycodrys novae-zealandiae

parasite

Phycodrys adamsiae

Figs 3.1A-C. DNA sequence networks of Phycodrys novae-zelandiae, its parasite $P$. novae-zealandiophila and $P$. adamsiae. Fig. 3.1A. Cox 1 haplotype network with four different haplotypes (C1-C4). Fig. 3.1B. RbcL haplotype network with three different haplotypes (R1-R3). Fig. 3.1C. Actin haplotype network with six haplotypes (A1A6). Small dark circle represents missing intermediates, lines = one mutational step. Parasite, host and P. adamsiae haplotypes highlighted in white, gray and hatched, respectively.

Partial $r b c \mathrm{~L}$ sequences of $530 \mathrm{bp}$ were obtained from Phycodrys novae-zelandiae $(\mathrm{n}=4)$, its parasite $(\mathrm{n}=3)$ and Phycodrys adamsiae $(\mathrm{n}=2)$. Three haplotypes were found: R1-R3. Three hosts and three parasites had haplotype R1 while R2 was represented in one host specimen and R3 in two specimens of Phycodrys adamsiae (Fig. 3.1B).

Actin sequences of 638 bp were obtained from $P$. novae-zelandiae $(n=4)$, its parasite $(n=3)$ and $P$. adamsiae $(\mathrm{n}=2)$. Six haplotypes were found: A1-A6. All three parasites had haplotype A2, while A1, A3 A4, and A5 was represented in one host sample each, and A6 in two specimens of Phycodrys adamsiae (Fig. 3.1C). 
The partial SSU alignment $(827 \mathrm{bp})$ for $P$. novae-zelandiae $(\mathrm{n}=3)$ and its parasite $(\mathrm{n}=3)$ showed that all sequences of host and parasite were identical (data not shown).

The molecular data of the parasite and its host, $P$. novae-zealandiae showed the same pattern of low or no variation for all four genes from different genomes and demonstrate that the parasite is closely related to its host. This new parasite belongs in the genus Phycodrys.

\section{Phycodrys novae-zelandiophila M.Preuss et Zuccarello sp. nov.}

\section{Figs 3.2A-I}

DIAGNOSIS: Thalli lightly pigmented (pale red), size 1-2 mm across, with multiple simple branches. Dioecious gametophytes. Carposporophyte 430-530 $\mu \mathrm{m}$ in diameter, surrounded by a pericarp, with rows of carposporangia. Spermatangia unknown. Tetrasporangia $40 \mu \mathrm{m}$ long $\mathrm{x}$ $32 \mu \mathrm{m}$ wide, tetrahedrally divided, scattered on surface of stichidial branches. Parasitic on Phycodrys novae-zelandiae Showe M.Lin et W.A.Nelson.

HOLOTYPE: WELT A033494, collected 27 November 2015, deposited in the Museum of New Zealand Te Papa Tongarewa.

GENBANK ACCESSION NUMBERS: cox1: MF319155, MF319157; rbcL: MF319166; actin: MF319160; SSU: MF319164.

ISOTYPE: WELT A033494, collected 27 November 2015, deposited in the Museum of New Zealand Te Papa Tongarewa.

TYPE LOCALITY: $41^{\circ} 43.667^{\prime} S, 174^{\circ} 12.917^{\prime} E$; drift, Marfells Beach, South Island, New Zealand.

ETYMOLOGY: novae-zelandiophila refers to the parasite's affinity to its host Phycodrys novae-zelandiae. 


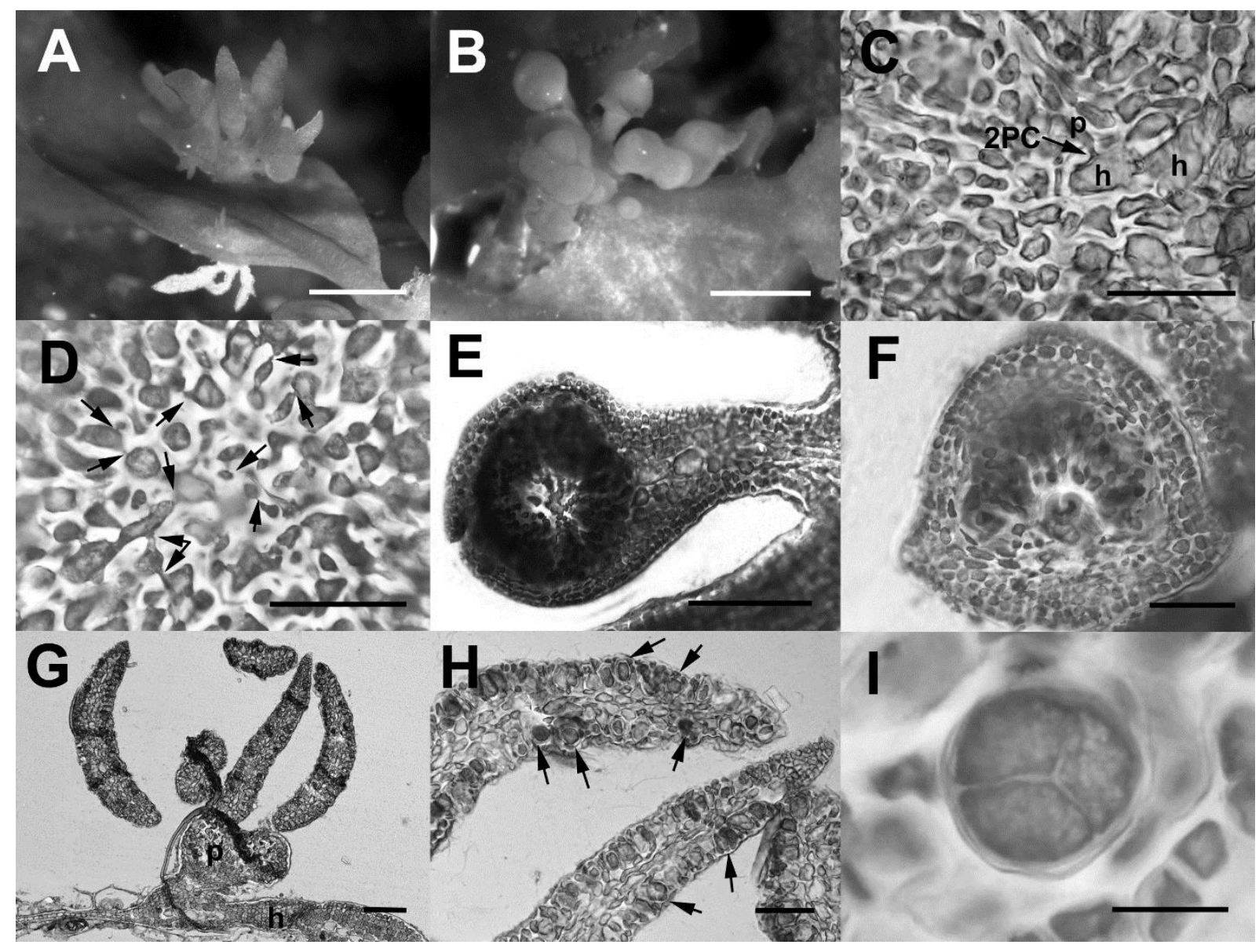

Figs 3.2A-I. Vegetative and reproductive structures of Phycodrys novae-zealandiophila sp. nov. on its host Phycodrys novae-zealandiae. Fig. 3.2A. Habit of a tetrasporophytic parasite growing on the central vein of its host. Scale bar = $1 \mathrm{~mm}$. Fig. 3.2B. Habit of cystocarpic gametophyte growing on host thallus. Scale bar $=1 \mathrm{~mm}$. Fig. 3.2C. Contact area between parasite and host. Parasite cell (p) forms secondary pit connection (2PC; arrow) with host cell (h). Scale bar $=100 \mu \mathrm{m}$. Fig. 3.2D. Parasite cells are highly connected with each other. Arrows indicate pit connections. Scale bar $=100 \mu \mathrm{m}$. Fig. 3.2E. Branch with mature cystocarp of parasite. Central fusion cell visible. Scale bar $=250 \mu \mathrm{m}$. Fig. 3.2F. Close-up of cystocarp of parasite, showing pericarp of approximately five cell layers. Scale bar $=100 \mu \mathrm{m}$. Fig. 3.2G. Cross section of parasite (p) tetrasporangial stichidia on its hosts (h). Scale bar $=200 \mu \mathrm{m}$. Fig. 3.2H. Tetraspores scattered on the surface of the tetrasporangial stichidia, tetrasporangia indicated by arrows. Scale bar $=100 \mu \mathrm{m}$. Fig. 3.2I. Mature tetrahedrally divided tetrasporangium. Scale bar $=20 \mu \mathrm{m}$. 
DISTRIBUTION: The collection at Te Papa contained 52 specimens of $P$. novae-zelandiae of which red algal parasites were observed on nine. The parasite was found from Mataikona $\left(40^{\circ} 47^{\prime} \mathrm{S}\right)$ on the North Island to Stewart Island (46 $\left.55^{\prime} \mathrm{S}\right)$, south of the South Island (Appendix 3.9).

\section{Habitat and vegetative morphology}

Phycodrys novae-zelandiophila grew on blades of Phycodry novae-zelandiae which had over 20 parasites on one blade, usually growing on the veins of the host (Fig. 3.2A). P. novaezelandiophila was found in spring (September, November), summer (January, February) and autumn (March, April) (Appendices 3.1, 3.9).

The thallus was light red, 1-2 mm in size (Figs 3.2A-B). It had a single base that penetrated and disrupted the cell layers of the host. Host cells were embedded between parasite tissue in the contact area. Secondary pit connections were found between large host cells and smaller parasitic cells in the contact area (Fig. 3.2C). The cells within the main body of the parasite thallus were highly connected, by either primary or secondary pit connections (Fig. 3.2D).

\section{Reproductive morphology}

Female gametophytes and tetrasporophytes were observed. Thalli bear branches with either fusiform stichidia bearing tetraspores (Fig. 3.2A) or apical, rounded cystocarps (Fig. 3.2B). All observed parasites were reproductive, but males were not found, suggesting dioecious gametophytes.

The female gametophyte had a narrow, pulvinate base that gave rise to several unbranched axes, most of which terminate in an apical cystocarp. Branches were polystromatic with a central axis of large cells surrounded by up to five layers of smaller cells. The inner layer of elongated cortical cells were spherical near the mature carposporophyte (Fig. 3.2E). The mature carposporophytes were approximately $430-530 \mu \mathrm{m}$ in diameter and surrounded by an approximately five cell thick pericarp $(62 \mu \mathrm{m} ; \mathrm{n}=9)$. The carposporophyte had a single central fusion cell that gave rise to rows of gonimoblast filaments. Carpospores were born in short chains of approximately four ovoid carpospores (19 x $10 \mu \mathrm{m}$; Fig. 3.2F). 
The tetrasporophyte grew from a rounded base approximately $500 \mu \mathrm{m}$ in diameter. The base produced multiple simple fusiform branches that rarely branch again (Figs 3.2A, G). Branches had scattered stichidia on their surfaces. The stichidial branch was around $654 \times 207 \mu \mathrm{m}(\mathrm{n}=$ 2) in size (Fig. 3.2G) with two to three inner layers of elongated cells and scattered globose tetrasporangia on the surface (Fig. 3.2H). Tetrasporangia were tetrahedrally divided approximately 32 x $40 \mu \mathrm{m}(\mathrm{n}=10$; Fig. 3.2I).

Comparision to host species and other parasites on congeneric species

The parasite shared carpospores borne in chains, from a central fusion cell and tetrahedrally divided tetraspores with its host species (P. novae-zelandiae) and two other Phycodrys species (P. adamsiae, $P$. franiae Showe M.Lin et W.A.Nelson), but differed in most other characters (Appendix 3.10). The new parasite was similar to other parasites (Asterocolax denticulatus (Tokida) Feldmann et Feldm.-Maz., Asterocolax gardneri (Setch.) Feldmann et Feldm.-Maz.) on Phycodrys spp., with similar thalli size and pigmentation, tetrahedrally divided tetraspores shattered over the surface, apical cystocarp that were born on branches. It differed in geographical distribution and host species (Appendix 3.11).

\subsubsection{Parasite on Cladhymenia oblongifolia}

The concatenated data set (1613 bp) of cox 1 and LSU rRNA contained eight samples of two parasite samples and their hosts, an uninfected C. oblongifolia and two other Cladhymenia species (individual gene data sets were similar - Appendices 3.4, 3.5). This data set supported the shared origin of the parasite and its host Cladhymenia oblongifolia with strong support (Fig. 3.3). Cladhymenia coronata (Lindauer et Setch.) P.Saenger and Cladhymenia lyalli Harvey were distinct from C. oblongifolia and its parasite.

The partial $r b c \mathrm{~L}$ data set $(537 \mathrm{bp})$ contained taxa representative of all three Cladhymenia species in New Zealand. All samples of $C$. oblongifolia grouped with high support (Fig. 3.4). The parasite grouped with $C$. lyalli with high support, and not $C$. oblongifolia as with the previous markers, and both appeared to be sister to C. coronata, but this relationship was only supported in the ML analysis. 


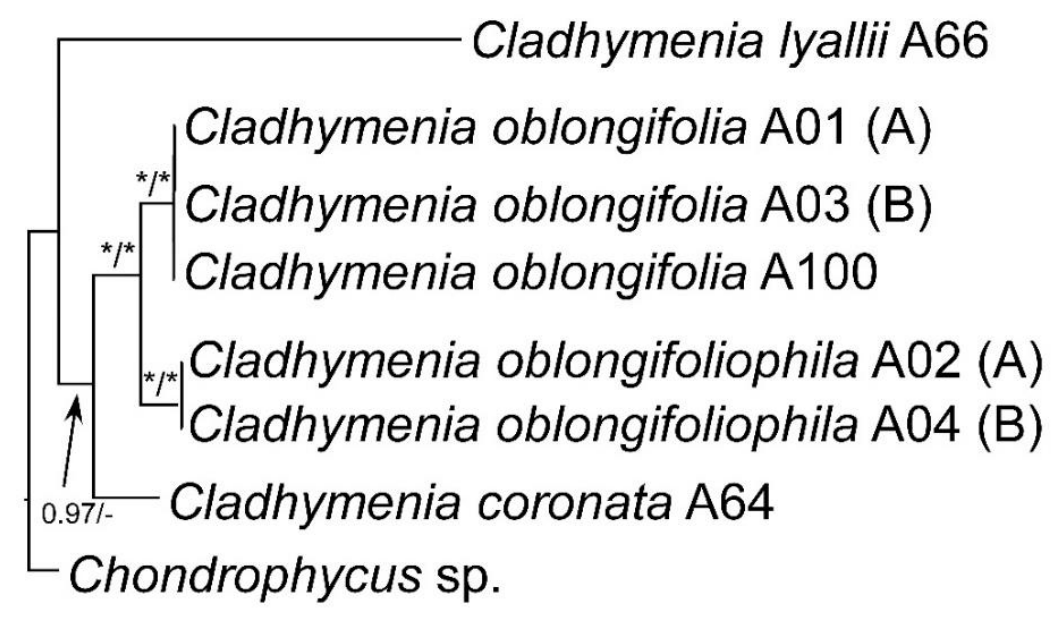

Fig. 3.3. Bayesian topology of concatenated cox 1 and LSU rRNA sequence data set for Cladhymenia oblongifolia, its parasite $C$. oblongifoliophila and two other Cladhymenia species: C. coronata and C. lyallii. Host and parasite from the same host plant are highlighted by capital letters in brackets (A, B). Details of collections in Appendix 3.1. Asterisks indicate posterior probability of 1.00 and bootstrap values of $100 \%$. Values < $85 \%$ ML bootstrap not shown. Outgroup was Chondrophycus sp.

The phylogenetic data of the parasite growing on C. oblongifolia showed two different patterns. Mitochondrial ( $\operatorname{cox} 1)$ and nuclei (LSU rRNA) data showed a shared ancestry of the parasite and host. The plastid marker showed a common ancestor between the parasite plastid and plastids of C. lyallii.

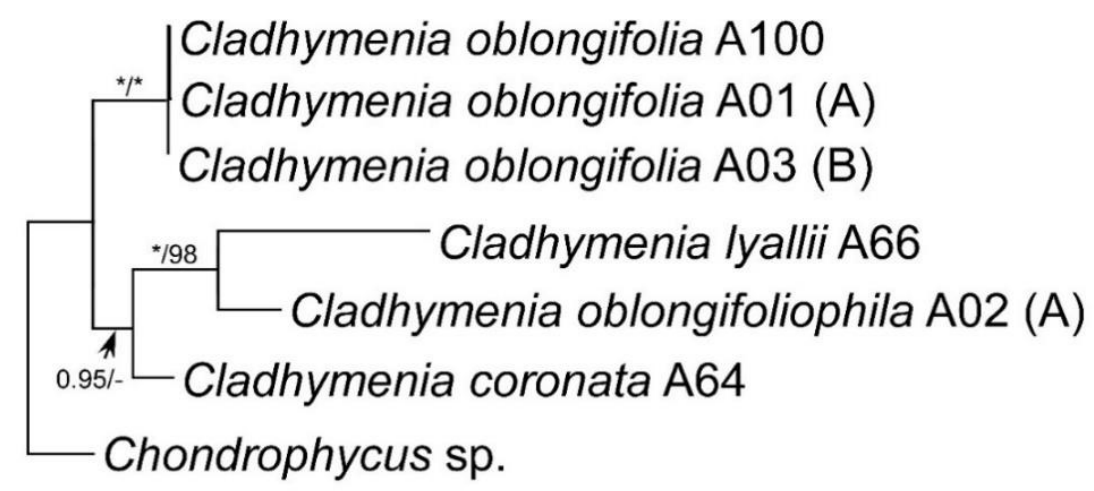

Fig. 3.4. Bayesian topology of $r b c \mathrm{~L}$ relationships for Cladhymenia oblongifolia, its parasite C. oblongifoliophila and two other Cladhymenia species: C. coronata and C. lyallii. Parasite and host combination is highlighted by capital letter in bracket (A). Details of collections in Appendix 3.1. Asterisks indicate posterior probability of 1.00 and bootstrap value of $100 \%$. Values < $85 \%$ ML bootstrap not shown. Outgroup used was Chondrophycus sp.

Our phylogenetic data, plus no records of parasites on Cladhymenia, indicated that this parasite is new and belongs within the genus Cladhymenia. It is described here as a new species. 


\section{Cladhymenia oblongifoliophila M.Preuss et Zuccarello sp. nov.}

\section{Figs 3.5A-I}

DIAGNOSIS: Thalli unpigmented, $2 \mathrm{~mm}$ across, with either smooth spheres or one roundish cushion. Dioecious gametophytes. Carposporophyte approximately 520-570 $\mu \mathrm{m}$, surrounded by a pericarp, no ostiole. Carposporangia, 55-100 x 14-24 $\mu \mathrm{m}$, long and clavate to lachrymiform. Spermatangia unknown. Tetrasporangia 45-55 $\mu \mathrm{m}$ across, tetrahedrally divided, formed in branches. Parasitic on Cladhymenia oblongifolia.

HOLOTYPE: WELT A033496, collected 21 September 2015, deposited in Museum of New Zealand Tongarewa (Te Papa).

GENBANK ACCESSION NUMBERS: cox1: MF319141; LSU: MF319145; rbcL: MF319151.

ISOTYPE: WELT A033496, collected 21 September 2015, deposited in Museum of New Zealand Tongarewa (Te Papa).

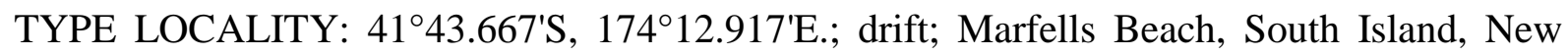
Zealand.

ETYMOLOGY: oblongifoliophila refers to the preference of the parasite to grow on Cladhymenia oblongifolia.

DISTRIBUTION: Te Papa herbarium collections contained 91 specimens of Cladhymenia oblongifolia and on eight of these parasites were observed (Appendix 3.12). The parasite was found from the north $\left(36^{\circ} 57^{\prime} \mathrm{S}\right)$ to the south of the North Island $\left(41^{\circ} 21^{\prime} \mathrm{S}\right)$ and on the Chatham Islands (latitude $=44^{\circ} 16^{\prime} \mathrm{S}$ ). The parasite is not common and has a patchy distribution. 


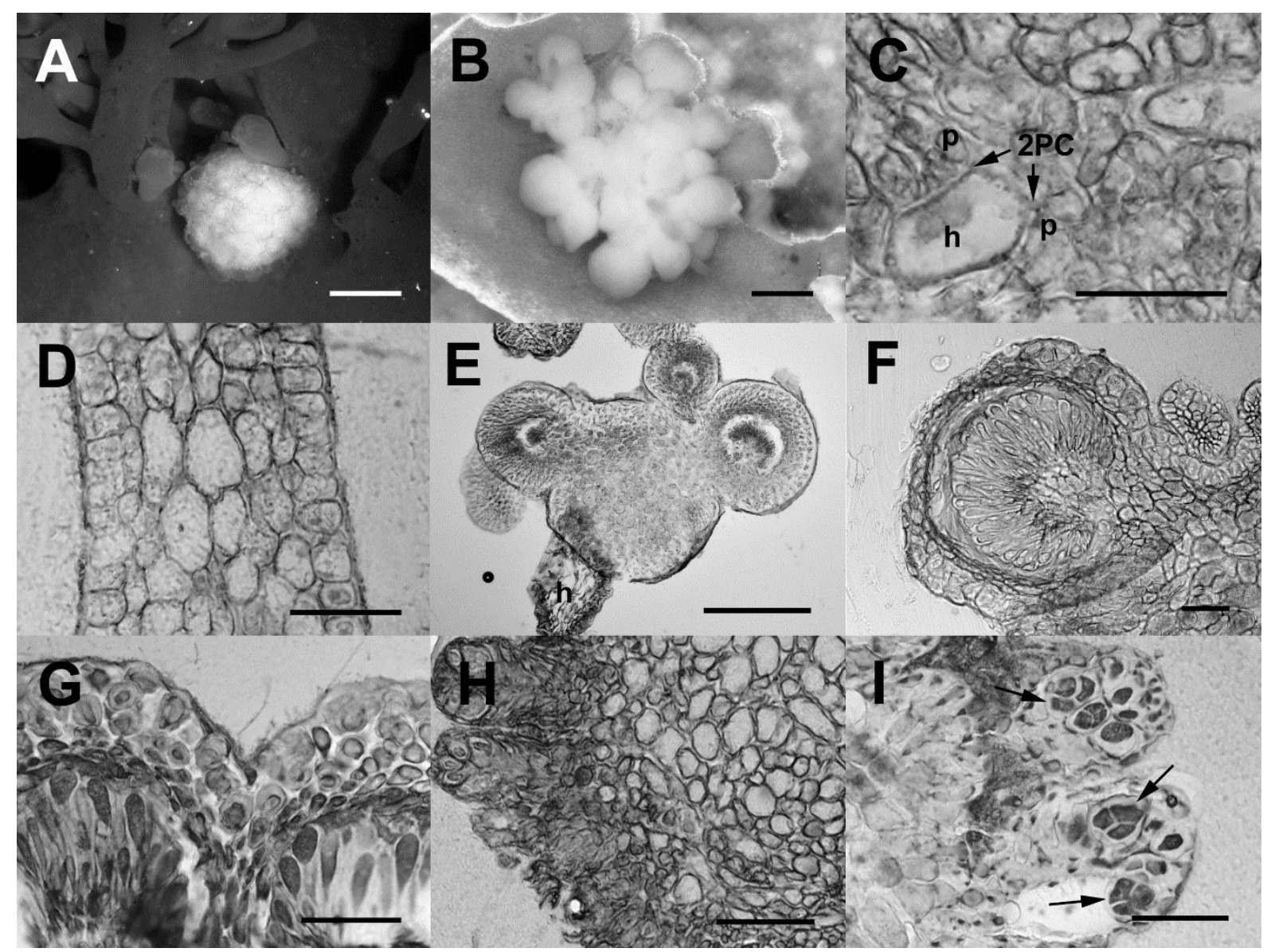

Figs 3.5A-I. Vegetative and reproductive structures of Cladhymenia olongifoliophila and its host Cladhymenia oblongifolia. Fig. 3.5A. Tetrasporophytic parasite thallus growing between the lateral proliferations of its host. Scale bar $=1 \mathrm{~mm}$. Fig. 3.5B. Parasitic female gametophyte, with enlarged cystocarps, on host. Scale bar $=550$ $\mu \mathrm{m}$. Fig. 3.5C. Contact area between parasite and host cells. Parasite cell (p) forms secondary pit connection (2PC; arrow) with host cell (h). Scale bar $=100 \mu \mathrm{m}$. Fig. 3.5D. Internal anatomy of uninfected host, C. oblongifolia, not disrupted by parasite penetration and used as guide for distinguishing between parasite and host cells in the contact area. Scale bar $=100 \mu \mathrm{m}$. Fig. 3.5E. Cross section of female $C$. oblongifoliophila with multiple cystocarps. Scale bar $=500 \mu \mathrm{m}$. Fig. 3.5F. Close-up of cystocarp, showing thick ostiole-less pericarp and carposporophyte. Scale bar $=100 \mu \mathrm{m}$. Fig. 3.5G. Close-up of pericarp and elongated carpospores. Scale bar $=100 \mu \mathrm{m}$. Fig. 3.5H. Tetrasporophytic thallus, showing internal anatomy and cluster of tetrasporangia. Scale bar $=200 \mu \mathrm{m}$. Fig. 3.5I. Tetrasporic clusters with tetrahedrally divided tetraspores (arrows). Scale bar $=100 \mu \mathrm{m}$. 
One host plant had over 20 parasites growing on the blade edges and marginal proliferations (Fig. 3.5A). The parasite was found in spring (September, November), summer (January, February) and autumn months (March, April) in New Zealand (Appendices 3.1, 3.12).

The parasite thallus was not pigmented, approximately $2 \mathrm{~mm}$ in diameter (Fig. 3.5B). The base of the parasite penetrated deeply into the host thallus. Host and parasite cells were intermixed in the contact area. Secondary pit connections were found between small parasite cells and larger host cells in the contact area (Fig. 3.5C). The vegetative structure of the host $C$. oblongifolia consists of five inner layers of large cells, an outer layer of smaller epidermal cells and a cuticle (Fig. 3.5D).

\section{Reproductive morphology}

Female gametophytes and tetrasporophytes were observed. Thalli bear either one rough roundish cushion (tetrasporophyte; Fig. 3.5A) or many smooth spheres of different size (female gametophyte; Fig. 3.5B). All observed parasites were reproductive, but males were not found. Female gametophytes were found on tetrasporophytic host plants.

Mature female gametophytes had circa 30 cystocarps, these were approximately 520-570 $\mu \mathrm{m}$ in diameter (Fig. 3.5E). Pericarp had 5-7 cell layers, approximately $100 \mu \mathrm{m}$ thick, without an ostiole (Fig. 3.5F). Carposporangia were clavate to lachrymiform, 55-100 x 14-24 $\mu \mathrm{m}$ (Fig. $3.5 \mathrm{G})$.

Internally the tetrasporophytes consisted of many round to oval large cells of different sizes (Fig. 3.5H). The tetrasporophytes formed small clusters on their surface, which contained tetrasporangia. Branches were $300 \mu \mathrm{m}$ long by $150 \mu \mathrm{m}$ wide. Tetrasporangia were approximately $45-55 \mu \mathrm{m}$ in diameter and tetrahedrally divided (Fig. 3.5I). 
The parasite shared the location of tetrahedrally divided tetraspores and the location of cystocarps with its host $C$. oblongifolia but differed in thallus size and pigmentation (Appendix $3.13)$.

\subsubsection{Parasite on Blastophyllis calliblepharoides and B. hombroniana}

Individual trees of $c o x 1$, LSU rRNA and $r b c \mathrm{~L}$ (Appendices 3.6-3.8) showed that the parasites closest relative is Judithia delicatissima (R.E.Norris) D'Archino et Showe M.Lin with high support for $\operatorname{cox} 1$ and $r b c \mathrm{~L}$ and good support for LSU rRNA. The congruent results in all three markers supported a concatenated data set for a more robust phylogeny.

The concatenated data set ( $c o x 1$, LSU rRNA and $r b c \mathrm{~L}$ ) contained 44 taxa and was $4827 \mathrm{bp}$ long with representatives of the two host species and their parasites. This data set showed strong support for the shared origin of the parasite and Judithia delicatissima. Both host species, Blastophyllis calliblepharoides and B. hombroniana, grouped together with high support (Fig. 3.6) and were not closely related to their parasites, but this relationship was not well supported.

The phylogenetic data for this parasite with markers of the three different genomes supported a shared ancestry of the parasite with Judithia delicatissima. Callocolax neglectus described on Callophyllis laciniata (Huds.) Kütz. (Batters 1895) from Europe was once recorded on Blastophyllis hombroniana (as Callophyllis hombroniana) from New Zealand (Cotton 1907) but most New Zealand Callophyllis spp. were shown to be different genera within the Kallymeniaceae (D'Archino et al. 2016; 2017) and the shared ancestry with endemic Judithia suggested that this parasite is most likely a new parasite species. 


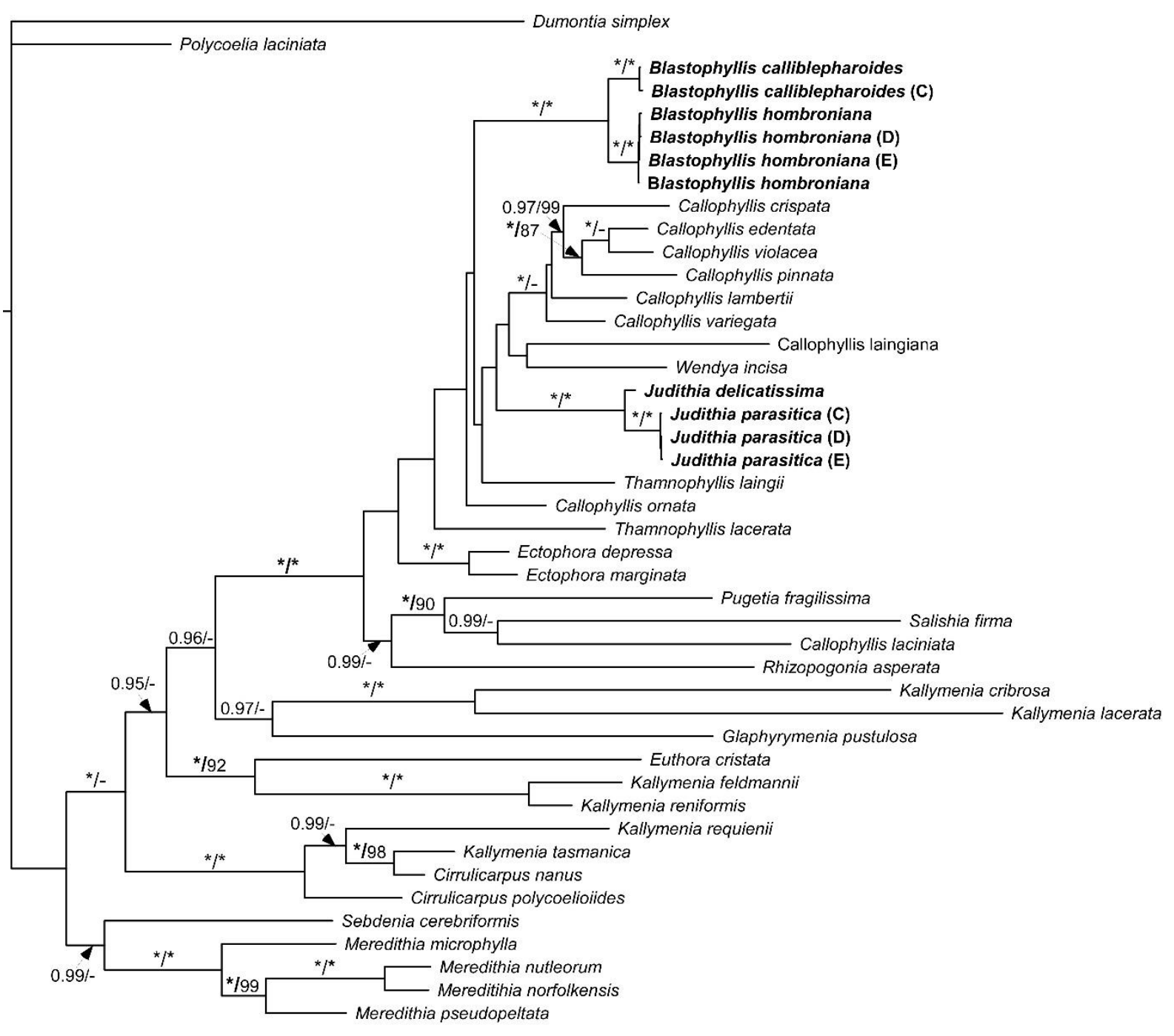

Fig. 3.6. Bayesian topology of concatenated $c o x 1, r b c \mathrm{~L}$ and LSU rRNA sequence data for the parasite Judithia parasitica and both hosts Blastophyllis calliblepharoides and B. hombroniana plus other representative within the Kallymeniaceae. Parasite and host combinations are highlighted by capital letters in brackets (C-E). New (Appendix 3.1) and GenBank samples (Appendix 3.3) were combined. Asterisks indicates posterior probability value of 1.00 and bootstrap value of $100 \%$. Values $<0.85$ posterior probability and $<85 \%$ ML bootstrap not shown. Outgroups Dumontia simplex and Polycoelia laciniata were removed to facilitate presentation. 


\section{Judithia parasitica M.Preuss et Zuccarello sp. nov. \\ Figs 3.7A-F}

DIAGNOSIS: Thalli pigmented (pale red), less than $1 \mathrm{~mm}$ across, with wide base and multiple simple branches. Female and male gametophytes unknown. Tetrasporangia 26 x $13 \mu \mathrm{m}$, cruciate divided, scattered on the surface of branches. Parasitic on Blastophyllis calliblepharoides and Blastophyllis hombroniana.

GENBANK ACCESSION NUMBERS: cox1: MF319180; LSU: MF319130; rbcL: MF319137.

HOLOTYPE: WELT A033495, collected 18 April 2012, deposited in Museum of New Zealand Te Papa Tongarewa.

ISOTYPE: WELT A033495, collected 18 April 2012, deposited in Museum of New Zealand Te Papa Tongarewa.

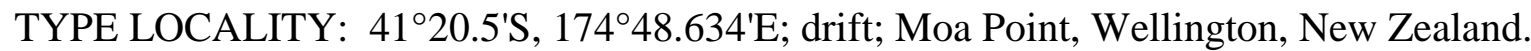

ETYMOLOGY: parasitica $($ Latin = parasitic) refers to the parasitic lifestyle of this alga.

DISTRIBUTION: Te Papa collections contained 44 specimens of B. calliblepharoides and parasites were observed on one specimen from Snares Island ( $\left.48^{\circ} 01^{\prime} \mathrm{S}\right)$, a subantarctic island of New Zealand. On 17 of the 45 specimens of $B$. hombroniana parasites were found. The specimens were from Bank Peninsula $\left(43^{\circ} 45^{\prime} S\right)$ on the South Island $\left(46^{\circ} 36^{\prime} \mathrm{S}\right)$, on Stewart Island and on the Auckland Islands (50`30’S), a subantarctic island of New Zealand (Appendix 3.14).

Habitat and vegetative morphology

Judithia parasitica grows on Blastophyllis calliblepharoides (previously Callophyllis calliblepharoides) and Blastophyllis hombroniana (previously Callophyllis hombroniana). The position of the parasite and its abundance on the two hosts appeared similar. The hosts had up to a few hundred parasites growing mainly on the edges of the main axis or branches (Fig. 3.7A). The parasite on B. calliblepharoides was found in autumn (April), summer (December), 
and on B. hombroniana in summer (December, January, February), autumn (March), winter (July, August) and spring (October, November) in New Zealand (Appendices 3.1, 3.14).

Thalli of $J$. parasitica were light red, with an average size of less than $1 \mathrm{~mm}(350-670 \mu \mathrm{m}$ length to $700-890 \mu \mathrm{m}$ in width). The parasite had a single, widely spreading base covering the host surface that did not penetrate deeply into the host thallus (Fig. 3.7B). Parasite cells formed secondary pit connection with the top layer of cells (epidermal or sub-epidermal) of the host (Fig. 3.7C). Parasite cells within the parasite thallus were highly connected to each other by either primary or secondary pit connections (Fig. 3.7D).

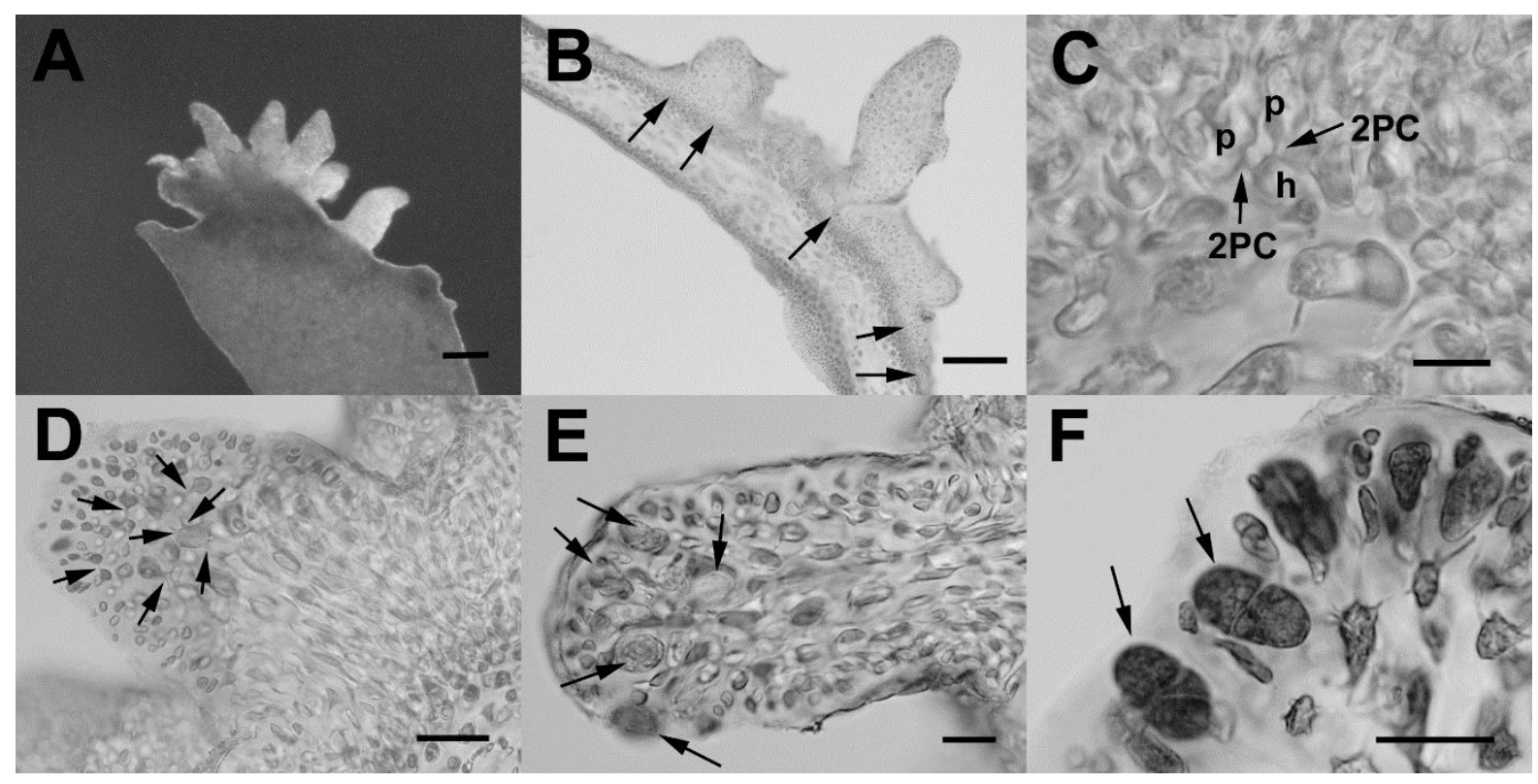

Figs 3.7A-F. Vegetative and reproductive structures of Judithia parasitica growing on its host Blastophyllis hombroniana. Fig. 3.7A. Tetrasporophytic parasite on the edge of the host blade. Scale bar $=200 \mu \mathrm{m}$. Fig. 3.7B. Cross section of parasite thallus with wide base (arrows) growing over the host thallus. Scale bar $=10 \mu \mathrm{m}$. Fig. 3.7C. Parasite cells (p) with secondary pit connection (2PC; arrows) to pigmented host cells (h). Scale bar $=20$ $\mu \mathrm{m}$. Fig. 3.7D. Parasite cells are highly connected with each other by primary and secondary pit connections (arrows). Scale bar $=100 \mu \mathrm{m}$. Fig. 3.7E. Longitudinal section of tetrasporic branch with tetrasporangia (arrows) scattered over the surface. Scale bar $=20 \mu \mathrm{m}$. Fig. 3.7F. Close-up of cruciately divided tetrasporangia (arrows). Scale bar $=20 \mu \mathrm{m}$. 
Tetrasporophytes were observed. Thalli bore multiple simple branches of different lengths with roundish tips. All observed parasite were either tetrasporophytic or non-reproductive, female and male gametophytes were not found.

The base of the tetrasporophyte produced multiple branches with inner elongated large cells and outer roundish small cells. Branches had tetrasporangia scattered on the surface (Fig. 3.7E). Tetrasporangia were cruciately divided, approximately $13 \times 26 \mu \mathrm{m}(\mathrm{n}=6$; Fig. 3.7F).

Comparison the parasite and its closest relative Judithia delicatissima

Judithia parasitica sp. nov. shared scattered cruciately divided tetrasporangia of similar size with J. delicatissima. The parasite differed is overall thallus size and branching (Appendix $3.15)$.

\subsection{Discussion}

This study describes three new red algal parasites from New Zealand that can be distinguished by their host specificity, growth form and reproductive structures. Our phylogeny indicates that the parasites share a common origin, in two cases, with their host genera (Phycodrys, Cladhymenia) or to a non-host genus (Judithia) that is in the same family (Kallymeniaceae) as the host genus (Blastophyllis).

A previous study hypothesized three different evolutionary scenarios of red algal parasite origin (Goff et al. 1996). First, some parasites (e.g., Bostrychiocolax australis Zuccarello et J.A.West, Gardneriella tuberifera Kylin, Rhodophyllis parasitica) evolved from their hosts and solely infect this host species (Goff et al. 1996; Zuccarello et al. 2004; Preuss \& Zuccarello 2014). Second, parasites (e.g., Faucheocolax attenuata Setch.) evolved and grow on one host species but also parasitize a second, closely related host species (Goff et al. 1996). Third, some parasites (e.g., Plocamiocolax pulvinata Setch.) evolved on one species, but now parasitize a secondary host and were lost from the original host species (Goff et al. 1996). Our data reflect the first and third scenario and reveals a possible fourth scenario. 
In the parasite Cladhymenia oblongifoliophila mitochondrial and nuclear markers indicate that the parasite shares an origin with its host $C$. oblongifolia, whereas the plastid marker $(r b c \mathrm{~L})$ shows that its closest relative is the apparently non-host species $C$. lyallii. There are several possibilities to explain the genetic patterns observed: 1) the parasite evolved from a common ancestor with $C$. oblongifolia and then switched host to $C$. lyallii, where it acquired plastids, as has been shown in Gracilaria babae ( $\mathrm{Ng}$ et al. 2014), and subsequently switched back to $C$. oblongifolia and was lost from $C$. lyallii; 2) the species, sharing a common ancestry with $C$. oblongifolia became a parasite on $C$. lyallii and acquired its plastid from this host, it then became a parasite of $C$. oblongifolia but was lost from $C$. lyallii; and 3) the species, sharing a common ancestry with $C$. oblongifolia, became a parasite on $C$. lyallii from which it acquired plastids and subsequently became a parasite of $C$. oblongifolia but has not been observed on $C$. lyallii.

Phycodrys novae-zelandiophila is an example of a parasite that is genetically nearly indistinguishable from its host and found only on this host species. Genetic distances are higher within the host than between parasite and host. Other parasites have been recorded on Phycodrys species from other parts of the world (Asterocolax denticulatus, Asterocolax gardneri, Choreocolax rabenhorstii). The common origin of $P$. novae-zelandiophila with its host, and the close phylogenetic relationship of other Phycodrys parasites to their hosts (Goff et al. 1997) suggest that parasites have evolved multiple time in this genus. Why parasites have evolved so many times in some genera is not yet known.

Judithia parasitica growing on two Blastophyllis spp. is another possible example of host switching with extinction on the original host species (Goff et al. 1996). All molecular markers indicate that $J$. parasitica's closest relative is $J$. delicatissima and neither is closely related to the two hosts in Blastophyllis. Judithia parasitica either evolved on a shared common ancestor of Judithia as a parasite or as a free-living organism and became parasitic or switched hosts either to both species of Blastophyllis or to the common ancestor of these two species. Host switching to distantly related hosts is not common. One example is Harveyella mirabilis (Rhodomelaceae) which also parasitizes Gonimophyllum skottsbergii Setch. (Delesseriaceae) (Zuccarello et al. 2004). 
Our study, and previous studies of different red algal parasites, showed that parasite and host are often sister-species (Goff et al. 1996; Goff et al. 1997; Zuccarello et al. 2004; Kurihara et al. 2010; Preuss \& Zuccarello 2014). Several parasitic relationships follow Emery's rule, originally developed for insects, that states that parasites are their hosts' closest relative (Emery 1909). These parasites evolved either by sympatric speciation from their host (Bourke \& Franks 1991) or were derived from two allopatrically non-parasitic species, one of which parasitize the other during secondary contact (Lowe et al. 2002). Emery's rule has been proposed for red algal parasites (Setchell 1918; Goff et al. 1997).

Morphological characters of the three parasites are congruent with their phylogenetic relationships and confirm them as red algal parasites. All three parasites were small, with reduced or no pigmentation and formed secondary pit connections to their hosts cells (Goff 1982; Wynne \& Scott 1989; Chapter 2). These criteria are the basis for many determinations of species as parasitic; nutrient status and detriment to the host have been seldom investigated (Kremer 1983; Apt 1984a; Goff 1976; 1982; Martin \& Pocock 1953).

Our data support the placement of our parasite species in the genus of its closest relative and maintains a taxonomy based on monophyly. Modern classification should reflect phylogenetic relationships (de Queiroz \& Gauthier 1992) and we support the idea that the origin of these parasites should be reflected in their taxonomy. This may require that the circumscription of a genus that has been demonstrated to contain a parasitic species be modified to include it ("and the parasites derived from it”), as previously suggested (Preuss \& Zuccarello 2014).

A common taxonomic problem of red algal parasites is that names are applied to parasites found on hosts from distant areas or within the same host genus. Callocolax neglectus growing on Callophyllis laciniata was described from Europe (Batters 1895) but recorded on Callophyllis hombroniana (Cotton 1907) in New Zealand. No molecular data are available for Callocolax from the north Atlantic. Another example is Dawsoniocolax bostrychiae (A.B.Joly et Yam.Tomita) A.B.Joly et Yam.-Tomita growing on Bostrychia radicans (Mont.) Mont. in Brazil (Joly \& Yamaguishi-Tomita 1969) which was later recorded on Bostrychia radicans in Australia (West \& Calumpong 1988), but phylogenetic and developmental studies showed that the Australian parasite is distinct (Bostrychiocolax australis, Zuccarello et al. 1994a). These two examples make it obvious that careful morphological and anatomical observations, in addition to molecular data, of host and parasite are necessary to distinguish species. 
In summary, we describe these three parasites as new species: Cladhymenia oblongifoliophila sp. nov. (Ceramiales), Phycodrys novae-zelandiophila sp. nov. (Ceramiales), and Judithia parasitica sp. nov. (Gigartinales) based on morphological and molecular evidence. The number of red algal parasites known from New Zealand has increased but further studies into this intriguing group are needed to understand their diversity, classification and evolutionary relationships with their hosts. 


\section{Chapter Four}

Development of the new red algal parasites Vertebrata aterrimophila sp. nov.

(Rhodomelaceae, Ceramiales) from New Zealand 


\subsection{Abstract}

Parasitic red algae grow only on other red algae and have over 120 described species. Developmental studies in red algal parasites are few, although they have shown that secondary pit connections formed between parasite and host and proposed that this was an important process in successful parasitism. Furthermore, it was recorded that the transfer of parasite nuclei by these secondary pit connections led to different host cell effects. We used developmental studies to reconstruct early stages and any host cell effects of a parasite on Vertebrata aterrima. A mitochondrial marker ( $\operatorname{cox} 1)$ and morphological observations (light-and fluorescence microscopy) were used to describe this new red algal parasite as Vertebrata aterrimophila sp. nov. Early developmental stages show that a parasite spores connects via secondary pit connections with a pericentral host cell after cuticle penetration. Developmental observations revealed a unique connection cell that grows into a "trunk-like" structure. Host cell transformation after infection by the parasite included an apparent increases in both carbohydrate concentrations and nuclear size, as well as structural changes of infected host cells. Analyses of molecular phylogenies and reproductive structures indicate that the closest relative of $V$. aterrimophila is its host, $V$. aterrima. Our study shows a novel developmental parasite stage ("trunk-like" cell) and highlights the need for further developmental studies to investigate the range of developmental patterns and host effects in parasitic red algae.

Key words: Biodiversity, Cytochrome c oxidase subunit 1, Infection, Parasitism, Phylogenetics, Rhodophyta, Secondary pit connections, Vertebrata aterrima 


\subsection{Introduction}

Parasitic red algae growing only on other red algae undergo unique development processes from spore attachment to reproductive maturity. While parasitic red algae are taxonomically quite diverse only a few studies have carefully examined parasite development, especially the early stages of infection and the cellular effects of infection on host cells (Chapter 2). An understanding of the diversity of these developmental processes is needed if any patterns, and evolutionary implications, are to be drawn.

Early on, in the study of these organisms, morphological characters were used to describe parasites that were closely related to their host (either same tribe or family) as "adelphoparasites" and those distantly related to their hosts as "alloparasites" (Feldmann \& Feldmann 1958, Goff 1982). Since then, phylogenetic studies showed that the terms "adelphoparasites" and "alloparasites" are an extreme oversimplification as there is a range of different degrees of relatedness between parasites and hosts (Zuccarello et al. 2004; Kurihara et al. 2010; Chapter 3). Close relationships between parasites and hosts range from low to no genetic marker variation (e.g., Rhodophyllis parasitica M.Preuss et Zuccarello; Preuss \& Zuccarello 2014) to parasites being sister to host species and nested within the host genus (e.g., Gracilariophila oryzoides Setch. et H.L.Wilson; Goff et al. 1996). Distant relationships are also found between parasite and host ranging from parasites grouped in the same family as the host (e.g., Ululania stellata Apt et Schlech; Kurihara et al. 2010) to ones in a different family, but the same order, as the hosts (e.g., Holmsella pachyderma (Reinsch) Sturch; Zuccarello et al. 2004). Regardless, the terms "adelphoparasites" and "alloparasites" have been continuously used in red algal parasites without reference to the extent of phylogenetic relationships.

In general, parasite spores attach and penetrate the host cuticle, by a spore infection peg, fusing with an epidermal or subepidermal host cell (Goff \& Coleman 1987). In some parasites the germination tube tip fuses, via a secondary pit connection with the epidermal host cell, e.g. Dawsoniocolax bostrychiae (A.B.Joly et Yam.-Tomita) A.B.Joly et Yam.-Tomita. Sometimes this germination tube tip expands to form the first parasite cell within the host thallus before fusion, e.g. Bostrychiocolax australis Zuccarello et J.A.West (Zuccarello \& West 1994a). In other parasites, the germination tube divides a few times while growing into the host thallus before connecting to subepidermal host cells, e.g. Harveyella mirabilis (Reinsch) F.Schmitz et Reinke (Goff 1976). This fusion between host and parasite is through a conjunctor cell, which 
leads to a secondary pit connection between parasite and host cells (Goff \& Coleman 1985) and is an imporant process in successful parasitism (Zuccarello et al. 2004; Chapter 2).

Secondary pit connection formation also transfers parasite organelles (e.g., nuclei, mitochondria) into host cells, and this is thought to lead to "control" of host cells by parasite nuclei, through a process called cellular transformation (Goff \& Coleman 1987; Salomaki \& Lane 2014). The first demonstration of host nuclear transfer was in the parasite Leachiella pacifica Kugrens, which transferred parasite nuclei into the host cells of Polysiphonia confusa Hollenb. These parasite nuclei did not divide or undergo DNA synthesis in the host cell (Goff \& Coleman 1984; 1985). Another example was the transfer of parasite nuclei of Gracilariophila oryzoides into the host cells of Gracilariopsis andersonii (Grunow) E.Y.Dawson. These parasite underwent DNA synthesis and divided in host cells (Goff \& Zuccarello 1994). Infected host cells containing parasite nuclei always showed some degree of morphological and developmental changes, including increases in starch concentration and nuclear ploidy level, plus the infection spread to surrounding host cells in some species (Goff \& Coleman 1987; Goff \& Zuccarello 1994).

After fusion of host and parasite cells, parasite growth can be superficial or endophytic. Superficial development is only known from the parasite Dawsoniocolax bostrychiae, where all growth is external to the host (Zuccarello \& West 1994a). The endophytic growth in all other parasites is either by parasite cells spreading through the host thallus, such as in the parasite Leachiella pacifica Kugrens (Goff \& Coleman 1987), or through spreading of the infection through infected host cells infecting neighboring cells (Goff \& Zuccarello 1994). Often uninfected host cells, parasite cells and infected heterokaryotic cells within the host thallus get pushed upwards forming the mass of the reproductively mature parasite thallus (Goff \& Coleman 1987; Goff \& Zuccarello 1994).

The Ceramiales is the largest red algal order within the Florideophyceae (Yang et al. 2016) with the highest diversity of red algal parasites (Chapter 2). They occur in four families: Ceramiaceae, Daysaceae, Delesseriaceae and Rhodomelaceae (Salomaki \& Lane 2014; Chapter 2). Most parasites in the Ceramiales are partially pigmented and grow on only one host species within the same order (Chapter 2). The family Rhodomelaceae contains many red algal parasites. The parasite Choreocolax polysiphonia Reinsch grows on Vertebrata lanosa (L.) T.A.Chr. (Reinsch 1875) and the parasite Leachiella pacifica grows on Polysiphonia paniculata 
(Mont.) J.N.Norris (as P. confusa, Goff \& Coleman 1985) and Polysiphonia hendryi N.L.Gardner (Kugrens 1982; Zuccarello et al. 2004). Both were first placed in the family Choreocolacaceae (order Gigartinales) (Sturch 1926), along with Harveyella mirabilis. Later, a phylogenetic study showed these parasites had a distant relationship to their hosts but are in the Rhodomelaceae (Zuccarello et al. 2004).

In this study, we describe the development and phylogenetic placement of a new red algal parasite species from New Zealand growing on Vertebrata aterrima (Hook.f. et Harv.) Kuntze. This study highlights a unique development structure in the parasite and adds to our understanding of variation in parasite development.

\subsection{Materials and Methods}

Samples of Vertebrata aterrima, and its parasite, were collected as drift at Castlepoint $\left(40^{\circ} 54^{\prime} 08^{\prime \prime} \mathrm{S}, 176^{\circ} 13^{\prime} 43^{\prime \prime} \mathrm{E}\right)$ or growing as an epiphyte on Carpophyllum maschalocarpum

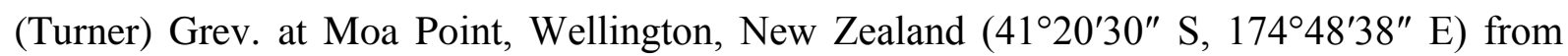
spring 2015 to spring 2016. All specimens were either pressed as herbarium vouchers, dried in silica gel, fixed in $2 \%$ glutaraldehyde in phosphate buffer $(0.1 \mathrm{M}, \mathrm{pH} 6.8)$ in $50 \%$ seawater or cultured in containers with sterile seawater.

For developmental experiments, approximately 200 uninfected hosts were infected by spores released from reproductively mature parasites collected in the field. Mature parasites were placed on uninfected host plants floating on a Nitex screen (400 $\mu \mathrm{m}$ mesh, Dynamic AquaSupply Ltd., Canada) in sterile seawater (salinity approximately 33) for one day and then removed. Hosts were removed from the Nitex screen and moved into sterile seawater. Infected host samples were cultured at approximately $15^{\circ} \mathrm{C}$ by 12 hours day $(14.5-4.5 \mu \mathrm{mol}$ photons $\mathrm{m}^{-2} \mathrm{~s}^{-1} 126$ constant fluorescent) and night cycle. Hosts were fixed at regular time intervals and three samples of every experiment were grown for 2-3 weeks to determine successful infection of host.

For morphological and developmental analyses, samples were either embedded in resin following Preuss \& Zuccarello (2014) or prepared for squashing following Goff \& Coleman (1984). For squash preparations, samples were softened in saturated chloral hydrate, transferred to slides coated with Haupt's solution (Haupt 1930) and squashed with carefully applied 
pressure of a soft rubber. Coverslips were removed in liquid nitrogen, then the samples were fully immersed in $70 \%$ ethanol and air dried until staining. Microscopic slides were stained with either $1.0 \mu \mathrm{g} \mathrm{mL}^{-1}$ DAPI in McIlvaine buffer ( $\mathrm{pH} 4.1$ ), $1 \%$ acidified aniline blue or $1 \%$ toluidine blue. Samples were examined using a microscope (Olympus AX-70, Tokyo, Japan) with an integrated camera (Olympus DP-70) and images were taking using Olympus cellSens software.

Reproductive observations of parasitic gametophytes on tetrasporophytic host plants and tetrasporophytic parasites on host gametophytes were used to confirm the outgrowth was an independent alga and not a host proliferation or bacterial infection.

For phylogenetic analyses, mature parasite thalli were selected. DNA was extracted following a modified CTAB protocol (Zuccarello \& Lokhorst 2005) and PCR amplified using the primers, GazF1 (TCA ACA AAT CAT AAA GAT ATT GG, Saunders 2005) and Mam2R (GTA TTA AAA TTW CKA TCW GTT A, Mamoozadeh \& Freshwater 2011) for partial cox1. PCR conditions consisted of an initial denaturing step at $94^{\circ} \mathrm{C}$ for $5 \mathrm{~min}$, followed by 35 cycles each $94^{\circ} \mathrm{C}$ for $1 \mathrm{~min}, 45^{\circ} \mathrm{C}$ for $1 \mathrm{~min}$, and $72^{\circ} \mathrm{C}$ for $1 \mathrm{~min}$, and a final extension step at $72^{\circ} \mathrm{C}$ for 10 min. Successful amplifications were purified using ExoSAP-IT (USB product; Affymetrix, Santa Clara, CA, USA) and commercially sequenced (Macrogen Inc., Seoul, Korea). Amplifiation of nuclear and plastid markers were unsuccessful. Sequences of the forward and reverse strands were assembled using Geneious 8.0.5 (http://www.geneious.com, Kearse et al. 2012) and edited sequences were aligned using MAFFT alignment using default settings. Taxon sampling (Appendix 4.1) for phylogenetic analyses was selected following Díaz-Tapia et al. (2017). Bayesian analysis was performed with MrBayes v.3.2.5 (Ronquist \& Huelsenbeck 2003) and maximum-likelihood trees (ML) with RAxML 7.2.8 (Stamatakis 2006) following Chapter 3.

All herbarium samples of $V$. aterrima (as Polysiphonia aterrima) at the Museum of New Zealand Te Papa Tongarewa in Wellington were searched for parasites under a dissecting microscope and observed parasites were recorded. 


\subsection{Results}

This study describes a new red algal parasite from New Zealand with a unique developmental structure. Our phylogenetic analysis indicates that the parasite shares a close relationship with its host.

\section{Developmental observations}

Released parasite spores were pigmented and spherical $(\sim 10-20 \mu \mathrm{m}$ in diameter) and attached to the host cuticle between host cells. The parasite spore developed a germination tube of up to $30 \mu \mathrm{m}$ in length (Fig. 4.1A). Germination only occurrs in the presence of the host. The germination tube connected to a pericentral host cell through a secondary pit connection (Fig. 4.1B). After the formation of a secondary pit connection between host and parasite, a "connection" cell developed from the germination tube and the parasite grew superficially from this cell by cell division (Fig. 4.1C). Further secondary pit connections between the parasite "connection" cell and several host cells were formed as the parasite grew (Fig. 4.1D). The growing parasite "connection" cell developed several branches that connected to the same or other host cells (Fig. 4.1E). The "connection" cell grew to be the largest parasite cell and was easily recognizable (Fig. 4.1F), sometimes two "connection" cells were present (Fig. 4.1G) and these cells developed into a "trunk-like" structure in mature parasite thalli (Fig. 4.1H). Parasite cells were multinucleate, and highly connected between parasite cells (Fig. 4.1I). Infected host cells contained many nuclei, which were almost double in size (5-10 $\mu \mathrm{m}$ diameter) in comparison to host nuclei in neighbouring non-infected host cells and parasite nuclei $(3-5 \mu \mathrm{m}$ diameter, Figs 4.1J-K). Parasite nuclei were not distinguishable these heterokaryotic cells. After infection, cytological changes in the infected host cells were observed and included an apparent increase in carbohydrates (Fig. 4.1K). Infected host cells were more susceptible to plasmolysis, suggesting structural changes in these cells (Fig. 4.1M). The infection of the parasite was highly localized and superficial, and no parasite cells were ever observed deeper in the tissue (Figs 4.1F-H, 4.1M). The infection did not spread to surrounding host cells, i.e. host cell was not directly connected to parasite cells (Figs $4.1 \mathrm{H}, 4.1 \mathrm{M}$ ). 


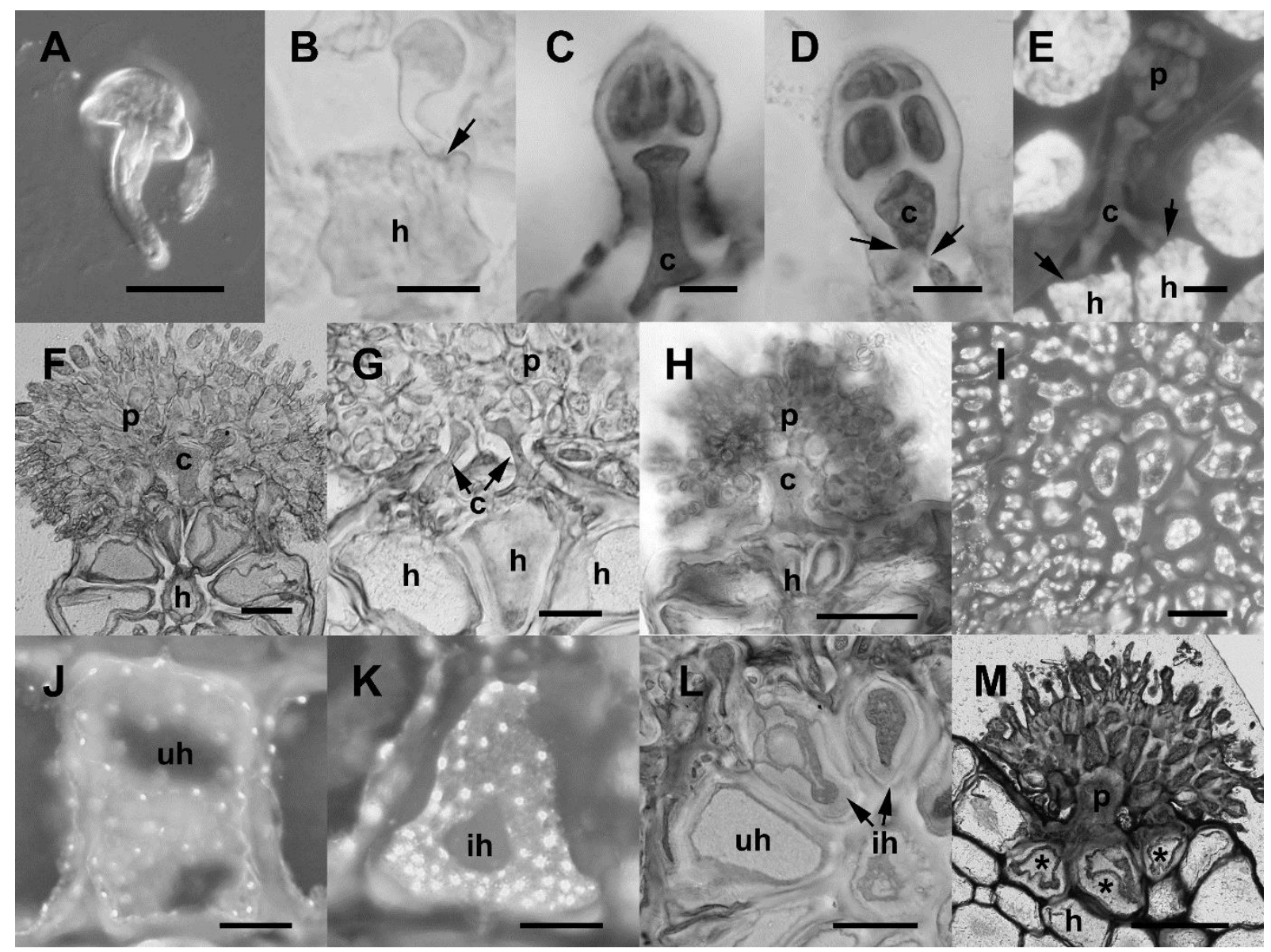

Figs 4.1A-M. Development of Vertebrata aterrimophila on its host Vertebrata aterrima. Fig. 4.1A. Phase contrast of germinated parasite spore, unattached to host, showing germination tube. Fig. 4.1B. Light microscopy of germinated parasite spore which connects through a secondary pit connection (arrow) to a host cell (h). Fig. 4.1C. Early stages of developing parasite with connection cell (c). Stained with aniline blue. Fig. 4.1D. Parasite growing on the surface and two secondary pit connections to host cells (arrow), one out of plane of focus. Fig. 4.1E. Autofluorescence shows non-autofluorescing parasite body (p) with large and branched connection cell (c), connecting to two host cells (arrow), plus bright autofluorescing host cells (h). Fig. 4.1F. Parasite (p) thallus, and cross section of host thallus, with large connection cell (c). Stained with aniline blue. Fig. 4.1G. In some parasites (p) two connection cells (c) were observed. Aniline blue staining. Fig. 4.1H. A mature connection cell (c), and developing parasite, resembles a 'trunk'-like connecting to various pericentral cells. Fig. 4.1I. Multi-nucleate parasite cells highly connected to each other. Stained with DAPI. Fig. 4.1J. Host nuclei in uninfected host cells (uh). Stained with DAPI. Fig. 4.1K. Host nuclei in infected host cell (ih), from same plant as Fig. 4.1J. Stained with DAPI. Fig. 4.1L. Infected host cells (ih) appear to have higher carbohydrate concentrations (indicated by darker aniline blue staining) than uninfected host cells (uh). Fig. 4.1M. Infected host cells (asterisks) are more susceptible to plasmolysis and show structural changes insides cells, stained with toluidine blue. Scale bars: Figs 4.1A-B, 4.1E, $20 \mu \mathrm{m}$, Figs 4.1C-D, $10 \mu \mathrm{m}$, Figs 4.1F, 4.1H, 4.1L, $100 \mu \mathrm{m}$, Figs 4.1G, 4.1I-4.1K, $50 \mu \mathrm{m}$, Fig. 4.1M, $200 \mu \mathrm{m}$. 


\section{Phylogenic results}

Partial cox 1 sequences (726 bp) were obtained for six samples of Vertebrata aterrima and five of its parasite. Pairwise distances within parasites were $0-0.7 \%$, and between hosts $0-1.4 \%$, and between host and parasite 7.2-8.5\%. All parasites grouped together and were sister to their host $V$. aterrima within the genus Vertebrataand this close relationship between parasite and host was strongly supported (Fig. 4.2). Our data showed that this was a new parasite and needed to be formally described.

\section{Vertebrata aterrimophila M.Preuss et Zuccarello sp. nov.}

\section{Figs 4.3A-K}

DIAGNOSIS: Thalli unpigmented to pigmented (dark brownish), 587-1500 $\mu \mathrm{m}$ in diameter with easily recognizable reproductive forms. Gametophytes dioecious. Cystocarps ovoid with ostioles and tear-drop shaped carpospores $(49-82 \mu \mathrm{m} \times 17-23 \mu \mathrm{m})$. Spermatangial branches without sterile apical cells. Tetrasporangia are tetrahedrally divided (33-43 $\mu \mathrm{m}$ x $30-38 \mu \mathrm{m})$ and are spirally arranged in branches. Parasitic on Vertebrata aterrima (Hook.f. et Harv.) Kuntze.

Cox1 GenBank Accession numbers: MH670282-MH670284.

HOLOTYPE: WELT A033493, collected as a parasite on Vertebrata aterrima from Moa Point,

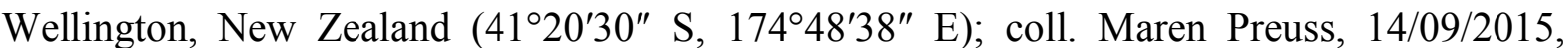
deposited in Museum of New Zealand Te Papa Tongarewa.

ISOTYPE: WELT A033493, deposited in Museum of New Zealand Te Papa Tongarewa.

TYPE LOCALITY: Moa Point, North Island, New Zealand.

ETYMOLOGY: The name aterrimophila refers to the parasites' affinity to its host Vertebrata aterrima. 


\section{Habitat}

Vertebrata aterrimophila usually grows between branches of Vertebrata aterrima and was observed in Wellington all year round. Most infected host thalli are highly parasitized with more than 100 parasites covering the whole thallus (Fig. 4.3A).

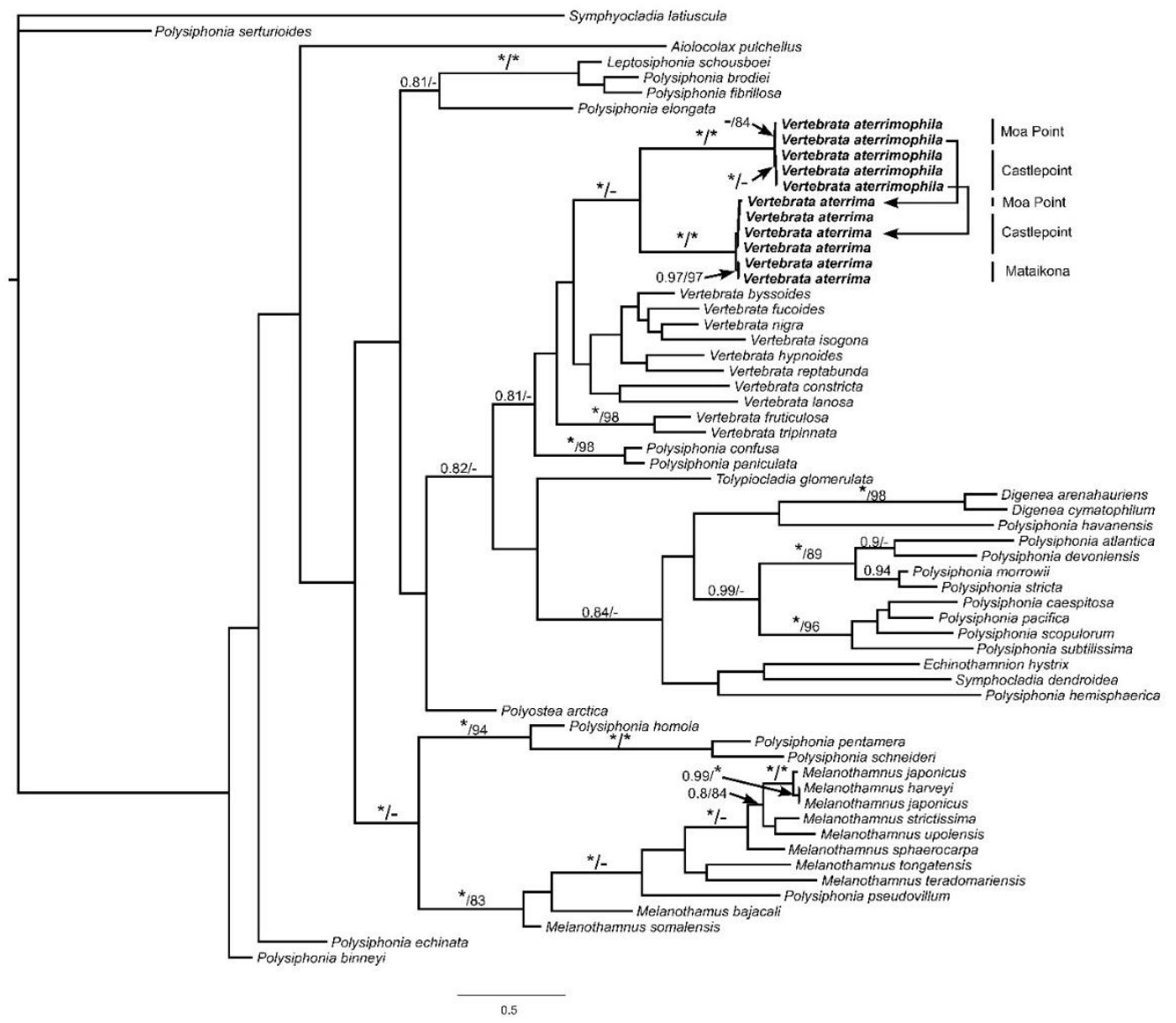

Fig. 4.2. Bayesian topology of partial cox 1 of Vertebrata species. Vertebrata aterrima and its parasite Vertebrata aterrimophila in bold. Symphyocladia latiuscula used as outgroup. Parasite and host combinations are connected by arrows and sampling locations given. Asterisks indicate posterior probability value of 1.00 /bootstrap values of $100 \%$. Values $<0.80$ posterior probability and $<80 \%$ ML bootstrap not shown and indicated with a dash.

Pigmentation and autofluorescence.

Parasites thalli can be pigmented or unpigmented and no clear pattern by location, size of parasite or reproductive stages was apparent. Small, not fully mature pigmented parasites ( 150 $\mu \mathrm{m}$ width) show faint autofluorescence (Fig. 4.3B). 


\section{Distribution}

Te Papa collections contained 31 specimens of $V$. aterrima and seven of those had parasites on them. The parasite was recorded from Pouawa $\left(38^{\circ} 36^{\prime} \mathrm{S}\right)$ on the east coast to Wellington $\left(41^{\circ}\right.$ $20^{\prime} \mathrm{S}$ ) in the North Island and in the Marlborough Sounds $\left(40^{\circ} 50^{\prime} \mathrm{S}\right)$ on the South Island (Appendix 4.2).

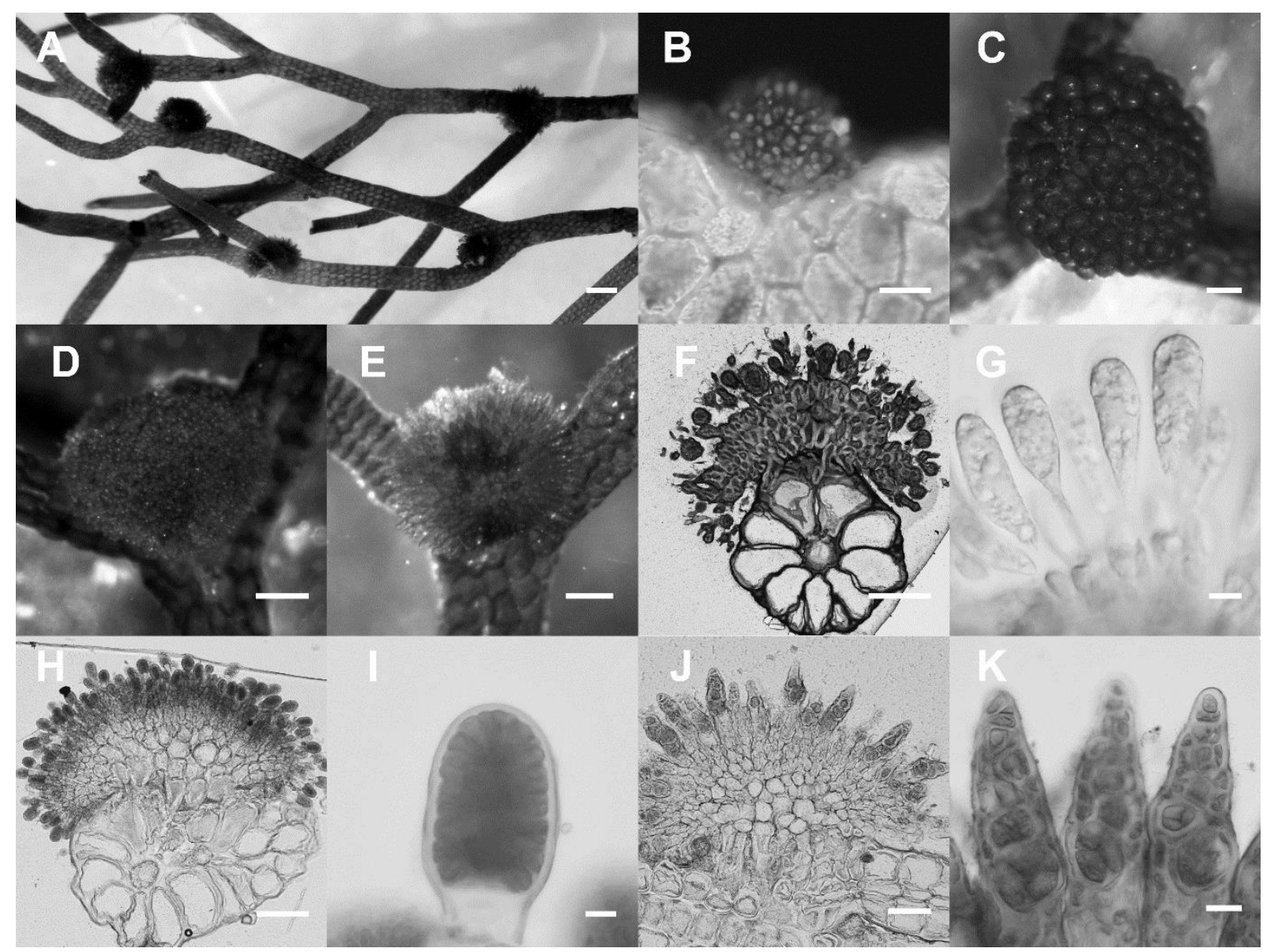

Figs 4.3A-K. Vegetative and reproductive structures of Vertebrata aterrimophila on its host Vertebrata aterrima.

Fig. 4.3A. Highly infected host thallus, parasites often found in host branch angles. Fig. 4.3B. Slight autofluorescence in a young parasite was detectable. Fig. 4.3C. Female gametophytes with many smooth spheres (cystocarps) of similar size. Fig. 4.3D. Male gametophyte of a roundish cushion with roundish tips (spermatangial stichidia). Fig. 4.3E. Tetrasporophyte with pointy branch tips (tetrasporangial stichidia). Fig. 4.3F. Female gametophyte with cystocarps over its surface. Resin-embedded transverse section. Fig. 4.3G. Elongated carpospores.Squash-preparastion. Fig. 4.3H. Male gametophytes covered with spermatangial branches. Resinembedded transverse section. Fig. 4.3I. Spermatangial stichidum with clusters of spermatia and lacking sterile apical cells. Squash-preparation. Fig. 4.3J. Tetrasporophyte is covered with acute tetrasporoangial stichidia. Squash-preparation. Fig. 4.3K. Tetrasporangium contain tetrahedrally divided tetraspores in a spiral arrangement. Scale bars: Fig. 4.3A, $400 \mu \mathrm{m}$, Fig. 4.3B, $50 \mu \mathrm{m}$, Figs 4.3CF, 4.3H, $200 \mu \mathrm{m}$, Figs 4.3G, 4.3I, $10 \mu \mathrm{m}$, Fig. 4.3J, $100 \mu \mathrm{m}$, Fig. $4.3 \mathrm{~K}, 20 \mu \mathrm{m}$. 


\section{Reproductive morphology}

Male, female and tetrasporophytes were observed. The parasite was dioecious. The parasite consisted of either many smooth spheres of similar sizes (female gametophyte, Fig. 4.3C) or one rough roundish cushion with roundish branches (male gametophyte, Fig. 4.3D) or elongate branches emanating from the thallus (tetrasporophyte; Fig. 4.3E). Gametophytic parasites were observed growing on tetrasporophytic hosts and tetrasporophytic parasites were observed growing on gametophytic hosts.

The entire surface of mature female gametophytes is covered with ovoid, ostiolate cystocarps (Fig. 4.3F), approximately 160-245 $\mu \mathrm{m}$ in diameter ( $\mathrm{n}=5$, Fig. 4.3F). Carposporophytes produced elongated tear-drop shaped carpospores, 49-82 $\mu \mathrm{m} \times 17-23 \mu \mathrm{m}(\mathrm{n}=10$, Fig. 4.3G).

Mature male gametophytes were covered with spermatangial branches (Fig. $4.3 \mathrm{H}$ ) of approximately 47-102 $\mu \mathrm{m} \times$ 37-68 $\mu \mathrm{m}$ and were lacking sterile apical cells (Fig. 4.3I).

Sporophytic parasites were covered by tetrasporangial stichidia of approximately $188-218 \mu \mathrm{m}$ in length and $31-37 \mu \mathrm{m}$ in diameter (Fig. 4.3J). Tetrasporangial stichidia contained spirally arranged pigmented tetrahedrally divided tetrasporangia approximately $33-43 \mu \mathrm{m}$ x 30-38 $\mu \mathrm{m}$ (Fig. $4.3 \mathrm{~K})$

\subsection{Discussion}

Our study showed some unqiue developmental structures of a novel parasite, and in conjuction with its phylogenetic relationship to its host Vertebrata aterrima, support its recognition as a new parasite.

The unique developmental characteristic of $V$. aterrimophila is a prominent "trunk-like" cell from which all parasite connections form, via secondary pit connections, to host cells. Most parasites have a rhizoidal filament fusing with underlying host cells (Nonomura 1979; Goff \& Coleman 1987; Goff \& Zuccarello 1994). Other parasites have several parasite cells within the host thallus which fuse with several host cells (Goff \& Coleman 1985). Only the parasite Dawsoniocolax bostrychiae uses the initial germination tube, and later rhizoidal filaments, derived from the external parasite body, to connect to underlying host cells (Zuccarello \& West 
1994a). The differences in when and which cell initially connects (e.g., internal parasite cell, germiantion tube, rhizoidal filaments), via secondary pit connections, to host cells varies greatly between the few species studied and further studies might reveal if other parasites have such a prominent connection cell or even new developmental pathways.

From the currently known developmental patterns, V. aterrimophila and D. bostrychiae are the only two parasites growing mainly superficially, which leads to other similarities between these two parasites (Zuccarello \& West 1994a). For example, host cells are not found immersed in either of these two parasite thalli (our study, Zuccarello \& West 1994a). All other red algal parasites grow at least partially endophytically, often with deep penetration by parasite cells leading to embedded host cells in parasite thalli (Goff 1976; Nonomura 1979; Goff \& Coleman 1987; Goff \& Zuccarello 1994). Shared developmental patterns between parasites might led to classifications based on these pattern that overrate similarities.

The only similarity between the development of all red algal parasites are secondary pit connections to their hosts during their early development, but these connections differ in their impacts on host cells. Secondary pit connections are used to transfer parasite nuclei into the host cell (Goff \& Coleman 1985) and infected host cells with parasite nuclei are altered ("host cell transformation”) (Goff \& Coleman 1985; Goff \& Zuccarello 1994; Chapter 2). Host cell transformation varies from few host cell changes caused by the parasites Bostrychiocolax australis, Dawsoniocolax bostrychiae, Leachiella pacifica and Vertebrata aterrimophila (our study, Goff \& Coleman 1985, Zuccarello \& West 1994a) to extreme host cell changes (e.g., heterokaryon syncytium) caused by the parasites Gracilariophila oryzoides and Gardneriella tuberifera (Goff \& Zuccarello 1994). After nuclei transfer morphological and physiological changes were observed in host cells including an increase of carbohydrates (Nonomura 1979; Goff \& Coleman 1987; Goff \& Zuccarello 1994), cell size 'hypertrophy' (Goff \& Coleman 1987; Zuccarello \& West 1994a), and increased cell wall thickness (Nonomura 1979; Goff \& Coleman 1987). In our study, we observed apparent increases in carbohydrate concentrations and nuclei size and infected host cells seems to be more susceptible to plasmolysis indicated by structural changes. 
Previous developmental studies were able to distinguish between transferred parasite and host nuclei in host cells. Differences in relative DNA contents were used to distinguish transferred parasite nuclei and host nuclei in infected host cells (Goff \& Coleman 1987). In the case of the parasite Bostrychiocolax australis, transferred parasite nuclei in host cells differed in size from host nuclei in infected host cells (Zuccarello \& West 1994a). In our study, all observed nuclei in infected host cells increased in size, and parasite and host nuclei could not be distinguished from each other. We do not know if the transferred parasite nuclei might increase in size in host cells, or if only a few parasite nuclei are being transferred and the parasite nuclei overlooked.

Mitochondrial marker ( $\operatorname{cox} 1$ ) shows that the parasite Vertebrata aterrimophila is genetically similar to, and shares a common origin with, its host $V$. aterrima. Many red algal parasites in the Ceramiales show a close host-parasite relationship (Goff et al. 1997; Zuccarello et al. 2004; Kurihara et al. 2010; Chapter 3). Previous morphological descriptions placed many parasites in independently parasitic genera (Kraft \& Abbott 2002, Kim \& Cho 2010), due to their obvious morphological differences from their hosts (e.g., small size). Phylogenetic analyses showed that most parasites should be placed in the genus of the parasites closest relative, often its host $(\mathrm{Ng}$ et al. 2014; Preuss \& Zuccarello 2014; Chapter 3). While many vegetative characters of the host genus are not found in the parasite (e.g., rhizoid type, pericentral cells), the reproductive characters support the molecular placement of the parasite within the host genus Vertebrata.

Based on the few known developmental studies a link was made between development pattern and parasite-host relationships.In closely related parasites ("adelphoparasites") there is greater host cell transformation, including spread to neighbouring cells via infected host cells, than there is between more distantly related parasite-host combinations ("alloparasites") (Blouin \& Lane 2012, Salomaki \& Lane 2014, Freese \& Lane 2017). This simplified classification of parasites as having "adelphoparasites" and "alloparasites" developmental patterns does not hold true. In V. aterrimophila, minimal host cell changes were observed eventhough they are closely related, similar to other parasites that are closely related to their hosts such as Bostrychiocolax australis (Zuccarello \& West 1994a) and Janczewskia morimotoi (Nonomura 1979). The phylogenetic relationship of these parasites to their hosts does not reflect host cell transformation and these hypotheses may be oversimplifications that do not reflect the variation of developments. Further studies combining developmental studies and phylogeny, especially of parasites that parasitize other orders within the Florideophyceae, are needed and additional knowledge about these parasites might help us understand their success and evolutionary trends. 
Red algal parasites are classified as parasites, but host nutrient dependency has rarely been demonstrated. The majority of red algal parasites are pigmented (Chapter 2) and $V$. aterrimophila is another example of a pigmented parasite. Our study showed that $V$. aterrimophila sometimes demonstrated faint auto-fluorescence, which might indicate a degree of photosynthetic ability. Nutrient transport from a host to the unpigmented parasite has been reported (Evans et al. 1973; Harlin 1973; Goff 1979). The degree of pigmentation and nutrient dependency was correlated in parasitic plants, where unpigmented species are fully host nutrient dependent (Westwood et al. 2010) and pigmented parasitic plants show a decreased host nutrient dependency, and in some cases even the ability to photosynthesis independently (Tesitel et al. 2010). The few studies in red algal parasites have shown that parasites seem to gain nutrients from their hosts (Evans et al. 1973; Harlin 1973; Goff 1979) but the extent of host nutrient dependency needs further investigation including quantifying the amount of nutrient gained by the parasite, the impact of the lost nutrients on the host, and the ability of pigmented parasites to photosynthesize. This information will help to establish the case for parasitic status.

Parasitic species are thought to have patchy distributions, which may be associated with different factors. Generally, the majority of potential host populations within a species are uninfected and there are a few highly infected host populations (Poulin 2013). Patchy distribution in parasites can be influenced by host susceptibility (Poulin 2013), and variation in host susceptibility to red algal parasite infection is known in hosts (Zuccarello \& West 1994a; b). Patchy distribution was also observed in the parasite $V$. aterrimophila with one local host population being infected and only a few other infected hosts collected or observed on vouchers. The majority of red algal parasites only grow on one or two host species (Chapter 2) but it is not completely known why different populations within a host species are being parasitized and others are not.

In summary, this developmental study documents a new early developmental pathway for a red algal parasite with a localized infection, superficial growth, and a prominent 'trunk-like' cell. Developmental patterns in red algal parasites are varied as are the phylogenetic relationships to their hosts. Further studies are needed before any generalization can be made. In particular, the parasites' nutritional requirements and nutritional independence from their hosts needs further study. 


\section{Chapter Five}

High mutation rates in a non-photosynthetic plastid hides phylogenetic relationships in the red algal parasite Pterocladiophila hemisphaerica 


\subsection{Abstract}

Red algal parasites are a poorly studied group but are often closely related to their hosts from which they presumably evolved directly, or share recent common ancestor. Parasite host switching is known based on phylogenetic parasite and host relationship, but only within the same algal order. We investigated the pigmented red algal parasite Pterocladiophila hemisphaerica, which grows on Pterocladia lucida (Gelidiales) and is currently placed in the Gracilariales. Whole organelle genomes (mitochondria, plastid) and a complete nuclear ribosomal cistron were assembled and annotated from Illumina sequencing. Compared to other red algae, the parasite had a similar mitochondrial genome structure, but a highly reduced plastid genome of 68,701 bp, making it the smallest known red algal plastid genome. All genes for photosynthesis and many other functions (e.g, ATP synthesis, biosynthetic processes, cytochrome complex assembly) were missing in the parasite plastid genome. Mitochondrial (mt) and plastid (cp) genome phylogenies placed Pterocladiophila hemisphaerica on long branches, either as sister to Ceramiales (mt) or Gracilariales (cp). Further analyses, filtering non-elevated plastid genes grouped the parasite either as sister to the Gracilariales (mt) or Gelidiales (cp) on shorter branches but without support. Nuclear phylogeny grouped the parasite $P$. hemisphaerica as sister to the Gelidiales and other red algal orders and was the only phylogenetic relationship with support, indicating that the parasite might have evolved on one of these red algal orders. Large data sets of genes and genomes, under differential selection pressures, could lead to incorrect relationships if not analysed carefully and checked with other biological data.

Key words: Evolutionary rates, Gene clock-likeness, Gelidiocolax, Gracilariales, Holmsella, Parasite origin, Parasitism, Photosynthesis loss, Pterocladia lucida, Pterocladiophilaceae 


\subsection{Introduction}

High-throughput-sequencing (HTS) has become a useful tool to resolve phylogenetic relationships (e.g., Díaz-Tapia et al. 2017; Verbruggen et al. 2017). Incorrect phylogenetic relationships can be produced even when larger data sets (e.g., HTS data) are being used (Shen et al. 2017). Some incorrect relationships can be influenced by long branch attraction (LBA), where fast-evolving taxa group together without reflecting their phylogenetic relationship (Felsenstein 1978; Bergsten 2005), for example, parasitic taxa are 'attracted' to unrelated taxa and not their closest free living relatives (Morin 2000; Evans et al. 2008). LBA was first demonstrated theoretically (Felsenstein 1978) and later shown in several studies using amino acid sequences (e.g., Moreira et al. 2000; Springer et al. 2001; Brinkmann et al. 2005); nucleotides (e.g., Yamamoto et al. 2001; Li et al. 2014); individual genes (e.g., Berger et al. 2003; Busse et al. 2003; Gómez et al. 2011); whole organelle genomes (e.g., Li et al. 2014) plus different inference methods (Yamamoto et al. 2001; Busse et al. 2003). It has been shown that filtering genes by clock-likeness can mitigate LBA (Doyle et al. 2015) but this method is not commonly used.

Parasitism is the most common form of symbiosis (de Vargas et al. 2015). Red algal parasites, red algae parasitic on other red algae, are highly diverse, with over 123 species (Chapter 2) and many independent transitions to the parasitic life style (Goff et al. 1996; Salomaki \& Lane 2014; Blouin \& Lane 2016; Chapter 3). While parasitic red algae are diverse, they are poorly studied.

Red algal parasites mostly infect members of the same family (Goff et al. 1996; Preuss \& Zuccarello 2014; Chapter 2) or occasionally different families within the same order, such as Harveyella mirabilis (Reinsch) F.Schmitz et Reinke (Rhodomelaceae, Ceramiales) growing on Gonimophyllum skottsbergii Setch. (Delesseriaceae, Ceramiales) (Zuccarello et al. 2004). The close relationships between many red algal parasites and their hosts led to the proposition that red algal parasites evolved from their host (Setchell 1918; Goff et al. 1997). Phylogenetic analyses demonstrated that some parasites and their host are more closely related to each other than to other species in the same host genus (Goff et al. 1997; Zuccarello et al. 2004; Chapter 3), whereas other parasites are more distantly related to their host species, possibly due to host switching (Zuccarello et al. 2004; Kurihara et al. 2010; Chapter 3). 
Red algal parasites exhibit reduced and unique morphological characters and therefore parasite origin and taxonomic placement can only accurately be determined by molecular methods. The parasite Benzaitenia yenoshimensis Yendo was grouped with different genera (Bostrychia, Laurencia, Levringiella) in the Rhodomelaceae (Kylin 1956; Morril 1976a) until nuclear rDNA analysis showed a close relationship of B. yenoshimensis with its host in the Chondrieae (Kurihara et al. 2010). The taxonomic placement of many other parasites has been changed based on molecular phylogenetic data (e.g., Zuccarello et al. 2004).

The pigmented red algal parasite Pterocladiophila hemisphaerica K.C.Fan et Papenf. grows on Pterocladia lucida (R.Brown ex Turner) J.Agardh in New Zealand (Fan \& Papenfuss 1959; Chapter 2) which is currently split into three cryptic species in New Zealand (Boo et al. 2015). The parasite was first placed tentatively in the Cryptonemiales (now split into: Ceramiales, Corallinales, Gigartinales (majority), Halymeniales and Hildenbrandia), presumably because the parasite has zonately divided tetrasporangia (Fan \& Papenfuss 1959). Later, $P$. hemisphaerica was transferred into the Gracilariales based on shared characters with the two parasites Holmsella and Gelidiocolax, which were simultaneously placed into a parasitic family, Pterocladiophilaceae (Fredericq \& Hommersand 1990).

Red algal parasites exhibit a unique organelle transfer mechanism of infection through secondary pit connections (Goff \& Coleman 1984; 1985), leading to cells containing components of both cell types ("heterokaryons"). Some studies suggested that the heterokaryon transformed into a parasite cell, reducing host nuclei but keeping host plastids (Goff \& Zuccarello 1994; Goff \& Coleman 1995). Newly formed parasite cells would then produce reproductive structures that contained parasite nuclei but host plastids (Goff \& Coleman 1995). While evidence suggested that parasites only contained host plastids (Goff \& Coleman 1995; Zuccarello et al. 2004), a reduced plastid of 90,243 bp, i.e. lacking all photosynthetic genes, was found in the parasite Choreocolax polysiphoniae Reinsch (Salomaki et al. 2015), the so called 'ghost plastid'. Currently, it is unknown if a highly reduced plastid is present in other red algal parasites.

This is the first study investigating the phylogenetic relationship of a red algal parasite using organelle genomes. HTS data were used to investigate if Pterocladiophila hemisphaerica has a highly reduced plastid genome. Organelle (plastid, mitochondria) genomes were compared between host and parasite to characterise their gene and functional similarities. Organelle 
phylogenies were also compared to nuclear ribosomal RNA relationships to determine the relationships produced by these three genetic regions.

\subsection{Materials and Methods}

Specimens of Pterocladia lucida and its parasite Pterocladiophila hemisphaerica were collected from shore (drift) at Akitio Beach (40 37' 25" S, 176 24' 39" E) in November 2011 and Kairakau Beach ( $39^{\circ} 56^{\prime} 30^{\prime \prime}$ S, $176^{\circ} 55^{\prime} 50^{\prime \prime}$ E) in May 2013, or by scuba in August 2016 at Princess Bay, Wellington, New Zealand (41' 20' 46" S, 174 47' 26" E). Drift specimens were dried in silica gel and scuba collections were freshly ground in liquid nitrogen and used for genomic sequencing.

Parasite pustules were cut off at the base with as much distance from the host parasite contact area as possible. All samples were extracted using a modified CTAB protocol (Zuccarello \& Lokhorst 2005). Extracted DNA was used to amplify partial cox1, LSU and SSU rDNA following established PCR conditions, purification and sequencing (Chapter 3). cox 1 sequences were used to identify clades of Pterocladia host species in New Zealand (Boo et al. 2015).

Library preparation and sequencing for the parasite Pterocladiophila hemisphaerica $(\mathrm{n}=\sim 100)$ and one uninfected specimen of Pterocladia lucida (host, $\mathrm{n}=1$ ) were performed separately using Illumina TruSeq DNA nano by Macrogen Inc. (Seoul, Korea). Libraries of 350 bp were sequenced using a HiSeq 2500 with read lengths of $101 \mathrm{bp}$ and paired ends. Sequenced reads were trimmed with CLC Genomic Workbench 7.5.1 (CLC bio, Aarhus, Denmark) with a quality threshold of 0.05. De novo assembly in CLC and SPAdes 3.8.1 (Nurk et al. 2013) were performed using automatic k-mer size and default parameters. Plastid, mitochondrial and nuclear contigs were identified with blastx searches against a custom-build database containing known Florideophyte genes. Long contigs identified as mtDNA and cpDNA were imported into Geneious 8.0.5 (Kearse et al. 2012). Different assemblers gave similar results but showed slight differences in lengths and further analysis was continued with SPAdes assemblies. Organelle genome circularity was manually checked by mapping $1000 \mathrm{bp}$ of the start and end sequences of the SPAdes contigs against the CLC scaffold. 
Gene prediction was carried out in MFannot (http://megasun.bch.umontreal.ca/cgibin/mfannot/mfannotInterface.pl) and tRNA prediction in ARAGORN (http://130.235.46.10./ ARAGORN/), manually checked and annotated in Geneious. Open reading frames (ORF) were used to identify missing genes and were manually annotated. Previously partial amplified nuclear genes of Pterocladiophila hemisphaerica and Pterocladia lucida were blast searched against contigs identifying whole SSU rDNA and LSU rDNA sequences and confirming identical overlapping sequences. RNAmmer Prediction server (Lagesen et al. 2007) was used to predict the beginning and end of genes. Biological functions of protein coding genes were determined in UniProt (http://uniprot.org) and conserved domains blasted against the NCBI site (https://www.ncbi.nlm.nih.gov/Structure/cdd/wrpsb.cgi).

Progressive Mauve alignment was used to compare plastid genomes using the full alignment option with default seed weight and automatically determined locally collinear blocks (LCB) score (Darling et al. 2004).

Taxon selection for phylogenetic analysis was based on available data for mitochondrial and plastid genomes in the subclass Rhodymeniophycidae with the Corallinales as outgroup, following Verbruggen et al. (2010) (Appendix 5.1). All protein coding genes were translated into amino acid sequences. MAFFT alignments v1.3.3 in Geneious were used for nuclear rRNA genes and translatorX v1.1 (Abascal et al. 2010) for mitochondrial and plastid protein-coding genes. Filtered genes were trimmed using the best automated method in trimAl (http://trimal.cgenomics.org) for nuclear rRNA genes or GBlocks (http://molevol. cmima.csic.es/castresana/Gblocks_server.html) for organelle protein coding genes.

IQ-Tree (Trifinopoulos et al. 2016) was used to construct maximum-likelihood (ML) trees, for trimmed nuclear rRNA using automated substitution models (28S: TVMe+I+G4, 18S: TIM3+F+I+G4) and 1000 ultrafast bootstraps. All amino acid alignments of concatenated mitochondrial and plastid genes were run in RAxML (Stamatakis 2006) to construct maximumlikelihood (ML) trees, using a cpRev model and bootstrap. Phylogenetic analyses for cox 1 were performed following Chapter 3. 
The inconsistent phylogenetic position of $P$. hemisphaerica and the observation of long branches led to further analyses in which genes with elevated rates of evolution in $P$. hemisphaerica were removed. Elevated gene rates in $P$. hemisphaerica were calculated by using the ratio of uncorrected distances between the outgroup (Calliarthron) and P. hemisphaerica and between an ingroup (mitochondria: Schimmelmannia, plastid: Caloglossa) and $P$. hemisphaerica. Any genes exceeding a pre-defined threshold (mitochondria: 0.9, plastid: 1.2) were removed. The red algal parasite Choreocolax polysiphoniae was also removed to avoid long branch attraction by this taxon. RAxML was used to infer ML trees on filtered data sets using cpRev model and 100 bootstrap.

\subsection{Results}

\section{Plastid genome}

The circular mapping plastid genome of Pterocladiophila hemisphaerica is highly reduced, consisting of only 68,701 bp (Fig. 5.1). The plastid contains only 70 genes without any photosynthesis and ATP synthesis genes (Fig. 5.1, Table 5.1) but many genes for genetic systems, metabolism, ribosomal proteins and transport are still present (Appendix 5.2). The plastid genome is densely packed with only $13 \%$ non-coding regions and all protein coding genes (67.5-85.7\% AT content), rRNAs (63.8-67.5\%) and tRNAs (47.3-73.0\%) show an A-T bias. The rRNA 5S gene (rrn5) is also missing from the parasite plastid genome (Appendix 5.2). The parasite plastid contains several ORFs not found in the host or other red algae: orf114 has a ribosomal protein L22 conserved domain, orf151 with a $\mathrm{N}$-terminal reserve transcriptase domain and orf407 is without any conserved domains. The host, Pterocladia lucida, has a standard red algal plastid genome size (176,635 bp) and organization (Appendix 5.3), and shares many genes with other free-living red algae $(n=184$, Fig. 5.1). In comparison to its host, the plastid genome of Pterocladiophila hemisphaerica has fewer protein coding genes, tRNAs and rRNAs (Fig. 5.1, Appendix 5.3).

The parasites Pterocladiophila hemisphaerica and Choreocolax polysiphoniae have in common a highly reduced plastid genome, but it is more reduced in $P$. hemisphaerica $(68,701$ versus $90,243 \mathrm{bp})$ with a core of shared genes $(\mathrm{n}=56)$ and a few unique genes (Fig. 5.1). Among the 10 genes that $P$. hemisphaerica shares with the two free-living species (Pterocladia lucida, Vertebrata lanosa (L.) T.A.Chr.) are genes for transport and fatty acid biosynthesis whereas the 
9 genes found in the parasite $C$. polysiphoniae and the two free-living species are genes for ATP synthesis, biosynthetic processes and RNA processing. P. hemisphaerica and its host Pterocladia lucida share one gene for ribonuclease and C. polysiphoniae and its host Vertebrata lanosa share one gene for translation (Fig. 5.1). In comparison to their host species and each other, there is significant gene rearrangement in the plastid genomes of the parasites (Appendix 5.4).

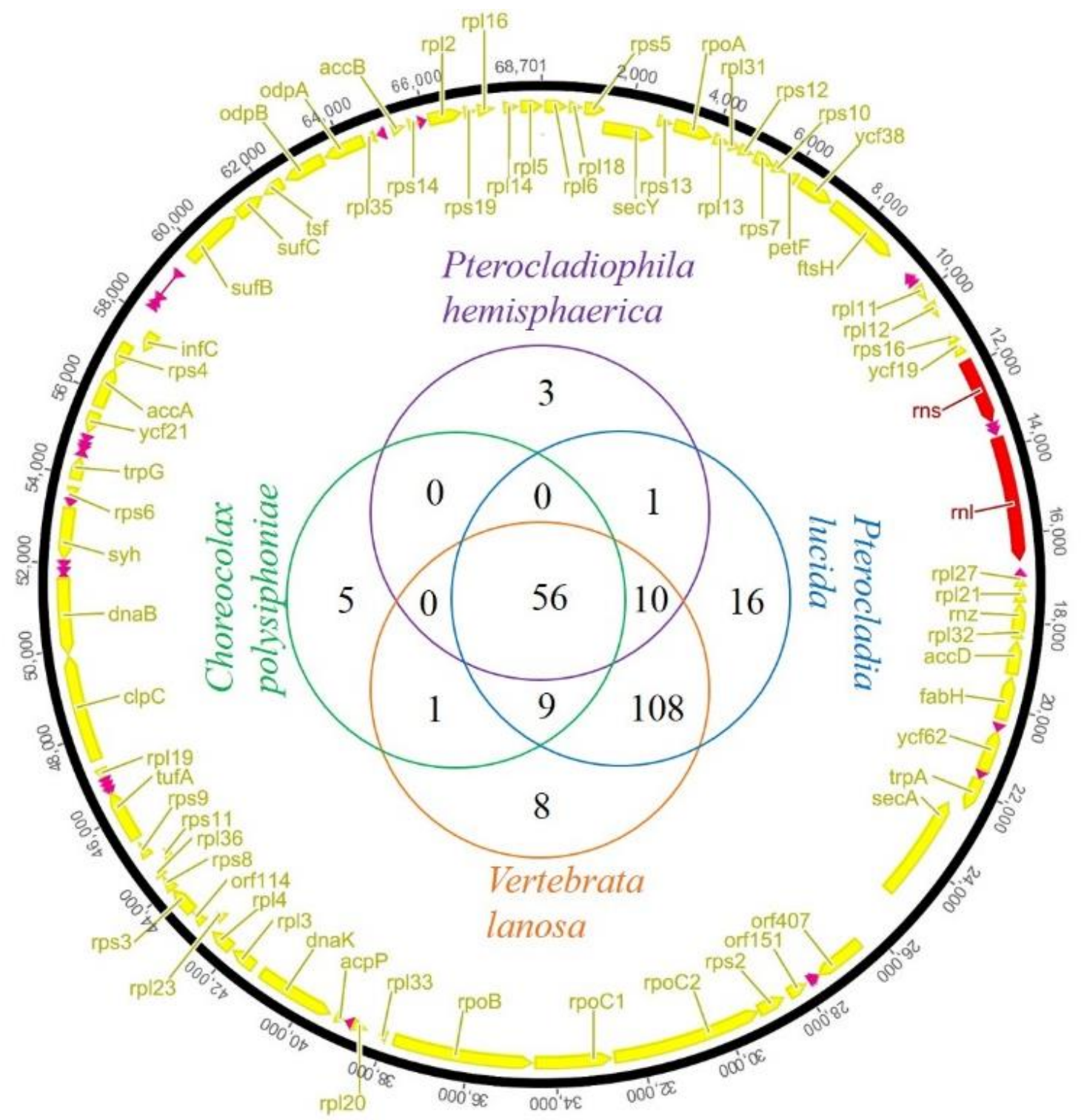

Fig. 5.1. The plastid genome of the parasite Pterocladiophila hemisphaerica with 70 protein coding genes (yellow), 2 rRNA's (red) and 26 tRNA's (pink). Venn diagram represents the unique and shared genes between the parasite Pterocladiophila hemisphaerica and its host Pterocladia lucida and the parasite Choreocolax polysiphoniae and its host Vertebrata lanosa. 
Table 5.1. Whole plastid genome size in the parasite Pterocladiophila hemisphaerica and its host Pterocladia lucida, plus the parasite Choreocolax polysiphoniae and its host Vertebrata lanosa (Salomaki et al. 2015). Length, AT content, number of protein coding genes, tRNA's, rRNAs and total number of genes. - = missing data.

\begin{tabular}{|c|c|c|c|c|c|c|}
\hline & $\begin{array}{l}\text { pDNA } \\
\text { size (bp) }\end{array}$ & $\begin{array}{l}\mathrm{AT} \\
\text { content } \\
(\%)\end{array}$ & $\begin{array}{l}\text { Protein } \\
\text { coding } \\
\text { genes }\end{array}$ & tRNA & rRNA & Total \\
\hline Pterocladiophila hemisphaerica & 68,701 & 74.2 & 70 & 26 & 2 & 98 \\
\hline Pterocladia lucida & 176,635 & 70.3 & 200 & 30 & 3 & 233 \\
\hline Choreocolax polysiphoniae & 90,243 & 79.5 & 71 & 24 & 3 & 98 \\
\hline Vertebrata lanosa & 167,158 & 70.0 & 192 & 27 & 3 & 222 \\
\hline
\end{tabular}

\section{Mitochondrial genome}

The circular mapping mitochondrial genome of Pterocladiophila hemisphaerica is $25,486 \mathrm{bp}$ long (Appendix 5.5). The mitochondrial genome contains 24 protein coding genes and is similar to the mitochondrial genome of its host Pterocladia lucida (cryptic species Group II, Table 5.2, Appendix 5.5-5.7). The parasite mitochondrial genome is extremely densely packed with less than $8 \%$ non-coding regions and a high A-T content in all protein coding $(70.7-89.1 \%$ AT content), rRNAs (59.5-73.7\%) and tRNAs (71.7-79.1\%) genes.

Table 5.2. Whole mitochondrial genomes of Pterocladiophila hemisphaerica and Pterocladia lucida. Length, AT content, number of protein coding genes, tRNAs, rRNAs and total number of genes.

\begin{tabular}{llllllc}
\hline & mtDNA & AT & Protein & tRNA & rRNA & Total \\
& size $(\mathrm{bp})$ & $\begin{array}{l}\text { content } \\
\text { coding }\end{array}$ & & & \\
& & $(\%)$ & genes & & & \\
\hline Pterocladiophila hemisphaerica & 25,486 & $77.5 \%$ & 24 & 24 & 3 & 51 \\
Pterocladia lucida & 25,257 & $70.4 \%$ & 24 & 23 & 3 & 50 \\
\hline
\end{tabular}




\section{Nuclear DNA}

The concatenated nuclear alignment (LSU and SSU rDNA) contained 226 taxa and was 3,611 bp long containing Pterocladiophila hemisphaerica and Pterocladia lucida and representatives of other Florideophyceae. A strongly supported ML topology showed Pterocladiophila hemisphaerica as sister to the Gelidiales and other red algal orders (Fig. 5.2).

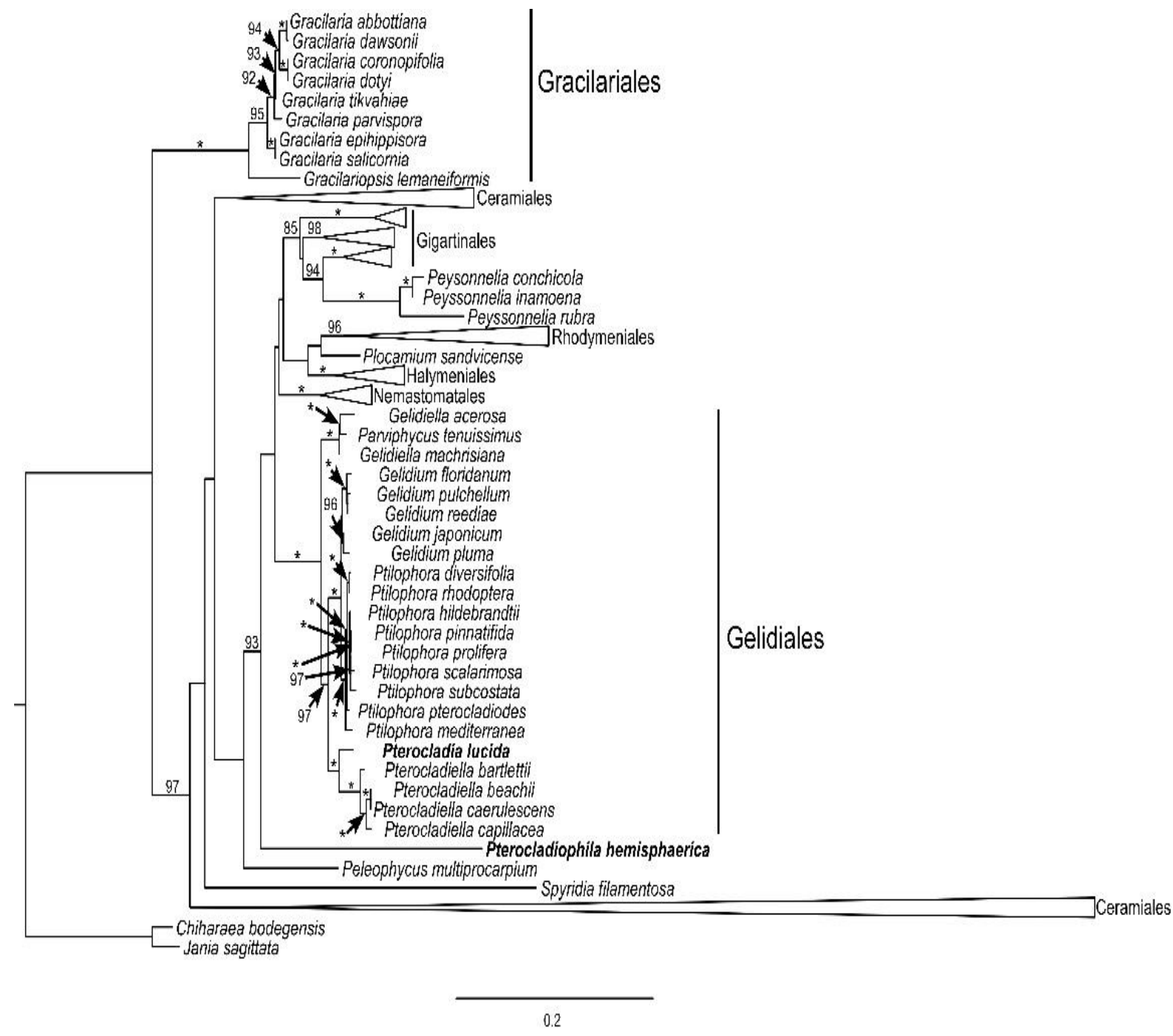

Fig. 5.2. ML topology of concatenated LSU and SSU rDNA sequence data set for the parasite Pterocladiophila hemisphaerica and its host Pterocladia lucida plus representatives of Gelidiales, Ceramiales, Gracilariales and other related taxa from GenBank (Appendix 5.1). Jania sagittata and Chiharaea bodegensis were used as outgroups. Asterisks indicate ultrafast ML bootstrap values of $100 \%$. Values $<85 \%$ ultrafast ML bootstrap not shown. P. hemisphaerica groups as sister to the Gelidiales and other red algal orders. 
The concatenated mitochondrial data set contained 43 taxa and was 6301 amino acids long with all protein coding genes included. ML topology showed an unsupported relationship for Pterocladiophila hemisphaerica on a long branch as sister to the Ceramiales (Fig. 5.3).

After the removal of mitochondrial genes with elevated rates, the remaining data set consisted of 7 genes (1,846 amino acids) and 43 taxa. $P$. hemisphaerica grouped in an unsupported relationship sister to the Gracilariales (Fig. 5.4).

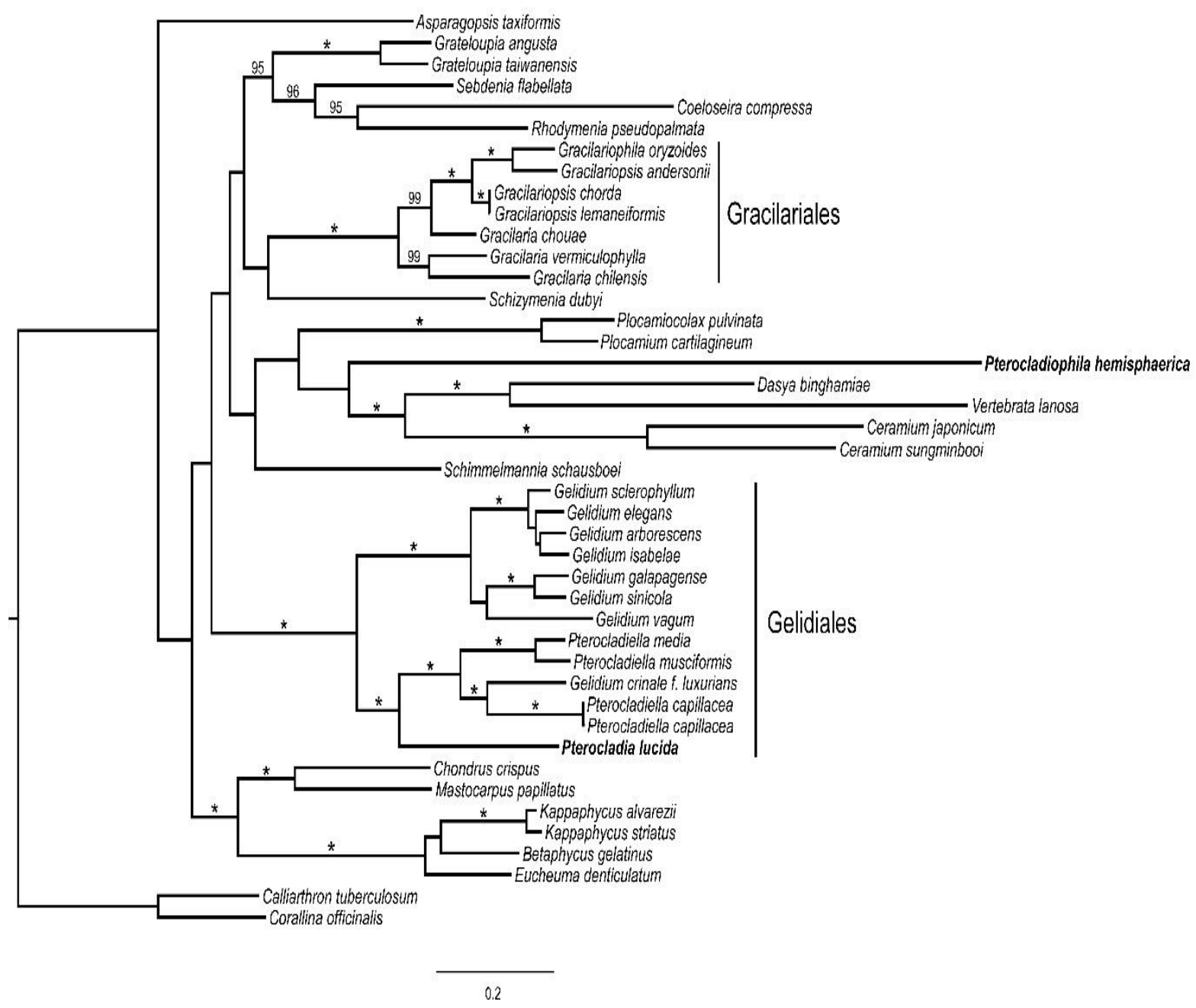

Fig. 5.3. ML topology of all concatenated mitochondrial protein coding genes of the parasite Pterocladiophila hemisphaerica with its host Pterocladia lucida plus representatives of other red algal taxa including members of the Gelidiales and Gracilariales. Calliarthron tuberculosum and Corallina officinallis were used as outgroups. Asterisks indicate fast ML bootstrap values of $100 \%$. Values $<85 \%$ fast ML bootstrap not shown. Pterocladiophila hemisphaerica groups unsupported as sister to the Ceramiales on a long branch. 
cpDNA

The concatenated plastid data set contained 82 taxa and was 55,461 amino acids long containing Pterocladiophila hemisphaerica. The ML topology showed an unsupported relationship of Pterocladiophila hemisphaerica, on a very long branch, as the sister lineage of Gracilariales (Fig. 5.5).

After the removal of plastid genes with elevated rates, the remaining data set consisted of a total of 158 genes with only 8 genes found in Pterocladiophila hemisphaerica (38,657 amino acids) and 82 taxa. In phylogenetic analyses of this data set, Pterocladiophila hemisphaerica grouped in an unsupported relationship sister to the Gelidiales (Fig. 5.6).

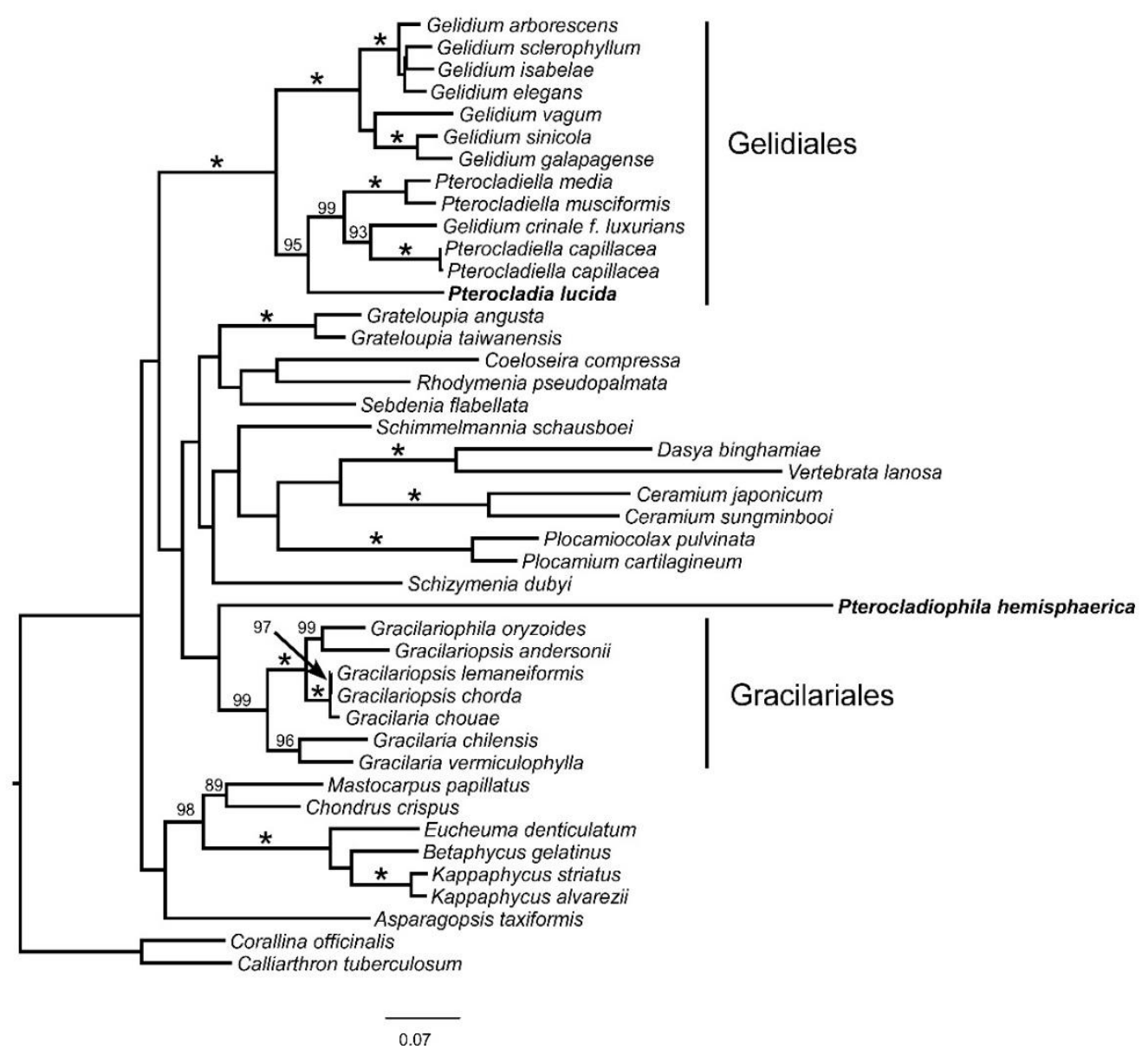

Fig. 5.4. ML topology of 7 trimmed mitochondrial genes without elevated rates of the parasite Pterocladiophila hemisphaerica shared with its host Pterocladia lucida plus representatives of other red algae taxa including members of the Gelidiales, Gracilariales and Ceramiales. Calliarthron tuberculosum and Corallina officinallis were used as outgroups. Asterisks indicate ML bootstrap values of $100 \%$. Values < $85 \%$ ML bootstrap not shown. Pterocladiophila hemisphaerica groups unsupported as a sister to the Gracilariales. 
Host organelle genomes in parasite data set

Host mtDNA, nDNA and cpDNA were identified within the HTS data of the parasite tissue. The overlap and resolution were high enough to assemble and annotate whole plastid and mitochondrial genomes of the host. Host organelle genomes sequenced separately, were almost identical to host contigs derived from parasite HTS data (3 bp difference each).

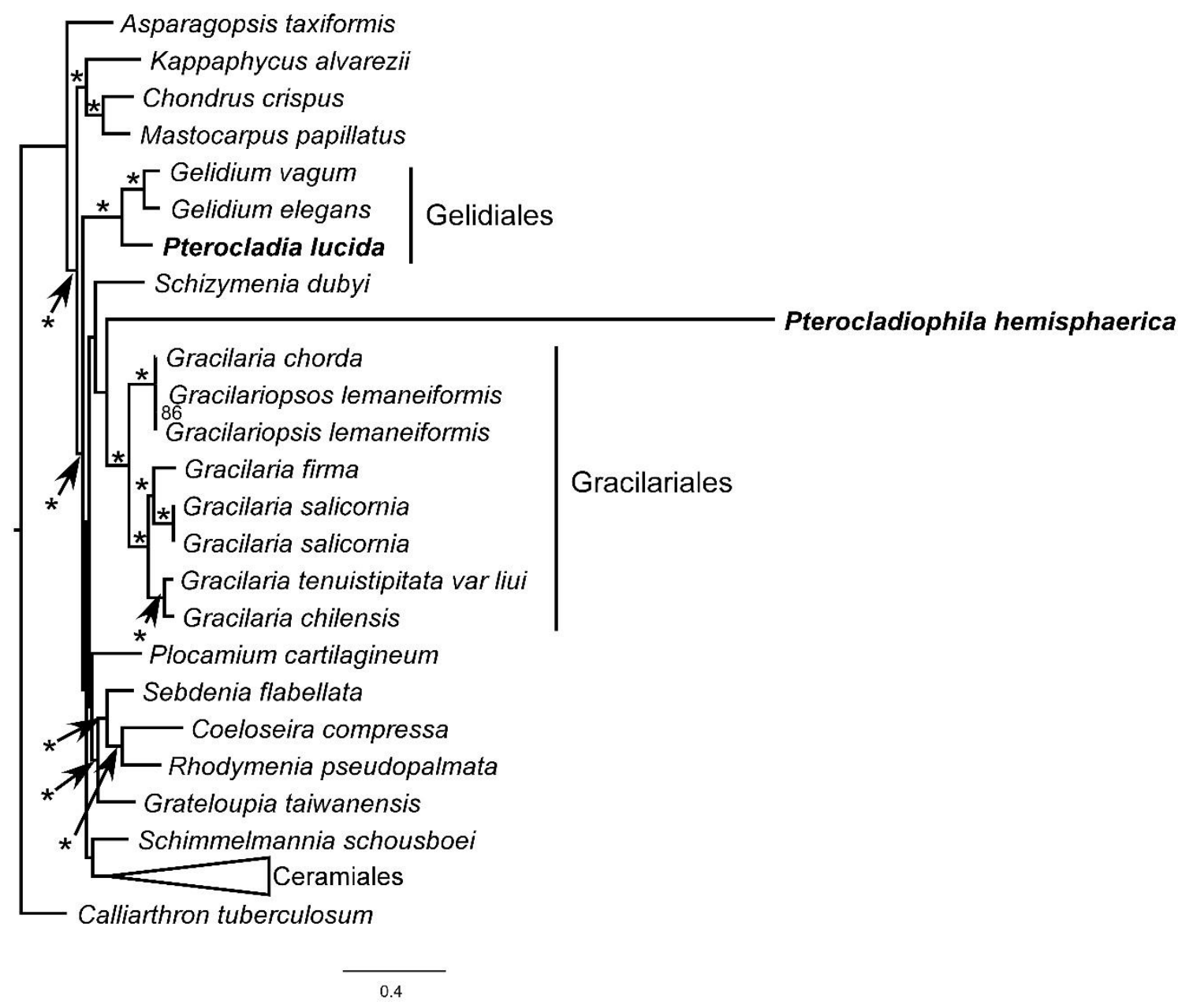

Fig. 5.5. ML topology of all concatenated plastid genes of the parasite Pterocladiophila hemisphaerica shared with its host Pterocladia lucida plus representatives of other red algal taxa including member of the Gelidiales, Gracilariales and Ceramiales. Calliarthron tuberculosum was used as an outgroup. Asterisks indicate ML bootstrap values of $100 \%$. Values $<85 \%$ ML bootstrap not shown. Pterocladiophila hemisphaerica groups is an unsupported position as sister to the Gracilariales on a long branch. 
Parasites were collected from two host populations (Akitio Beach and Kairakau) belonging to different cryptic species of Pterocladia lucida (Boo et al. 2015; Appendix 5.8).

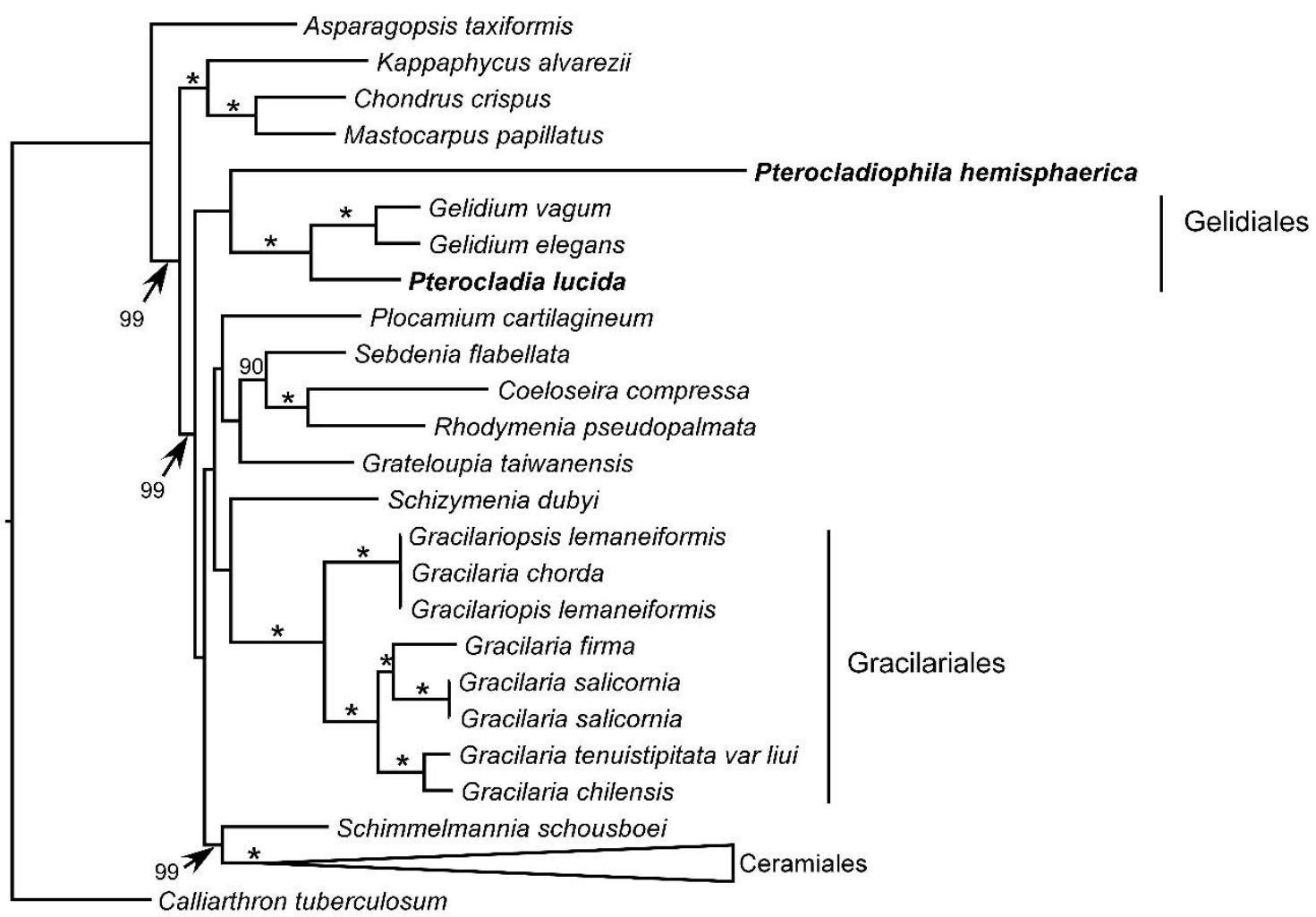

0.2

Fig. 5.6. ML topology of a total of 158 trimmed genes with only 8 plastid genes without elevated rates of the parasite Pterocladiophila hemisphaerica shared with its host Pterocladia lucida plus representatives of other red algae taxa including members of the Gelidiales, Gracilariales and Ceramiales. Calliarthron tuberculosum was used as an outgroup. Asterisks indicate ML bootstrap values of $100 \%$. Values < $85 \%$ ML bootstrap not shown. Pterocladiophila hemisphaerica groups unsupported as a sister to the Gelidiales.

In summary, the parasite $P$. hemisphaerica has a highly reduced plastid genome and a similar mitochondrial genome in comparison to its host. Nuclear rDNA phylogenetic relationships indicate that $P$. hemisphaerica does not belong to the Gracilariales but more likely to the Gelidiales (possibly sister to all included Gelidiales species and other included red algal orders). Organelle genome data sets show different phylogenetic relationship of the parasite without support. The parasite is always on long branches but removal of genes with elevated rates increase branch length. 


\subsection{Discussion}

This is the first study investigating plastid and mitochondrial genomes between parasite and host, and is only the second report of a full red algal parasite plastid genome. For the first time, phylogenetic relationships of a red algal parasites and their host were studied using complete organelle data sets, and our results highlight the importance of careful interpretation of phylogenetic analyses that can be affected by long branch attraction.

The evolution from a free-living ancestor to a parasite has led to a highly reduced plastid genome in $P$. hemisphaerica. This has been found in only one other red algal parasite, Choreocolax polysiphoniae (Salomaki et al. 2015), but is a characteristic of many unpigmented parasitic plants (Bungard 2004; Krause 2008; Bellot et al. 2016). While reduced, the plastid genomes of $P$. hemisphaerica and $C$. polysiphoniae share the majority of protein coding genes, with a similar complement of genes lost, mostly photosynthesis-related genes. Studies of parasitic plants with different degrees of photosynthetic ability showed that rearrangements and gene deletion similarities and difference can be traced between taxa (Wicke et al. 2013; Ravin et al. 2016; Frailey et al. 2018). Our study showed that it is possible to successfully reconstruct host organelles from a 'parasite' data set and this technique might help to increase sampling. Host cells are often embedded in parasite thalli (Goff 1976; Goff \& Coleman 1987; Preuss \& Zuccarello 2014; Chapter 3) plus the parasite may contain heterokaryotic cells containing both host and parasite genomes (Goff \& Coleman 1995; Blouin \& Lane 2016). Increased taxon sampling of red algal parasites, with different relationships to their hosts, will show if there is any pattern in gene loss/rearrangement in red algal parasite evolution.

A reduced plastid genome is not surprising in an unpigmented parasite like C. polysiphoniae but a highly reduced plastid genome is found in pigmented $P$. hemisphaerica. This indicates that pigmented parasite cells rely on host plastids for pigment production and possibly photosynthesis. Whether these host plastids are supplied with protein subunits from parasite nuclear-encoded genes or rely on host nuclear genes, residing in heterokaryotic cells (Zuccarello \& West 1994a; Goff \& Coleman 1995; Blouin \& Lane 2016), is unknown. The evolutionary distance between the parasite, sister to all Gelidiales, and its Pterocladia host, may make protein interactions in oligomers problematic, as has been shown during hybrid breakdown between species crosses due to mitochondria-nuclear incompatibilities or plastidnuclear incompatibilities (Ellison \& Burton 2008; Zeng et al. 2016). 
The mitochondrial genome of $P$. hemisphaerica is highly conserved in size, architecture and gene number, similar to its host and other Florideophyceae (Yang et al. 2015; Salomaki \& Lane 2017). Reduction of mitochondrial genomes is known for some parasitic taxa such as the apicomplexan Plasmodium (Feagin 2000), parasitic plants (Skippington et al. 2015) and the diplomonad Giardia intestinalis (Jedelský et al. 2011); these studies stand in contrast to the full complement of genes in the mitochondrial genome of $P$. hemisphaerica. The conservation of mitochondrial genome architecture between P. hemisphaerica and other red algae would indicate that they are under similar evolutionary constraints, in contrast to the plastid. And yet our analysis of full mitochondrial data sets does show elevated mutation rates, and contrasting phylogenetic placement, between the parasite and nearly all other red algal taxa. Whether this is due to selective changes during parasitism, e.g., associated with lower energy requirements in heterokaryon cells, and/or changes in error rates from suboptimal oligomer repair complexes, is not known.

Currently, the parasite Pterocladiophila hemisphaerica is placed with two other parasite genera (Holmsella and Gelidiocolax) in the Gracilariales as these parasites share the morphological characteristics of a 2-celled carpogonial branch, straight spermatangial chains and transverse divisions of spermatangial parent cells (Fredericq \& Hommersand 1990). The placement of Holmsella spp. within the Gracilariales was confirmed with a nuclear DNA marker (Zuccarello et al. 2004). Our nuclear data set indicates that $P$. hemisphaerica is not part of the Gracilariales but shares a sister relationship with several orders, including the Gelidiales (order of host species). All known red algal parasites infect only species in the same order (Goff 1982; Goff et al. 1996; Zuccarello et al. 2004; Kurihara et al. 2010; Chapter 3) and this would support the placement of $P$. hemisphaerica with the Gelidiales. This distance between parasite and host could be due to an early divergence of the parasitic lineage before present day Gelidiales diversification, suggesting that this could be an ancient parasitism. Further studies of the complete nuclear genomes may support the placement of the parasite with the Gelidiales.

Organelle genome data could not resolve the taxonomic position of $P$. hemisphaerica and always placed the parasite on unsupported long branches with a variety of red algal orders. Our plastid data set grouped $P$. hemisphaerica as an unsupported sister with the Gracilariales on a long branchand after removal of plastid genes with elevates rates grouped the parasite still unsupported with the Gelidiales. The full mitochondrial data set grouped $P$. hemisphaerica 
unsupported with the Ceramiales on a long branch and also after removal of mitochondrial genes with elevated rates. The lack of resolution in both organelle data sets, influenced by spurious signals, even with filtered genes, demonstrates that phylogenies cannot always provide reliable placement of these red algal parasites

Our study shows that phylogenetic results from whole organelle genome data sets need to be carefully interpreted. Determining parasite origin from genomes that have high evolutionary rates or are under different selection regimes, could lead to incorrect relationships. The unique morphological characters of $P$. hemisphaerica have always caused uncertainty in its taxonomic placement (Fan \& Papenfuss 1959), and its placement in the Gracilariales and family Pterocladiophilaceae, was mostly due to general characters and the fact that other parasites were placed there (Fredericq \& Hommersand 1990). Our nuclear data indicates that the parasite did not evolve in the Gracilariales but its taxonomic placement is still uncertain. P. hemisphaerica might have evolved in the Gelidiales, one of the other red algal orders such as Gigartinales, or in an early divergent lineage before the present day Gelidiales and/or of the other red algal orders. 


\section{Chapter Six}

Comparative studies of photosynthetic capacity in three pigmented red algal parasites using chlorophyll $a$ concentrations and PAM fluorometry 


\subsection{Abstract}

Over 100 species of red algae have been described as parasites on other red algae, but the majority show some degree of pigmentation. This raises the question of their parasitic status, especially their abilities to photosynthesize and their dependence on their host for fixed carbon. Are they considered parasites only based on morphological characters, for example, reduced size and secondary pit connection to the host? Translocation of nutrients from host to parasite have been shown for very few red algal parasites, and these were mostly unpigmented. This study investigated three pigmented red algal parasites (Rhodophyllis parasitica, Vertebrata aterrimophila and Pterocladiophila hemisphaerica) from New Zealand. We quantified their chlorophyll $a$ content and also measured their PSII capacity using PAM fluorometry. All three parasites contained chlorophyll $a$. The parasites Rhodophyllis parasitica and Vertebrata aterrimophila were not able to photosynthesize and must therefore be fully nutrientional dependent on their host. The parasite Pterocladiophila hemisphaerica was able to photosynthesize independently, but based on molecular characteristics we suggest that it relies on the host plastid to carry out photosynthesis. Our results support the parasitic status of all three species and highlights the necessity of more studies investigating the differences in host dependency in red algal parasites.

Key words: Host dependency, Parasitism, Photosynthesis, Pterocladia lucida, Pterocladiophila hemisphaerica, Rhodophyllis membranacea, Rhodophyllis parasitica, Rhodophyta, Vertebrata aterrima, Vertebrata aterrimophila 


\subsection{Introduction}

Determining the symbiotic status of organisms (e.g., commensalism, mutualism, parasitism) or endo- and epiphytism, is challenging. In a parasitic relationship, one organism benefits while the other organism is harmed (Price 1980), but this can change during the course of the symbiotic interaction (Neuhauser \& Fargione 2004). Parasites and endo-/epiphytes can both be host specific (Goff 1982; González \& Goff 1989; Reif et al. 2005; Gauna \& Parodi 2008) and therefore rely on the host for habitat, even though endo-/epiphytes are able to grow separately from the host in culture (González \& Goff 1989; Notoya \& Miyashita 1999; Gauna \& Pant; Pant \& Thapa 2012). In some cases, parasitic plants are also able to be cultivated without their hosts (Furuhashi 1991). Unpigmented algae can be considered parasites, as their only source of nutrition is from their host, but to distinguish parasitism from other symbiotic relationships, a negative host effect also needs to be shown. The classification of pigmented algae, which appear to have host dependency is even more problematic.

Parasitism has been invoked in many red algae, with over 100 parasite species described (Chapter 2). The majority of red algal parasites are taxonomically closely related to their host species (Goff 1982) with a continuum to distantly related host species (Zuccarello et al. 2004; Blouin \& Lane 2012; Chapter 3). Parasites can have either a plastid captured from their hosts (Goff \& Coleman 1995; Goff et al. 1996), their own plastid comparable in size and genetic composition with other non-parasitic red algae, or a highly reduced plastid genome with few or no photosynthesis gene remaining (Salomaki et al. 2015).

Early description of these organisms classified them as parasites (Reinsch 1875; Schmitz \& Falkenberg 1897). Later, the characteristics of reduced size, deep host penetration and reduced pigmentation, were used for morphological descriptions of their parasitic status (Setchell 1918). More recently the presence and absence of secondary pit connections between parasite and host cells was considered an important character to infer parasitic status (Chapter 2). A majority of red algal parasites are also pigmented (Chapter 2) and this pigmentation calls into question their parasitic status. 
Negative effects on host cells and host fitness by parasite infection is only known in a few red algal parasite species. These negative effects range from degradative changes in infected host cells (Goff 1982; Apt 1984a), loss of cell cycle regulation (Goff 1976; Goff \& Coleman 1985) and infection spreading to surrounding host cells (Goff \& Coleman 1995). Studies showing nutrient transfer to red algal parasites are rather limited and focus mainly on unpigmented species. Experiments with ${ }^{14} \mathrm{CO}_{2}$ showed nutrient translocation from host to parasites (Harlin 1973; Callow et al. 1979). The translocation of nutrients was also shown into the parasite Harveyella mirabilis (Reinsch) F.Schmitz et Reinke from the cortical host cell via the contact area between host and parasite thalli (Goff 1979; Kremer 1983).

Pulse amplitude modulated fluorometry (PAM) is a non-invasive tool to relate chlorophyll fluorescence to photosynthesis (Parkhill et al. 2001; Murchie \& Lawson 2013). Estimates of optimal photochemical efficiency of PSII (effective quantum yield, $\Delta \mathrm{F} / \mathrm{Fm}$ ', light adapted) and photosynthesis potential of PSII (maximum quantum yield, Fv/Fm, dark adapted) are commonly used to show photoinhibition and stress (Kromkamp \& Forster 2003; Murchie \& Lawson 2013). Red algae in culture commonly have Fv/Fm values of around 0.5-0.6 (e.g., Figueroa et al. 1997; Bischof et al. 2000; Lüder et al. 2001; Liu \& Pang 2010). Photosynthetic ability has been demonstrated by measuring Fv/Fm in pigmented parasitic land plants (Strong 2000; van der Kooij et al. 2000) but not in red algal parasites.

The majority of red algal parasites in New Zealand are pigmented (10 of the 13 described species). The parasite Rhodophyllis parasitica M.Preuss et Zuccarello is lightly pigmented and found on its closest relative Rhodophyllis membranacea (Harv.) Hook.f. et Harv. (Preuss \& Zuccarello 2014), Vertebrata aterrimophila M.Preuss et Zuccarello is unpigmented to dark brown and found on the host Vertebrata aterrima (Hook.f. et Harv.) Kuntze (Chapter 4), and Pterocladiophila hemisphaerica K.C.Fan et Papenf. is dark red and found on its host Pterocladia lucida (R.Br.) J.Agardh (Fan \& Papenfuss 1959).

This study investigates the chlorophyll $a$ concentration as well as $\mathrm{Fv} / \mathrm{Fm}$ and $\Delta \mathrm{F} / \mathrm{Fm}$ quantum yield of PSII in these three pigmented parasites and their hosts to investigate their ability to photosynthesize away from their hosts and to provide more understanding of their parasitic status. 


\subsection{Materials and Methods}

Specimens of Rhodophyllis parasitica were collected in January, Vertebrata aterrimophila in September 2017 at Moa Point (41 20' 30" S, 174 48' 38" E) and Pterocladiophila hemisphaerica in June 2017 at Princess Bay (41 20' 46" S, 174 47' 26" E) from shore or by SCUBA in Wellington, New Zealand. Fresh specimens were transported in an ice chest in seawater to the laboratory and sorted.

Wet weight of algal tissue was determined by measurement of $1.5 \mathrm{ml}$ tubes with and without blotted algal tissue. Tissue was then ground in $0.5 \mathrm{ml}$ of $100 \%$ ethanol in $1.5 \mathrm{ml}$ tubes and transferred to glass tube with $9.5 \mathrm{ml}$ of $100 \%$ ethanol. Glass tubes were fully covered with aluminium foil and left for 24 hours in the dark and at $4{ }^{\circ} \mathrm{C} .3 \mathrm{ml}$ of each sample was measured twice (300-650nm) with an AU-10 Fluorometer (Turner Designs, Sunnyvale, California). A second measurement was done after adding $250 \mu \mathrm{l}$ of $1 \mathrm{M} \mathrm{HCl}$. The difference between the two measurements gives the chlorophyll $a$ concentration (Strickland \& Parsons 1972).

Parasites of similar size were removed from the surface of the host using a razor blade. The parasite and one piece of uninfected host tissue were placed separately in 6-well plates with sterile seawater (salinity approximately 33). Triplicates of removed parasites and uninfected host were used to measure $\mathrm{Fv} / \mathrm{Fm}$ and $\Delta \mathrm{F} / \mathrm{Fm}$ ' yield of photosystem II at $540 \mathrm{~nm}$ using a MultiColor-PAM (Walz, Effentrich, Germany). The first measurements were taken directly after the parasite was removed from its host (Day $0,0 \mathrm{~h}$, light adapted) and second set of measurements after an overnight dark acclimation period (Day 1, 0h, dark adapted). The third set of measurements were in light at different time intervals (Day 1, 2h, 4h, 6h, 8h) after the dark adapted measurement (light acclimated). All light experiments were performed at 14.5-4.5 $\mu \mathrm{mol}$ photons $\mathrm{m}^{-2} \mathrm{~s}^{-1}$ constant fluorescent light (Spectro sense 2+, Skye, Wales, UK) and $15 \pm 1^{\circ} \mathrm{C}$. The uninfected host was used as a control following the same procedures.

Statistical analyses of chlorophyll $a$ concentration per $\mathrm{g}$ and $\Delta \mathrm{F} / \mathrm{Fm}$ ' over time involved performing linear mixed effects models using $\mathrm{R}$ version 3.2.5 software (R Core Team 2016) and the nlme package (Pinheiro et al. 2017). The final model was determined via backwards selection, and significant differences in $\Delta \mathrm{F} / \mathrm{Fm}^{\prime}$ over time were determined using planned comparisons. 


\subsection{Results}

Fluorometry showed chlorophyll $a$ concentrations were significantly different for all host and parasite combinations $(P=0.0335)$. All three parasites have less chlorophyll $a$ per $g$ than their host species (Fig. 6.1).

On Day 0, after parasite removal from host, $\Delta \mathrm{F} / \mathrm{Fm}$ (light adapted) was not measurable in the parasites Rhodophyllis parasitica and Vertebrata aterrimophila, and was $0.37 \pm 0.01$ (mean \pm S.E.) in Pterocladiophila hemisphaerica, whereas $\Delta \mathrm{F} / \mathrm{Fm}^{\prime}$ in the hosts was $0.44 \pm 0.01$ in Rhodophyllis membranacea, $0.35 \pm 0.05$ in Vertebrata aterrima and $0.45 \pm 0.03$ in Pterocladia lucida (Fig. 6.2).

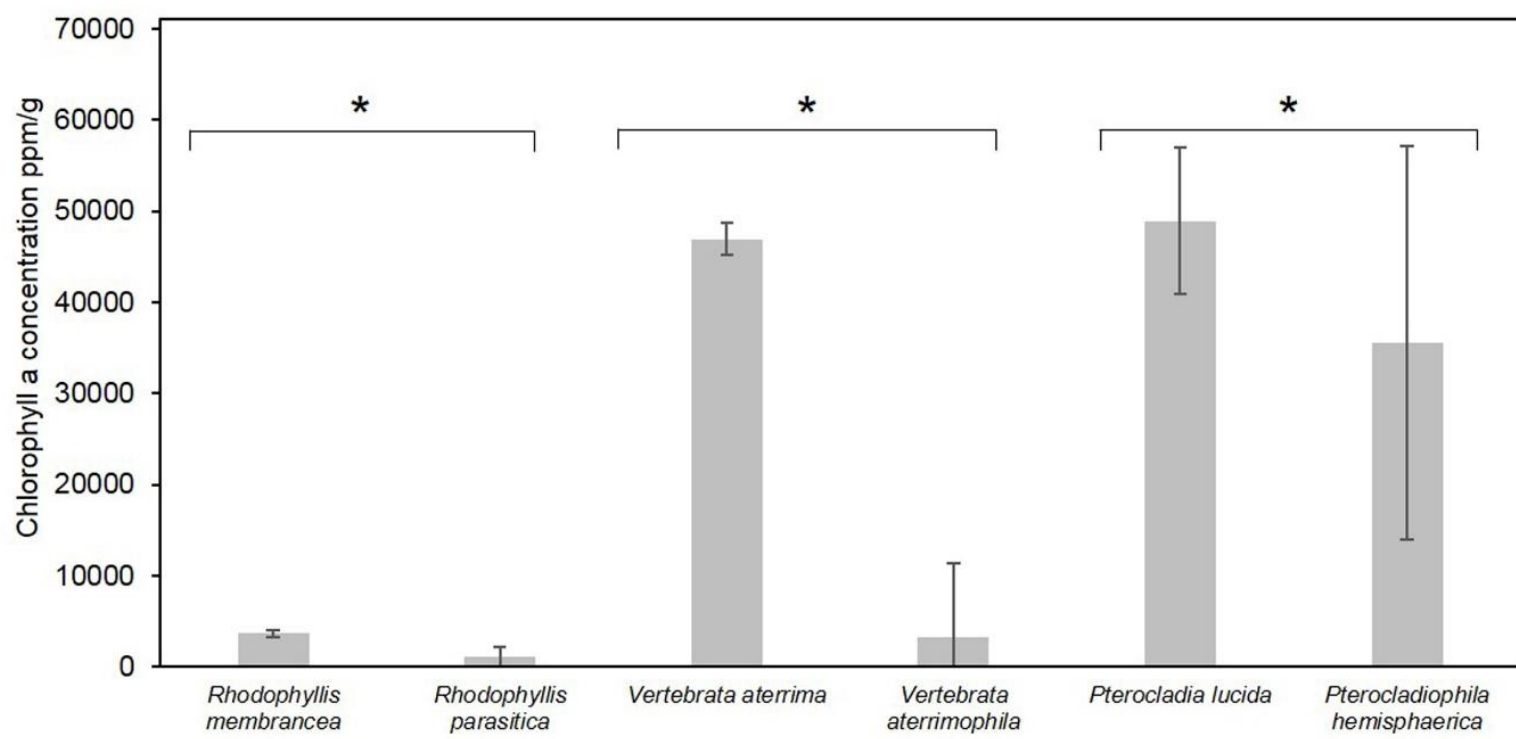

Fig. 6.1. Chlorophyll $a$ concentration in parts per millions (ppm) per $\mathrm{g}$ in three parasites and their hosts. Rhodophyllis membranacea (host) and Rhodophyllis parasitica (parasite), Vertebrata aterrima (host) and Vertebrata aterrimophila (parasite), Pterocladia lucida (host) and Pterocladiophila hemisphaerica (parasite). Values are means \pm S.E. $(n=3)$. Significant differences (asterisk) are found between species and host and parasite combinations $(P=0.0335)$.

On Day 1 (time 0h), Fv/Fm (dark adapted) was not measurable in $R$. parasitica and $V$. aterrimophila, and $0.35 \pm 0.02$ in Pterocladiophila hemisphaerica; and $0.28 \pm 0.04$ in $R$. membranacea, $0.23 \pm 0.06$ in $V$. aterrima and $0.36 \pm 0.03$ in $P$. lucida. 
Over an $8 \mathrm{~h}$ period, $\Delta \mathrm{F} / \mathrm{Fm}$ (light adapted) continued to be undetectable in $R$. parasitica and $V$. aterrimophila and was between 0.3-0.4 in their host species (R. membranacea, V. aterrima, respectively) (Fig. 6.2, Appendix 6.1). Planned comparisons showed $\Delta \mathrm{F} / \mathrm{Fm}$ ' was significantly different between $R$. parasitica and its host $(P<0.0001)$ and $V$. aterrimophila and its host $(P$ $<0.0001) . \Delta \mathrm{F} / \mathrm{Fm}^{\prime}$ in the parasite Pterocladiophila hemisphaerica and its host Pterocladia lucida were between $0.35-0.25$ and planned comparisons showed $\Delta \mathrm{F} / \mathrm{Fm}$ ' was not significantly different between the parasite and its host $(P=0.923)$ (Fig. 6.2). The overall linear mixed effects model showed significant differences between parasite and hosts $\left(F_{1,6}=148.2886, P<\right.$ $0.0001)$, between species $\left(F_{2,6}=10.5595, P=0.0108\right)$ and between species, host and parasite $\left(F_{2,6}=31.6903, P=0.0006\right)$, and no significant differences with time $\left(F_{1,53}=0.00643, P=\right.$ $0.9364)$.
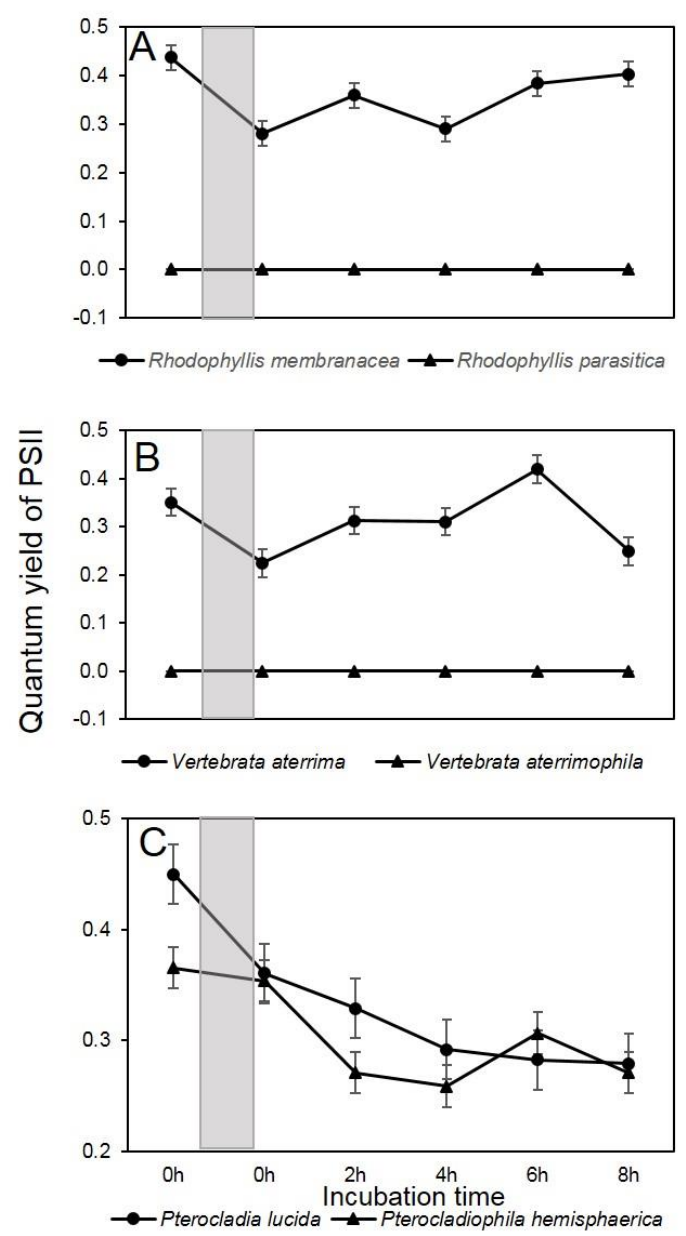

Fig. 6.1A-C. $\Delta \mathrm{F} / \mathrm{Fm}$ ' (Day0, 0h, first points), Fv/Fm (Day1, 0h, dark acclimated), and $\Delta \mathrm{F} / \mathrm{Fm}$ ' values over time (Day1, 2h, 4h, 6h, 8h) in three parasites and their hosts: A. Rhodophyllis membranacea (host) and Rhodophyllis parasitica (parasite), B. Vertebrata aterrima (host) and Vertebrata aterrimophila, C. Pterocladia lucida (host) and Pterocladiophila hemisphaerica (parasite). Values are means \pm S.E. $(n=3)$. Significant differences are found between $R$. parasitica and its host $R$. membranacea $(P<0.0001)$ and $V$. aterrimophila and its host V. aterrima $(P$ $<0.0001)$. Grey shadow indicates overnight dark acclimation period. 


\subsection{Discussion}

Our study shows that all three pigmented parasites contain chlorophyll $a$ but only the parasite Pterocladiophila hemisphaerica was able to photosynthesize independently, whereas the parasites Rhodophyllis parasitica and Vertebrata aterrimophila have lost their photosynthetic ability. $R$. parasitica and $V$. aterrimophila are therefore classified as parasites as they must rely fully on photosynthates from their hosts. The low chlorophyll $a$ concentration might indicate the gradually loss of pigments in these parasites, or is caused by embedded host cells in the tissues of some parasitic taxa such as Rhodophyllis parasitica (Preuss \& Zuccarello 2014). Loss of photosynthetic ability is known from parasitic land plants, without any chlorophyll, such as species of Orobranche, but not in species that contain chlorophyll (e.g., Cuscuta, Westwood et. al. 2010). Red algal species contain additional photosynthetic pigments, such as phycobiliproteins (Hurd et al. 2014), and the presence of these pigments should be investigated in future research.

The parasite Pterocladiophila hemisphaerica has a higher chlorophyll $a$ concentration than the other parasites and $\Delta \mathrm{F} / \mathrm{Fm}^{\prime}$ and $\mathrm{Fv} / \mathrm{Fm}$ of PSII could be measured, demonstrating that $P$. hemisphaerica is able to photosynthesize independently. Photosynthetic ability is not proof that the parasite is self-sufficient and does not gain any photosynthates from the host. Several pigmented parasitic land plants are also able to photosynthesize independently but still gain most of the nutrients from their host (Tesitel et al. 2010). Translocation experiments are needed to fully understand the nutrient dependence of $P$. hemisphaerica. While it can photosynthesize P. hemisphaerica does show several morphological characteristics that have been used to support its 'parasite' designation, especially secondary pit connection between host and parasite cells (Evans et al. 1978), a crucial character to determine parasitic status (Goff \& Coleman 1985; Wynne \& Scott 1989; Chapter 2).

The photosynthetic ability of $P$. hemisphaerica is unexpected as its plastid genome is highly reduced, with no genes for photosynthetic processes (Chapter 5). This suggests that the parasite either has all photosynthetic genes in its nuclear genome or uses the host plastids. Nuclear genomes of red algal parasites have not been sequenced, but it is likely that the parasite uses host plastids, as host plastid in parasite cells ("organelle capture") have been shown in other red algal parasites (Goff \& Coleman 1995). Host plastids have been found in the parasites: Plocamiocolax pulvinata Setch., Gracilariophila oryzoides Setch. et H.L.Wilson, and 
Gardneriella tuberifera Kylin (Goff \& Coleman 1995). These parasites are unpigmented, and the function of the host plastids, if any, needs further investigation.

Pterocladiophila hemisphaerica might have a similar host dependency as the parasite Choreocolax polysiphoniae Reinsch in which photosynthetic ability was assumed when $\mathrm{CO}_{2}$ fixation increased over time in unattached specimens (Callow et al. 1979). C. polysiphoniae also has a plastid with a reduced genome (Salomaki et al. 2015). We suggest that some parasites with reduced plastid genomes may retain the host plastids in their cells to use for photosynthetic processes. The nuclear-derived plastid proteins for plastid function either come from host nuclei in heterokaryotic cells, or from parasite nuclear RNA transcripts. This second scenario would require interactions of parasite nuclear-derived-plastid proteins with host plastid genomederived proteins to produce functional plastids. Sequencing of the transcriptome of the parasite and host would address these possibilities.

Fv/Fm values were similar between all host species (Rhodophyllis membranacea, Vertebrata aterrima and Pterocladia lucida) and the parasite Pterocladiophila hemisphaerica, but were much lower than in other red algae (usually around 0.6, Figueroa et al. 1997; Lüder et al. 2001). The lower values of Fv/Fm may demonstrate stress or photoinhibition (Park et al. 2002; Mallick \& Mohn 2003) or downregulation of photosynthesis (Groom \& Baker 1992; Velez-Ramirez et al. 2017) in our experiments. The similarities of the Fv/Fm values in our study (when measurable) and similar values to $\Delta \mathrm{F} / \mathrm{Fm}$ ' suggests an influence of our culture conditions.

In summary, pigmented red algal parasites can be as dependent on host photosynthates as unpigmented parasites. Other pigmented red algal parasites have the ability to photosynthesize independently, but their degree of host nutritional dependency needs further studies. Host dependency in red algal parasites cannot be determined by degree of pigmentation and needs individual assessment. 


\section{Chapter Seven}

General Discussion 


\subsection{Findings}

My $\mathrm{PhD}$ thesis contributes significantly to red algal parasite knowledge with five main findings. Firstly, many parasitic species have been described but our general knowledge of these parasites and parasitic process are still poorly studied. I summarized data of all known parasites and produced a comprehensive review of the current state of knowledge. Secondly, I performed phylogenetic analyses that revealed contrasting evolutionary relationships of three new red algal parasites: Cladhymenia oblongifoliophila, Phycodrys novae-zelandiophila and Judithia parasitica from New Zealand. Thirdly, I studied the development of the new parasite Vertebrata aterrimophila, discovering a different development from most previously reported, with localised infection and few changes inside the infected host cells. Fourthly, I sequenced and assembled the organelle genomes of the red algal parasite Pterocladiophila hemisphaerica. This parasite has a reduced non-photosynthetic plastid genome, which makes determining its phylogenetic relationships problematic, but careful analysis places it as sister to its host order, the Gelidiales. Lastly, I compared the photosynthetic ability of three pigmented red algal parasites.

My $\mathrm{PhD}$ research clearly demonstrated that there are many aspects of these parasites that we do not know nor fully understand (Chapter 2), and the many new findings in this thesis add to our current knowledge of parasites, including parasite and host relationships (Chapters 3-5), development (Chapter 4), genome evolution (Chapter 5) and physiology (Chapter 6). This increases knowledge of the diversity of red algal parasites, and New Zealand macroalgae, by describing four new species (Chapters 3-4). One unexpected discovery was the photosynthetic ability revealed in the pigmented red algal parasite Pterocladiophila hemisphaerica (Chapter 6) that has a reduced non-photosynthetic plastid genome (Chapter 5). 


\subsection{Diversity and evolution in parasites}

Diversity of red algal parasites was estimated to be between 100-121 species (Goff 1982; Blouin \& Lane 2012; Salomaki \& Lane 2014; Blouin \& Lane 2016). This study showed that 120 species have been described in the literature (Chapter 2) with several newly described species from this study adding to the current recorded diversity (Chapters 3-4). Understanding red algal parasite diversity will help us to understand their success within red algae, and makes the choice of study organisms more varied. Future research should investigate their diversity in New Zealand and around the world. New Zealand has many more red algal parasites, that were either collected during my field work or observed in the Te Papa herbarium, that have not been formally described. A combined study using extensive fieldwork around New Zealand, including scuba and herbarium investigations, is required to discover more of these undescribed species, which should be morphologically and phylogenetically (using mitochondrial, nuclear and plastid markers) investigated to determine the parasite's origin and placement.

Phylogenetic studies have become a common tool to identify new parasite species (Sekimoto et al. 2009; Skovgaard \& Salomonsen 2009), investigate their origin (Litaker et al. 1999; Skovgaard et al. 2007; Barkman et al. 2008) and host switching (Fraser \& Waters 2013; Pelser et al. 2016). Molecular data are still rather limited for red algal parasites with only $27 \%$ of all red algal parasites having been sequenced (Chapter 2). Phylogenetic analyses of the four new red algal parasites: (Cladhymenia oblongifoliophila, Phycodrys novae-zelandiophila, Judithia parasitica and Vertebrata aterrimophila) show contrasting patterns of phylogenetic relationships by using a range of markers from all three genomes (cpDNA: $r b c \mathrm{~L}, \mathrm{nDNA}$ : actin, LSU rRNA; mtDNA: cox1) (Chapters 3-4). Current phylogenies are clearly limited by the availability of sequences online (GenBank) as well as a consequence of taxon sampling. Future research should sequence as many of these described species and phylogenies using markers of all three genomes (mitochondrial, plastid, nuclear), and sequence data should also be included in new species descriptions to assist with understanding the parasite relationships with its host and the parasite's taxonomic placement. 
The few phylogenetic studies that have been conducted on red algal parasites often only looked at either genes in the nuclear genome (Goff et al. 1996; 1997; Zuccarello et al. 2004) or genes from the nuclear and mitochondrial genome (Kurihara et al. 2010) and rarely at genes from all three genomes (Preuss \& Zuccarello 2014). This study showed that phylogenetic data from all three genomes are available for only $2.5 \%$ of all species (Chapter 2). In some cases, genes from three genomes can show the same phylogenetic relationships, as shown in Judithia parasitica and Phycodrys novae-zelandiophila. (Chapter 3). However, in other cases, mitochondrial and nuclear genes show a pattern that differs from the plastid genes, e.g., Cladhymenia oblongifoliophila, indicating one mitochondrial and nuclear origin (host species) and one plastid origin (another Cladhymenia species) (Chapter 3). My results demonstrate the importance of studying all three genomes to understand parasite evolutionary history. In cases where there is a close phylogenetic relationship between parasite and host, it is often hard to get variable markers that show any difference between parasite and host. An alternative might be the use of uncommon markers (e.g., actin) or designing new primers for more variable genes or genomic regions (introns, spacers). Another alternative could be the use of single nucleotide polymorphisms (SNPs) and microsatellites for studying population pattern within species and within parasites and hosts. The small thallus size and small population size have to be carefully considered for obtaining the necessary amount of DNA and also how many parasites within and between populations can be collected and compared.

Evolutionary rates can differ between genomes of parasites and free-living taxa (Bromham et al. 2013). These differences in evolutionary rates might lead to long branch attraction (LBA), where fast evolving taxa group together but which does not reflect their phylogenetic relationship (Bergsten 2005). Our study showed the parasite Pterocladiophila hemisphaerica on very long branches in the mitochondrial and plastid data sets giving conflicting phylogenies for the parasite (Chapter 6). In the end, to avoid LBA, our study used non-elevated rates in plastid genes of the parasite and showed the origin of the parasite as sister to its host order, which aligns with our current knowledge of these parasites (Chapter 6). The robustness of using genes with non-elevated rates should be tested with other data sets. LBA might be caused by different factors, e.g., elevated mutation rates, and interpretation of the analyses needs to address these factors. LBA can be a serious problem, and is found in an increasing number of data sets, often hidden under different names, e.g., model misperfection (Bergsten 2005): this study demonstrates that parasite data sets can also be influenced by LBA. 


\subsection{Organelle genome evolution}

Organelle genomes are extremely limited in red algal parasites (Chapter 2). The mitochondrial genomes of the parasites Gracilariophila oryzoides and Plocamiocolax pulvinata are similar in size, gene content, order and arrangement to other non-parasitic red algae (Hancock et al. 2010). Our study shows a similar mitochondrial genome in size, gene content, order and arrangement of the parasite Pterocladiophila hemisphaerica and its host Pterocladia lucida (Chapter 5). In contrast, the plastid genome of the parasite Choreocolax polysiphonia is highly reduced without photosynthetic genes (Salomaki et al. 2015). Our study showed that this reduced plastid, without photosynthetic genes, is also found in the red algal parasite Pterocladiophila hemisphaerica but both parasite plastids differ in their gene arrangements and, to some degree, gene content (Chapter 5).

Reduced non-photosynthetic plastid genomes are often associated with parasitic plants and algae (Wolfe et al. 1992; Wilson et al. 1996; de Konig \& Keeling 2006; Cusimano \& Wicke 2016) and this study shows that in a pigmented red algal parasite a reduced non-photosynthetic plastid genome can be found (Chapter 6). Even though reduced plastid genomes are common, the underlying mechanisms (e.g., patterns of gene deletion) are poorly studied (Cusimano \& Wicke 2006). Future research should focus on sequencing a range of red algal parasites with different relatedness to their hosts (and therefore possibly different ages of parasite origin) and determine, by plastid characterization, if the gene deletion processes can be reconstructed. Parasites that are closely related to their hosts might have some photosynthetic genes as it is unlikely that all genes get transferred to the nuclear or deleted at once. Ideally, taxon sampling should be on countries where a rich parasite flora has been reported e.g., USA (26 species), South Africa (13 species), Australia (11 species) (Chapter 2) and New Zealand (13 species) (Chapters 3-4).

Host nutrient dependency is rarely discussed in red algal parasites and this is the first study demonstrating differences in photosynthetic ability in pigmented red algal parasites (Chapter 6). Interestingly, the photosynthetic ability in the pigmented red algal parasite Pterocladiophila hemisphaerica (Chapter 6) with the reduced plastid (Chapter 5) must be either due to the use of the host plastid in parasite cells, or that the parasite has transferred all missing photosynthetic genes into the nuclear genome (Chapter 6). Currently, no nuclear genomes are sequenced in red algal parasites and this lack of knowledge is one limitation to fully understand their host nutrient 
dependency. Some parasitic nuclear genomes (e.g., in Plasmodium, Microsporidia) have undergone deletion or compaction processes (Keeling \& Slamovits 2005). Parasitic plants with reduced plastids have transferred plastid genes into the nuclear genome either as full-length (possible functional) or nearly full-length genes (Cusimano \& Wicke 2016). Generally, sequenced nuclear genomes of parasites are limited in number, with a focus on parasitic species of human importance (e.g., medical, veterinary) and this may lead to bias in the generalisations that are being derived from these data (Poulin \& Randhawa 2015). Nuclear sequencing is needed to clarify the photosynthetic ability of $P$. hemisphaerica and to understand nuclear genome organization (e.g., size, gene numbers, missing genes) in comparison to other red algae and the parasite's closest relatives. Transcriptome data would also be useful to look at in Pterocladiophila hemisphaerica or other red algal parasites to determine which genes are important (up-regulated) for its lifestyle. Furthermore, comparing differences in gene expression in infected and uninfected host species should show the impact of the parasite on its hosts' transcriptome and how infected host species adapt when being parasitized.

\subsection{Is there enough evidence to label red algal parasites as parasites?}

Red algal parasites have been labelled as parasites from the earliest studies published (Richard 1891; Schmitz \& Falkenberg 1897; Setchell 1914) before any benefit for the parasite (e.g., transfer of nutrients from host to parasite; Evans et al. 1973) and any harm for the host (e.g., cellular changes within infected host cells; Goff 1976) were demonstrated. Further evidence of negative impacts on the host is still limited (Chapter 2). This study shows clearly that pigmented parasites can still be totally nutrient dependent on their hosts while other pigmented parasites are able to photosynthesize independently (Chapter 6). An apparent increase in carbohydrate concentrations, nuclei size increase and structural changes in infected host cells of Vertebrata aterrima were demonstrated (Chapter 4). At the moment, there is evidence that these parasites gain some nutrients from their hosts and have mostly limited impact on the host itself, which might reflect a more commensalistic relationship (benefit for one organism and no positive or negative effect for the other organism) rather than parasitic relationship. Future research should focus on studying the impact of these parasites on their hosts, and more extensive data should help to clarify if it is appropriate to classify these organisms as parasites. Comparing reproductive output or photosynthetic ability of infected and uninfected host species, e.g., for Vertebrata aterrima, would be one approach. 


\subsection{Pigmentation in parasites}

The majority of red algal parasites are pigmented (Chapter 2) and to our knowledge this is the first study looking at chlorophyll concentrations in parasites (Chapter 6). The methods to determine chlorophyll concentrations are simple and do not give any information on other different pigments present. High-performance liquid chromatography (HPLC) was previously used to determine different chlorophyll and carotenoid groups in red algae (Schubert et al. 2006; Heriyato et al. 2015). In plant parasites, HPLC showed that the parasitic plant Cuscuta reflexa uses lutein instead of neoxanthin in its light harvesting complex (Bungard et al. 1999). Comparing parasitic plants to non-parasitic plants showed that parasites have a lower chlorophyll $a$ to chlorophyll $b$ ratio (Esteban et al. 2015). HPLC would be a useful tool to compare red algal parasites with different degrees of pigmentation and their hosts and other free-living red algae. Pigment similarity might be used to show close parasite and host relationships and any changes should be due to the parasitic lifestyle.

\subsection{Distribution pattern of parasites}

Distribution of red algal parasites is still poorly understood and more data is needed (Chapter 2). This study used field collections and herbarium specimens to derive information about the distribution of the four parasites: Cladhymenia oblongifoliophila, Judithia parasitica, Phycodrys novae-zelandiophila and Vertebrata aterrimophila (Chapters 3-4) in New Zealand. Generally all four species were rather patchy in their distribution and during fieldwork many uninfected host individuals were observed. Future research should study the distribution of the parasite within the range of its host. The parasite Vertebrata aterrimophila would be a good choice because the host (Vertebrata aterrima) is found on Carpophyllum maschalocarpum and Cystophora spp., which makes the possible parasite sites easier to find. 


\subsection{Summary}

In conclusion, red algal parasites provide a rich opportunity to increase understanding in parasitism given their high diversity, different host and parasite relationships, and the different degree of pigmentation they exhibit. Taxonomic studies will be a helpful tool to understand how diverse these parasites are with continuously describing new species and phylogenetic analyses to reveal the number of parasite species of the same or closely related host species. Furthermore this additional taxonomic data will help to understand which specific families and genera are most parasitized. Studying reduced plastid genomes in red algal parasites will make a significant contribution to understanding gene deletion processes over time and the adaptive genetic changes occurring in the transition from free-living to parasitic organisms. Further investigations of host nutrient dependency will improve understanding of the advantages the parasitic life style confers for these species. 
References 
Abascal, F., Zardoya, R. \& Telford, M. J. 2010. TranslatorX: multiple alignment of nucleotide sequences guided by amino acid translations. Nucleic Acids Res. 38:W7-13.

Abbott, I. A. \& Hollenberg, G. J. 1992. Marine Algae of California. Stanford University Press, Stanford, California.

Adey, W. H. \& Sperapani, C. P. 1971. The biology of Kvaleya epilaeve, a new parasitic genus and species of Corallinaceae. Phycologia 10:29-42.

Adey, W. H., Masaki, T. \& Akioka, H. 1974. Ezo epiyessoense, a new parasitic genus and species of Corallinaceae (Rhodophyta, Cryptonemiales). Phycologia 13:329-344.

Adey, W. H., Hernandez-Kantun, J. J., Johnson, G., Gabrielson, P. W. \& Vis M. 2015. DNA sequencing, anatomy, and calcification patterns support a monophyletic, subarctic, carbonate reef-forming Clathromorphum (Hapalidiaceae, Corallinales, Rhodophyta). Phycologia 51:159-203.

Agapow, P. M., Bininda-Emonds, O. R., Crandall, K. A., Gittleman, J. L., Mace, G. M., Marshall, J. C. \& Purvis, A. 2004. The impact of species concept on biodiversity studies. Q. Rev. Biol. 79:161-179.

Apt, K. E. 1984a. Effects of the symbiotic red alga Hypneocolax stellaris on its host Hypnea musciformis (Hypneaceae, Gigartinales). J. Phycol. 20:148-150.

Apt, K. E. 1984b. The morphology of Phaeocolax kajimurai (Rhodomelaceae, Rhodophyta), a host specific epiphyte on Lobophora variegata (Phaeophyta). Phycologia 23:239-247.

Apt, K. E. 1987. A new species of Janczewskia (Rhodomelaceae, Rhodophyta) from the Hawaiian Islands. Phycologia 26:328-333.

Apt, K. E. \& Schlech, K. E. 1998. Ululania stellata gen. et sp. nov. (Rhodomelaceae), a new genus and species of parasitic red algae from Hawaii. Phycologia 37:157-161.

Ashen, J. B. \& Goff, L. J. 1998. Galls on the marine red alga Prionitis lanceolata (Halymeniaceae): specific induction and subsequent development of an algal-bacterial symbiosis. Am. J. Bot. 85:1710-1721.

Baardseth, E. 1941. The marine algae of Tristan da Cunha. Results of the Norwegian Scientific Expedition to Tristan da Cunha 1937-1938. Det Norske Videnskaps-Akademi, Oslo.

Barkman, T. J., McNeal, J. R., Lim, S. H., Coat, G., Croom, H. B., Young, N. D. \& Depamphilis, C. W. 2007. Mitochondrial DNA suggests at least 11 origins of parasitism in angiosperms and reveals genomic chimerism in parasitic plants. BMC Evol. Biol. 7:248.

Batters, E. A. L. 1892. Gonimophyllum buffhami: a new marine algae. J. Bot. 30:65-67.

Batters, E. A. L. 1895. On some new British marine algae. Ann. Bot.-London 9:307-321. 
Bellot, S., Cusimano, N., Luo, S., Sun, G., Zarre, S., Groger, A., Temsch, E. \& Renner, S. S. 2016. Assembled plastid and mitochondrial genomes, as well as nuclear genes, place the parasite family Cynomoriaceae in the Saxifragales. Genome Biol. Evol. 8:22142230 .

Berger, S., Fettweiss, U., Gleissberg, S., Liddle, L. B., Richter, U., Sawitzky, H. \& Zuccarello, G. C. 2003. 18S rDNA phylogeny and evolution of cap development in Polyphysaceae (formerly Acetabulariaceae; Dasycladales, Chlorophyta). Phycologia 42:506-561.

Bergsten, J. 2005. A review of long-branch attraction. Cladistics 21:163-193.

Bischof, K., Hanelt, D. \& Wiencke, C. 2000. Effects of ultraviolet radiation on photosynthesis and related enzyme reactions of marine macroalgae. Planta 211:555-562.

Blouin, N. A. \& Lane, C. E. 2012. Red algal parasites: Models for a life history evolution that leaves photosynthesis behind again and again. BioEssays 34:226-235.

Blouin, N. A. \& Lane, C. E. 2016. Red algae provide fertile ground for exploring parasite evolution. Perspect. Phycol. 3:11-19.

Boo, G. H., Nelson, W. A., Preuss, M., Kim, J. Y. \& Boo, S. M. 2015. Genetic segregation and differentiation of a common subtidal alga Pterocladia lucida (Gelidiales, Rhodophyta) between Australia and New Zealand. J. Appl. Phycol. 28:2027-2034.

Børgesen, F. 1920. The marine algae of the Danish West Indies. Part 3. Rhodophyceae. Dansk. Bok. Arkiv 3:369-498.

Bourke, A. F. G. \& Franks, N. R. 1991. Alternative adaptations, sympatric speciation and the evolution of parasitic, inquiline ants. Biol. J. Linn. Soc. 43:157-178.

Brinkmann, H., van der Giezen, M., Zhou, Y., Poncelin de Raucourt, G. \& Philippe, H. 2005. An empirical assessment of long-branch attraction artefacts in deep eukaryotic phylogenomics. Syst. Biol. 54:743-757.

Bromham, L., Cowman, P. F. \& Lanfear, R. 2013. Parasitic plants have increased rates of molecular evolution across all three genomes. BMC Evol. Biol. 13:126.

Bula-Meyer, G. 1985. Champiocolax sarae gen. et sp. nov., an adelphohemiparasite of the Champiaceae (Rhodymeniales, Rhodophyta). Phycologia 24:429-435.

Bungard, R. A. 2004. Photosynthetic evolution in parasitic plants: insight from the chloroplast genome. BioEssays 26:235-247.

Bungard, R. A., Ruban, A. V., Hibberd, J. M., Press, M. C., Horton, P. \& Scholes, J. D. 1999. Unusual carotenoid composition and a new type of xanthophyll cycle in plants. Proc. Natl. Acad. Sci. USA 96:1135-1139. 
Busse, I., Patterson, D. J. \& Preisfeld, A. 2003. Phylogeny of phagotrophic euglenids (Euglenozoa): A molecular approach based on culture material and environmental samples. J. Phycol. 39:828-836.

Callow, J. A., Callow, M. E. \& Evans, L. V. 1979. Nutritional studies on the parasitic red alga Choreocolax polysiphoniae. New Phytol. 83:451-462.

Chang, C. F. \& Xia, B. M. 1978. Studies on the parasitic red algae of China. Studia Marina Sinica 14:119-127.

Clayden, S. L. \& Saunders, G. W. 2010. Recognition of Rubrointrusa membranacea gen. et comb. nov., Rhodonematella subimmersa gen. et comb. nov (with a reinterpretation of the life history) and the Meiodiscaceae fam. nov within the Palmariales (Rhodophyta). Phycologia 49:283-300.

Clement, M., Posada, D. \& Crandall, K. A. 2000. TCS: a computer program to estimate gene genealogies. Mol. Ecol. 9:1657-1659.

Corradi, N., Akiyoshi, D. E., Morrison, H. G., Feng, X., Weiss, L. M., Tzipori, S. \& Keeling, P. J. 2007. Patterns of genome evolution among the microsporidian parasites Encephalitozoon cuniculi, Antonospora locustae and Enterocytozoon bieneusi. PLoS One 2:e1277.

Cotton, A. D. 1907. Marine algae from the Chatham Islands. Bulletin of Miscellaneous Information (Royal Botanic Gardens, Kew) 1907:37-43.

Cribb, T. H., Bray, R. A., Wright, T. \& Pichelin, S. 2002. The trematodes of groupers (Serranidae: Epinephelinae): Knowledge, nature and evolution. Parasitology 124:S2342.

Cusimano, N. \& Wicke, S. 2016. Massive intracellular gene transfer during plastid genome reduction in nongreen Orobanchaceae. New Phytol. 210:680-693.

Dalen, J. \& Nelson, W. A. 2013. Te Papa's list of New Zealand marine macroalgae. Te Papa, Wellington.

D’Archino, R., Nelson, W. A., Yang, M. Y. \& Kim M.-S. 2015. New record of Hypnea flexicaulis in New Zealand and description of Calliblepharis psammophilus sp. nov. Bot. Mar. 58:485-497.

D’Archino, R., Lin, S-M., Gabrielson, P.W. \& Zuccarello G. C. 2016. Why one species in New Zealand, Pugetia delicatissima (Kallymeniaceae, Rhodophyta), should become two new genera, Judithia gen. nov. and Wendya gen. nov. Eur. J. Phycol. 51:83-98. 
D'Archino, R., Nelson, W. A. \& Sutherland, J. E. 2017. Neither Callophyllis nor Gelidium: Blastophyllis gen. nov. and Zuccarelloa gen. nov. (Kallymeniaceae, Rhodophyta) for three New Zealand species. Phycologia 56:549-560.

Darling, A. C., Mau, B., Blattner, F. R. \& Perna, N. T. 2004. Mauve: Multiple alignment of conserved genomic sequences with rearrangements. Genome Res. 14:1394-1403.

Dawson, E. Y. 1945. Notes on pacific coast marine algae. III. Madroño 8:93-97.

de Bary, A. 1879. Die Erscheinungen der Symbiose. Karl J. Trübner, Strassbourg.

Delivopoulos, S. G. \& Diannelidis, B. E. 1990. Ultrastructure of carposporophyte development in the red alga Caulacanthus ustulatus (Gigartinales: Caulacanthaceae). Mar. Bio. 106:145-152.

de Koning, A. P. \& Keeling, P. J. 2006. The complete plastid genome sequence of the parasitic green alga Helicosporidium sp. is highly reduced and structured. BMC Biol. 4:12.

de Oliveira Filho, E. C. \& Ugadim, Y. 1973. Levringiella polysiphoniae a new species of parasitic red algae (Rhodophyta, Rhodomelaceae). Boletim de Botânica 1:95-99.

de Queiroz, K. \& Gauthier, J. 1992. Phylogenetic taxonomy. Annu. Rev. Ecol. Syst. 23:449480.

de Vargas, Audic, S., Henry, N., Decelle, J., Mahe, F., Logares, R., Lara, E., Berney, C., Le Bescot, N., Probert, I., Carmichael, M., Poulain, J., Romac, S., Colin, S., Aury, J. M., Bittner, L., Chaffron, S., Dunthorn, M., Engelen, S., Flegontova, O., Guidi, L., Horak, A., Jaillon, O., Lima-Mendez, G., Lukes, J., Malviya, S., Morard, R., Mulot, M., Scalco, E., Siano, R., Vincent, F., Zingone, A., Dimier, C., Picheral, M., Searson, S., KandelsLewis, S., Tara Oceans Coordinators, Acinas, S. G., Bork, P., Bowler, C., Gorsky, G., Grimsley, N., Hingamp, P., Iudicone, D., Not, F., Ogata, H., Pesant, S., Raes, J., Sieracki, M. E., Speich, S., Stemmann, L., Sunagawa, S., Weissenbach, J., Wincker, P. \& Karsenti, E. 2015. Ocean plankton. Eukaryotic plankton diversity in the sunlit ocean. Science 348: 1261605.

Díaz-Tapia, P., Maggs, C. A., West, J. A. \& Verbruggen, H. 2017. Analysis of chloroplast genomes and a supermatrix inform reclassification of the Rhodomelaceae (Rhodophyta). J. Phycol. 5:920-937.

Dixon, P. S. \& Irvine, L. M. 1995. Seaweeds of the British Isles. Volume 1 Rhodophyta. Part 1 Introduction, Nemaliales, Gigartinales. HMSO, London.

Dobson, A., Lafferty, K. D., Kuris, A. M., Hechinger, R. F. \& Jetz, W. 2008. Colloquium paper: homage to Linnaeus: how many parasites? How many hosts? PNAS 105:11482-11489. 
Doyle, V. P., Young, R. E., Naylor, G. J. \& Brown, J. M. 2015. Can we identify genes with increased phylogenetic reliability? Syst. Biol. 64:827-837.

Edelstein, T. 1972. Halosacciocolax lundii, sp. nov., a new red alga parasitic on Rhodymenia palmata (L.) Grev. Brit. J. Phycol. 7:249-253.

Ellison, C. K. \& Burton, R. S. 2008. Interpopulation hybrid breakdown maps to the mitochondrial genome. Evolution 62:631-638.

Emery, C. 1909. Über den Ursprung der dulotischen, parasitischen und myrmekophilen Ameisen. Biologischen Centralblatt 29:352-362.

Esteban, R., Barrutia, O., Artetxe, U., Fernandez-Marin, B., Hernandez, A. \& Garcia-Plazaola, J. I. 2015. Internal and external factors affecting photosynthetic pigment composition in plants: a meta-analytical approach. New Phytol. 206:268-280.

Evans, L. V., Callow, J. A. \& Callow, M. E. 1973. Structural and physiological studies on the parasitic red alga Holmsella. New Phytol. 72:393-402.

Evans, L. V., Callow, J. A. \& Callow, M. E. 1978. Parasitic red algae: an appraisal. In Irvine, D. E. G. \& Price, J. G. [Eds.] Modern approaches to the taxonomy of red and brown Algae. Academic Press, London and New York.

Evans, N. M., Lindner, A., Raikova, E. V., Collins, A. G. \& Cartwright, P. 2008. Phylogenetic placement of the enigmatic parasite, Polypodium hydriforme, within the phylum Cnidaria. BMC Evol. Biol. 8:139.

Fan, K. C. \& Papenfuss, G. F. 1959. Red algal parasites occurring on members of the Gelidiales. Madroño 15:33-38.

Feagin, J. E. 2000. Mitochondrial genome diversity in parasites. Int. J. Parasitol. 30:371-390.

Feldmann, J. \& Feldmann, G. 1951. Un nouveau genre de Rhodophycée parasite d'une Delesseriacée. Compte Rendu Hebdomadaire des Séances de l'Académie des Sciences 233:1137-1139.

Feldmann, J. \& Feldmann, G. 1958. Recherches sur quelques Floridées parasites. Revue Générale de Botanique.

Feldmann, J. \& Feldmann, G. 1961. Une nouvelle espèce de Delesseriacée adelphoparasite: Gonimocolax roscoffensis nov. sp. Bull. Soc. Bot. Fr. 108:18-24.

Feldmann, J. \& Feldmann, G. 1963. Une nouvelle espèce de Floridée parasite du genre Gelidiocolax Gardner. Revue Générale de Botanique 70:557-571.

Felsenstein, J. 1978. Cases in which parsimony or compatability methods will be positively misleading. Syst. Zool. 27:401-410. 
Felsenstein, J. 1985. Confidence limits on phylogenies - an approach using the bootstrap. Evolution 39:783-791.

Figueroa F. L., Salles S., Aguileral J., Jiménez C., Mercadol J., Vinegla B., Flores-Moya A. \& M., A. 1997. Effects of solar radiation on photoinhibition and pigmentation in the red alga Porphyra leucosticta. Mar. Ecol. Prog. Ser. 151:81-90.

Frailey, D. C., Chaluvadi, S. R., Vaughn, J. N., Coatney, C. G. \& Bennetzen, J. N. 2018. Gene loss and genome rearrangement in the plastids of five hemiparasites in the family Orobanchaceae. BMC Plant Biol. 18:30.

Fraser, C. I. \& Waters, J. M. 2013. Algal parasite Herpodiscus durvillaeae (Phaeophyceae: Sphacelariales) inferred to have traversed the Pacific Ocean with its buoyant host. $J$. Phycol. 49:202-206.

Fredericq, S. \& Hommersand, M. 1990. Morphology and systematics of Holmsella pachyderma (Pterocladiophilaceae, Gracilariales). Brit. Phycol. J. 25:39-51.

Freese, J. M. \& Lane, C. E. 2017. Parasitism finds many solutions to the same problems in red algae (Florideophyceae, Rhodophyta). Mol. Biochem. Parasitol. 214:105-111.

Furuhashi, K. 1991. Establishment of a successive culture of an obligatory parasitic flowering plant, Cuscuta japonica, in vitro. Plant Sci. 79:241-216.

Ganesan, E. K. 1970. A new species of Gelidiocolax gardner (Choreocolacaceae, Rhodophyta) from the Caribbean Sea. Bol. Inst. Oceanogr. Univ. Oriente 9:93-102.

Gauna, M. C. \& Parodi, E. R. 2018. Green epi-endophytes in Hymenena falklandica (Rhodophyta) from the Patagonian coasts of Argentina: preliminary observations. Phy. Res. 56:172-182.

Gerung, G. S. \& Yamamoto, H. 2002. The taxonomy of parasitic genera growing on Gracilaria (Rhodophyta, Gracilariaceae). In Abbott, I. A. \& McDermid, K. J. [Eds.] Taxonomy of economic seaweeds with reference to some Pacific species. Vol. VIII. California Sea Grant College, La Jolla, pp. 209-213.

Goff, L. J. 1976. The biology of Harveyella mirabilis (Cryptonemiales; Rhodophyceae). V. Host responses to parasite infection. J. Phycol. 12:313-328.

Goff, L. J. 1979. The biology of Harveyella mirabilis (Cryptonemiales, Rhodophyceae). VI. Translocation of photoassimilated. J. Phycol. 15:82-87.

Goff, L. J. 1982. The biology of parasitic red algae. In Round, F. E. \& Chapman, D. J. [Eds.] Progress in Phycological Research. Elsevier Biomedical Press, Amsterdam, pp. 289369. 
Goff, L. J. \& Coleman, A. W. 1984. Transfer of nuclei from a parasite to its host. P. Natl. Acad. Sci. USA 81:5420-5424.

Goff, L. J. \& Coleman, A. W. 1985. The role of secondary pit connections in red algal parasitism. J. Phycol. 21:483-508.

Goff, L. J. \& Coleman, A. W. 1987. Nuclear transfer from parasite to host. In Lee, J. J. \& Fredrick, J. F. [Eds.] Endocytobiology. New York Academy of Sciences, New York, pp. 402-423.

Goff, L. J. \& Zuccarello, G. C. 1994. The evolution of parasitism in red algae - cellular interactions of adelphoparasites and their hosts. J. Phycol. 30:695-720.

Goff, L. J. \& Coleman, A. W. 1995. Fate of parasite and host organelle DNA during cellulartransformation of red algae by their parasites. Plant Cell 7:1899-1911.

Goff, L. J., Moon, D. A., Nyvall, P., Stache, B., Mangin, K. \& Zuccarello, G. C. 1996. The evolution of parasitism in the red algae: Molecular comparisons of adelphoparasites and their hosts. J. Phycol. 32:297-312.

Goff, L. J., Ashen, J. \& Moon, D. 1997. The evolution of parasites from their hosts: A case study in the parasitic red algae. Evolution 51:1068-1078.

Gomez, F., Lopez-Garcia, P. \& Moreira, D. 2011. Molecular phylogeny of dinophysoid dinoflagellates: the systematic position of Oxyphysis oxytoxoides and the Dinophysis hastata Group (Dinophysales, Dinophyceae). J. Phycol. 47:393-406.

González, M. A. \& Goff, L. J. 1989. The red algal epiphytes Microcladia coulteri and M. californica (Rhodohycea, Ceramiaceae), I. Taxonomy, life history and phenology. J. Phycol. 25:545-558.

Gregory, B. D. 1930. New light on the so-called parasitism of Accinococcus aggregatus, Kütz, and Sterrocolax decipiens, Schmitz. Ann. Bot. 44:767-769.

Groom, Q. J. \& Baker, N. R. 1992. Analysis of light-induced depressions of photosynthesis in leaves of a wheat crop during the winter. Plant Physiol. 100:1217-1223.

Guiry, M. D. 2012. How many species of algae are there? J. Phycol. 48:1057-1063.

Guiry, M. D. \& Selivanova, O. N. 2007. Masakiella, nom. nov. pro Masakia N.G. Klochkova (Corallinaceae, Rhodophyta), non Masakia (Nakai) Nakai (Celastraceae, Tracheophyta). Phycologia 46:235-236.

Guiry, M. D. \& Guiry, G. M. 2016. AlgaeBase. World-wide electronic publication, National University of Ireland, Galway. http://www.algaebase.org;

Hancock, L., Goff, L. J. \& Lane, C. 2010. Red algae lose key mitochondrial genes in response to becoming parasitic. Genome Biol. Evol. 2:897-910. 
Harlin, M. M. 1973. Transfer of products between epiphytic marine algae and host plants. $J$. Phycol. 9:243-248.

Harvey, W. H. \& Hooker, J. D. 1845. XXXVI. Algae L. In Hooker, J. D. [Ed.] Flora antarctica. London, pp. 175-193.

Harvey, A. S., Broadwater, S. T., Woelkerling, W. L. \& Mitrovski, P. J. 2003. Choreonema (Corallinales, Rhodophyta): 18s rDNA phylogeny and resurrection of the Hapalidiaceae for the subfamilies Choreonematoideae, Austrolithoideae, and Melobesioideae. $J$. Phycol. 39:988-998.

Haupt, A. W. 1930. A gelatin fixative for paraffin sections. Stain Technol. 5:97-98.

Hausdorf, B. 2011. Progress toward a general species concept. Evolution 65:923-931.

Heriyanto, I., Limantara, L. \& Brotosudarmo, T. H. P. 2015. Composition of photosynthetic pigments in a red alga Kappaphycus alvarezi cultivated in different depths. Procedia Chem. 14:193-201.

Hollenberg, G. J. 1970. Phycological notes IV, including new marine algae and new records for California. Phycologia 9:61-72.

Hudson, P. J., Dobson, A. P. \& Newborn, D. 1998. Prevention of population cycles by parasite pemoval. Science 282:2256-2258.

Hurd, C. L., Harrison, P. J., Bischof, K. \& Lobban, C. S. 2014. Seaweed ecology and physiology. Cambridge University Press, Cambridge.

Jackson, A. P. 2015. The evolution of parasite genomes and the origins of parasitism. Parasitology 142:S1-5.

Jedelský, P. L., Dolezal, P., Rada, P., Pyrih, J., Smid, O., Hrdy, I., Sedinova, M., Marcincikova, M., Voleman, L., Perry, A. J., Beltran, N. C., Lithgow, T. \& Tachezy, J. 2011. The minimal proteome in the reduced mitochondrion of the parasitic protist Giardia intestinalis. PLoS One 6:e17285.

Joly, A. B. 1966. Centrocerocolax, a new parasitic genus of Rhodophyta. Rickia 2:73-77.

Joly, A. B. \& Oliveira, E. C. 1966. Spyridiocolax and Heterodasya two new genera of the Rhodophyceae. Sellowia 18:115-125.

Joly, A. B. \& Yamaguishi-Tomita, N. 1969. Note on Dawsoniella Joly \& Yamaguishi-Tomita. Rickia 4:209-210.

Karvonen, A. \& Seehausen, O. 2012. The role of parasitism in adaptive radiations - when might parasites promote and when might they constrain ecological speciation? Int. J. Ecol. 2012:1-20. 
Kearse, M., Moir, R., Wilson, A., Stones-Havas, S., Cheung, M., Sturrock, S., Buxton, S., Cooper, A., Markowitz, S., Duran, C., Thierer, T., Ashton, B., Meintjes, P. \& Drummond, A. 2012. Geneious Basic: an integrated and extendable desktop software platform for the organization and analysis of sequence data. Bioinformatics 28:16471649.

Keeling, P. J. \& Fast, N. M. 2002. Microsporidia: biology and evolution of highly reduced intracellular parasites. Annu. Rev. Microbiol. 56:93-116.

Keeling, P. J. 2004. Diversity and evolutionary history of plastids and their hosts. Am. J. Bot. 91:1481-1493.

Keeling, P. J. \& Slamovits, C. H. 2005. Causes and effects of nuclear genome reduction. Curr. Opin. Genet. Dev. 15:601-608.

Keeling, P. J., Corradi, N., Morrison, H. G., Haag, K. L., Ebert, D., Weiss, L. M., Akiyoshi, D. E. \& Tzipori, S. 2010. The reduced genome of the parasitic microsporidian Enterocytozoon bieneusi lacks genes for core carbon metabolism. Genome Biol. Evol. 2:304-309.

Keeling, P. J. \& Rayner, J. C. 2015. The origins of malaria: there are more things in heaven and earth. Parasitology 142:16-25

Kim, M.-S. \& Cho, G.-Y. 2010. A new red algal parasite, Symphyocolax koreana gen. et sp. nov. (Rhodomelaceae, Ceramiales), from Korea. Algae 25:105-113.

Kraft, G. T. \& Gabrielson, P. W. 1983. Tikvahiella candida gen. et sp. nov. (Solieriaceae, Rhodophyta), a new adelphoparasite from southern Australia. Phycologia 22:47-57.

Kraft, G. T. \& Abbott, I. A. 2002. The anatomy of Neotenophycus ichthyosteus gen. et sp. nov. (Rhodomelaceae, Ceramiales), a bizarre red algal parasite from the central Pacific. Eur. J. Phycol. 37:269-278.

Krause, K. 2008. From chloroplasts to "cryptic" plastids: evolution of plastid genomes in parasitic plants. Curr. Genet. 54:111-121.

Kremer, B. P. 1983. Carbon economy and nutrition of the alloparasitic red alga Harveyella mirabilis. Mar. Biol. 76:231-239.

Kromkamp, J. C. \& Forster, R. M. 2003. The use of variable fluorescence measurements in aquatic ecosystems: differences between multiple and single turnover measuring protocols and suggested terminology. Eur. J. Phycol. 38:103-112.

Kugrens, P. 1982. Leachiella pacifica, gen. et sp. nov., a new parasitic red alga from Washington and California. Am. J. Bot. 69:306-319. 
Kugrens, P. \& Delivopoulos, S. G. 1985. Ultrastructure of auxiliary and gonimoblast cells during carposporophyte development in Faucheocolax attenuata (Rhodophyta). J. Phycol. 21:240-249.

Kurihara, A., Abe, T., Tani, M. \& Sherwood, A. R. 2010. Molecular phylogeny and evolution of red algal parasites: A case study of Benzaitenia, Janczewskia, and Ululania (Ceramiales). J. Phycol. 46:580-590.

Kylin, H. \& Skottsberg, C. 1919. Zur Kenntnis der subantarktischen und antarktischen Meeresalgen. II. Rhodophyceen. Litographisches Institut des Generalstabs, Stockholm.

Kylin, H. 1941. Californische Rhodophyceen. Acta Universitatis Lundensis, Lund.

Kylin, H. 1956. Die Gattungen der Rhodophyceen. CWK Gleerups Förlag, Lund.

Lagesen, K., Hallin, P., Rodland, E. A., Staerfeldt, H. H., Rognes, T. \& Ussery, D. W. 2007. RNammer: consistent annotation of rRNA genes in genomic sequences. Nucleic Acids Res. 35:3100-3108.

Leander. B.S. 2007. Marine gregarines: evolutionary prelude to the apicomplexan radiation? Trends Parasitol. 24:60-67.

Le Gall, L. \& Saunders, G. W. 2010. DNA barcoding is a powerful tool to uncover algal diversity: a case study of the Phyllophoraceae (Gigartinales, Rhodophyta) in the Canadian flora. J. Phycol. 46:374-389.

Le Roux, L. E. \& Avenant-Oldewage, A. 2010. Checklist of the fish parasitic genus Cichlidogyrus (Monogenea), including its cosmopolitan distribution and host species. Afr. J. Aquat. Sci. 35:21-36.

Levring, T. 1941. Die Meeresalgen der Juan Fernandez-Inseln. Die Corallinaceen der Juan Fernandez-Inseln. In: Skottsberg, C. [Ed.] The natural history of Juan Fernandez and Easter Island. Almqvist \& Wiksells Boktryckeri, Uppsala. pp. 601-757.

Li, W., Zhang, T. Y., Tang, X. X. and Wang, B. Y. 2010. Oomycetes and fungi: important parasites on marine algae. Acta Oceanol. Sin. 29:74-81.

Li, T., Hua, J., Wright, A. M., Cui, Y., Xie, Q., Bu, W. \& Hillis, D. M. 2014. Long-branch attraction and the phylogeny of true water bugs (Hemiptera: Nepomorpha) as estimated from mitochondrial genomes. BMC Evol. Biol. 14:99.

Liu, F. and Pang, S. J. 2010. Stress tolerance and antioxidant enzymatic activities in the metabolisms of the reactive oxygen species in two intertidal red algae Grateloupia turuturu and Palmaria palmata. J. Exp. Mar. Biol. Ecol. 382:82-87. 
Litaker, R. W., Tester, P. A., Colorni, A., Levy, M. G. \& Noga, E. J. 1999. The phylogenetic relationship of Pfiesteria piscicida, Cryptoperidiniopsoid sp. Amyloodinoum ocellatum and a Pfiesteria-like dinoflagellate to other dinoflagellates and apicomplexans. $J$. Phycol. 35:1379-1389.

Lowe, R. M., Ward, S. A. \& Crozier, R. H. 2002. The evolution of parasites from their hosts: intra- and interspecific parasitism and Emery's rule. P. Roy. Soc. B-Biol. Sci. 269:13011305 .

Lüder, U., Knoetzel, J. \& Wiencke, C. 2001. Acclimation of photosynthesis and pigments to seasonally changing light conditions in the endemic Antartic red macroalgae Palmaria decipiens. Polar Biol. 24:598-603.

Maggs, C. A. \& Hommersand, M. H. 1993. Seaweeds of the British Isles. Volume 1. Rhodophyta. Part 3A. Ceramiales, HMSO, London.

Mallick, N. \& Mohn, F. H. 2003. Use of chlorophyll fluorescence in metal-stress research: a case study with the green microalga Scenedesmus. Ecotox. Environ. Safe. 55:64-69.

Mamoozadeh, N. R. \& Freshwater, D. W. 2011. Taxonomic notes on Caribbean Neosiphonia and Polysiphonia (Ceramiales, Florideophyceae): five species from Florida, USA and Mexico. Bot. Mar. 54:269-292.

Martin, M. T. \& Pocock, M. A. 1953. South African parasitic Florideae and their hosts. 2. Some South African parasitic Florideae. Proc. Linn. Soc. Lond. 55:48-64.

McBride, D. L., Kugrens, P. \& West, J. A. 1974. Light and electron microscopic observations on red algal galls. Protoplasma 79:249-264.

McCandless, E. L. \& Vollmer, C. M. 1984. The nemathecium of Gymnogongrus chiton (Rhodophyceae, Gigartinales): immunochemical evidence of meiosis. Phycologia 23:119-123.

McFadden, M. E. 1911. On a Colacodasya from southern California. University of California Publications in Botany 4:143-150.

Melchionna, M. \& De Masi, F. 1978. The fine structure of the vegetative cells of Erythrocystis montagnei, a symbiotic red alga. Cytobios 20:113-119.

Moreira, D., Le Guyader, H. \& Philippe, H. 2000. The origin of red algae and the evolution of chloroplasts. Nature 405:69-72.

Morin, L. 2000. Long branch attraction effects and the status of "basal eukaryotes": phylogeny and structural analysis of the ribosomal RNA gene cluster of the free-living Diplomonad Trepomonas agilis. J. Eukaryot. Microbiol. 47:167-177. 
Morril, J. 1976a. Notes on parasitic Rhodomelaceae, I: The morphology and systematic position of Benzaitenia yenoshimensis Yendo, a parasitic red alga from Japan. P. Acad. Nat. Sci. Phila. 127:203-215.

Morrill, J. 1976b. Notes on parasitic Rhodomelaceae, II: The morphology and systematic position of the parasitic red alga Jantinella verrucaeformis (Setchell and McFadden) Kylin. P. Acad. Nat. Sci. Phila. 127:217-231.

Morrill, J. 1976c. Notes on parasitic Rhodomelaceae, III: Meridiocolax narcissus, a new red alga parasitic on Polysiphonia ferulacea Suhr from the Florida Keys. P. Acad. Nat. Sci. Phila. 127:233-248.

Morril, J. 1977. Notes on parasitic Rhodomelaceae, IV: Dipterocolax fernandezianum, a new genus parasitizing Dipterosiphonia parva from the Juan Fernández Islands. P. Acad. Nat. Sci. Phila. 128:133-146.

Müller, M., Mentel, M., van Hellemond, J. J., Henze, K., Woehle, C., Gould, S. B., Yu, R. Y., van der Giezen, M., Tielens, A. G. \& Martin, W. F. 2012. Biochemistry and evolution of anaerobic energy metabolism in eukaryotes. Microbiol. Mol. Biol. Rev. 76:444-495.

Murchie, E. H. \& Lawson, T. 2013. Chlorophyll fluorescence analysis: a guide to good practice and understanding some new applications. J. Exp. Bot. 64:3983-3998.

Nelson, W. A. \& D'Archino, R. 2014. Three new macroalgae from the Three Kings Islands New Zealand including the first southern Pacific Ocean record of the Furcellariaceae (Rhodophyta). Phycologia 53:602-613.

Nelson, W. A., Sutherland, J. E., Farr, T. J., Hart, D. R., Neil, K. F., Kim, H. J., Yoon, H. S. \& Gabrielson, P. W. 2015. Multi-gene phylogenetic analyses of New Zealand coralline algae: Corallinapetra novaezelandiae gen. et sp. nov. and recognition of the Hapalidiales ord. nov. J. Phycol. 51:454-468.

Neuhauser, C. \& Fargione, J. E. 2004. A mutualism- parasitism continuum model and its application to plant - mycorrhizae interactions. Ecol. Model. 177:337-352.

Ng, P. K, Lim, P. E., Kato, A. \& Phang, S. M. 2013. Molecular evidence confirms the parasite Congracilaria babae (Gracilariaceae, Rhodophyta) from Malaysia. J. Appl. Phycol. 26:1287-1300.

Ng, P. K., Lim, P. E. \& Phang, S. M. 2014. Radiation of the red algal parasite Congracilaria babae onto a secondary host species, Hydropuntia sp. (Gracilariaceae, Rhodophyta). PLoS One 9:e97450. 
Ng, P. K., Lim, P. E. \& Phang, S. M. 2015. Small-scale genetic structure of Gracilaria salicornia and its red algal parasite, G. babae (Gracilariaceae, Rhodophyta), in Malaysia. Bot. Mar. 58:175-187.

Noble, J. M. \& Kraft, G. T. 1983. Three new species of parasitic red algae (Rhodophyta) from Australia: Holmsella australis sp. nov., Meridiocolax bracteata sp. nov. and Trichidium pedicellatum gen. et sp. nov. Br. Phycol. J. 18:391-413.

Nonomura, A. M. 1979. Development of Janczewskia morimotoi (Ceramiales) on its host Laurencia nipponica (Ceramiales, Rhodophyceae). J. Phycol. 15:154-162.

Nonomura, A. M. \& West, J. A. 1981. Host specificity of Janczewskia (Ceramiales, Rhodophyta). Phycologia 20:251-258.

Norris, R. E. \& Wynne, M. J. 1969 '1968'. Notes on marine algae of Washington and southern British Columbia. III. 1:133-146.

Norris, R. E. 1988. Two new red algal parasites on Kuetzingia natalensis (Rhodomelaceae, Rhodophyta). Bot. Mar. 31:345-352.

Notoya, M. \& Miyashita, A. 1999. Life history, in culture, of the obligate epiphyte Porphyra moriensis (Bangiales, Rhodophyta). Hydrobiologia 399:121-125.

Nurk, S., Bankevich, A., Antipov, D., Gurevich, A., Korobeynikov, A., Lapidus, A., Prjibelsky, A., Pyshkin, A., Sirotkin, A., Sirotkin, Y., Stepanauskas, R., McLean, J., Lasken, R., Clingenpeel, S. R., Woyke, T., Tesler, G., Alekseyev, M. A. \& Pevzner, P. A. 2013. Assembling genomes and mini-metagenomes from highly chimeric reads. In Deng, M., Jiang, R., Sun, F. \& Zhang, X. [Eds.] Research in computational molecular biology: 17th annual international conference, RECOMB 2013, Beijing, China, April 7-10, 2013. Proceedings. Springer Berlin Heidelberg, Berlin, Heidelberg, pp. 158-170.

Ouahi, M. 1993. Contribution à l'étude biologique, systématique, phénologique et écologique du Gelidiocolax verruculata sp. nov., parasite des Gélidiacées du littoral marocain: station de Mohammedia. Doctorate de thèse 3ème Cycle, Université Mohammed V.

Pant, B. \& Thapa, D. 2012. In vitro mass propagation of an epiphytic orchid, Dendrobium primulinum Lindl. through shoot tip culture. Afr. J. Biotechnol. 11:9970-9974.

Park, M. G., Cooney, S. K., Yih, W. \& Coats, D. W. 2002. Effects of two strains of the parasitic dinoflagellate Amoebophrya on growth, photosynthesis, light absorption, and quantum yield of bloom-forming dinoflagellates. Mar. Ecol. Prog. Ser. 227:281-292.

Parkhill, J. P., Maillet, G. \& Cullen, J. J. 2001. Fluorescence-based maximal quantum yield for PSII as a diagnostic of nutrient stress. J. Phycol. 37:517-529. 
Pelser, P. B., Nickrent, D. L. \& Barcelona, J. F. 2016. Untangling a vine and its parasite: host specificity of Philippine Rafflesia (Rafflesiaceae). Taxon 65:739-758.

Phillips, L. E. 2000. Taxonomy of the New Zealand-endemic genus Pleurostichidium (Rhodomelaceae, Rhodophyta). J. Phycol. 36:773-786.

Pinheiro, J., Bates, D., DebRoy S., Sarkar D. \& Team, R. C. 2017. nlme: linear and nonlinear mixed effects models. R package version 3.1-131.

Pocock, M. A. 1953. South African parasitic Florideae and their hosts. 1. Four members of the Rhodomelaceae which act as hosts for parasitic Florideae. Bot. J. Linn. Soc. 55:34-47.

Pocock, M. A. 1956. South African parasitic Florideae and their hosts: 3. Four minute parasitic Florideae. Proc. Linn. Soc. Lond. 167:11-41.

Poulin, R. 1995. "Adaptive" changes in the behaviour of parasitized animals: a critical review. Int. J. Parasitol. 25:1371-1383.

Poulin, R. 2011. The many roads to parasitism: a tale of convergence. In Rollinson, D. \& Hay, S. I. [Eds.] Advances in Parasitology. Elsevier, Burlington, pp. 1-40.

Poulin, R. 2013. Explaining variability in parasite aggregation levels among host samples. Parasitology 140:541-546.

Poulin, R. \& Randhawa, H. S. 2015. Evolution of parasitism along convergent lines: from ecology to genomics. Parasitology 142:S6-S15.

Preuss, M. \& Zuccarello, G. C. 2014. What's in a name? Monophyly of genera in the red algae: Rhodophyllis parasitica sp. nov. (Gigartinales, Rhodophyta); a new red algal parasite from New Zealand. Algae 29:279-288.

Price, P. W. 1980. Evolutionary biology of parasites. Princenton Press, New Jersey.

Purvis, A. \& Hector, A. 2000. Getting the measure of biodiversity. Nature 405:212-219.

Quandt, C. A., Bushley, K. E. \& Spatafora, J. W. 2015. The genome of the truffle-parasite Tolypocladium ophioglossoides and the evolution of antifungal peptaibiotics. BMC Genomics 16:553.

Queval, G. \& Foyer, C. H. 2012. Redox regulation of photosynthetic gene expression. Philos. Trans. R. Soc. Lond. B. 367:3475-3485.

Race, H. L., Herrmann, R. G. \& W., M. 1999. Why have organelles retained genomes? Trends Genet. 15:364-370. 
Ravin, N. V., Gruzdev, E. V., Beletsky, A. V., Mazur, A. M., Prokhortchouk, E. B., Filyushin, M. A., Kochieva, E. Z., Kadnikov, V. V., Mardanov, A. V. \& Skryabin, K. G. 2016. The loss of photosynthetic pathways in the plastid and nuclear genomes of the nonphotosynthetic mycoheterotrophic eudicot Monotropa hypopitys. BMC Plant Biol. 16:238.

Reif, B. P., Mathiasen, R. L., Kenaley, S. C. \& Allan, G. J. 2015. Genetic structure and morphological differentiation of three western North American dwarf Mistletoes (Arceuthobium: Viscaceae). Syst. Bot. 40:191-207.

Reinsch, P. F. 1875. Contributiones ad algologiam et fungologiam. Lipsiae: T. O. Weigel,1875.

Reinsch, P. F. 1890. Zur Meeresalgenflora von Süd-Georgien. In Neumayer, G. [Ed.] Die internationale Polarforschung 1882-1883: Geschichtlicher Theil und in einem Anhange mehrere einzelne Abhandlungen physikalischen und sonstigen Inhalts. Verlag von A. Asher, Berlin, pp. 366-449.

Revill, M. J., Stanley, S. \& Hibberd, J. M. 2005. Plastid genome structure and loss of photosynthetic ability in the parasitic genus. J. Exp. Bot. 56:2477-2486.

Richards, H. M. 1891. On the structure and development of Choreocolax polysiphoniae, Reinsch. P. Am. Acad. Arts Sci. 26:46-63.

Ronquist, F. \& Huelsenbeck, J. P. 2003. MrBayes 3: Bayesian phylogenetic inference under mixed models. Bioinformatics 19:1572-1574.

Roossinck, M. J. 2011. The good viruses: viral mutualistic symbioses. Nature 9:99-108.

Rosenvinge, L. K. 1931. The marine algae of Denmark; contributions to their natural history. Part IV. Rhodophyceae IV. (Gigartinales, Rhodymeniales, Nemastomatales). Andr. Host \& Son, KGL. Hof-Boghandel, Kopenhagen.

Salomaki, E. D. \& Lane, C. E. 2014. Are all red algal parasites cut from the same cloth? Acta Soc. Bot. Pol. 83:369-375.

Salomaki, E. D., Nickles, K. R. \& Lane, C. E. 2015. The ghost plastid of Choreocolax polysiphoniae. J. Phycol. 51:217-221.

Salomaki, E. D. \& Lane, C. E. 2017. Red algal mitochondrial genomes are more complete than previously reported. Genome Biol. Evol. 9:48-63.

Saunders, G. W., Chiovitti, A. \& Kraft, G. T. 2004. Small-subunit rDNA sequences from representatives of selected families of the Gigartinales and Rhodymeniales (Rhodophyta). 3. Delineating the Gigartinales sensu stricto. Can. J. Bot. 82:43-74.

Saunders, G. W. 2005. Applying DNA barcoding to red macroalgae: a preliminary appraisal holds promise for future applications. Philos. T. Roy. Soc. B. 360:1879-1888. 
Saunders, G. W. \& Clayden, S. L. 2010. Providing a valid epithet for the species widely known as Halosacciocolax kjellmanii S. Lund (Palmariales, Rhodophyta) - Rhodophysema kjellmanii sp. nov. Phycologia 49:628-628.

Saunders, G. W. \& McDonald, B. 2010. DNA barcoding reveals multiple overlooked Australian species of the red algal order Rhodymeniales (Florideophyceae), with resurrection of Halopeltis J. Agardh and description of Pseudohalopeltis gen. nov. Botany 88:639-667.

Schmitz, F. \& Falkenberg, P. 1897. Rhodomelaceae. In Engler, A. \& Prantl, K. [Eds.] Die natürlichen Pflanzenfamilien nebst ihren Gattungen und wichtigeren Arten insbesondere den Nutzplanzen unter Mitwirkung zahlreicher hervorragender Fachgelehrten. Verlag von Wilhelm Engelmann, Leipzig, pp. 421-480.

Schneider, C. W. \& Wynne M. J. 2007. A synoptic review of the classification of red algal genera a half century after Kylin's "Die Gattungen der Rhodophyceen". Bot. Mar. 50:197-249.

Schneider, C. W. \& Wynne M. J. 2013. Second addendum to the synoptic review of red algal genera. Bot. Mar. 56:111-118.

Schnetter, R., Richter, U., Schmesmer, A. \& Bulameyer, G. 1983. Licht- und elektronenmikroskopische Untersuchungen an Grateloupiocolax colombiana gen. et spec. nov. (Halymeniaceae, Rhodophyceae). Beitr. Biol. Pflanzen 58:77-94.

Schubert, N., García-Mendoza, E. \& Pacheco-Ruiz, I. 2006. Carotenoid composition of marine red algae. J. Phycol. 42:1208-1216.

Sekimoto, S., Klochkova, T. A., West, J. A., Beakes, G. W. \& Honda, D. 2009. Olpidiopsis bostrychiae sp. nov.: an endoparasitic oomycete that infects Bostrychia and other red algae (Rhodophyta). Phycologia 48:460-472.

Seoane-Camba, J. A. 1982. Sobre una rodofícea parásita de Gelidiáceas. Collect. Bot. 13:911918.

Setchell, W. A. 1914. Parasitic Florideae, I. University of California Publications in Botany 6:1-34.

Setchell, W. A. 1918. Parasitism among the red algae. P. Am. Philos. Soc. 57:155-172.

Setchell, W. A. 1923. Parasitic Florideae, II. University of California Publications in Botany 10:393-396.

Setchell, W. A. \& Gardner, N. L. 1924. New marine algae from the Gulf of California. Expedition of the California Academy of Science to the Gulf of California in 1921, Proceeding of the California Academy of Science, San Francisco pp. 695-949. 
Setchell, W.A. \& Gardner, N. L. 1930. Marine algae of the Revillagigedo Islands Expedition in 1925. Proceedings of the California Academy of Science 4:109-215.

Shen, X. X., Hittinger, C. T. \& Rokas, A. 2017. Contentious relationships in phylogenomic studies can be driven by a handful of genes. Nat. Ecol. Evol. 1:126.

Sherwood, A. R., Kurihara, A., Conklin, K. Y., Sauvage, T. \& Prestling, G. G. 2010. The Hawaiian Rhodophyta Biodiversity Survey (2006-2010): a summary of principal findings. BMC Plant Biol. 10:258.

Silva, P. C., Basson, P. W. \& Moe, R. L. 1996. Catalogue of the benthic marine algae of the Indian Ocean. University of California Publications in Botany, Berkeley.

Skippington, E., Barkman, T. J., Rice, D. W. \& Palmer, J. D. 2015. Miniaturized mitogenome of the parasitic plant Viscum scurruloideum is extremely divergent and dynamic and has lost all nad genes. Proc. Natl. Acad. Sci. USA 112:E3515-3524.

Skottsberg, C. 1953. On two collections of Antarctic marine algae. Arkiv für Botanik 2:531566.

Skovgaard, A., Massana, R. \& Saiz, E. 2007. Parasitic species of the genus Blastodinium (Blastodiniphyceae) are peridinioid dinoflagellates. J. Phycol. 43:553-560.

Skovgaard, A. \& Salomonsen, X. M. 2009. Blastodinium galatheanum sp. nov. (Dinophyceae) a parasite of the planktonic copepod Acartia negligens (Crustacea, Calanoida) in the central Atlantic Ocean. Eur. J. Phycol. 44:425-438.

Slamovits, C. H., Fast, N. M., Law, J. S. \& Keeling, P. J. 2004. Genome compaction and stability in microsporidian intracellular parasites. Curr. Biol. 14:891-896.

Sparling, S. R. 1957. The structure and reproduction of some members of the Rhodymeniaceae. University of California Publications in Botany, Berkeley and Los Angeles 29:319-396.

Springer, M. S., DeBry, R. W., Douady, C., Amrine, H. M., Madsen, O., de Jong, W. W. \& Stanhope, M. J. 2001. Mitochondrial versus nuclear gene sequences in deep-level mammalian phylogeny reconstruction. Mol. Biol. Evol. 18:132-143.

Stamatakis, A. 2006. RAxML-VI-HPC: maximum likelihood-based phylogenetic analyses with thousands of taxa and mixed models. Bioinformatics 22:2688-2690.

Strickland, J. D. H. \& Parsons, T. R. 1972. A Practical Hand Book of Seawater Analysis. Fisheries Research Board of Canada Bulletin 157, Ottawa.

Strong, G. 2000. Are mistletoes shade plants? CO2 assimilation and chlorophyll fluorescence of temperate mistletoes and their hosts. Ann. Bot.-London 85:511-519.

Sturch, H. H. 1926. Choreocolax polysiphoniae, Reinsch. Ann. Bot.-London 40:585-605. 
Suzuki, S., Endoh, R., Manabe, R. I., Ohkuma, M. \& Hirakawa, Y. 2018. Multiple losses of photosynthesis and convergent reductive genome evolution in the colourless green algae Prototheca. Sci. Rep.-UK 8:940.

Tanaka, T. \& Nozawa, Y. 1960. One red algal parasite from Japan. Mem. Fac. Fish. Kagoshima Univ. 9:107-112.

Tesitel, J., Plavcova, L. \& Cameron, D. D. 2010. Interactions between hemiparasitic plants and their hosts. Plant Signal. Behav. 5:1072-1076.

Tokida, J. 1934. Phycological observations. I. Trans. Sapporo Natural History Society 13:196202.

Tokida. J. 1947. Notes on some new or little known marine algae. J. Jpn. Bot. 21:127-130.

Townsend, R. A. \& Huisman, J. M. 2004. Epulo multipedes gen. et sp. nov. (Corallinaceae, Rhodophyta), a coralline parasite from Australia. Phycologia 43:288-295.

Trifinopoulos, J., Nguyen, L. T., von Haeseler, A. \& Minh, B. Q. 2016. W-IQ-TREE: a fast online phylogenetic tool for maximum likelihood analysis Nucleic Acids Res. 44:W232235.

van der Kooij, T. A., Krause, K., Dorr, I. \& Krupinska, K. 2000. Molecular, functional and ultrastructural characterisation of plastids from six species of the parasitic flowering plant genus Cuscuta. Planta 210:701-707.

Velez-Ramirez, A. I., Carreno-Quintero, N., Vreugdenhil, D., Millenaar, F. F. \& van Ieperen, W. 2017. Sucrose and starch content negatively correlates with PSII maximum quantum efficiency in tomato (Solanum lycopersicum) exposed to abnormal light/dark cycles and continuous light. Plant Cell Physiol. 58:1339-1349.

Verbruggen, H., Maggs, C. A., Saunders, G. W., Le Gall, L., Yoon, H. S. \& De Clerck, O. 2010. Data mining approach identifies research priorities and data requirements for resolving the red algal tree of life. BMC Evol. Biol. 10:16.

Verbruggen, H., Marcelino, V. R., Guiry, M. D., Cremen, M. C. M. \& Jackson, C. J. 2017. Phylogenetic position of the coral symbiont Ostreobium (Ulvophyceae) inferred from chloroplast genome data. J. Phycol. 53:790-803.

Vergés, A., Izquierdo, C. \& Verlaque, M. 2005. Rhodymeniocolax mediterraneus sp. nov. (Rhodymeniales, Rhodophyta), parasitic on Rhodymenia ardissonei from the western Mediterranean Sea. Phycologia 44:510-516.

Wagner, F. S. 1954. Contributions to the morphology of the Delesseriaceae. University of California Publications in Botany 27:279-346. 
Weber-van Bosse, A. 1923. Liste des algues du Siboga. III. Rhodophyceae. Seconde partie. Ceramiales. Siboga-Expeditie Monographie, Leiden 59c:311-392.

Weber-van Bosse, A. 1928. Liste des algues du Siboga, IV. Rhodophyceae. Troisème partie. Gigartinales et Rhodymeniales et tableau de la distribution des Chlorophycées, Phaeophycées et Rhodophycées de l'Archipel Malaisien. Siboga-Expeditie Monographie, Leiden 59d: 393-533.

Weinstein, S. B. \& Kuris, A. M. 2016. Independent origins of parasitism in Animalia. Biol. Lett.-UK 12:20160324.

Werren, J. H. 2011. Selfish genetic elements, genetic conflict, and evolutionary innovation. Proc. Natl. Acad. Sci. USA 108:10863-10870.

West, J. A. \& Calumpong, H. P. 1988. Dawsoniocolax bostrychiae (Choreocolacaceae, Gigartinales), an alloparasitic red alga new to Australia. Phycologia 27:463-468.

Westwood, J. H., Yoder, J. I., Timko, M. P. \& de Pamphilis, C. W. 2010. The evolution of parasitism in plants. Trends Plant Sci. 15:227-235.

Wicke, S., Muller, K. F., de Pamphilis, C. W., Quandt, D., Wickett, N. J., Zhang, Y., Renner, S. S. \& Schneeweiss, G. M. 2013. Mechanisms of functional and physical genome reduction in photosynthetic and nonphotosynthetic parasitic plants of the broomrape family. Plant Cell 25:3711-3725.

Wilson, H. L. 1990. Gracilariophila a new parasite on Gracilaria confervoides. University of California Publication in Botany 4:75-85.

Wilson, R. J., Denny, P. W., Preiser, P. R., Rangachari, K., Roberts, K., Roy, A., Whyte, A., Strath, M., Moore, D. J., Moore, P. W. \& Williamson, D. H. 1996. Complete gene map of the plastid- like DNA of the malaria parasite Plasmodium falciparum. J. Mol. Biol. 261:155-172.

Wolfe, K. H., Morden, C. W. \& Palmer, J. D. 1992. Function and evolution of a minimal plastid genome from a nonphotosynthetic parasitic plant. Proc. Natl. Acad. Sci. USA 89:1064852.

Womersley, H. B. S. 1994. The marine benthic flora of southern Australia. Rhodophyta. Part IIIA, Bangiophyceae and Florideophyceae. Australian Biological Resources Study, Canberra and the State Herbarium of South Australia, Canberra.

Womersley, H. B. S. 1996. The marine benthic flora of southern Australia. Rhodophyta. Part IIIB, Gracilariales, Rhodymeniales, Corellinales and Bonnemaisoniales Australian Biological Resources Study, Canberra and the State Herbarium of South Australia, Canberra. 
Womersley, H. B. S. 1998. The marine benthic flora of southern Australia. Rhodophyta. Part IIIC, Ceramiales - Ceramiaceae, Dasyaceae. Australian Biological Resources Study, Canberra and the State Herbarium of South Australia, Canberra.

Wynne, M. J. 1970. Marine algae of Amchitka Island (Aleutian Islands). I. Delesseriaceae. Syesis 3:95-144.

Wynne, M. J. \& Scott, F. 1989. Pitycolax, a new genus of adelphoparasitic red algae from Ile Amsterdam, Southern Indian Ocean. Cryptogamie Algol. 10:23-32.

Wynne, M. J. \& Heine, J. N. 1992. Collections of marine red algae from St. Matthew and St. Lawrence Islands, the Bering Sea. Nova Hedwigia 55:55-97.

Womersley, H. B. S. 2003. The marine benthic flora of Southern Australia, Rhodophyta, Part IIID, Ceramiales -Delesseriaceae, Sarcomeniaceae, Rhodymelaceae. Australian Biological Resources Study/State Herbarium of South Australia, Canberra.

Wynne, M. J. \& Schneider, C. W. 2010. Addendum to the synoptic review of red algal genera. Bot. Mar. 53:291-299.

Wynne, M. J. 2013. The red algal families Delesseriaceae and Sarcomeniaceae. Koeltz Scientific Books, Königsstein.

Yamamoto, H. 1986. Congracilaria babae gen. et sp. nov. (Gracilariaceae), an adelphoparasite growing on Gracilaria salicornia of Japan. Bull. Fac. Fish. Hokkaido Univ. 37:281290.

Yamamoto, M., Nozaki, H. \& Kawano, S. 2001. Evolutionary relationships among multiple modes of cell division in the genus Nannochloris (Chlorophyta) revealed by genome size, actin gene multiplicity, and phylogeny. J. Phycol. 37:106-120.

Yang, M. Y. \& Kim, M. S. 2015. Taxonomy of Grateloupia (Halymeniales, Rhodophyta) by DNA barcode marker analysis and a description of Pachymeniopsis volvita sp. nov. J. Appl. Phycol. 27:1373-1384.

Yang, E. C., Kim, K. M., Kim, S. Y., Lee, J., Boo, G. H., Lee, J. H., Nelson, W. A., Yi, G., Schmidt, W. E., Fredericq, S., Boo, S. M., Bhattacharya, D. \& Yoon, H. S. 2015. Highly conserved mitochondrial genomes among multicellular red algae of the Florideophyceae. Genome Biol. Evol. 7:2394-2406.

Yang, E. C., Boo, S. M., Bhattacharya, D., Saunders, G. W., Knoll, A. H., Fredericq, S., Graf, L. \& Yoon, H. S. 2016. Divergence time estimates and the evolution of major lineages in the florideophyte red algae. Sci. Rep.-UK 6:21361. 
Yoneshigue, Y. \& Deoliveira, E. C. 1984. Algae from Cabo-Frio upwelling area 2. Gelidiocolax pustulata (Gelidiaceae, Rhodophyta) - an unusual new putative parasitic species. J. Phycol. 20:440-443.

Yoshida, T. \& Mikami, H. 1996. Sorellocolax stellaris gen. et sp. nov., a hemiparasitic alga (Delesseriaceae, Rhodophyta) from the east coast of Honshu, Japan. Phycol. Res. 44:125-128.

Zeng, Y. F., Zhang, J. G., Duan, A. G. \& Abuduhamiti, B. 2016. Genetic structure of Populus hybrid zone along the Irtysh River provides insight into plastid-nuclear incompatibility. Sci. Rep.-UK 6:28043.

Zinova, A. D. 1963. Delesseriaceae apud Insulas Kerguelen et Macquarie. Trudy Botanicheskogo Instituta Akademii Nauk SSSR. Sporovye Rasteniya 16:52-67.

Zinova, A. D. 1967. Opredelitel zelenikh, burikh i krasnich odoroslei juzhnikh morei SSSR [Guide to the green, brown and red algae of the southern seas of USSR]. Academia Nauk USSR, Botanical Garden of the VL Komarov Botanical Institute, Moscow, Leningrad.

Zuccarello, G. C. \& West, J. A. 1994a. Comparative development of the red algal parasites Bostrychiocolax australis gen. et $\mathrm{sp}$. nov. and Dawsoniocolax bostrychiae (Choreocolacaceae, Rhodophyta). J. Phycol. 30:137-146.

Zuccarello, G. C. \& West. J. A. 1994c. Genus and race specificity in the red algal parasite Leachiella pacifica (Choreocolacaceae, Rhodophyta). Phycologia 33:213-238.

Zuccarello, G. C. \& West, J. A. 1994c. Host specificity on the red algal parasites Bostrychioclax australis and Dawsoniocolax bostrychiae (Choreocolacaceae, Rhodophyta). J. Phycol. 30:462-473.

Zuccarello, G. C., West, J., Kamiya, M. \& King, R. 1999. A rapid method to score plastid haplotypes in red seaweeds and its use in determining parental inheritance of plastids in the red alga Bostrychia (Ceramiales). Hydrobiologia 401:207-214.

Zuccarello, G. C., Moon, D. \& Goff, L. J. 2004. A phylogenetic study of parasitic genera placed in the family Choreocolacaceae (Rhodophyta). J. Phycol. 40:937-945.

Zuccarello, G. C. \& Lokhorst, G. M. 2005. Molecular phylogeny of the genus Tribonema (Xanthophyceae) using $r b c \mathrm{~L}$ gene sequence data: monophyly of morphologically simple algal species. Phycologia 44:384-392.

Zucccarello, G. C. \& West, J. A. 2006. Molecular phylogeny of the subfamily Bostrychioideae (Ceramiales, Rhodophyta): Subsuming Stictosiphonia and highlighting polyphyly in species of Bostrychia. Phycologia 45:24-36. 
Zuccarello, G. C. 2008. A fungal gall of Catenella nipae (Caulacanthaceae, Rhodophyta) and a review of Catenellocolax leeuweni. Bot. Mar. 51:436-440. 
Appendices 
Appendix 2.1. Synoptic list of described species of red algal parasites, arranged by order (listed alphabetically) and family. Parasites are characterized by: Host it has been described on; Year of original description; Parasitic character (up = unpigmented, $\mathrm{p}=$ pigmented, $\mathrm{rm}=$ reduced morphology mentioned, $2 \mathrm{PC}=$ secondary pit connections between parasite and host reported, $\mathrm{pe}=$ penetration into the host thallus reported; and which reproductive structures were described: $\mathrm{M}=$ male, $\mathrm{F}=$ female, $\mathrm{T}=$ sporophyte); Type locality; Distribution and Rank [+ = red algal parasite characters are met (i.e. $2 \mathrm{PC}$ and sporophyte and gametophyte present); +/o = species could be a parasite but characters are missing (i.e. either no $2 \mathrm{PC}$ or no sporophyte or no gametophyte reported); $\mathrm{o}=$ species could be a parasite but many characters are missing (i.e. missing $2 \mathrm{PC}$ and either no sporophyte or gametophyte); o/- = not enough information for informative decision about the species, could be an outgrowth of the host or an epiphyte]. Parasitic species with synonyms are indicated with \#. All references are given in Supplemental Appendix 2.2.

$\begin{array}{llllll}\text { Parasite Host } & \text { Year } & \text { Parasitic character } & \text { Type locality Distribution Rank Refence }\end{array}$

up $\mathrm{p} \quad \mathrm{rm} \quad 2 \mathrm{PC}$ pe $\mathrm{M} \quad \mathrm{F} \quad \mathrm{T}$

\begin{tabular}{llllllllll}
\hline & up & p & rm & 2PC & pe & M & F & T
\end{tabular}

\title{
Ceramiales
}

\section{Ceramiaceae}

Centrocerocolax

Okamura, Ceramium spp.

(n)

(1)

.

$\begin{array}{ll} & \\ & \\ \text { Episporium } & \text { Centroceras clavulatum } \\ \text { centroceratis } & \text { (C.Agardh) Mont. } \\ \text { K.Möbius } & \end{array}$

K.Möbius

\begin{abstract}
(C.Agardh) Mont.
\end{abstract}

$1885 \mathrm{x}$

Sao P

\section{ulo, Brazil \\ Canary Is.,
Curaçao,}

Mexico,

Venezuela
Dirk Hartog
Island, Western
Australia

Australia, $\quad+\quad$ Pocock 1956;
East Africa,
South

South

Coppejans et 


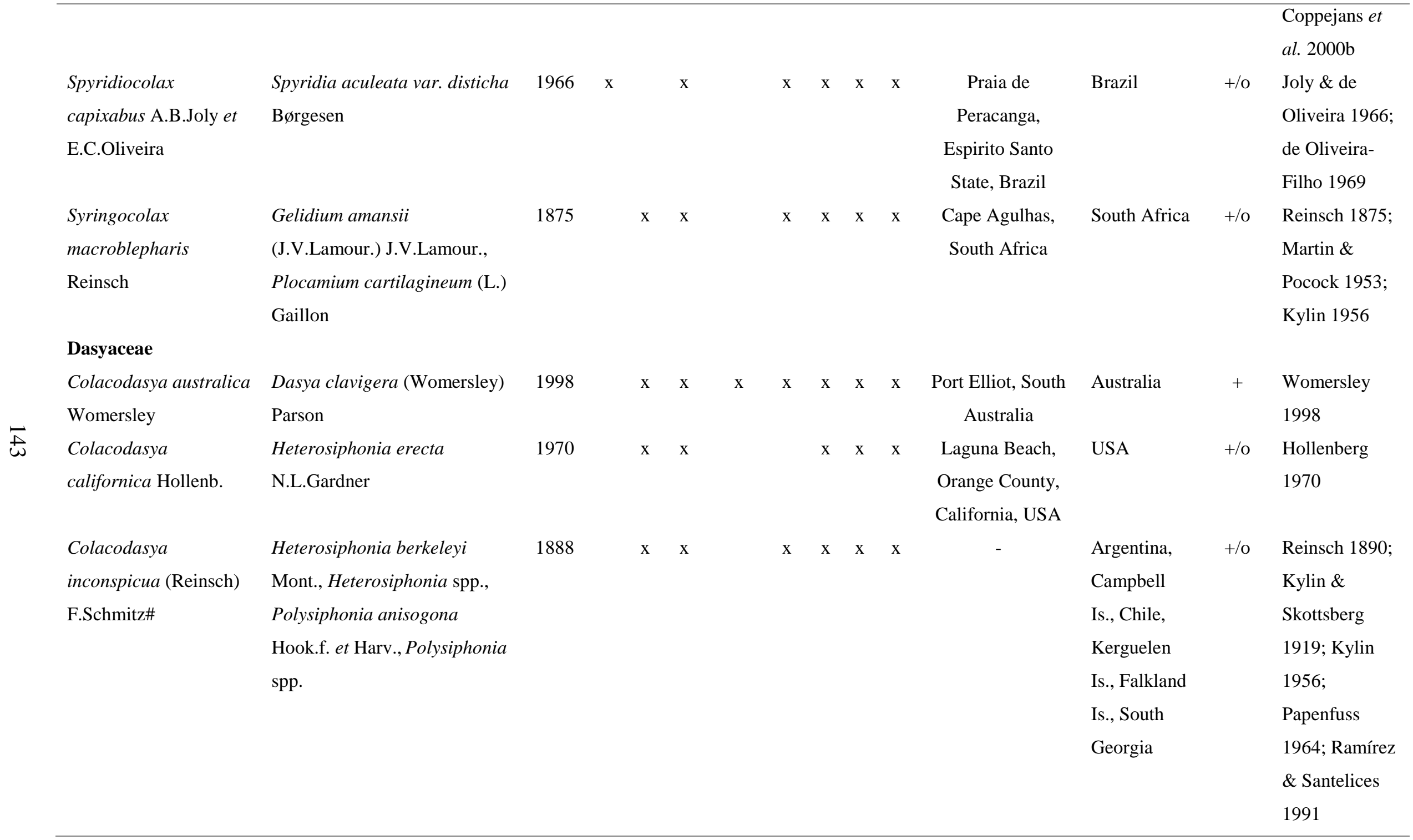




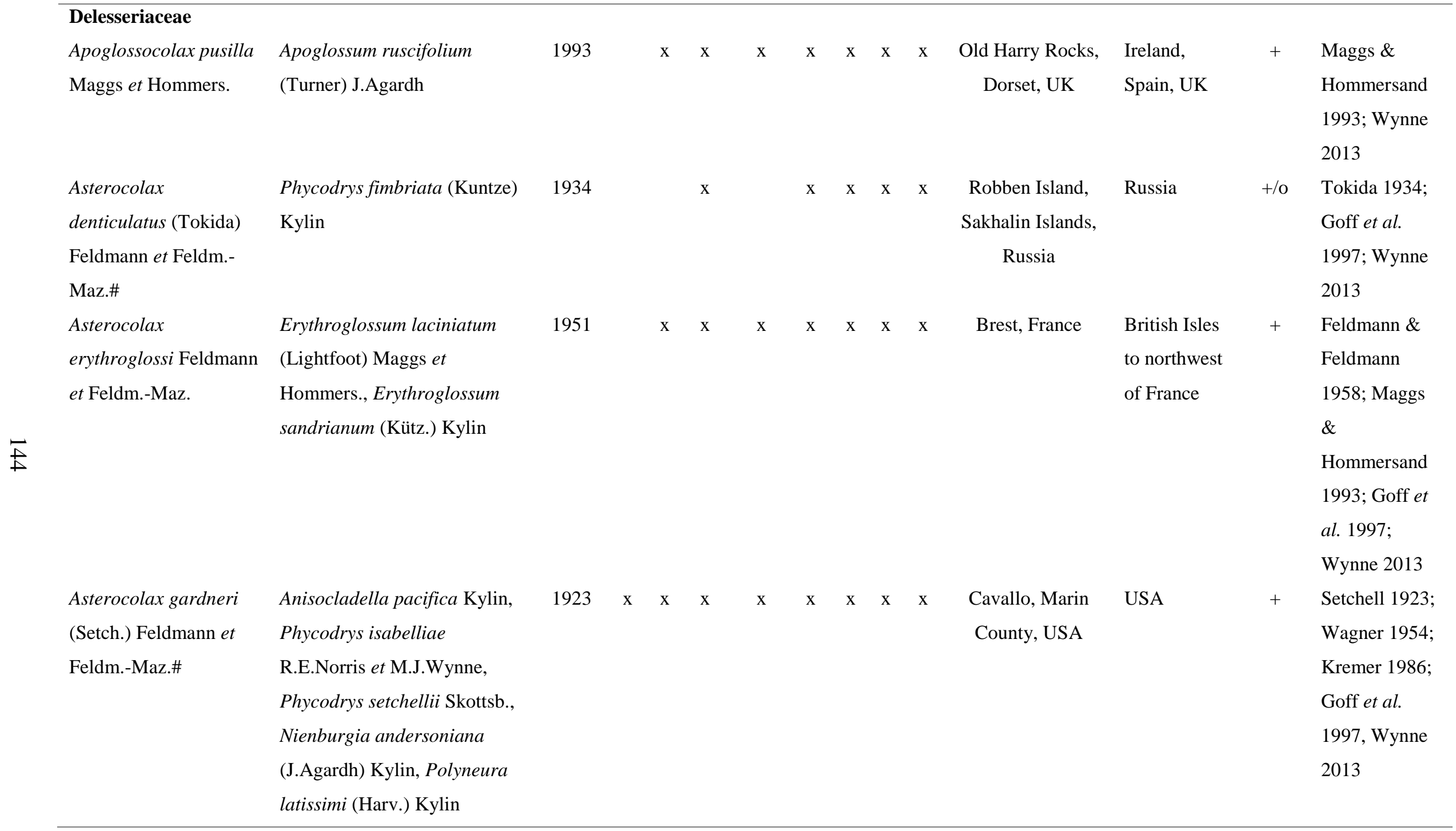




\begin{tabular}{|c|c|c|c|c|c|c|c|c|c|c|c|c|c|c|}
\hline $\begin{array}{l}\text { Asterocolax } \\
\text { hypophyllophilus } \\
\text { M.JWynne }\end{array}$ & $\begin{array}{l}\text { Mikamiella ruprechtiana } \\
\text { (Zinova) M.J.Wynne }\end{array}$ & 1970 & $\mathrm{x}$ & $\mathrm{x}$ & $\mathrm{x}$ & & & $\mathrm{x}$ & $\mathrm{x}$ & $\mathrm{x}$ & $\begin{array}{l}\text { Makarius Point, } \\
\text { Amchitka Island, } \\
\text { Aleutian Islands }\end{array}$ & Aleutian Is. & $+/ 0$ & $\begin{array}{l}\text { Wynne 1970; } \\
\text { Goff et al. } \\
1997\end{array}$ \\
\hline $\begin{array}{l}\text { Gonimocolax australis } \\
\text { (Skottsb.) Kylin\# }\end{array}$ & $\begin{array}{l}\text { Myriogramme livida (Hook.f. } \\
\text { et Harv.) Kylin, Schizoseris } \\
\text { spp. }\end{array}$ & 1919 & & $\mathrm{x}$ & $\mathrm{x}$ & & $\mathrm{x}$ & $\mathrm{x}$ & $\mathrm{x}$ & $\mathrm{x}$ & Falkland Islands & Falkland Is. & $+/ 0$ & $\begin{array}{l}\text { Kylin \& } \\
\text { Skottsberg } \\
\text { 1919; Kylin } \\
\text { 1956; Wynne } \\
2013\end{array}$ \\
\hline $\begin{array}{l}\text { Gonimocolax } \\
\text { corymbosus Baardseth }\end{array}$ & $\begin{array}{l}\text { Schizoseris dichotoma } \\
\text { (Hook.f. et Harv.) Kylin, } \\
\text { Schizoseris multifoliata } \\
\text { Baardseth }\end{array}$ & 1941 & & $\mathrm{x}$ & $\mathrm{x}$ & $\mathrm{x}$ & $\mathrm{x}$ & $\mathrm{x}$ & $\mathrm{x}$ & $\mathrm{x}$ & $\begin{array}{l}\text { Seal Bay, Tristan } \\
\text { da Cunha }\end{array}$ & $\begin{array}{l}\text { Nightingale } \\
\text { Is., Tristan } \\
\text { da Cunha }\end{array}$ & + & $\begin{array}{l}\text { Baardseth } \\
\text { 1941; Kylin } \\
\text { 1956; Wynne } \\
2013\end{array}$ \\
\hline $\begin{array}{l}\text { Gonimocolax } \\
\text { roscoffensis Feldmann } \\
\text { et Feldm.-Maz }\end{array}$ & $\begin{array}{l}\text { Drachiella spectabilis J.Ernst } \\
\text { et Feldmann }\end{array}$ & 1961 & & $\mathrm{x}$ & $\mathrm{x}$ & & $\mathrm{x}$ & & $\mathrm{x}$ & & Roscoff, France & $\begin{array}{l}\text { North } \\
\text { Atlantic of } \\
\text { Europe }\end{array}$ & o & $\begin{array}{l}\text { Feldmann \& } \\
\text { Feldmann } \\
\text { 1961; Guiry } \\
1997\end{array}$ \\
\hline $\begin{array}{l}\text { Gonimophyllum } \\
\text { africanum M.T.Martin } \\
\text { et Pocock }\end{array}$ & $\begin{array}{l}\text { Acrosorium maculatum } \\
\text { (Sonder ex Kütz.) Papenf., } \\
\text { Acrosorium spp., } \\
\text { Botryoglossum platycarpus } \\
\text { (Turner) Kütz., Botryocarpa } \\
\text { prolifera Grev., } \\
\text { Delesseriaceae spp., } \\
\text { Neuroglossum binderianium } \\
\text { Kütz. }\end{array}$ & 1953 & & $\mathrm{x}$ & $\mathrm{x}$ & & & $\mathrm{x}$ & $\mathrm{x}$ & $\mathrm{x}$ & $\begin{array}{l}\text { Cove Rock, near } \\
\text { East London, } \\
\text { South Africa }\end{array}$ & $\begin{array}{l}\text { Brazil, South } \\
\text { Africa, } \\
\text { Uruguay }\end{array}$ & $+/ 0$ & $\begin{array}{l}\text { Martin \& } \\
\text { Pocock 1953; } \\
\text { Maggs \& } \\
\text { Hommersand } \\
\text { 1993; Wynne } \\
2013\end{array}$ \\
\hline
\end{tabular}




\begin{tabular}{|c|c|c|c|c|c|c|c|c|c|c|c|c|c|}
\hline $\begin{array}{l}\text { Gonimophyllum } \\
\text { buffhamii Batters }\end{array}$ & $\begin{array}{l}\text { Acrosorium ciliolatum (Harv.) } \\
\text { Kylin, Cryptopleura ramosa } \\
\text { (Huds.) L.Newton }\end{array}$ & 1892 & $\mathrm{x}$ & $\mathrm{x}$ & $\mathrm{x}$ & $\mathrm{x}$ & $\mathrm{x}$ & $\mathrm{x}$ & $\mathrm{x}$ & - & $\begin{array}{l}\text { British Isles } \\
\text { to Spain }\end{array}$ & + & $\begin{array}{l}\text { Batters 1892; } \\
\text { Wagner 1954; } \\
\text { Kylin 1956; } \\
\text { Maggs \& } \\
\text { Hommersand } \\
\text { 1993; Wynne } \\
2013\end{array}$ \\
\hline $\begin{array}{l}\text { Gonimophyllum } \\
\text { insulare F.S.Wagner }\end{array}$ & $\begin{array}{l}\text { Hymenena semicostata } \\
\text { (J.Agardh) Kylin }\end{array}$ & 1954 & & $\mathrm{x}$ & & $\mathrm{x}$ & $\mathrm{x}$ & $\mathrm{x}$ & $\mathrm{x}$ & $\begin{array}{c}\text { Half Moon Bay, } \\
\text { Stewart Island, } \\
\text { New Zealand }\end{array}$ & $\begin{array}{l}\text { Argentina, } \\
\text { New } \\
\text { Zealand }\end{array}$ & $+/ o$ & $\begin{array}{l}\text { Wagner 1954; } \\
\text { Wynne } 2013\end{array}$ \\
\hline $\begin{array}{l}\text { Gonimophyllum } \\
\text { skottsbergii Setch. }\end{array}$ & $\begin{array}{l}\text { Cryptopleura crispa Kylin, } \\
\text { Hymenena flabelligera } \\
\text { (J.Agardh) Kylin, } \\
\text { Cryptopleura ruprechtianum } \\
\text { (J.Agardh) Kylin }\end{array}$ & 1923 & & $\mathrm{x}$ & & $\mathrm{x}$ & $\mathrm{x}$ & $\mathrm{x}$ & $\mathrm{x}$ & $\begin{array}{l}\text { Lands End, San } \\
\text { Francisco, } \\
\text { California, USA }\end{array}$ & $\begin{array}{l}\text { North } \\
\text { America }\end{array}$ & $+/ 0$ & $\begin{array}{l}\text { Setchell 1923; } \\
\text { Wagner 1954; } \\
\text { Zuccarello et } \\
\text { al. } 2004\end{array}$ \\
\hline $\begin{array}{l}\text { Phitycolax inconspicua } \\
\text { M.J.Wynne et F.J.Scott }\end{array}$ & $\begin{array}{l}\text { Phitymophora amansioides } \\
\text { (Sonder) Womersley }\end{array}$ & 1989 & $\mathrm{x}$ & $\mathrm{x}$ & $\mathrm{x}$ & $\mathrm{x}$ & $\mathrm{x}$ & $\mathrm{x}$ & $\mathrm{x}$ & $\begin{array}{l}\text { Ile de Amsterdam, } \\
\text { Indian Ocean }\end{array}$ & $\begin{array}{l}\text { Indian } \\
\text { Ocean }\end{array}$ & + & $\begin{array}{l}\text { Wynne \& } \\
\text { Scott } 1989 \\
\text { Wynne } 2013\end{array}$ \\
\hline $\begin{array}{l}\text { Polycoryne compacta } \\
\text { Zinova }\end{array}$ & $\begin{array}{l}\text { Myriogramme kerguelensis } \\
\text { Levring }\end{array}$ & 1963 & & $\mathrm{x}$ & & & & $\mathrm{x}$ & $\mathrm{x}$ & $\begin{array}{l}\text { Kergules Islands, } \\
\text { Indian Ocean }\end{array}$ & $\begin{array}{l}\text { Indian } \\
\text { Ocean }\end{array}$ & $+/ o$ & $\begin{array}{l}\text { Zinova 1963; } \\
\text { Papenfuss } \\
\text { 1964; Goff } \\
\text { 1982; Wynne } \\
2013\end{array}$ \\
\hline $\begin{array}{l}\text { Polycoryne radiata } \\
\text { Skottsb. }\end{array}$ & Nitophyllum sp. & 1919 & & $\mathrm{X}$ & & $\mathrm{x}$ & & $\mathrm{x}$ & $\mathrm{x}$ & South Georgia & $\begin{array}{l}\text { South } \\
\text { Georgia, }\end{array}$ & $+/ 0$ & $\begin{array}{l}\text { Kylin \& } \\
\text { Skottsberg }\end{array}$ \\
\hline
\end{tabular}




\begin{tabular}{|c|c|c|c|c|c|c|c|c|c|c|c|c|c|c|}
\hline & & & & & & & & & & & & $\begin{array}{l}\text { Macquarie } \\
\text { Is. }\end{array}$ & & $\begin{array}{l}\text { 1919; } \\
\text { Papenfuss } \\
\text { 1964; Wynne } \\
2013\end{array}$ \\
\hline $\begin{array}{l}\text { Sorellocolax stellaris } \\
\text { T.Yoshida et Mikami }\end{array}$ & $\begin{array}{l}\text { Sorella repens (Okamura) } \\
\text { Hollenb. }\end{array}$ & 1996 & & $\mathrm{x}$ & $\mathrm{x}$ & & $\mathrm{x}$ & $\mathrm{x}$ & $\mathrm{x}$ & $\mathrm{x}$ & $\begin{array}{c}\text { Onagawa, } \\
\text { Honshu, Japan }\end{array}$ & China, Japan & $+/ 0$ & $\begin{array}{l}\text { Yoshida \& } \\
\text { Mikami 1996; } \\
\text { Wynne } 2013\end{array}$ \\
\hline Rhodomelaceae & & & & & & & & & & & & & & \\
\hline $\begin{array}{l}\text { Aiolocolax pulchella } \\
\text { Pocock }\end{array}$ & $\begin{array}{l}\text { Polysiphonia atlantica } \\
\text { Kapraun } \text { et J.N.Norris, } \\
\text { Polysiphonia caespitosa } \\
\text { (Pocock) Hollenb., } \\
\text { Polysiphonia devoniensis } \\
\text { Maggs et Hommers. }\end{array}$ & 1956 & $\mathrm{x}$ & & $\mathrm{x}$ & $\mathrm{x}$ & $\mathrm{x}$ & $\mathrm{x}$ & $\mathrm{x}$ & $\mathrm{x}$ & $\begin{array}{l}\text { Muizenberg, } \\
\text { South Africa }\end{array}$ & $\begin{array}{l}\text { Canary Is., } \\
\text { Namibia, } \\
\text { Portugal, } \\
\text { South } \\
\text { Africa, Spain }\end{array}$ & + & $\begin{array}{l}\text { Pocock 1956; } \\
\text { Pérez-Cirera et } \\
\text { al. 1989; John } \\
\text { et al. 2004; } \\
\text { Araújo et al. } \\
\text { 2009; Diaz- } \\
\text { Tapia \& } \\
\text { Bárbara } 2013\end{array}$ \\
\hline $\begin{array}{l}\text { Antarctocolax lambii } \\
\text { Skottsb. }\end{array}$ & $\begin{array}{l}\text { Picconiella plumosa (Kylin) } \\
\text { G.De Toni }\end{array}$ & 1953 & & $\mathrm{x}$ & $\mathrm{x}$ & & $\mathrm{x}$ & $\mathrm{x}$ & $\mathrm{x}$ & $\mathrm{x}$ & $\begin{array}{c}\text { Melchior Islands, } \\
\text { Palmer } \\
\text { Archipelago, } \\
\text { Antarctica }\end{array}$ & Antarctica & $+/ \mathrm{o}$ & $\begin{array}{l}\text { Skottsberg } \\
1953 ; \\
\text { Hommersand } \\
\text { et al. } 2009\end{array}$ \\
\hline $\begin{array}{l}\text { Benzaitenia } \\
\text { yenoshimensis Yendo }\end{array}$ & $\begin{array}{l}\text { Chondria crassicaulis Harv., } \\
\text { Chondria spp., Laurencia } \\
\text { spp., Palisada peniculata } \\
\text { (Kütz.) Cassano, Sentíes, Gil- } \\
\text { Rodriquez et M.T.Fujii }\end{array}$ & 1913 & & $\mathrm{x}$ & $\mathrm{x}$ & $\mathrm{x}$ & & $\mathrm{x}$ & $\mathrm{x}$ & $\mathrm{x}$ & Japan & Japan, Korea & + & $\begin{array}{l}\text { Kylin 1956; } \\
\text { Morrill 1976a; } \\
\text { Kim et al. } \\
2008\end{array}$ \\
\hline
\end{tabular}




\begin{tabular}{|c|c|c|c|c|c|c|c|c|c|c|c|c|c|c|}
\hline $\begin{array}{l}\text { Bostrychiocolax } \\
\text { australis Zuccarello et } \\
\text { J.A.West }\end{array}$ & $\begin{array}{l}\text { 'Bostrychia radicans' (Mont.) } \\
\text { Mont. }\end{array}$ & 1994 & $\mathrm{x}$ & & $\mathrm{x}$ & $\mathrm{x}$ & $\mathrm{x}$ & $\mathrm{x}$ & $\mathrm{x}$ & $\mathrm{x}$ & $\begin{array}{l}\text { Florence Bay, } \\
\text { Magnetic Island, } \\
\text { Queensland, } \\
\text { Australia }\end{array}$ & Australia & + & $\begin{array}{l}\text { Zuccarello \& } \\
\text { West 1994a }\end{array}$ \\
\hline $\begin{array}{l}\text { Chamaethamnion } \\
\text { pocockiae R.E.Norris }\end{array}$ & $\begin{array}{l}\text { Kentrophora natalensis } \\
\text { (J.Agardh) S.M.Wilson et } \\
\text { Kraft }\end{array}$ & 1988 & & & $\mathrm{x}$ & & & $\mathrm{x}$ & $\mathrm{x}$ & $\mathrm{x}$ & $\begin{array}{c}\text { Palm Beach, near } \\
\text { Port Edward, } \\
\text { Natal, South } \\
\text { Africa }\end{array}$ & South Africa & $+/ o$ & $\begin{array}{l}\text { Norris 1988; } \\
\text { Womersley } \\
2003\end{array}$ \\
\hline $\begin{array}{l}\text { Chamaethamnion } \\
\text { schizandra Falkenb. }\end{array}$ & $\begin{array}{l}\text { Polysiphonia decipiens Mont., } \\
\text { Micropeuce feredayae (Harv.) } \\
\text { Kylin ex Silva }\end{array}$ & 1897 & & $\mathrm{x}$ & $\mathrm{x}$ & & $\mathrm{x}$ & $\mathrm{x}$ & $\mathrm{x}$ & $\mathrm{x}$ & - & $\begin{array}{l}\text { Argentina, } \\
\text { Australia }\end{array}$ & $+/ o$ & $\begin{array}{l}\text { Schmitz \& } \\
\text { Falkenberg } \\
1897 ; \\
\text { Womersley } \\
2003\end{array}$ \\
\hline $\begin{array}{l}\text { Choreocolax } \\
\text { americanus Reinsch }\end{array}$ & Lophura spp. & 1875 & & & $\mathrm{x}$ & & $\mathrm{x}$ & & & & - & USA & o/- & Reinsch 1875 \\
\hline $\begin{array}{l}\text { Choreocolax destructor } \\
\text { Reinsch }\end{array}$ & $\begin{array}{l}\text { Chondracanthus teedei } \\
\text { (Mertens) Kütz. }\end{array}$ & 1875 & & & $\mathrm{x}$ & & $\mathrm{x}$ & & & & - & Adriatic Sea & $\mathrm{o} /-$ & Reinsch 1875 \\
\hline $\begin{array}{l}\text { Choreocolax } \\
\text { polysiphoniae }\end{array}$ & $\begin{array}{l}\text { Cystoclonium purpureum } \\
\text { (Hudson) Batters, }\end{array}$ & 1875 & $\mathrm{x}$ & & $\mathrm{x}$ & $\mathrm{x}$ & $\mathrm{x}$ & $\mathrm{x}$ & $\mathrm{x}$ & $\mathrm{x}$ & - & $\begin{array}{l}\text { North } \\
\text { Atlantic }\end{array}$ & + & $\begin{array}{l}\text { Reinsch 1875; } \\
\text { Goff \& }\end{array}$ \\
\hline Reinsch & $\begin{array}{l}\text { Neosiphonia confusa } \\
\text { (Hollenb.) J.N.Norris, } \\
\text { Vertebrata lanosa (L.) } \\
\text { T.A.Chr. }\end{array}$ & & & & & & & & & & & Ocean & & $\begin{array}{l}\text { Coleman } \\
\text { 1985; Setchell } \\
\text { 1918; } \\
\text { Zuccarello et } \\
\text { al. } 2004\end{array}$ \\
\hline
\end{tabular}




\begin{tabular}{|c|c|c|c|c|c|c|c|c|c|c|c|c|c|c|}
\hline $\begin{array}{l}\text { Choreocolax } \\
\text { rabenhorstii Reinsch }\end{array}$ & Phycodrys rubens (L.) Batters & 1875 & & & $\mathrm{x}$ & & $\mathrm{x}$ & & & & $\begin{array}{c}\text { Gloucester, } \\
\text { Massachusetts, } \\
\text { USA }\end{array}$ & USA & $\mathrm{o} /-$ & Reinsch 1875 \\
\hline $\begin{array}{l}\text { Choreocolax } \\
\text { rhodymeniae Reinsch }\end{array}$ & $\begin{array}{l}\text { Palmaria decipiens (Reinsch) } \\
\text { Ricker, Palmaria georgica } \\
\text { (Reinsch) R.W.Ricker }\end{array}$ & 1888 & & & $\mathrm{x}$ & & & & & & South Georgia & $\begin{array}{l}\text { South } \\
\text { Georgia }\end{array}$ & $\mathrm{o} /-$ & $\begin{array}{l}\text { Reinsch 1890; } \\
\text { Papenfuss } \\
\text { 1964; } \\
\text { Edelstein } 1972\end{array}$ \\
\hline $\begin{array}{l}\text { Choreocolax tumidus } \\
\text { Reinsch }\end{array}$ & $\begin{array}{l}\text { Ceramium spp., } \\
\text { Ceramium virgatum Roth } \\
\text { Cystoclonium purpureum }\end{array}$ & 1875 & & $\mathrm{x}$ & $\mathrm{x}$ & & $\mathrm{x}$ & & & & $\begin{array}{l}\text { West Gloucester, } \\
\text { Massachusetts, } \\
\text { USA }\end{array}$ & $\begin{array}{l}\text { English } \\
\text { Channel, } \\
\text { USA }\end{array}$ & $\mathrm{o} /-$ & $\begin{array}{l}\text { Reinsch 1875; } \\
\text { Setchell 1918; } \\
\text { Lyle } 1920\end{array}$ \\
\hline $\begin{array}{l}\text { Colacopsis lophurellae } \\
\text { Kylin }\end{array}$ & $\begin{array}{l}\text { Lophurella hookeriana } \\
\text { (J.Agardh) Falkenb. }\end{array}$ & 1919 & & & $\mathrm{x}$ & & $\mathrm{x}$ & $\mathrm{x}$ & $\mathrm{x}$ & $\mathrm{x}$ & $\begin{array}{l}\text { Tierra del Fuego, } \\
\text { Argentina and } \\
\text { Falkland Islands }\end{array}$ & $\begin{array}{l}\text { Argentina, } \\
\text { Campbell } \\
\text { Is., Falkland } \\
\text { Is., New } \\
\text { Zealand }\end{array}$ & $+/ 0$ & $\begin{array}{l}\text { Kylin \& } \\
\text { Skottsberg } \\
\text { 1919; Kylin } \\
\text { 1956; Dalen \& } \\
\text { Nelson } 2013\end{array}$ \\
\hline $\begin{array}{l}\text { Colacopsis pulvinata } \\
\text { (F.Schmitz) G.De } \\
\text { Toni\# }\end{array}$ & $\begin{array}{l}\text { Osmundaria serrata (Suhr) J. } \\
\text { Agardh }\end{array}$ & 1897 & $\mathrm{x}$ & & $\mathrm{x}$ & & $\mathrm{x}$ & $\mathrm{x}$ & $\mathrm{x}$ & $\mathrm{x}$ & Southeast Africa & $\begin{array}{l}\text { Southeast } \\
\text { Africa, } \\
\text { South Africa }\end{array}$ & $+/ 0$ & $\begin{array}{l}\text { Kylin 1956; } \\
\text { Norris } 1988\end{array}$ \\
\hline $\begin{array}{l}\text { Colacopsis smitheniae } \\
\text { R.E.Norris }\end{array}$ & $\begin{array}{l}\text { Aneurianna nozawae (Norris) } \\
\text { L.E.Philipps }\end{array}$ & 1988 & & & $\mathrm{x}$ & $\mathrm{x}$ & $\mathrm{x}$ & $\mathrm{x}$ & $\mathrm{x}$ & $\mathrm{x}$ & $\begin{array}{c}\text { Jesser Point, } \\
\text { Sodwana, Natal, } \\
\text { South Africa }\end{array}$ & South Africa & + & Norris 1988 \\
\hline $\begin{array}{l}\text { Colacopsis velutina } \\
\text { (M.T.Martin } \text { et } \\
\text { Pocock) R.E.Norris\# }\end{array}$ & $\begin{array}{l}\text { Rhodomelopsis africana } \\
\text { Pocock }\end{array}$ & 1953 & $\mathrm{x}$ & $\mathrm{x}$ & $\mathrm{x}$ & $\mathrm{x}$ & $\mathrm{x}$ & $\mathrm{x}$ & $\mathrm{x}$ & $\mathrm{x}$ & $\begin{array}{c}\text { Riet River, Three } \\
\text { Sisters, South } \\
\text { Africa }\end{array}$ & $\begin{array}{l}\text { Kerguelen } \\
\text { Is., South } \\
\text { Africa }\end{array}$ & + & $\begin{array}{l}\text { Martin \& } \\
\text { Pocock 1953; }\end{array}$ \\
\hline
\end{tabular}


Fan 1963;

Norris 1988

Dawsoniocolax bostrychiae (A.B.Joly

et Yam.-Tomita) Joly

et Yam.-Tomita\#

'Bostrychia calliptera'

(Mont.) Mont., 'Bostrychia

montagnei' Harv., 'Bostrychia

radicans' (Mont.) Mont.
1970

$x$

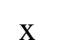

$\mathrm{x}$

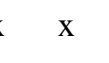

$\mathrm{X}$

Brazil

(Dickie) Skottsb. et Levring

fernandezianus

J.Morrill

$\overline{\mathrm{g}}$

Harveyella mirabilis

(Reinsch) F.Schmitz et

Reinke\#
Gonimophyllum skottsbergii

Setch., Odonthalia floccosa

(Esper) Falkenb., Odonthalia

washingtoniensis Kylin,

Rhodomela confervoides

(Huds.) P.C.Silva
977

Juan Fernández

Chile

Islands, Chile

Bohuslän,
Sweden

Arctic,

North

Atlantic

Coast, North

Pacific

Coast $+\quad$ Joly \&

Yamaguishi-

Tomita 1969;

Guimaraes

1993;

Zuccarello et

al. 2004

+/o Morrill 1977

$+\quad$ Reinsch 1875;

Kylin 1956;

Goff \& Cole

1975;

Edelstein \&

McLachlan

1977; Lee

1980;

Wetherbee $e t$

al. 1984;

López-

Rodriquez et

al. 2003; 


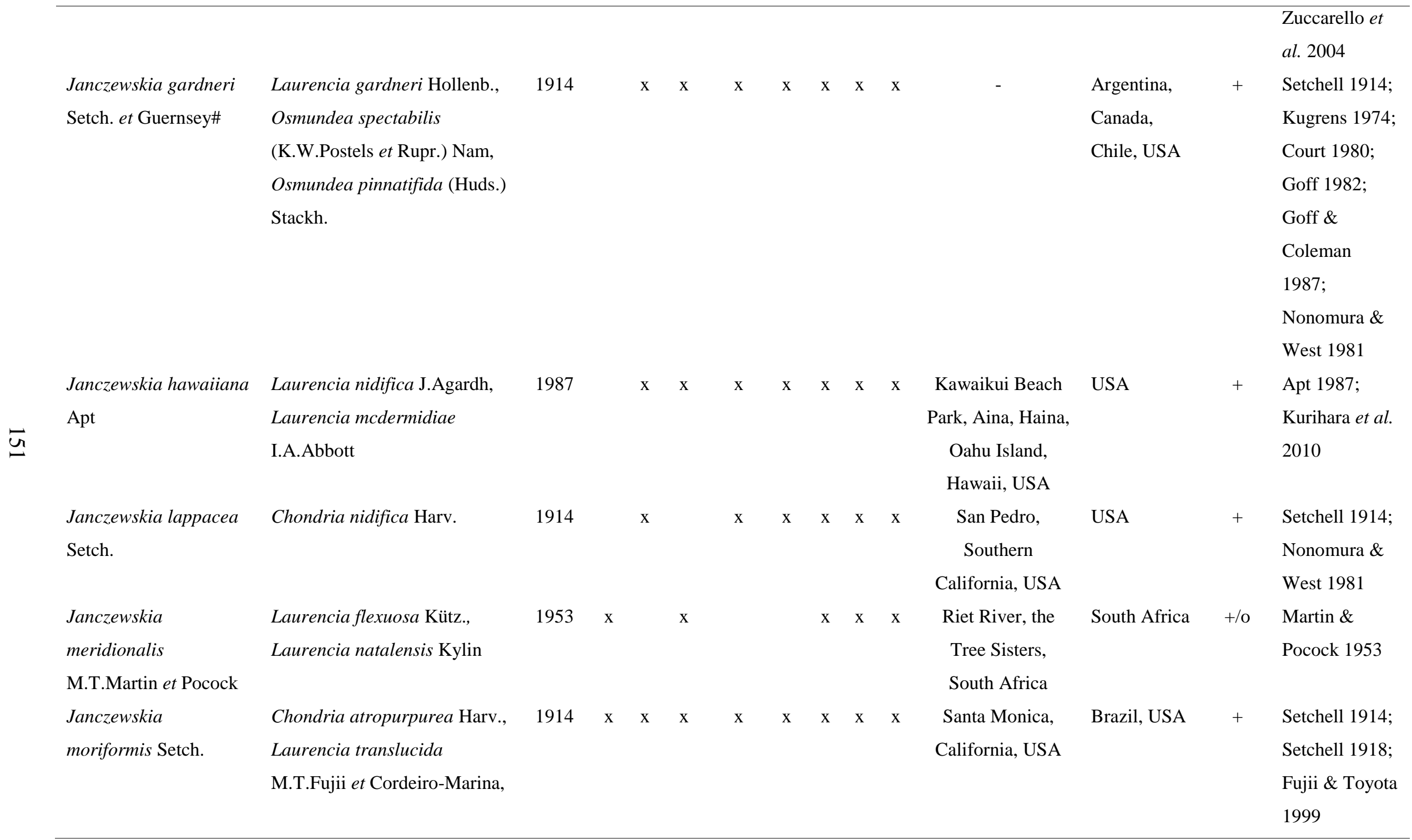


Palisada flagellifera

(J.Agardh) K.W.Nam

Janczewskia morimotoi Laurencia nipponica Yamada

Tokida\#

\begin{tabular}{|c|c|c|c|c|c|c|c|c|c|c|c|c|c|c|}
\hline $\begin{array}{l}\text { Janczewskia } \\
\text { ramiformis C.F.Chang }\end{array}$ & Laurencia okamurae Yamada & 1978 & & $\mathrm{x}$ & $\mathrm{x}$ & & & $\mathrm{x}$ & $\mathrm{x}$ & $\mathrm{x}$ & $\begin{array}{l}\text { Shilaoren, } \\
\text { Shanddong }\end{array}$ & China & $+/ 0$ & $\begin{array}{l}\text { Chang \& Xia } \\
1978\end{array}$ \\
\hline et B.M.Xia & & & & & & & & & & & Province, China & & & \\
\hline Janczewskia solmsii & Laurencia subopposita & 1914 & $\mathrm{x}$ & & $\mathrm{x}$ & & $\mathrm{x}$ & $\mathrm{x}$ & $\mathrm{x}$ & $\mathrm{x}$ & California, USA & USA & $+/ 0$ & Setchell 1914; \\
\hline Guernsey & (J.Agardh) Setch. & & & & & & & & & & & & & Setchell 1918 \\
\hline Janczewskia tasmanica & Laurencia forsteri (Mertens ex & 1897 & $\mathrm{x}$ & & $\mathrm{x}$ & $\mathrm{x}$ & $\mathrm{x}$ & $\mathrm{x}$ & $\mathrm{x}$ & $\mathrm{x}$ & Tasmania, & Australia & + & Setchell 1914; \\
\hline \multirow[t]{3}{*}{ Falkenb.\# } & Turner) Grev., Laurencia & & & & & & & & & & Australia & & & Setchell 1918; \\
\hline & heteroclada Harv., Laurencia & & & & & & & & & & & & & Womersley \\
\hline & spp. & & & & & & & & & & & & & 2003 \\
\hline Janczewskia & Acanthophora spicifera & 1923 & & & $\mathrm{x}$ & & $\mathrm{x}$ & & $\mathrm{x}$ & & Strait de Bali, & Indonesia & $\mathrm{o} /-$ & Weber-van \\
\hline teysmannii Weber & (M.Vahl) Børgesen & & & & & & & & & & Indonesia & & & Bosse 1923 \\
\hline \multicolumn{15}{|l|}{ Bosse } \\
\hline Janczewskia & Laurencia obtusa (Huds.) & 1877 & $\mathrm{x}$ & $\mathrm{x}$ & $\mathrm{x}$ & $\mathrm{x}$ & $\mathrm{x}$ & $\mathrm{x}$ & $\mathrm{x}$ & $\mathrm{x}$ & Mediterranean & Adriatic Sea, & + & Setchell 1914; \\
\hline \multirow[t]{4}{*}{ verruciformis Solms } & J.V.Lamour. & & & & & & & & & & Sea & Canary Is., & & Feldmann \& \\
\hline & & & & & & & & & & & & Mediter- & & Feldmann \\
\hline & & & & & & & & & & & & ranean Sea & & 1958; Haroun \\
\hline & & & & & & & & & & & & & & et al. 2002 \\
\hline Jantinella sinicola & Chondria acrorhizophora & 1924 & & & $\mathrm{x}$ & & $\mathrm{x}$ & $\mathrm{x}$ & $\mathrm{x}$ & $\mathrm{x}$ & Eureka, La Paz, & North & + & Setchell \& \\
\hline (Setch. et N.L.Gardner) & Setch. et N.L.Gardner, & & & & & & & & & & California, USA & Pacific & & Gardner 1924; \\
\hline Kylin\# & & & & & & & & & & & & Ocean & & Setchell \& \\
\hline
\end{tabular}




\begin{tabular}{|c|c|c|c|c|c|c|c|c|c|c|c|c|c|c|}
\hline & $\begin{array}{l}\text { Chondria clarionensis Setch. } \\
\text { et N.L.Gardner }\end{array}$ & & & & & & & & & & & & & $\begin{array}{l}\text { Gardner 1930; } \\
\text { Kylin } 1941\end{array}$ \\
\hline $\begin{array}{l}\text { Jantinella } \\
\text { verruciformis (Setch. et } \\
\text { M.E.McFadden) }\end{array}$ & $\begin{array}{l}\text { Chondria spp., Mychodea } \\
\text { episcopalis J.Agardh }\end{array}$ & 1911 & $\mathrm{x}$ & & $\mathrm{x}$ & $\mathrm{x}$ & $\mathrm{x}$ & $\mathrm{x}$ & $\mathrm{x}$ & $\mathrm{x}$ & $\begin{array}{c}\text { San Pedro, } \\
\text { California, USA }\end{array}$ & USA & + & $\begin{array}{l}\text { McFadden } \\
\text { 1911; Morrill } \\
\text { 1976b }\end{array}$ \\
\hline Kylin\# & & & & & & & & & & & & & & \\
\hline $\begin{array}{l}\text { Laurenciocolax } \\
\text { polysporus Zinova et } \\
\text { Perest. }\end{array}$ & $\begin{array}{l}\text { Laurencia caspica Zinova et } \\
\text { Zaberzhinskaya }\end{array}$ & 1964 & & & $\mathrm{x}$ & & $\mathrm{x}$ & $\mathrm{x}$ & $\mathrm{x}$ & $\mathrm{x}$ & $\begin{array}{l}\text { Caspian Sea, } \\
\text { Russia }\end{array}$ & Russia & $+/ \mathrm{o}$ & Zinova 1967 \\
\hline $\begin{array}{l}\text { Leachiella pacifica } \\
\text { Kugrens }\end{array}$ & $\begin{array}{l}\text { Neosiphonia paniculata } \\
\text { (Mont.) J.N.Norris, } \\
\text { Polysiphonia hendryi } \\
\text { N.L.Gardner, Pterosiphonia } \\
\text { bipinnata (Postels et Rupr.) } \\
\text { Falkenb., Pterosiphonia } \\
\text { dendroidea (Mont.) Falkenb., } \\
\text { Pterosiphonia spp. }\end{array}$ & 1982 & $\mathrm{x}$ & & $\mathrm{x}$ & $\mathrm{x}$ & $\mathrm{x}$ & $\mathrm{x}$ & $\mathrm{x}$ & $\mathrm{x}$ & $\begin{array}{l}\text { Cattle Point, San } \\
\text { Juan Island, } \\
\text { Washington, USA }\end{array}$ & Japan, USA & + & $\begin{array}{l}\text { Kugrens 1982; } \\
\text { Matsumoto \& } \\
\text { Yoshida 1991; } \\
\text { Zuccarello et } \\
\text { al. } 2004\end{array}$ \\
\hline $\begin{array}{l}\text { Levringiella gardneri } \\
\text { (Setch.) Kylin\# }\end{array}$ & $\begin{array}{l}\text { Pterosiphonia baileyi (Harv.) } \\
\text { Falkenb. }\end{array}$ & 1923 & $\mathrm{x}$ & $\mathrm{x}$ & $\mathrm{x}$ & $\mathrm{x}$ & $\mathrm{x}$ & $\mathrm{x}$ & $\mathrm{x}$ & $\mathrm{x}$ & $\begin{array}{l}\text { Santa Monica, } \\
\text { California, USA }\end{array}$ & USA & + & $\begin{array}{l}\text { Setchell 1923; } \\
\text { Kylin 1956; } \\
\text { Kugrens \& } \\
\text { West 1973; } \\
\text { Goff } 1982\end{array}$ \\
\hline $\begin{array}{l}\text { Levringiella } \\
\text { microscopica (Levring) } \\
\text { Kylin\# }\end{array}$ & Pterosiphonia spp. & 1941 & & & $\mathrm{x}$ & & $\mathrm{x}$ & $\mathrm{x}$ & $\mathrm{x}$ & $\mathrm{x}$ & $\begin{array}{l}\text { Juan Fernandez } \\
\text { Island, Chile }\end{array}$ & Chile & $+/ o$ & $\begin{array}{l}\text { Levring 1941; } \\
\text { Kylin } 1956\end{array}$ \\
\hline
\end{tabular}




\begin{tabular}{|c|c|c|c|c|c|c|c|c|c|c|c|c|c|}
\hline $\begin{array}{l}\text { Meridiocolax bracteata } \\
\text { J.M.Noble } \text { et } \text { Kraft }\end{array}$ & $\begin{array}{l}\text { Polysiphonia sparsa (Setch.) } \\
\text { Hollenb. }\end{array}$ & 1983 & & $\mathrm{x}$ & $\mathrm{x}$ & $\mathrm{x}$ & $\mathrm{x}$ & $\mathrm{x}$ & $\mathrm{x}$ & $\begin{array}{c}\text { Ned's Beach, } \\
\text { Lord Howe } \\
\text { Island, Australia }\end{array}$ & Australia & + & $\begin{array}{l}\text { Noble \& Kraft } \\
1983\end{array}$ \\
\hline $\begin{array}{l}\text { Meridiocolax narcissus } \\
\text { Morrill }\end{array}$ & $\begin{array}{l}\text { Neosiphonia ferulacea (Suhr } \\
\text { ex J.Agardh) S.M.Guim. et } \\
\text { M.T.Fujii }\end{array}$ & 1976 & $\mathrm{x}$ & $\mathrm{x}$ & $\mathrm{x}$ & & $\mathrm{x}$ & $\mathrm{x}$ & $\mathrm{x}$ & $\begin{array}{c}\text { Key West Florida, } \\
\text { USA }\end{array}$ & USA & + & Morrill 1976c \\
\hline $\begin{array}{l}\text { Meridiocolax } \\
\text { polysiphoniae } \\
\text { (E.C.Oliveira et } \\
\text { Ugadim) Morrill\# }\end{array}$ & $\begin{array}{l}\text { Polysiphonia denudata } \\
\text { (Dillwyn) Grev. ex Harv. }\end{array}$ & 1973 & & $\mathrm{x}$ & & $\mathrm{x}$ & $\mathrm{x}$ & $\mathrm{x}$ & $\mathrm{x}$ & Brazil & Brazil & $+/ o$ & $\begin{array}{l}\text { de Oliveira \& } \\
\text { Ugadim 1973; } \\
\text { Noble \& Kraft } \\
1983\end{array}$ \\
\hline $\begin{array}{l}\text { Microcolax africanus } \\
\text { M.T.Martin et Pocock }\end{array}$ & $\begin{array}{l}\text { Streblocladia tenuissima } \\
\text { Pocock }\end{array}$ & 1953 & $\mathrm{x}$ & $\mathrm{x}$ & & $\mathrm{x}$ & $\mathrm{x}$ & $\mathrm{x}$ & $\mathrm{x}$ & $\begin{array}{l}\text { Cove Rock, near } \\
\text { East London, } \\
\text { South Africa }\end{array}$ & South Africa & $+/ o$ & $\begin{array}{l}\text { Martin \& } \\
\text { Pocock } 1953\end{array}$ \\
\hline $\begin{array}{l}\text { Microcolax } \\
\text { botryocarpa (Hook.f. } \\
\text { et } \text { Harv.) F.Schmitz\# }\end{array}$ & $\begin{array}{l}\text { Streblocladia glomerulata } \\
\text { (Mont.) Papenf., Streblocladia } \\
\text { neglecta F.Schmitz }\end{array}$ & 1845 & $\mathrm{x}$ & $\mathrm{x}$ & & & $\mathrm{x}$ & $\mathrm{x}$ & $\mathrm{x}$ & $\begin{array}{l}\text { Auckland Islands, } \\
\text { New Zealand }\end{array}$ & $\begin{array}{l}\text { Auckland } \\
\text { Is., } \\
\text { Campbell Is. }\end{array}$ & $+/ \mathrm{o}$ & $\begin{array}{l}\text { Harvey \& } \\
\text { Hooker 1845; } \\
\text { Schmitz \& } \\
\text { Falkenberg } \\
\text { 1897; Kylin } \\
\text { 1956; Goff } \\
1982\end{array}$ \\
\hline $\begin{array}{l}\text { Neotenophycus } \\
\text { ichthyosteus Kraft et } \\
\text { I.A.Abbott }\end{array}$ & $\begin{array}{l}\text { Neosiphonia poko (Hollenb.) } \\
\text { I.A.Abbott }\end{array}$ & 2002 & & $\mathrm{x}$ & $\mathrm{x}$ & $\mathrm{x}$ & $\mathrm{x}$ & $\mathrm{x}$ & $\mathrm{x}$ & $\begin{array}{c}\text { Johnston Island, } \\
\text { Johnston Atoll }\end{array}$ & Pacific Is. & + & $\begin{array}{l}\text { Kraft \& } \\
\text { Abbott } 2002\end{array}$ \\
\hline
\end{tabular}




\begin{tabular}{|c|c|c|c|c|c|c|c|c|c|c|c|c|c|c|}
\hline $\begin{array}{l}\text { Onychocolax } \\
\text { polysiphoniae Pocock }\end{array}$ & Polysiphonia incompta Harv. & 1956 & & & $\mathrm{x}$ & & $\mathrm{x}$ & $\mathrm{x}$ & $\mathrm{x}$ & $\mathrm{x}$ & $\begin{array}{l}\text { The Kowie, } \\
\text { beyond Salt Vlei, } \\
\text { South Africa }\end{array}$ & South Africa & $+/ \mathrm{o}$ & Pocock 1956 \\
\hline $\begin{array}{l}\text { Sporoglossum } \\
\text { lophurellae Kylin }\end{array}$ & $\begin{array}{l}\text { Lophurella hookeriana } \\
\text { (J.Agardh) Falkenb. }\end{array}$ & 1919 & & & $\mathrm{x}$ & & & $\mathrm{x}$ & $\mathrm{x}$ & $\mathrm{x}$ & Falkland Islands & $\begin{array}{l}\text { Argentina, } \\
\text { Campbell } \\
\text { Is., Chile, } \\
\text { Falkland Is. }\end{array}$ & $+/ o$ & $\begin{array}{l}\text { Kylin \& } \\
\text { Skottsberg } \\
\text { 1919; } \\
\text { Papenfuss } \\
\text { 1964; Ramírez } \\
\text { \& Santelices } \\
1991\end{array}$ \\
\hline $\begin{array}{l}\text { Symphyocolax koreana } \\
\text { M.S.Kim }\end{array}$ & $\begin{array}{l}\text { Symphyocladia latiuscula } \\
\text { (Harv.) Yamada }\end{array}$ & 2010 & & $\mathrm{x}$ & $\mathrm{x}$ & $\mathrm{x}$ & & $\mathrm{x}$ & $\mathrm{x}$ & $\mathrm{x}$ & $\begin{array}{c}\text { Molundae, Busan, } \\
\text { Korea }\end{array}$ & Korea & + & $\begin{array}{l}\text { Kim \& Cho } \\
2010\end{array}$ \\
\hline $\begin{array}{l}\text { Stromatocarpus } \\
\text { parasiticus Falkenb. }\end{array}$ & $\begin{array}{l}\text { Placophora monocarpa } \\
\text { (Mont.) Papenf., Polysiphonia } \\
\text { virgata (C.Agardh) Spreng. }\end{array}$ & 1897 & $\mathrm{x}$ & & $\mathrm{x}$ & $\mathrm{x}$ & $\mathrm{x}$ & $\mathrm{x}$ & $\mathrm{x}$ & $\mathrm{x}$ & - & South Africa & + & $\begin{array}{l}\text { Schmitz \& } \\
\text { Falkenberg } \\
\text { 1897; Martin } \\
\& \text { Pocock } \\
\text { 1953; Kylin } \\
1956\end{array}$ \\
\hline $\begin{array}{l}\text { Trichidium } \\
\text { pedicellatum } \\
\text { J.M.Noble } \text { et Kraft }\end{array}$ & $\begin{array}{l}\text { Lophocladia kuetzingii } \\
\text { (Kuntze) P.C.Silva }\end{array}$ & 1983 & & $\mathrm{x}$ & $\mathrm{x}$ & $\mathrm{x}$ & $\mathrm{x}$ & $\mathrm{x}$ & $\mathrm{x}$ & $\mathrm{x}$ & $\begin{array}{c}\text { Port Denison, } \\
\text { Western Australia }\end{array}$ & Australia & + & $\begin{array}{l}\text { Noble \& Kraft } \\
1983\end{array}$ \\
\hline $\begin{array}{l}\text { Tylocolax microcarpus } \\
\text { F.Schmitz }\end{array}$ & $\begin{array}{l}\text { Lenormandia spectabilis } \\
\text { Sonder }\end{array}$ & 1897 & & & $\mathrm{x}$ & & $\mathrm{x}$ & $\mathrm{x}$ & $\mathrm{x}$ & $\mathrm{x}$ & $\begin{array}{c}\text { South Coast } \\
\text { Australia }\end{array}$ & Australia & $+/ o$ & $\begin{array}{l}\text { Schmitz \& } \\
\text { Falkenberg } \\
1897\end{array}$ \\
\hline
\end{tabular}




\begin{tabular}{|c|c|c|c|c|c|c|c|c|c|c|c|c|c|c|}
\hline $\begin{array}{l}\text { Ululania stellata Apt } e t \\
\text { Schlech }\end{array}$ & $\begin{array}{l}\text { Acanthophora pacifica } \\
\text { (Setch.) Kraft, Acanthophora } \\
\text { spicifera }\end{array}$ & 1998 & $\mathrm{x}$ & & $\mathrm{x}$ & $\mathrm{x}$ & $\mathrm{x}$ & $\mathrm{x}$ & $\mathrm{x}$ & $\mathrm{x}$ & $\begin{array}{c}\text { Oahu, Hawaii, } \\
\text { USA }\end{array}$ & USA & + & $\begin{array}{l}\text { Womersley } \\
2003 \\
\text { Apt \& Schlech } \\
1998\end{array}$ \\
\hline $\begin{array}{l}\text { Corallinales } \\
\text { Corallinaceae }\end{array}$ & & & & & & & & & & & & & & \\
\hline $\begin{array}{l}\text { Ezo epiyessoense } \\
\text { W.H.Adey, T.Masaki } \\
\text { et Akioka }\end{array}$ & $\begin{array}{l}\text { Lithophyllum crouaniorium } \\
\text { Foslie, Lithophyllum } \\
\text { yessoense Foslie, Titanoderma } \\
\text { pustulatum (J.V.Lamour.) } \\
\text { Nägeli }\end{array}$ & 1974 & $\mathrm{x}$ & $\mathrm{x}$ & $\mathrm{x}$ & $\mathrm{x}$ & $\mathrm{x}$ & $\mathrm{x}$ & $\mathrm{x}$ & $\mathrm{x}$ & Hokkaido, Japan & Japan, UK & + & $\begin{array}{l}\text { Adey } \text { et al. } \\
\text { 1974; } \\
\text { Chamberlain } \\
1988 ; \\
\text { Chamberlain } \\
1999\end{array}$ \\
\hline $\begin{array}{l}\text { Masakiella bossiellae } \\
\text { (Klochkova) Guiry et } \\
\text { Selivanova\# }\end{array}$ & Bossiella sp. & 2007 & & $\mathrm{x}$ & $\mathrm{x}$ & & & $\mathrm{x}$ & $\mathrm{x}$ & & Sea of Japan & Sea of Japan & o & $\begin{array}{l}\text { Guiry \& } \\
\text { Selivanova } \\
2007\end{array}$ \\
\hline Hapalidiaceaeae & & & & & & & & & & & & & & \\
\hline $\begin{array}{l}\text { Choreonema thuretii } \\
\text { (Bornet) F.Schmitz\# }\end{array}$ & $\begin{array}{l}\text { Jania micrarthrodia } \\
\text { J.V.Lamour., Jania rosea } \\
\text { (Lam.) Decaisne, Jania rubens } \\
\text { (L.) J.V.Lamour., Jania } \\
\text { tenella (Kütz.) Grunow, Jania } \\
\text { verrucosa J.V.Lamour. }\end{array}$ & 1889 & $\mathrm{x}$ & $\mathrm{x}$ & $\mathrm{x}$ & & $\mathrm{x}$ & $\mathrm{x}$ & $\mathrm{x}$ & $\mathrm{x}$ & $\begin{array}{c}\text { Pointe de } \\
\text { Querqueville, } \\
\text { France }\end{array}$ & $\begin{array}{l}\text { Australia, } \\
\text { Ecuador, } \\
\text { Galapagos } \\
\text { Is., Japan, } \\
\text { Mediter- } \\
\text { ranean Sea, } \\
\text { Mexico, }\end{array}$ & $+/ o$ & $\begin{array}{l}\text { Kylin 1956; } \\
\text { Pocock 1956; } \\
\text { Zinova 1964; } \\
\text { Woelkerling } \\
\text { 1987; } \\
\text { Womersley } \\
\text { 1996; }\end{array}$ \\
\hline
\end{tabular}




\begin{tabular}{|c|c|c|c|c|c|c|c|c|c|c|c|c|c|}
\hline & & & & & & & & & & & $\begin{array}{l}\text { New } \\
\text { Zealand, } \\
\text { North } \\
\text { Atlantic, } \\
\text { South } \\
\text { Africa, } \\
\text { Russia }\end{array}$ & & $\begin{array}{l}\text { Broadwater \& } \\
\text { LaPointe } \\
\text { 1997; } \\
\text { Broadwater } \text { et } \\
\text { al. 2002; } \\
\text { Dalen \& } \\
\text { Nelson } 2013\end{array}$ \\
\hline $\begin{array}{l}\text { Epulo multipedes } \\
\text { R.A.Towns. et } \\
\text { Huisman }\end{array}$ & Jania verrucosa J.V.Lamour. & 2004 & $\mathrm{x}$ & $\mathrm{x}$ & & $\mathrm{x}$ & $\mathrm{x}$ & $\mathrm{x}$ & $\mathrm{x}$ & $\begin{array}{l}\text { Long Reef Point, } \\
\text { New South } \\
\text { Wales, Australia }\end{array}$ & Australia & $+/ o$ & $\begin{array}{l}\text { Townsend \& } \\
\text { Huisman } 2004\end{array}$ \\
\hline $\begin{array}{l}\text { Kvaleya epilaeve } \\
\text { W.H.Adey et } \\
\text { Sperapani }\end{array}$ & $\begin{array}{l}\text { Phymatolithon laeve } \\
\text { (Rosenv.) Düwel } \text { et Wegeberg }\end{array}$ & 1971 & $\mathrm{x}$ & $\mathrm{x}$ & & $x$ & $\mathrm{x}$ & $\mathrm{x}$ & $\mathrm{x}$ & Trömsöy, Norway & $\begin{array}{l}\text { Canada, } \\
\text { Iceland, } \\
\text { Norway, } \\
\text { USA }\end{array}$ & $+/ o$ & $\begin{array}{l}\text { Adey \& } \\
\text { Sperapani } \\
1971\end{array}$ \\
\hline $\begin{array}{l}\text { Gigartinales } \\
\text { Cystocloniaceae }\end{array}$ & & & & & & & & & & & & & \\
\hline $\begin{array}{l}\text { Hypneocolax stellaris } \\
\text { Børgesen }\end{array}$ & $\begin{array}{l}\text { Hypnea cornuta (Kütz.) } \\
\text { J.Agardh, Hypnea } \\
\text { musciformis (Wulfen) } \\
\text { J.V.Lamour., Hypnea } \\
\text { ramentacea (C.Agardh) } \\
\text { J.Agardh, Hypnea valentiae }\end{array}$ & 1920 & $\mathrm{x}$ & $\mathrm{x}$ & $\mathrm{x}$ & $\mathrm{x}$ & $\mathrm{x}$ & $\mathrm{x}$ & $\mathrm{x}$ & $\begin{array}{l}\text { Lime Tree Bay, } \\
\text { St. Croix, USA }\end{array}$ & $\begin{array}{l}\text { Canary Is., } \\
\text { Colombia, } \\
\text { Mexico, } \\
\text { USA, } \\
\text { Venezuela }\end{array}$ & + & $\begin{array}{l}\text { Børgesen } \\
\text { 1920; } \\
\text { Albornoz \& } \\
\text { Ganesan 1994; } \\
\text { Haroun } \text { et al. } \\
\text { 2002; Lipkin } \\
\text { \& Silva 2002; }\end{array}$ \\
\hline
\end{tabular}




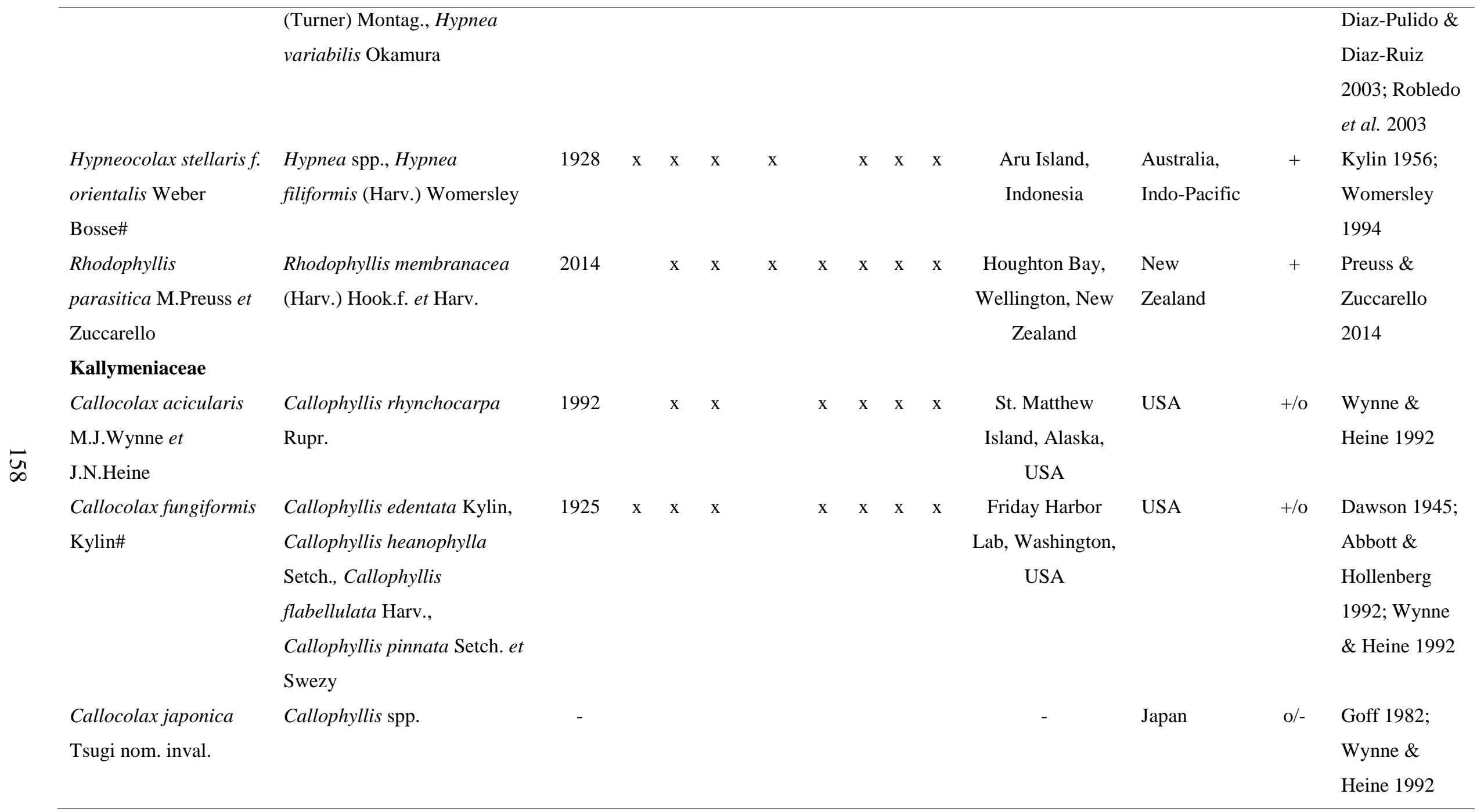




\begin{tabular}{|c|c|c|c|c|c|c|c|c|c|c|c|c|c|c|}
\hline $\begin{array}{l}\text { Callocolax neglectus } \\
\text { F.Schmitz ex Batters }\end{array}$ & $\begin{array}{l}\text { Callophyllis hombroniana } \\
\text { (Mont.) Kütz., Callophyllis } \\
\text { laciniata (Huds.) Kütz. }\end{array}$ & 1895 & $\mathrm{x}$ & $\mathrm{x}$ & $\mathrm{x}$ & & $\mathrm{x}$ & & $\mathrm{x}$ & $\mathrm{x}$ & - & $\begin{array}{l}\text { North } \\
\text { Atlantic } \\
\text { Coast, New } \\
\text { Zealand }\end{array}$ & $+/ \mathrm{o}$ & $\begin{array}{l}\text { Batters 1895; } \\
\text { Cotton 1907; } \\
\text { Kylin 1930; } \\
\text { Wynne \& } \\
\text { Heine 1992; } \\
\text { Guiry } 1996\end{array}$ \\
\hline Phyllophoraceae & & & & & & & & & & & & & & \\
\hline $\begin{array}{l}\text { Coccotylus hartzii } \\
\text { (Rosenv.) L.Le Gall et } \\
\text { G.W.Saunders\# }\end{array}$ & $\begin{array}{l}\text { Coccotylus truncatus (Pall.) } \\
\text { M.J.Wynne et J.N.Heine }\end{array}$ & 1898 & & $\mathrm{x}$ & $\mathrm{x}$ & $\mathrm{x}$ & $\mathrm{x}$ & $\mathrm{x}$ & $\mathrm{x}$ & $\mathrm{x}$ & Greenland & $\begin{array}{l}\text { Arctic, } \\
\text { North } \\
\text { Atlantic } \\
\text { Coast }\end{array}$ & $+/ 0$ & $\begin{array}{l}\text { Rosenvinge } \\
\text { 1931; Newroth } \\
\text { \& Taylor } \\
\text { 1968; Evans et } \\
\text { al. 1978; Le } \\
\text { Gall \& } \\
\text { Saunders } 2010\end{array}$ \\
\hline Solieriaceae & & & & & & & & & & & & & & \\
\hline $\begin{array}{l}\text { Gardneriella tuberifera } \\
\text { Kylin }\end{array}$ & $\begin{array}{l}\text { Agardhiella coulteri (Harv.) } \\
\text { Setch., Sarcodiotheca } \\
\text { gaudichaudii (Mont.) } \\
\text { P.W.Gabrielson }\end{array}$ & 1941 & $\mathrm{x}$ & & $\mathrm{x}$ & $\mathrm{x}$ & $\mathrm{x}$ & $\mathrm{x}$ & $\mathrm{x}$ & $\mathrm{x}$ & - & USA & + & $\begin{array}{l}\text { Kylin 1956; } \\
\text { Goff 1981; } \\
\text { Goff \& } \\
\text { Hommersand } \\
\text { 1982; Goff \& } \\
\text { Zuccarello } \\
1994\end{array}$ \\
\hline $\begin{array}{l}\text { Tikvahiella candida } \\
\text { Kraft } \text { et } \\
\text { P.W.Gabrielson\# }\end{array}$ & Solieria robusta (Grev.) Kylin & 1983 & $\mathrm{x}$ & & $\mathrm{x}$ & $\mathrm{x}$ & $\mathrm{x}$ & $\mathrm{x}$ & $\mathrm{x}$ & $\mathrm{x}$ & $\begin{array}{c}\text { Port Phillip Bay, } \\
\text { Victoria, } \\
\text { Australia }\end{array}$ & Australia & + & $\begin{array}{l}\text { Goff 1982; } \\
\text { Kraft \& }\end{array}$ \\
\hline
\end{tabular}




\section{Gracilariales}

Gracilariaceae

Gracilaria babae $(\mathrm{H}$.

Gracilaria salicornia

1986

X $\quad \mathrm{X}$

Yamam.) P.K.Ng,

(C.Agardh) E.Y.Dawson,

P.E.Lim et Phang\#

Hydropuntia sp.

\section{Gracilariophila} oryzoides Setch. et

H.L.Wilson\#
Gracilaria multipartita

(Clem.-Munoz) Harv.,

Gracilariopsois andersonnii

(Kylin) E.Y.Dawson,

Gracilariopsis confervoides

Rmiki,Y. Lemoine, R.Kling et

Cabioch, Gracilariopsis

lemaneiformis (Bory de Saint-

Vincent) E.Y.Dawson, Acleto

et Foldvik
$1910 \mathrm{x}$

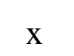

$\begin{array}{ll}\text { Fort Point, } & \text { Canada, } \\ \text { Monterey, } & \text { USA }\end{array}$

California, USA

\section{Okinoerabu \\ Island, \\ Kagoshima}

Prefecture, Japan

Thailand

Japan,
Malaysia,

Papua New

Guinea,

\section{Yamamoto}

1986;

Coppejans \&

Millar 2000;

Kongkittayapu

$\mathrm{n} \&$ Chirapart

2011; Ng et al.

2014

\section{Wilson 1990;}

Norris \&

Wynne 1969

'1968';

Fredericq $e t$

al. 1989;

Gerung \&

Yamamoto

2002 


\section{Gracilariophila}

gardneri Setch.

Gracilaria textorii var.

cunninghamii (Farl.)

E.Y.Dawson

\section{Pterocladiophilaceae}

Gelidiocolax

christianae Feldmann

Gelidium spathulatum (Kütz.)

Bornet

et Feldm.-Maz.

\begin{tabular}{ll} 
Gelidiocolax & Gelidium cantabricum \\
deformans Seoane- & Seoane-Camba, Gelidium \\
Camba & corneum (Huds.) J.V.Lamour \\
Gelidiocolax & Gelidium floridanum \\
\hline$-\quad$ desikacharyi Ganesan & W.R.Taylor \\
Gelidiocolax lyndae & Kentrophora natalensis \\
R.E.Norris & (J.Agardh) S.M.Wilson et \\
Gelidiocolax & Kraft \\
mammillatus K.C.Fan & Pterocladiella capillacea \\
et Papenf. & (S.G.Gmel.) Santel. et
\end{tabular}

1923

$\mathrm{x}$

$\mathrm{X} x$

Santa Monica,

California, USA

\section{USA,}

1963 


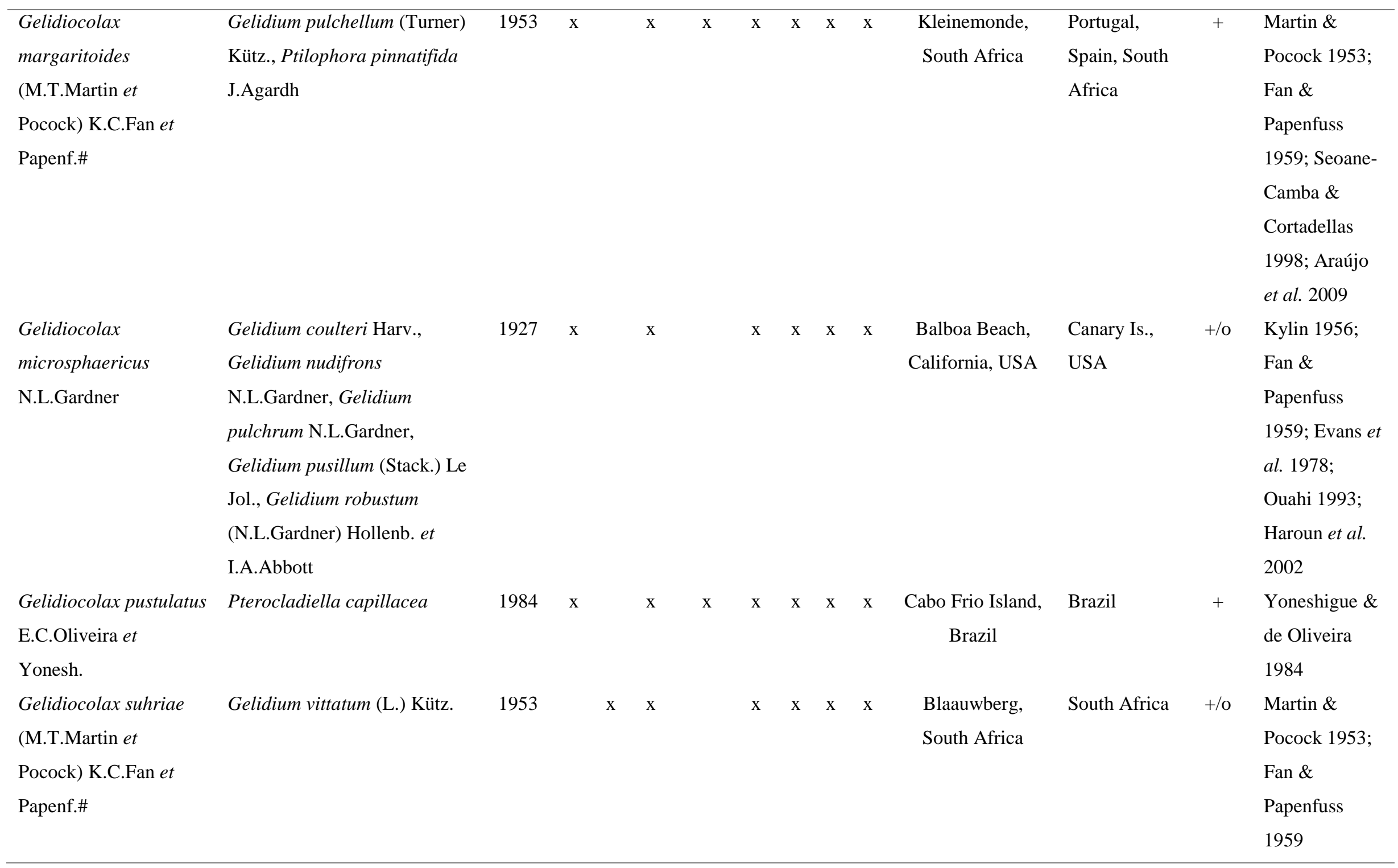




\begin{tabular}{|c|c|c|c|c|c|c|c|c|c|c|c|c|c|c|}
\hline $\begin{array}{l}\text { Gelidiocolax } \\
\text { verruculatus Ouahi et } \\
\text { Najiim nom. inval. }\end{array}$ & $\begin{array}{l}\text { Gelidum attenuatum (Turner) } \\
\text { Thur., Gelidium pulchellum } \\
\text { (Turner) Kütz., Gelidium } \\
\text { pusillum, Pterocladiella } \\
\text { capillacea }\end{array}$ & - & $\mathrm{x}$ & & $\mathrm{x}$ & $\mathrm{x}$ & $\mathrm{x}$ & $\mathrm{x}$ & $\mathrm{x}$ & $\mathrm{x}$ & - & Morocco & + & Ouahi 1993 \\
\hline $\begin{array}{l}\text { Holmsella pachyderma } \\
\text { (Reinsch) Sturch\# }\end{array}$ & $\begin{array}{l}\text { Gracilaria gracilis (Stackh.) } \\
\text { Steentoft, L.M.Irvine } \text { et } \\
\text { Farnham, Gracilariopsis } \\
\text { longissima (S.G.Gmel.) } \\
\text { Steentoft, L.M.Irvine et } \\
\text { Farnham, Gracilariopsis spp. }\end{array}$ & 1875 & $\mathrm{x}$ & & $\mathrm{x}$ & $\mathrm{x}$ & $\mathrm{x}$ & $\mathrm{x}$ & $\mathrm{x}$ & $\mathrm{x}$ & - & $\begin{array}{l}\text { Ireland, } \\
\text { Spain, UK }\end{array}$ & + & $\begin{array}{l}\text { Fredericq \& } \\
\text { Hommersand } \\
1990 ; \\
\text { Womersley } \\
\text { 1996; } \\
\text { Zuccarello et } \\
\text { al. } 2004\end{array}$ \\
\hline $\begin{array}{l}\text { Holmsella australis } \\
\text { J.M.Noble et } \text { Kraft }\end{array}$ & $\begin{array}{l}\text { Gracilaria cliftonii Withell, } \\
\text { A.Millar } \text { et Kraft }\end{array}$ & 1983 & $\mathrm{x}$ & & $\mathrm{x}$ & $\mathrm{x}$ & $\mathrm{x}$ & $\mathrm{x}$ & $\mathrm{x}$ & $\mathrm{x}$ & $\begin{array}{c}\text { Flinders, Victoria, } \\
\text { Australia }\end{array}$ & Australia & + & $\begin{array}{l}\text { Wetherbee \& } \\
\text { Quirk 1982; } \\
\text { Noble \& Kraft } \\
1983\end{array}$ \\
\hline $\begin{array}{l}\text { Pterocladiophila } \\
\text { hemisphaerica K.C.Fan } \\
\text { et Papenf. }\end{array}$ & $\begin{array}{l}\text { Pterocladiella bartlettii } \\
\text { (W.R.Taylor) Santel., } \\
\text { Pterocladia lucida (R.Brown } \\
\text { ex Turner) J.Agardh }\end{array}$ & 1959 & & $\mathrm{x}$ & $\mathrm{x}$ & $\mathrm{x}$ & $\mathrm{x}$ & $\mathrm{x}$ & $\mathrm{x}$ & $\mathrm{x}$ & $\begin{array}{c}\text { Island Bay, } \\
\text { Wellington, New } \\
\text { Zealand }\end{array}$ & $\begin{array}{l}\text { Caribbean, } \\
\text { New } \\
\text { Zealand }\end{array}$ & + & $\begin{array}{l}\text { Fan \& } \\
\text { Papenfuss } \\
\text { 1959; Evans et } \\
\text { al. 1978; } \\
\text { Stegenga \& } \\
\text { Vroman } 1986\end{array}$ \\
\hline $\begin{array}{l}\text { Halymeniales } \\
\text { Halymeniaceae }\end{array}$ & & & & & & & & & & & & & & \\
\hline
\end{tabular}




\begin{tabular}{|c|c|c|c|c|c|c|c|c|c|c|c|c|}
\hline $\begin{array}{l}\text { Grateloupiocolax } \\
\text { colombiana Schnetter } \\
\text { et Bula-Meyer }\end{array}$ & $\begin{array}{l}\text { Grateloupia filicina } \\
\text { (J.V.Lamour.) C.Agardh }\end{array}$ & 1983 & $\mathrm{x}$ & $\mathrm{x}$ & $\mathrm{x}$ & $\mathrm{x}$ & $\mathrm{x}$ & $\mathrm{x}$ & $\begin{array}{c}\text { Ensenada de } \\
\text { Concha, } \\
\text { Colombia }\end{array}$ & Colombia & $+/ \mathrm{o}$ & $\begin{array}{l}\text { Schnetter et al. } \\
1983\end{array}$ \\
\hline $\begin{array}{l}\text { Kintokiocolax } \\
\text { aggregato-ceranthus }\end{array}$ & $\begin{array}{l}\text { Grateloupia angusta } \\
\text { (Okamura) Kawaguchi et }\end{array}$ & 1960 & $\mathrm{x}$ & $\mathrm{x}$ & $\mathrm{x}$ & & $\mathrm{x}$ & $\mathrm{x}$ & $\begin{array}{l}\text { Hananose, } \\
\text { Kagashima }\end{array}$ & $\begin{array}{l}\text { Japan, } \\
\text { Korea }\end{array}$ & $+/ \mathrm{o}$ & $\begin{array}{l}\text { Tanaka \& } \\
\text { Nozawa 1960; }\end{array}$ \\
\hline Tak.Tanaka et Nozawa & H.W.Wang & & & & & & & & Prefecture, Japan & & & $\begin{array}{l}\text { Yang \& Kim } \\
2015\end{array}$ \\
\hline
\end{tabular}

\title{
Palmariales
}

\section{Palmariaceae}

Neohalosacciocolax

Halosaccion minjaii I.K.Lee

1978

aleutica I.K.Lee et

Kurogi

‡) Rhodophysema

kjellmanii

G.W.Saunders et

Clayden\#

\begin{abstract}
Devaleraea ramentacea (L.)
\end{abstract}
1959

Guiry, Palmaria palmata (L.)

F.Weber et D.Mohr

Massacre Bay,

Aleutian Is. Attu Island,

$+\quad$ Lee \& Kurogi

Aleutian Islands

$\begin{array}{clll}\text { Wreck of the } & \text { Arctic, } & \text { t/o } & \text { Edelstein } \\ \text { Ithaca, Manitoba, } & \text { North } & \text { 1972; Jonsson } \\ \text { Canada } & \text { Atlantic } & \text { \& Chesnoy } \\ & \text { Ocean, } & 1988 ; \text { Wynne } \\ & \text { North } & \text { \& Heine 1992; } \\ & \text { Pacific } & \text { Saunders \& } \\ & \text { Ocean } & \text { Clayden 2010 }\end{array}$

\section{Plocamiales}

Plocamiaceae

Plocamiocolax

Plocamium cartilagineum (L.) $\quad 1923$ X $\quad$ X $\quad$ X

$\begin{array}{cl}\text { Carmel Bay, } & \text { Canada, } \\ \text { California, USA } & \text { USA }\end{array}$


Plocamiocolax

papenfussianus

Plocamium corallorhiza

(Turner) Hook.f. et Harv.

M.T.Martin et Pocock

\section{Rhodymeniales}

\section{Champiaceae}

Champiocolax lobatus

Womersley

Champiocolax sarae

$\bar{a}$

Bula-Meyer

Champia compressa Harv.,

Champia parvula (C.Agardh)

Harv., Champia salicornoides

Harv.

\section{Faucheaceae}

Faucheocolax

attenuata Setch.

Gloiocladia laciniata

(J.Agardh) N.Sánchez et

Rodríguez-Prieto, Gloiocladia

fryeana (Setch.) N.Sánchez et

Rodríguez-Prieto

Gloiocolax novae-

zelandiae Sparling

Gloioderma saccata

(J.Agardh) R.E.Norris
$1953 x$
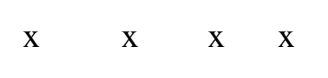

\section{$\mathrm{X}$} Africa

South Africa

$+\quad$ Martin \&

Pocock 1953

Rhodymeniaceae
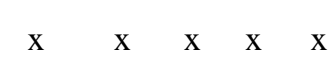
Chengue Inlet,
Caribbean Coast
of Colombia

Colombia

$1923 \times$ X $x$
$\mathrm{X}$

$\mathrm{x}$

Carmel Bay,
California, USA

USA

Setchell 1923;

Sparling 1957

1957

$\mathrm{x}$

X

$\mathrm{X}$
Eastbourne, New New
Zealand
Zealand

+ $\quad$ Sparling 1957 


\begin{tabular}{|c|c|c|c|c|c|c|c|c|c|c|c|c|c|c|}
\hline $\begin{array}{l}\text { Rhodymeniocolax } \\
\text { botryoideus Setch. }\end{array}$ & $\begin{array}{l}\text { Rhodymenia sp., } \\
\text { Rhodymenia pacifica Kylin }\end{array}$ & 1923 & & $\mathrm{x}$ & $\mathrm{x}$ & $\mathrm{x}$ & $\mathrm{x}$ & $\mathrm{x}$ & $\mathrm{x}$ & $\mathrm{x}$ & $\begin{array}{l}\text { Whites Point, San } \\
\text { Pedro, California, } \\
\text { USA }\end{array}$ & USA & + & $\begin{array}{l}\text { Setchell 1923; } \\
\text { Sparling 1957; } \\
\text { Womersley } \\
1996\end{array}$ \\
\hline $\begin{array}{l}\text { Rhodymeniocolax } \\
\text { mediterraneus Vergés, } \\
\text { Izquierdo et } \\
\text { M.Verlaque }\end{array}$ & $\begin{array}{l}\text { Rhodymenia ardissonei } \\
\text { (Kuntze) Feldmann }\end{array}$ & 2005 & $\mathrm{x}$ & $\mathrm{x}$ & $\mathrm{x}$ & $\mathrm{x}$ & $\mathrm{x}$ & $\mathrm{x}$ & $\mathrm{x}$ & $\mathrm{x}$ & $\begin{array}{c}\text { Cala St. Francesc, } \\
\text { Blanes, Spain }\end{array}$ & $\begin{array}{l}\text { France, } \\
\text { Spain }\end{array}$ & + & $\begin{array}{l}\text { Vergés et al. } \\
2005\end{array}$ \\
\hline Incertae sedis & & & & & & & & & & & & & & \\
\hline Gracilariocolax & Gracilaria canaliculata & 1928 & & $\mathrm{x}$ & $\mathrm{x}$ & & & $\mathrm{x}$ & $\mathrm{x}$ & $\mathrm{x}$ & Sula Besi, Sula & China, & $+/ o$ & Weber-van \\
\hline deformans (Weber & Sonder, Gracilaria salicornia & & & & & & & & & & Islands, Indonesia & Indonesia & & Bosse 1928; \\
\hline Bosse) Gerung et & & & & & & & & & & & & & & Chang \& Xia \\
\hline H.Yamam. & & & & & & & & & & & & & & $\begin{array}{l}\text { 1978; Gerung } \\
\text { \& Yamamoto } \\
2002\end{array}$ \\
\hline $\begin{array}{l}\text { Gracilariocolax } \\
\text { henriettae Weber }\end{array}$ & Gracilaria hauckii P.C.Silva & 1928 & & $\mathrm{x}$ & $\mathrm{x}$ & & & $\mathrm{x}$ & $\mathrm{x}$ & $\mathrm{x}$ & $\begin{array}{c}\text { Nusa Kembangan, } \\
\text { Indonesia }\end{array}$ & Indonesia & $+/ \mathrm{o}$ & $\begin{array}{l}\text { Weber-van } \\
\text { Bosse } 1928\end{array}$ \\
\hline Bosse\# & & & & & & & & & & & & & & \\
\hline $\begin{array}{l}\text { Gracilariocolax } \\
\text { infidelis (Weber Bosse) }\end{array}$ & $\begin{array}{l}\text { Gracilaria canaliculata, } \\
\text { Gracilaria minor (Sond.) }\end{array}$ & 1928 & & $\mathrm{x}$ & $\mathrm{x}$ & & & $\mathrm{x}$ & $\mathrm{x}$ & $\mathrm{x}$ & $\begin{array}{l}\text { Tual, Kai Islands, } \\
\text { Indonesia }\end{array}$ & $\begin{array}{l}\text { China, } \\
\text { Indonesia, }\end{array}$ & $+/ o$ & $\begin{array}{l}\text { Chang \& Xia } \\
\text { 1978; Terada }\end{array}$ \\
\hline Gerung et H.Yamam.\# & Durair., Gracilaria salicornia & & & & & & & & & & & Thailand & & $\begin{array}{l}\text { et al. 1999; } \\
\text { Gerung \& } \\
\text { Yamamoto } \\
2002\end{array}$ \\
\hline
\end{tabular}




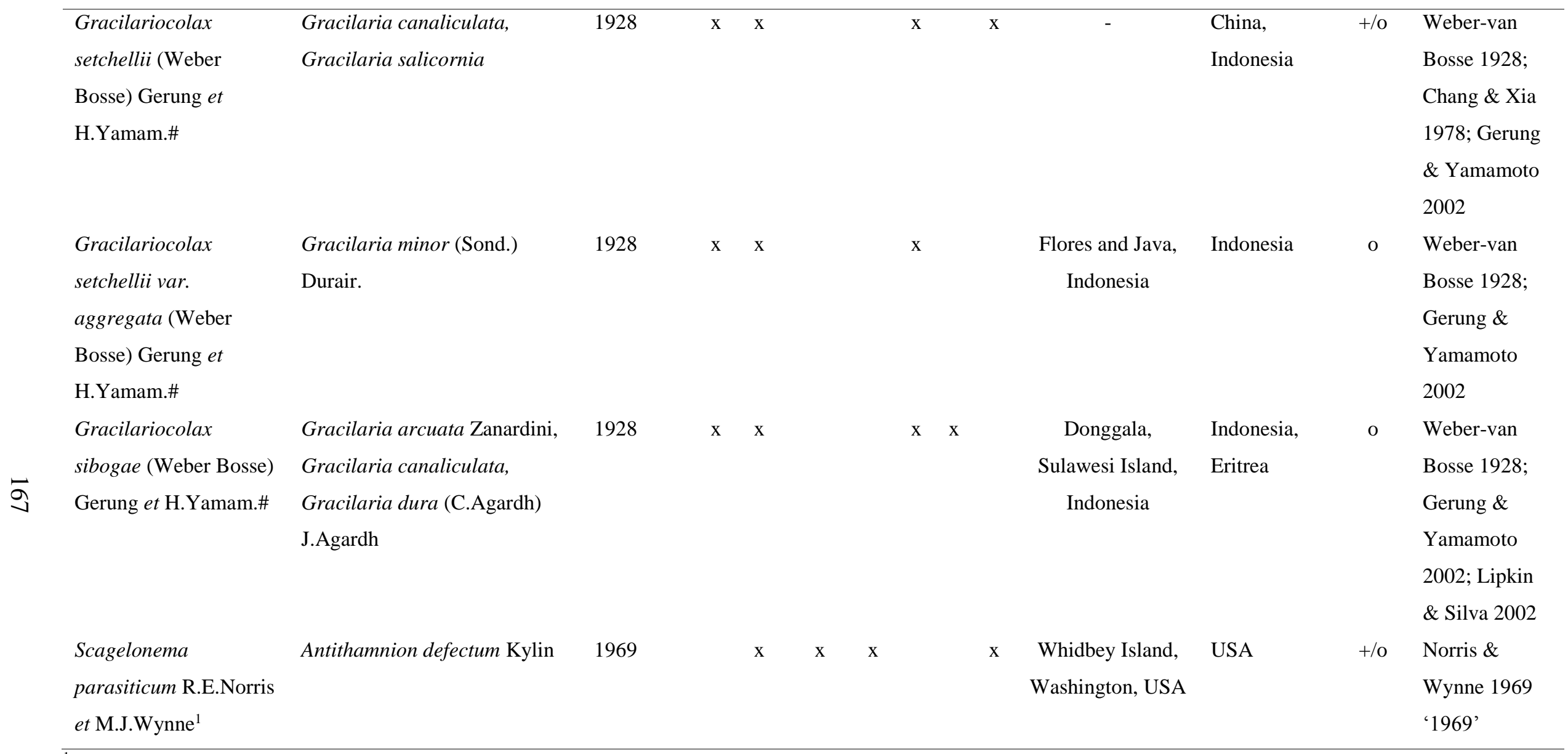

${ }^{1}$ Scagelonema was formerly included in the Ceramiaceae but its position is currently uncertain. 
Albornoz, O. \& Ganesan, E. K. 1994. Marine macro algae of Falcón state, Venezuela-2: two new additions of Rhodophyta for Venezuela. Bol. Centro. Invest. Biol. 28:19-32.

Araújo, R., I. Bárbara, M. Tibaldo, E. Berecibar, P. Díaz-Tapia, R. Pereira, R. Santos and I. Sousa-Pinto. 2009. Checklist of benthic marine algae and cyanobacteria of Northern Portugal. Bot. Mar. 52:24-46.

Broadwater, S. T. \& LaPointe, E. A. 1997. Parasitic interactions and vegetative ultrastructure of Choreonema thuretii (Corallinales, Rhodophyta). J. Phycol. 33:396-407.

Broadwater, S. T., Harvey, A. S., Lapointe, E. A. \& Woelkerling, W. J. 2002. Conceptacle structure of the parasitic coralline red alga Choreonema thuretii (Corallinales) and its taxonomic implications. J. Phycol. 38:1157-1168.

Chamberlain, Y. M. 1988. Observations on an autogenous fertile outgrowth of Lithophyllum crouanii (Corallinales, Rhodophyta) from southern England. Phycologia 27:378-386.

Chamberlain, Y. 1999. The occurrence of Ezo epiyessoense Adey, Masaki \& Akioka (Rhodophyta, Corallinaceae) in England with a summary of parasitism and endophytism in nongeniculate Corallinaceae. Cryptogamie Algol. 20:155-165.

Coppejans, E., De Clerck, O., Leliaert, F. \& Dargent, O. 2000a. Progress of the taxonomic research on the macroalgae (Chlorophyta, Phaeophyta and Rhodophyta) along the East African coast. oceandocs.org.

Coppejans, E., Leliaert, F. \& De Clerck, O. 2000b. Annotated list of new records of marine macroalgae for Kenya and Tanzania, since Isaac's and Jaasund's publications. Biol. Jaarb. Dodonaea 67:31-93.

Court, G. J. 1980. Photosynthesis and translocation studies of Laurencia spectabilis and its symbiont Janczewskia gardneri (Rhodophyceae). J. Phycol. 16:270-279.

de Oliveira Filho, E. C. 1969. Algas marinhas do sul do estado do Espírito Santo (Brasil). ICeramiales. Boletim da Faculdade de Filosofia, Ciências e Letras, Universidade de São Paulo 7-277.

Díaz-Pulido, G. \& Díaz-Ruíz, M. 2003. Diversity of benthic marine algae of the Colombian Atlantic. Biota Colombiana 4:203-246.

Díaz-Tapia, P. \& Bárbara, I. 2013. Seaweeds from sand-covered rocks of the Atlantic Iberian Peninsula. Part 1. The Rhodomelaceae (Ceramiales, Rhodophyta). Cryptogamie Algol. 34:325-422. 
Edelstein, T. \& McLachlan, J. 1977. On Choreocolax odonthaliae Levring (Cryptonemiales, Rhodophyceae). Phycologia 16:287-293.

Fan, K. C. 1963. Studies of the reproductive organs of red algae III. The south African genus Melanocolax. Acta Bot. Sin. 11:200-203.

Feldmann, J. \& Feldmann, G. 1958. Recherches sur quelques Floridées parasites. Revue Générale de Botanique.

Fredericq, S., Hommersand, M. H. \& Norris, J. N. 1989. Morphological observations of the adelphoparasite Gracilariophila oryzoides. Jap. J. Phycol. 37:167-179.

Fujii, M. \& Toyota, G. 1999. Morphological studies of the parasitic red alga Janczewskia moriformis (Rhodomelaceae, Ceramiales) from Brazil. Phycologia 38:1-7.

García, M. \& Gómez, S. 2004. Marine benthic macroalgae of the locality Carmen de Uria, Vargas State, Venezuela. Acta Bot. Venez. 27:43-55.

Goff, L. J. \& Cole, K. 1975. The biology of Harveyella mirabilis (Cryptonemiales, Rhodophyceae). II. Carposporophyte development as related to the taxonomic affiliation of the parasitic red alga, Harveyella mirabilis. Phycologia 14:227-238.

Goff, L. J. 1981. The role of bispores in the life history of the parasitic red alga, Gardneriella tuberifera (Solieriaceae, Gigartinales) Phycologia 20:397-406.

Goff, L. J. \& Hommersand, M. H. 1982. Reproductive development of the parasitic red alga Gardneriella tuberifera (Solieriaceae, Gigartinales). J. Phycol. 18:295-304.

Guimaraes, S. M. P. B. 1993. Morphology and systematics of the red algal parasite Dawsoniocolax bostrychiae (Choreocolacaceae, Rhodophyta). Phycologia 32:251-258.

Guiry, M. D. 1997. Benthic red, brown and green algae. In Howson, C. M. \& Picton, B. E. [Eds.] The species directory of the marine fauna and flora of the British Isles and surrounding seas, Ulster Museum, Belfast, pp. 316-341.

Haroun, R. J., Gil-Rodriguez, M. C., de Castro, J. D. \& Harouna, R. J. 2002. A checklist of the marine plants from the Canary Islands (Central Eastern Atlantic Ocean). Bot. Mar. 45:139-169.

Hommersand, M. H., Moe, R. L., Amsler, C. D. \& Fredericq, S. 2009. Notes on the systematics and biogeographical relationships of Antarctic and sub-Antarctic Rhodophyta with descriptions of four new genera and five new species. Bot. Mar. 52:509-534.

John, D. M., Prud'homme van Reine, W.F., Lawson, G. W., Kostermans, T. B. \& Price, J. H. 2004. A taxonomic and geographic catalogue of the seaweeds of Western Coast of Africa and adjacent islands. Gebr. Borntraeger Verlagsbuchhandlungen, Berlin, Stuttgart. 
Jonsson, S. \& Chesnoy, L. 1988. Halosacciocolax kjellmanii, parasite arctique de Devaleraea ramentacea (Palmariales, Rhodophyta): Organisation et rapports hôte-parasite. Bull. Soc. Bot. Fr. 135:211-227.

Kim, M.-S., Kim, M., Chung, M.-H., Kim, J.-H. \& Chung, I.-K. 2008. Species composition and biomass of intertidal seaweeds in Chuja Island. Algae 23:301-310.

Kongkittayapun, N. \& Chirapart, A. 2011. Morphometric and molecular analysis of Gracilaria salicornia and its adelphoparasite in Thailand. Scienceasia 37:6-16.

Kremer, B. P. 1986. Parasitische Rotalgen. Biologie in unserer Zeit 16:152-158.

Kugrens, P. 1974. Light and electron microscopic studies on the development and liberation of Janczewskia gardneri Setch. spermatia (Rhodophyta). Phycologia 13:295-306.

Kugrens, P. \& West, J. A. 1973. The ultrastructure of carpospore differentiation in the parasitic red alga Levringiella gardneri (Setch.) Kylin. Phycologia 12:163-173.

Kylin, H. 1930. Ueber die Entwicklungsgeschichte der Florideen. Acta Universitatis Lundensis, Lund.

Lee, I. K. \& Kurogi, M. 1978. Neohalosacciocolax aleutica gen. et sp. nov. (Rhodophyta), parasitic on Halosaccion minjaii I. K. Lee from the North Pacific. Br. Phycol. J. 13:131139.

Lipkin, Y. \& Silva, P. C. 2002. Marine algae and seagrasses of the Dahlak Archipelago, southern Red Sea. Nova Hedwigia 75:1-90.

López Rodriguez, M. C., Bárbara Criado, I. \& Cremades Ugarte, J. 2003. Morfología y distribución de Choreocolax polysiphoniae y Harveyella mirabilis (Gigartinales, Rhodophyta), dos parásitos marinos en la Península Ibérica. Anales Jardín Botánico de Madrid 60:213-215.

Lyle, L. 1920. The marine algae of Guernsey. J. Bot. 58:1-53.

Mateo-Cid, L. E., Mendoza-Gonzalez, A. C. \& Searles, R. B. 2006. A checklist and seasonal account of the deepwater Rhodophyta around Cozumel Island on the Caribbean coast of Mexico. Caribb. J. Sci. 42:39-52.

Matsumoto, M. \& Yoshida, T. 1991. Leachiella pacifica Kugrens (Choreocolacaceae, Rhodophyceae), new to Japan. Jpn. J. Phycol. 39:15-20.

Newroth, P. R. \& Taylor, A. R. A. 1968. The distribution of Ceratocolax hartzii. Br. Phycol. Bull. 3:543-46.

Papenfuss, G. F. 1964. Catalogue and bibliography of Antarctic and Sub-Antarctic benthic marine algae. In Lee, M. O. [Ed.] Bibliography of the Antarctic Seas. American Geophysical Union, Washington D. C., pp. 1-76. 
Pérez-Cirera, J. L., Cremades, J. \& I., B. 1989. El endemismo sudafricano Aiolocolax pulchella Pocock (Ceramiales?, Rhodophyta), parásito de Falkenbergiella caespitosa Pocock, en las costas atlánticas de Europa. Anales Jard. Bot. 46:83-88.

Ramírez, M.E. \& Santelices, B. 1991. Catálogo de las algas marinas bentónicas de la costa temperada del Pacífico de Sudamérica. No. 5. Monografías Biológicas, Santiago.

Robledo, D., Y. Freile-Pelegrín, and I. Sánchez-Rodriguez 2003. Marine benthic algae from the Campeche Banks, México. Proceedings of the XVII International Seaweed Symposium. Oxford University Press, Oxford.

Saunders, G. W. \& Lehmkuhl, K. V. 2005. Molecular divergence and morphological diversity among four cryptic species of Plocamium (Plocamiaceae, Florideophyceae) in northern Europe. Eur. J. Phycol. 40:293-312.

Seoane-Camba, J. A. 1996. A comparative study of the intercellular connections between parasite and host in two Gelidiocolax (Gelidiacea?, Rhodophyta) - Gelidium (Gelidiaceae, Rhodophyta) algal parasitic systems. An. Jardin. Bot. Mad. 54:50-54.

Seoane-Camba, J. A. S. \& Cortadellas, N. 1998. Ultrastructural study of the pit connections of Gelidiocolax Gardner (parasitic Rodophyta)/Estudi ultraestructural de les sinapsis de Gelidiocolax Gardner (Rhodophyta paràsit). Acta Bot. Barc. 45:107-113.

Stegenga, H. \& Vroman, M. 1986. Pterocladiophila hemisphaerica (Rhodophyta, Cryptonemiales) in the Caribbean. Acta Bot. Neerl. 35:1-4.

Stegenga, H. \& Vroman, M. 1987. Notes on some Ceramiaceae (Rhodophyta) from Curaçao, especially those from the exposed northeast coast. Blumea 32:397-426.

Terada, R., Yamamoto, H. \& Muraoka, D. 1999. Observations on an adelphoparasite growing on Gracilaria salicornia from Thailand. In Abbott, I. A. [Ed.] Taxonomy of economic seaweeds. California Sea Grant College Program, La Jolla, California.

Wetherbee, R. \& Quirk, H. M. 1982. The fine structure and cytology of the association between the parasitic red alga Holmsella australis and its red algal host Gracilaria furcellata. Protoplasma 110:153-165.

Wetherbee, R., Quirk, H. M., Mallett, J. E. \& Ricker, R. W. 1984. The structure and formation of host-parasite pit connections between the red algal alloparasite Harveyella mirabilis and its red algal host Odonthalia floccosa. Protoplasma 119:62-73.

Woelkerling, W. J. 1987. The disposition of Chaetolithon and its type species, C. deformans (Corallinaceae, Rhodophyta). Phycologia 26:227-280. 
Zinova, A. D. 1964. The composition and character of algal flora at the Antarctic Coast and in the vicinity of Kerguelen and MacQuarie Islands. Soviet Antarctic Expedition Information Bulletin (Elsevier) 1:123-125. 


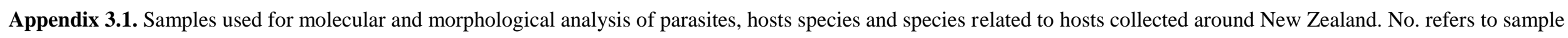
extraction number used for sequencing and associated GenBank Accession numbers.

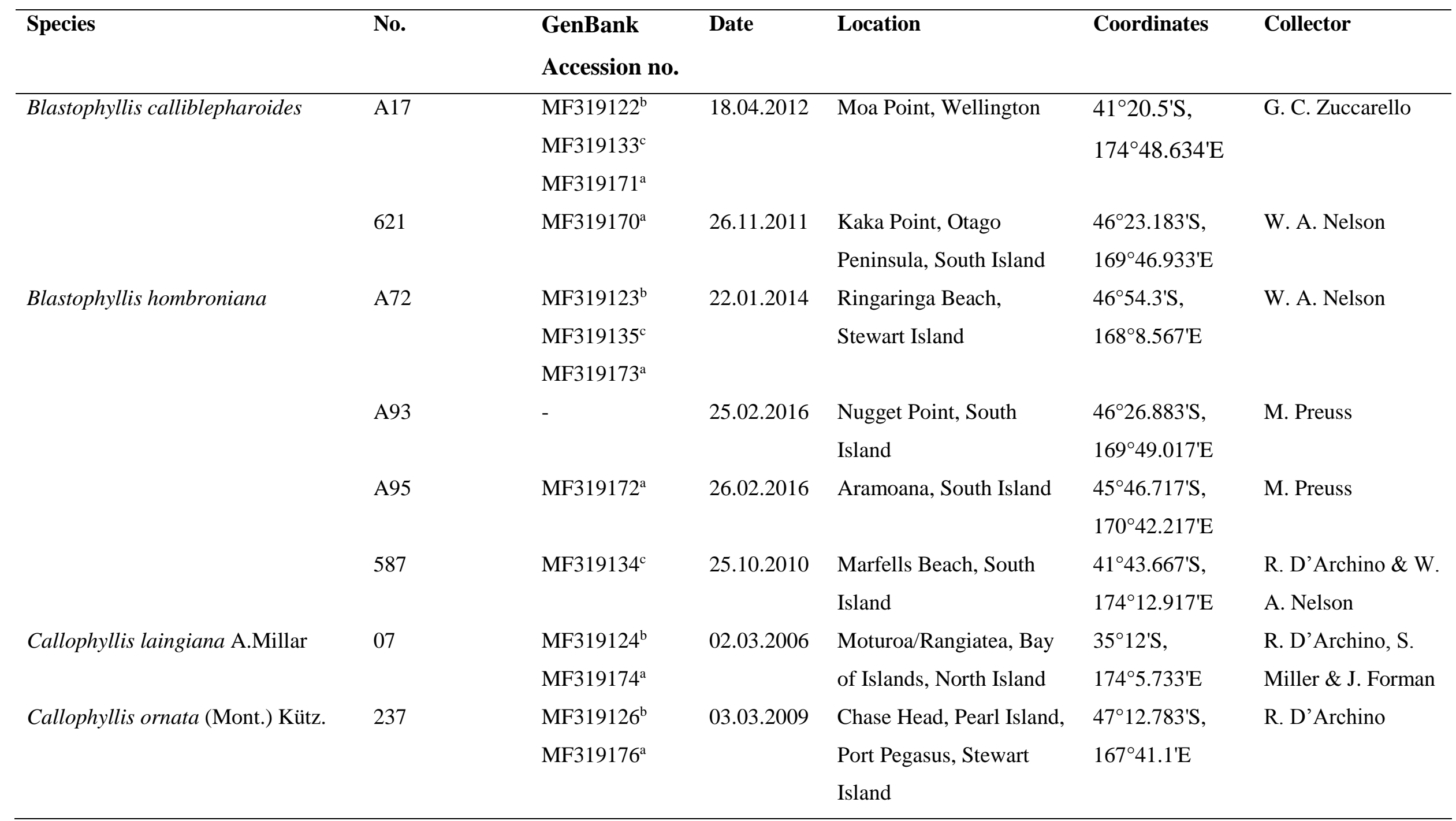




\begin{tabular}{|c|c|c|c|c|c|c|}
\hline \multirow[t]{3}{*}{ Cladhymenia coronata } & A64 & MF319142 ${ }^{\mathrm{a}}$ & 12.12 .2012 & Horseshoe Bay, Stewart & $46^{\circ} 52.433 ' \mathrm{~S}$ & C. Hepburn \\
\hline & & MF319146 ${ }^{\mathrm{b}}$ & & Island & $168^{\circ} 7.6^{\prime} \mathrm{E}$ & \\
\hline & & MF319152 & & & & \\
\hline \multirow[t]{4}{*}{ Cladhymenia lyallii } & A66 & MF319143 ${ }^{\mathrm{a}}$ & 13.04 .2013 & Catton's Cave, Rosemary & $34^{\circ} 10.933 ' \mathrm{~S}$, & R. D'Archino \\
\hline & & MF319147b & & Island, Princes Islands, & $172^{\circ} 3.383^{\prime} \mathrm{E}$ & \\
\hline & & MF319150 & & Three Kings & & \\
\hline & & & & Islands/Manawatāwhi & & \\
\hline \multirow[t]{7}{*}{ Cladhymenia oblongifolia } & A01 & MF319138 & 11.11.2014 & Marfells Beach, South & $41^{\circ} 43.667 \mathrm{~S}$ & M. Preuss \\
\hline & & MF319148 & & Island & $174^{\circ} 12.917^{\prime} \mathrm{E}$ & \\
\hline & $\mathrm{A} 03$ & MF319140a & 11.11.2014 & Marfells Beach, South & $41^{\circ} 43.667 ' \mathrm{~S}$ & M. Preuss \\
\hline & & MF319144 ${ }^{\mathrm{b}}$ & & Island & $174^{\circ} 12.917^{\prime} \mathrm{E}$ & \\
\hline & & MF319149 & & & & \\
\hline & A100 & MF319139a & 18.03.2016 & Owenga house, Chatham & $44^{\circ} 1.208^{\prime} \mathrm{S}$ & M. Preuss \\
\hline & & & & Island & $176^{\circ} 22.767^{\prime} \mathrm{W}$ & \\
\hline \multirow[t]{2}{*}{ Ectophora depressa J.Agardh } & 26 & MF319127 & 31.01 .2006 & Waitangi wharf, Chatham & $43^{\circ} 56.716 ' \mathrm{~S}$, & W. A. Nelson \\
\hline & & MF319177 & & Island & $176^{\circ} 33.633^{\prime} \mathrm{W}$ & \\
\hline Ectophora marginata D'Archino et & 046 & MF319128 & 06.04 .2006 & Karikari Bay, Northland, & $34^{\circ} 52.683^{\prime} \mathrm{S}$ & D. Freeman \& N. \\
\hline W.A.Nelson & & MF319178 & & North Island & $173^{\circ} 22.833^{\prime} \mathrm{E}$ & Shears \\
\hline Judithia delicatissima (R.E.Norris) & 113 & MF319129 & 07.12 .2006 & Marfells Beach, South & $41^{\circ} 43.667 ' \mathrm{~S}$ & W. A. Nelson \& K. \\
\hline D'Archino et Showe M.Lin & & MF319179a & & Island & $174^{\circ} 12.917^{\prime} \mathrm{E}$ & Neill \\
\hline \multirow[t]{2}{*}{ Phycodrys adamsiae } & A91 & MF319158 ${ }^{\mathrm{d}}$ & 30.05 .2011 & Ranfurly Bank, Hicks & $37^{\circ} 32.733^{\prime} \mathrm{S}$ & - \\
\hline & & MF319169 & & Bay, North Island & $178^{\circ} 53.55^{\prime} \mathrm{E}$ & \\
\hline
\end{tabular}




\begin{tabular}{|c|c|c|c|c|c|c|}
\hline & A92 & - & 01.06 .2011 & Ranfurly Bank, Hicks & $37^{\circ} 32.733^{\prime} \mathrm{S}$ & - \\
\hline & & & & Bay, North Island & $178^{\circ} 53.55^{\prime} \mathrm{E}$ & \\
\hline \multirow[t]{15}{*}{ Phycodrys novae-zelandiae } & A05 & MF319153 ${ }^{\mathrm{a}}$ & 11.11.2014 & Marfells Beach, South & $41^{\circ} 43.667 ' \mathrm{~S}$ & M. Preuss \\
\hline & & MF319159 & & Island & $174^{\circ} 12.917^{\prime} \mathrm{E}$ & \\
\hline & & MF319164 & & & & \\
\hline & & MF319167 & & & & \\
\hline & A07 & MF319154 & 11.11.2014 & Marfells Beach, South & $41^{\circ} 43.667^{\prime} \mathrm{S}$ & M. Preuss \\
\hline & & MF319161 ${ }^{\mathrm{d}}$ & & Island & $174^{\circ} 12.917^{\prime} \mathrm{E}$ & \\
\hline & $\mathrm{A} 27$ & MF319156 & 02.02 .2015 & Akitio Beach, South & $40^{\circ} 37.417 \mathrm{~S}$ & M. Preuss \\
\hline & & MF319162 ${ }^{\mathrm{d}}$ & & Island & $176^{\circ} 24.65^{\prime} \mathrm{E}$ & \\
\hline & & MF319168 & & & & \\
\hline & A78 & MF319163 & 21.09 .2015 & Marfells Beach, South & $41^{\circ} 43.667 ' \mathrm{~S}$ & M. Preuss \\
\hline & & & & Island & $174^{\circ} 12.917^{\prime} \mathrm{E}$ & \\
\hline & A84 & - & 21.09 .2015 & Marfells Beach, South & $41^{\circ} 43.667^{\prime} \mathrm{S}$ & M. Preuss \\
\hline & & & & Island & $174^{\circ} 12.917^{\prime} \mathrm{E}$ & \\
\hline & A103 & - & 19.02.2016 & Princess Bay, Wellington, & $41^{\circ} 20.767 ' \mathrm{~S}$ & M. Preuss \\
\hline & & & & North Island & $174^{\circ} 47.433^{\prime} \mathrm{E}$ & \\
\hline \multirow{2}{*}{$\begin{array}{l}\text { Rhizopogonia asperata (Harv.) } \\
\text { Kylin }\end{array}$} & 187 & MF319131 ${ }^{\mathrm{b}}$ & 08.11 .2006 & Evans Bay, Wellington, & $41^{\circ} 18.683^{\prime} \mathrm{S}$ & W. A. Nelson \\
\hline & & MF319181 & & North Island & $174^{\circ} 47.8^{\prime} \mathrm{E}$ & \\
\hline Thamnophyllis laingii (J.Agardh) & 117 & MF319132 & 12.07.1998 & Brighton, Dunedin, South & $45^{\circ} 56.833^{\prime} \mathrm{S}$ & W. A. Nelson \\
\hline R.E.Norris & & MF319182 & & Island & $170^{\circ} 20.067^{\prime} \mathrm{E}$ & \\
\hline Wendya incisa D'Archino et Showe & 282 & MF319125 & 07.10 .2010 & Mataikona, North Island & $40^{\circ} 47.3 \mathrm{~S}$ & W. A. Nelson \& R. \\
\hline M.Lin & & MF319175 & & & $176^{\circ} 16.033^{\prime} \mathrm{E}$ & D'Archino \\
\hline
\end{tabular}




\section{Parasites:}

Cladhymenia oblongifoliophila

on Cladhymenia oblongifolia

Judithia parasitica

on Blastophyllis calliblepharoides

Judithia parasitica

$\bar{a}$

on Blastophyllis hombroniana

Phycodrys novae-zelandiophila
on Phycodrys novae-zelandiae

on Phycodrys novae-zelandiae
A02

A04

A73

MF319141

MF319145

MF319151c

MF319130

MF319137

MF319180

$-$

A96

A06

A08

A28

MF319136

MF319164

MF319155

MF319157
11.11.2014 Marfells Beach, South

Island, NZ

11.11.2014 Marfells Beach, South

Island, NZ

18.04.2012 Moa Point, Wellington,

NZ

22.01.2014 Ringaringa Beach,

Stewart Island, NZ

MF319160

MF319166
41ํㄴ.667'S, M. Preuss

$174^{\circ} 12.917^{\prime} \mathrm{E}$

414․667'S, M. Preuss

$174^{\circ} 12.917^{\prime} \mathrm{E}$

$41^{\circ} 20.5^{\prime} \mathrm{S}, \quad$ G. C. Zuccarello

$174^{\circ} 48.634^{\prime} \mathrm{E}$

46도' 54 'S, W. A. Nelson

$168^{\circ} 8.567^{\prime} \mathrm{E}$

4546.717'S, M. Preuss

$170^{\circ} 42.217^{\prime} \mathrm{E}$

414․667'S, M. Preuss

$174^{\circ} 12.917^{\prime} \mathrm{E}$ $41^{\circ} 43.667 ' \mathrm{~S}$,

$174^{\circ} 12.917^{\prime} \mathrm{E}$

$40^{\circ} 37.417 ' \mathrm{~S}$,

M. Preuss

M. Preuss Island, NZ

Akitio Beach, South

Island, NZ $176^{\circ} 24.65^{\prime} \mathrm{E}$ 
Appendix 3.2. Primers used for PCR amplifying and sequencing.

\begin{tabular}{|c|c|c|}
\hline $\begin{array}{l}\text { Primer } \\
\text { name }\end{array}$ & Primer sequence & Reference \\
\hline \multicolumn{3}{|l|}{ Actin } \\
\hline Act1.f1 & GCC CGC GGT TGT CAT YGA CAA TGG & (Kamiya et al. 2011) \\
\hline Act1.r1 & GCS GCR ATA ACC TTA ATC TTC AT & (Kamiya et al. 2011) \\
\hline \multicolumn{3}{|l|}{$\operatorname{Cox} 1$} \\
\hline GazF1 & TCA ACA AAT CAT AAA GAT ATT GG & (Saunders 2005) \\
\hline GazR1 & ACT TCT GGA TGT CCA AAA AAY CA & (Saunders 2005) \\
\hline \multicolumn{3}{|l|}{ LSU } \\
\hline X.LSU.f & GAT GAC CCG CTG AAT TTA AG & (Harper \& Saunders 2001) \\
\hline X.LSU.r & AGC GCC ATC CAT TTT YAG GG & (Harper \& Saunders 2001) \\
\hline Y.LSU.f & GCA GGA CGG TGG CCA TGG AAG T & (Harper \& Saunders 2001) \\
\hline Y.LSU.r & CAG AGC ACT GGG CAG AAA TCA C & (Harper \& Saunders 2001) \\
\hline Z.LSU.f & GCA ACG GGC AAA GGG AAT CCG & (Harper \& Saunders 2001) \\
\hline Z.LSU.r & TGA TAG GAA GAG CCG ACA TCG A & (Harper \& Saunders 2001) \\
\hline \multicolumn{3}{|l|}{ SSU } \\
\hline GO4 & CAG AGG TGA AAT TCT TGG AT & (Harper \& Saunders 2001) \\
\hline $\mathrm{JO} 4$ & AAA CCT TGT TAC GAC TTC TCC & (Harper \& Saunders 2001) \\
\hline \multicolumn{3}{|l|}{$r b c \mathbf{L}$} \\
\hline F8 & GGT GAA TTC CAT ACG CTA AAA TG & (Wang et al. 2000) \\
\hline F145 & CAA CCA GGW GTA GAT CCA GTA GAA GC & (Kim et al. 2010) \\
\hline R753 & GCT CTT TCA TAC ATA TCT TCC & (Freshwater \& Rueness 1994) \\
\hline
\end{tabular}


Appendix 3.3. List of species used in molecular analyses and their GenBank Accession numbers for $\operatorname{cox} 1, r b c \mathrm{~L}$ and LSU sequences.

\begin{tabular}{|c|c|c|c|}
\hline \multirow[t]{2}{*}{ Species } & \multicolumn{3}{|c|}{ GenBank Accession numbers } \\
\hline & $\underline{\operatorname{cox} 1}$ & $\underline{r b c \mathrm{~L}}$ & $\underline{\text { LSU rRNA }}$ \\
\hline Blastophyllis calliblepharoides & & HM587174 & HM587201 \\
\hline Blastophyllis hombroniana & & & HM587205 \\
\hline Callophyllis cristata Okamura & KM675349 & KR231932 & KR231920 \\
\hline Callophyllis edentata Kylin & JX034268 & KC130228 & AY171604 \\
\hline Callophyllis laciniata (Huds.) Kütz. & JF903294 & KF280968 & JF833333 \\
\hline Callophyllis laingiana A.Millar & & HM587176 & JX296178 \\
\hline Callophyllis lambertii (Turner) Kütz. & HM917637 & HQ910509 & JX296155 \\
\hline Callophyllis ornata (Mont.) Kütz. & & HM587180 & HM587214 \\
\hline Callophyllis pinnata Setch. et Swezy & JX034365 & AY294397 & AY171608 \\
\hline Callophyllis variegata (Bory) Kütz. & JX034431 & KF280964 & HM587220 \\
\hline Callophyllis violacea J.Agardh & JX034438 & CVU04191 & JX296161 \\
\hline Chondrophycus sp. & HQ423050 & FJ785310 & KX145615 \\
\hline Cirrulicarpus nanus (J.Agardh) Womersley & KF280934 & KF280981 & KF280956 \\
\hline Cirrulicarpus polycoelioides (J.Agardh) & HM915947 & KF280972 & JX296142 \\
\hline \multicolumn{4}{|l|}{ Womersley } \\
\hline Dumontia simplex Cotton & AY971153 & KT310711 & JN403052 \\
\hline Ectophora depressa J.Agardh & & GQ376535 & JN543696 \\
\hline Ectophora marginata & & HM587177 & HM587212 \\
\hline Euthora cristata (C.Agardh) J.Agardh & GU140145 & JX969805 & KF280993 \\
\hline Glaphyrymenia pustulosa J.Agardh & KC157606 & KF280988 & JX296147 \\
\hline Judithia delicatissima D'Archino et & & KR231930 & JN543699 \\
\hline \multicolumn{4}{|l|}{ W.A.Nelson } \\
\hline Kallymenia cribrosa Harv. & KF280930 & EU349216 & KF280953 \\
\hline Kallymenia feldmannii Codomier & KJ083054 & EU543487 & KJ083095 \\
\hline Kallymenia lacerata Feldmann & KJ083056 & KJ083103 & KJ086096 \\
\hline Kallymenia tasmanica Harv. & HM917780 & KC157624 & KF280954 \\
\hline Kallymenia reniformis (Turner) J.Agardh & KJ960795 & KJ404065 & KJ083098 \\
\hline Kallymenia requienii (J.Agardh) J.Agardh & KJ083091 & KJ083106 & KJ083099 \\
\hline Meredithia microphylla (J.Agardh) J.Agardh & KJ083093 & KC157626 & KC157656 \\
\hline
\end{tabular}




\begin{tabular}{|c|c|c|c|}
\hline $\begin{array}{l}\text { Meredithia norfolkensis G.W.Saunders et } \\
\text { C.W.Schneid. }\end{array}$ & KF280922 & KF280971 & KF280949 \\
\hline $\begin{array}{l}\text { Meredithia nutleorum G.W.Saunders et } \\
\text { C.W.Schneid. }\end{array}$ & KF280921 & KF280969 & KF280948 \\
\hline $\begin{array}{l}\text { Meredithia pseudopeltata G.W.Saunders et } \\
\text { C.W.Schneid. }\end{array}$ & KF280929 & KF280984 & KF280959 \\
\hline Polycoelia laciniata J.Agardh & KT307606 & KF280983 & KF280958 \\
\hline Pugetia fragilissima Kylin & HQ919395 & KR231931 & AY171614 \\
\hline Rhizopogonia asperata (Harv.) Kylin & & HM587196 & JN543700 \\
\hline $\begin{array}{l}\text { Salishia firma (Kylin) Clarkston et } \\
\text { G.W.Saunders }\end{array}$ & JF903349 & HQ910506 & JF833329 \\
\hline Sebdenia cerebriformis N'Yeurt et Payri & KU568457 & KU568458 & KU568459 \\
\hline $\begin{array}{l}\text { Thamnophyllis lacerata Womersley et } \\
\text { R.E.Norris }\end{array}$ & KF280931 & KF280979 & JX296176 \\
\hline Thamnophyllis laingii (J.Agardh) R.E.Norris & & HM587198 & JX543698 \\
\hline Wendya incisa & & KR2331927 & KR231921 \\
\hline
\end{tabular}




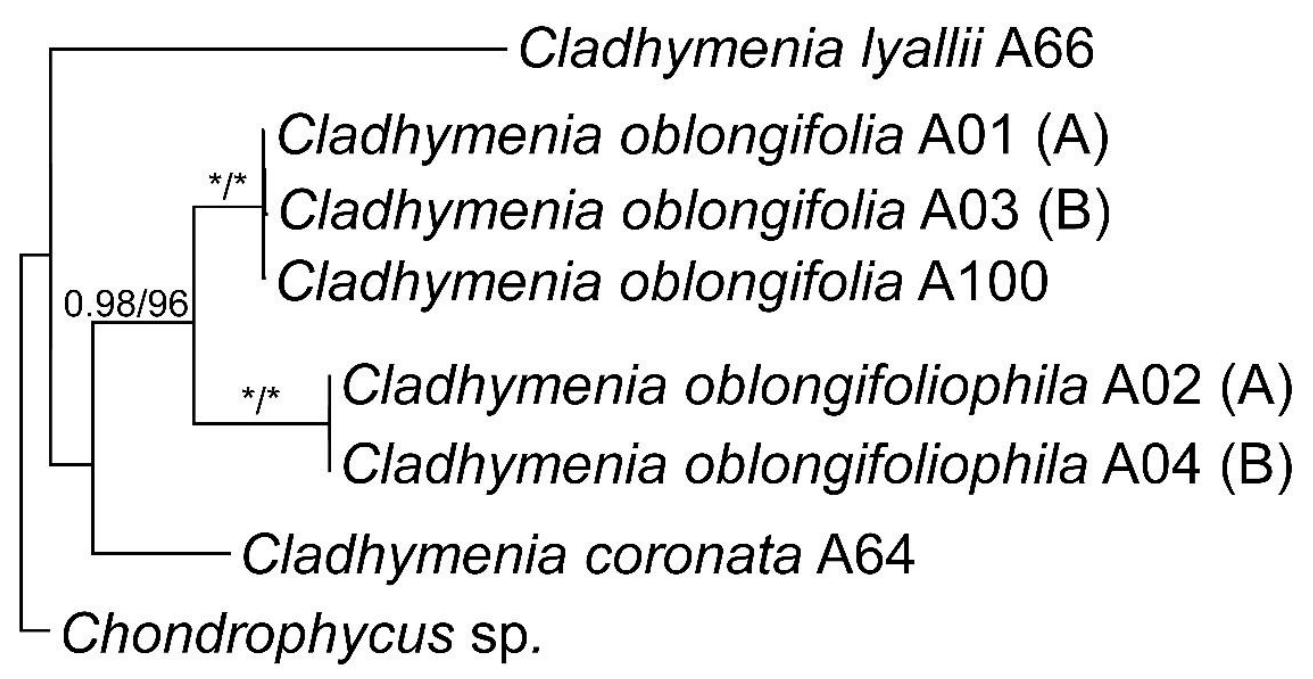

\begin{abstract}
Appendix 3.4. Bayesian topology of cox 1 sequence data for Cladhymenia oblongiofolia and its parasite Cladhymenia oblongifoliophila and two other species of Cladhymenia: C. coronata and C. lyallii. Sequences with numbers indicate new sequences (Appendix 3.1) and capital letters in brackets (A-B) indicate parasite and host combinations. Asterisks indicate posterior probability of 1.00 and ML bootstrap value of $100 \%$. Outgroup used was Chondrophycus sp. from GenBank (Appendix 3.3).
\end{abstract}




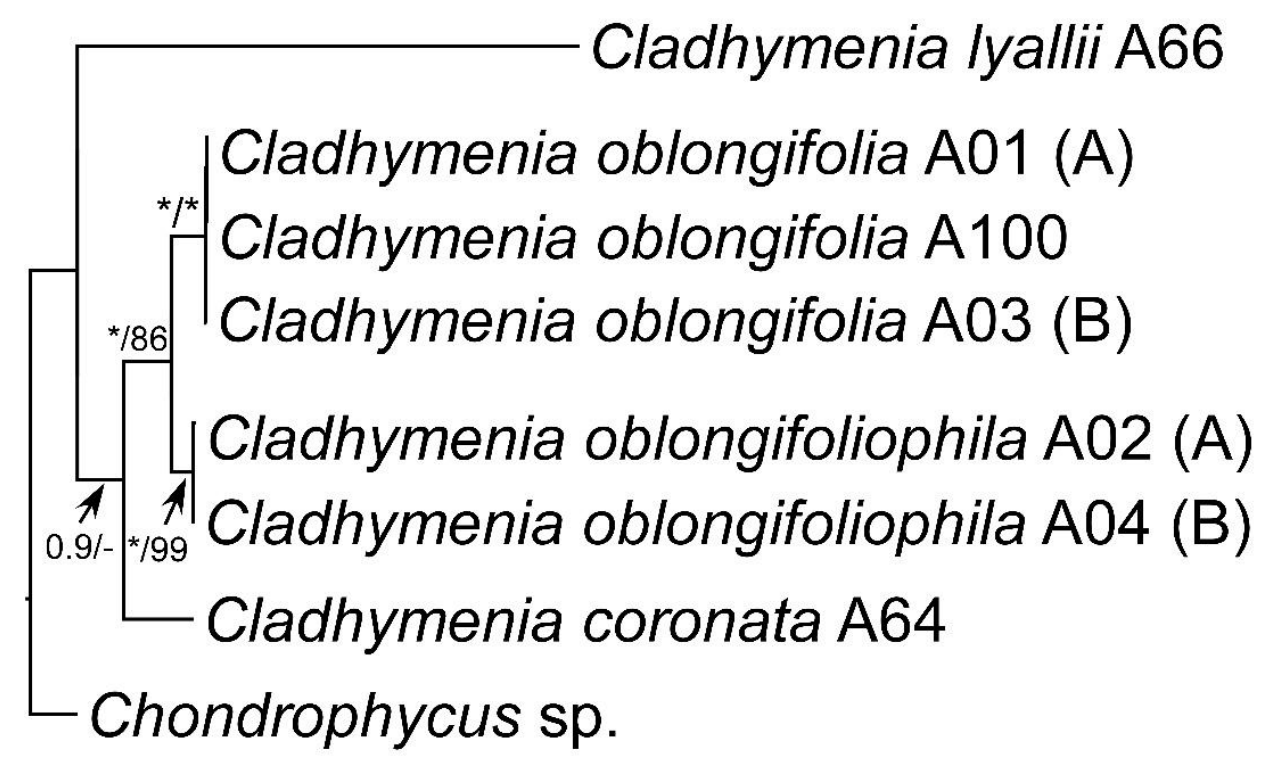

Appendix 3.5. Bayesian topology of LSU rRNA sequence data for Cladhymenia oblongifolia and its parasite Cladhymenia oblongifoliophila and two other species of Cladhymenia: C. coronata and C. lyallii. Sequences with numbers indicate new sequences (Appendix 3.1) and capital letters in brackets (A-B) indicate parasite and host combinations. Asterisks indicate posterior probability of 1.00 for MrBayes and bootstrap value of 100 of RAxML. Outgroup used was Chondrophycus sp. from GenBank (Appendix 3.3). 


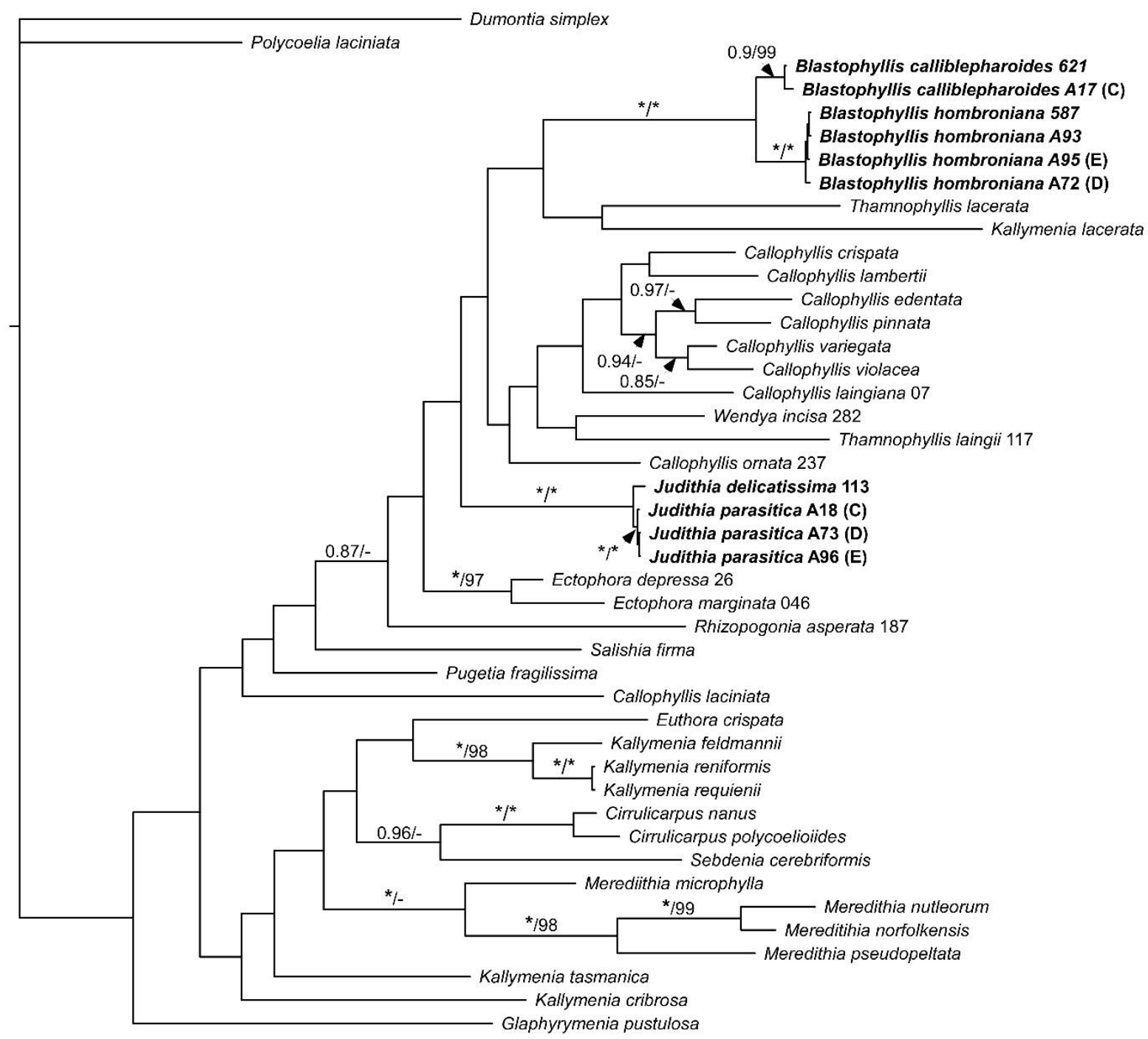

Appendix 3.6. Bayesian topology of cox 1 phylogenetic analysis for Judithia parasitica and its two host species Blastophyllis calliblepharoides and Blastophyllis hombroniana and other representative within the Kallymeniaceae. Parasite and host combinations are indicated by capital letters in brackets (C-E). Sequences with extraction numbers indicate new sequences (see Appendix 3.1 for collection information) and samples without numbers were downloaded from GenBank (Appendix 3.3). Asterisks indicate posterior probability of 1.00 and ML bootstrap value of $100 \%$. Values $<0.85$ posterior probability or $<85 \%$ ML bootstrap not shown. Outgroup used were Dumontia simplex and Polycoelia laciniata. 


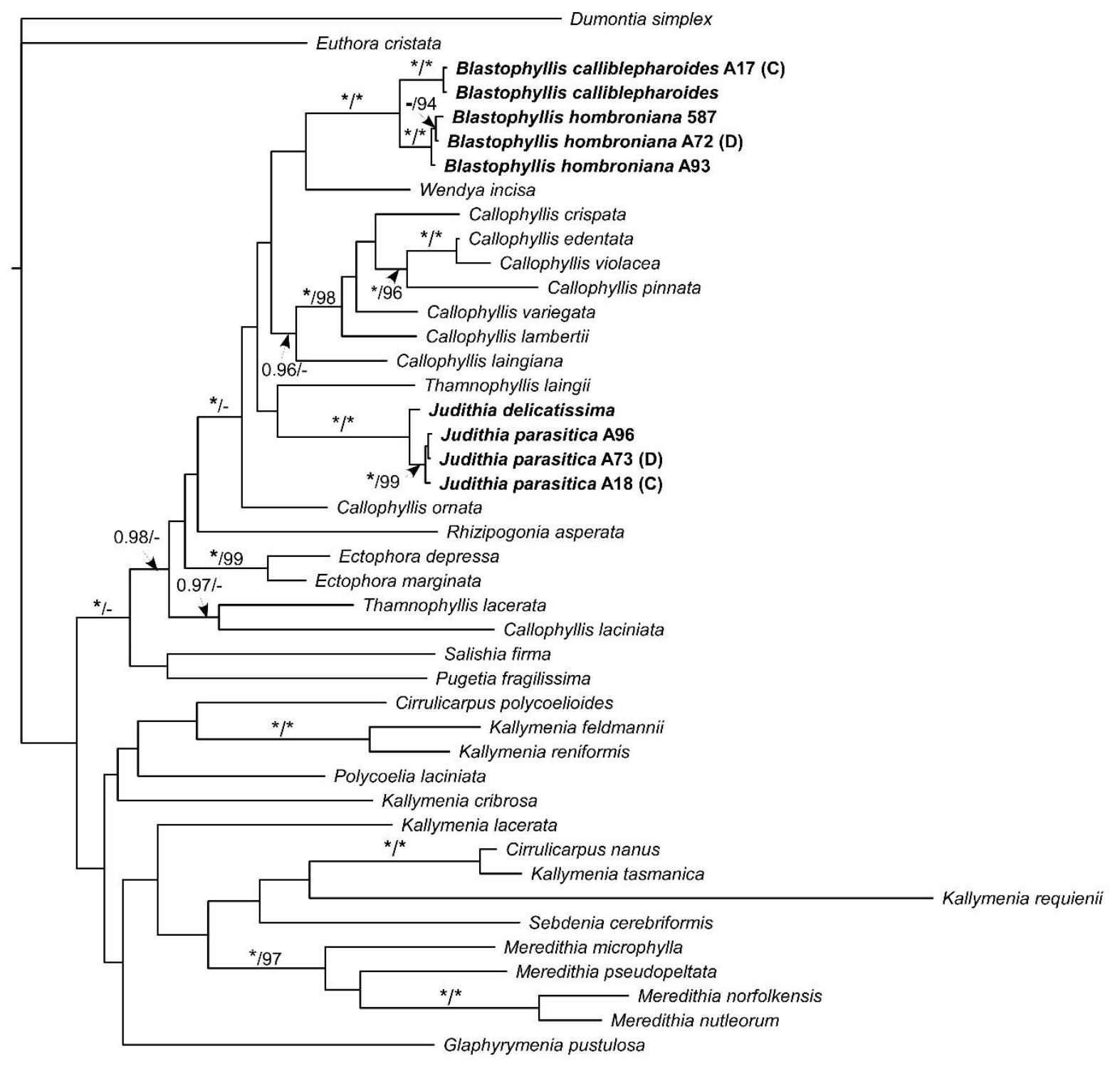

Appendix 3.7. Bayesian topology of $r b c \mathrm{~L}$ data for Judithia parasitica and its two host species Blastophyllis calliblepharoides and Blastophyllis hombroniana and other representative within the Kallymeniaceae. Parasite and host combinations are indicated by capital letters in brackets (C-D). Sequences with numbers indicate new sequences (see Appendix 3.1 for collection information) and samples without numbers were downloaded from GenBank (Appendix 3.3). Asterisks indicate posterior probability of 1.00 and bootstrap value of $100 \%$. Values < 0.85 posterior probability or $<85 \%$ ML bootstrap not shown. Outgroup used was Dumontia simplex. 


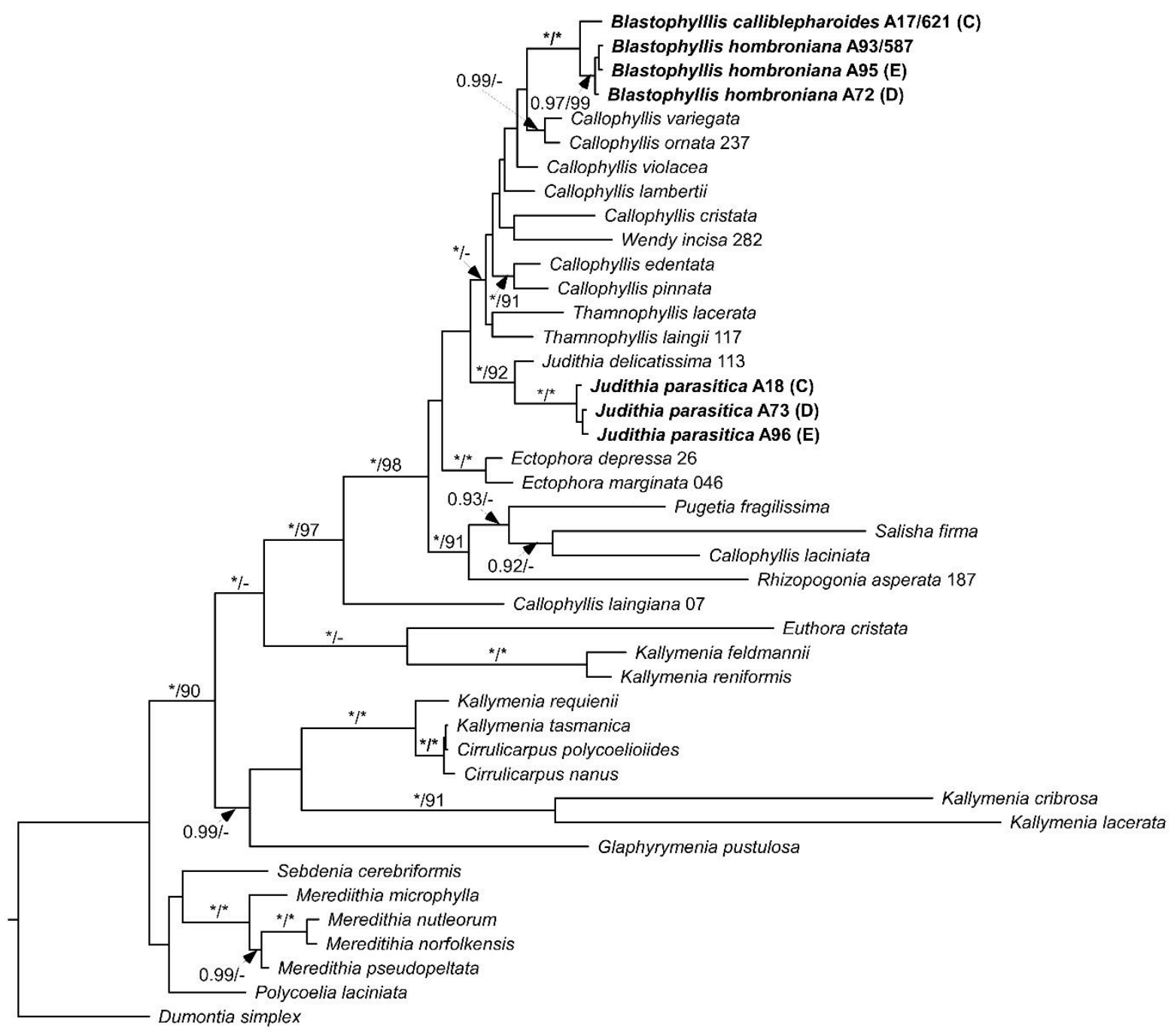

Appendix 3.8. Bayesian topology of LSU rRNA sequence data for the parasite Judithia parasitica and its two host species Blastophyllis calliblepharoides and Blastophyllis hombroniana and other representative within the Kallymeniaceae. Parasite and host combinations are indicated by capital letters in brackets (C-E). Sequences with numbers indicate new sequences (see Appendix 3.1 for collection information) and samples without numbers were downloaded from GenBank (Appendix 3.3) and combined. Sequences with several numbers are combined to represent one species. Asterisk indicate posterior probability of 1.00 and bootstrap value of $100 \%$. Values $<0.85$ posterior probability or $<85 \%$ ML bootstrap value not shown. Outgroup used was Dumontia simplex. 
Appendix 3.9. WELT vouchers of Phycodrys novae-zelandiophila on its host Phycodrys novae-zealandiae with red algal parasites from New Zealand, arranged north to south.

\begin{tabular}{|c|c|c|c|c|}
\hline $\begin{array}{l}\text { WELT } \\
\text { voucher no. }\end{array}$ & $\begin{array}{l}\text { Collection } \\
\text { date }\end{array}$ & Location & Coordinates & Collector \\
\hline $\mathrm{A} 2939 \mathrm{a} / \mathrm{b}$ & 07.03 .1970 & Mataikona, East Wairarapa, North Island & $40^{\circ} 47^{\prime} \mathrm{S}, 176^{\circ} 16^{\prime} \mathrm{E}$ & N. M. Adams \\
\hline A026386 & 28.11.2001 & Lyall Bay, Wellington, North Island & $41^{\circ} 21^{\prime} \mathrm{S}, 174^{\circ} 48^{\prime} \mathrm{E}$ & W. A. Nelson \\
\hline A19043 & 26.04.1990 & Port Underwood, Horahora Kakahu Island, South Island & $41^{\circ} 19^{\prime} \mathrm{S}, 174^{\circ} 08^{`} \mathrm{E}$ & C. Duffy \\
\hline A024384 & 29.09 .2007 & Otago Harbour, Waipuna Bay, Te Ngaru, South Island & $45^{\circ} 47^{\prime} \mathrm{S}, 170^{\circ} 40^{\prime} \mathrm{E}$ & K. Neill \\
\hline A6952 & 23.11 .1971 & Aquarium Street, Portobello, Otago Harbour, South Island & $45^{\circ} 50^{\prime} \mathrm{S}, 170^{\circ} 37^{\prime} \mathrm{E}$ & E. J. Batham \\
\hline A2979 & 26.01.1970 & Paterson Inlet, Stewart Island & $46^{\circ} 55^{\prime} \mathrm{S}, 168^{\circ} 05^{\prime} \mathrm{E}$ & P. Cresswell \\
\hline
\end{tabular}




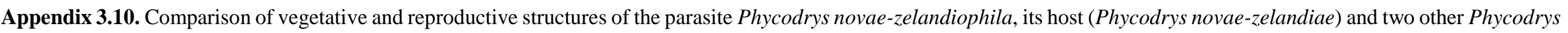
species from New Zealand: $P$. adamsiae and $P$. franiae.

\begin{tabular}{|c|c|c|c|c|}
\hline & $\begin{array}{l}\text { Phycodrys novae-zelandiophila } \\
\text { sp. nov. }\end{array}$ & $\begin{array}{l}\text { Phycodrys novae- } \\
\text { zelandiae }\end{array}$ & Phycodrys franiae & Phycodrys adamsiae \\
\hline \multicolumn{5}{|l|}{ Thallus } \\
\hline Size & $1-2 \times 1-2 \mathrm{~mm}$ & $8-15 \times 3-5 \mathrm{~cm}$ & $4-11 \times 4-12 \mathrm{~cm}$ & $3-8 \times 1-8 \mathrm{~cm}$ \\
\hline Growth form & Upright, several single branches & Blades & Blades & Blades \\
\hline Pigmentation & Light red & Rose-pink to dark red & Rose-pink to dark red & Brownish to dark red \\
\hline \multicolumn{5}{|l|}{ Reproductive structures } \\
\hline Gametophyte & Dioecious & Dioecious & Dioecious & Dioecious \\
\hline \multicolumn{5}{|l|}{ Carposporophyte } \\
\hline Size in diameter & $430-530 \mu \mathrm{m}$ & $650-900 \mu \mathrm{m}$ & $600-950 \mu \mathrm{m}$ & $680-850 \mu \mathrm{m}$ \\
\hline Carpospores & Born in short chains & In terminal clusters & Born in short chains & Born in short chains \\
\hline Central Fusion cell & Yes & Yes & Yes & Yes \\
\hline \multicolumn{5}{|l|}{ Tetrasporangia } \\
\hline Location & $\begin{array}{l}\text { Scattered on the surface in } \\
\text { stichidia }\end{array}$ & $\begin{array}{l}\text { Both sides of fertile } \\
\text { blade }\end{array}$ & In fertile blade & In marginal bladelets \\
\hline Form & Tetrahedrally divided & Tetrahedrally divided & Tetrahedrally divided & Tetrahedrally divided \\
\hline Size & $32 \times 40 \mu \mathrm{m}$ in diameter & $55 \times 65 \mu \mathrm{m}$ in diameter & $45 \times 60 \mu \mathrm{m}$ in diameter & $35-45 \times 55-60 \mu \mathrm{m}$ in diameter \\
\hline Reference & This study & Lin \& Nelson 2009 & Lin \& Nelson 2009 & Lin \& Nelson 2009 \\
\hline
\end{tabular}




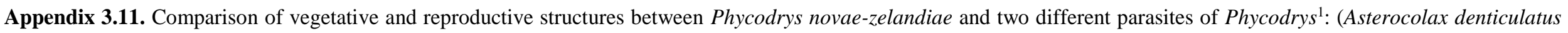
and Asterocolax gardneri) $*=$ indicates that more host species are known but from different genera.

\begin{tabular}{|c|c|c|c|}
\hline & Asterocolax denticulatus & Asterocolax gardneri & $\begin{array}{l}\text { Phycodrys novae- } \\
\text { zelandiophila sp. nov. }\end{array}$ \\
\hline $\operatorname{Host}(\mathrm{s})$ & Phycodrys fimbriata (Kuntze) Kylin & $\begin{array}{l}\text { Phycodrys isabelliae R.E. Norris \& } \\
\text { M.J. Wynne, Phycodrys setchellii } \\
\text { Skottsb.* }\end{array}$ & Phycodrys novae-zelandiae \\
\hline Distribution & Tyuleny Island (as Robben Island), Russia & California, USA & New Zealand \\
\hline Thallus (width) & - & $2-3 \mathrm{~mm}$ & $1-2 \mathrm{~mm}$ \\
\hline Pigmentation & - & Yes & Yes \\
\hline \multicolumn{4}{|l|}{ Tetrasporophyte } \\
\hline Division & Tetrad or obliquely cruciate & - & Tetrahedrally \\
\hline Shape & Oblong-obovate & - & Globose \\
\hline Location & Scattered over the surface & Scattered over the surface & Scattered over the surface \\
\hline Size & - & - & $40 \times 32 \mu \mathrm{m}$ \\
\hline \multicolumn{4}{|l|}{ Female gametophyte } \\
\hline Cystocarp size & $500 \times 840 \mu \mathrm{m}$ in diameter & - & $430 \times 530 \mu \mathrm{m}$ in diameter \\
\hline $\begin{array}{l}\text { Cystocarps on } \\
\text { branch }\end{array}$ & One, rarely two & One, born in chains & One, born in chains \\
\hline References & Tokida 1934 & Setchell 1923; Wagner 1954 & This study \\
\hline
\end{tabular}

${ }^{1}$ Exclusion of Choreocolax rabenhorstii growing on Phycodrys rubens (L.) Batters for lack of morphological data. 
Appendix 3.12. Te Papa voucher specimens of Cladhymenia oblongifolia with Cladhymenia oblongifoliophila in New Zealand, arranged from north to south.

\begin{tabular}{|c|c|c|c|c|}
\hline $\begin{array}{l}\text { WELT } \\
\text { voucher }\end{array}$ & $\begin{array}{l}\text { Collection } \\
\text { date }\end{array}$ & Location & Coordinates & Collector \\
\hline A13737a, b & 29.09 .1973 & Piha, Auckland, North Island & $36^{\circ} 57^{\prime} \mathrm{S}, 174^{\circ} 28^{\prime} \mathrm{E}$ & C. H. Hay \\
\hline A 17564 & 22.04 .1984 & Maketu Bay, Bay of Plenty, North Island & $37^{\circ} 45^{\prime} \mathrm{S}, 176^{\circ} 28^{\prime} \mathrm{E}$ & W. A. Nelson \\
\hline A025857 & 26.02 .1993 & Marlborough Sounds, D’Urville Island, South Island & $40^{\circ} 48^{\prime} \mathrm{S}, 173^{\circ} 47^{\prime} \mathrm{E}$ & W. A. Nelson \\
\hline A4332 & 18.03 .1971 & Lyall Bay, Wellington, North Island & $41^{\circ} 21^{\prime} \mathrm{S}, 174^{\circ} 48^{\prime} \mathrm{E}$ & A. N. Baker \\
\hline A17109a, b, c & 30.01 .1973 & Mangere Island, Chatham Islands & $44^{\circ} 16^{\prime} \mathrm{S}, 176^{\circ} 18^{\prime} \mathrm{W}$ & C. H. Hay \\
\hline
\end{tabular}


Appendix 3.13. Comparison of Cladhymenia oblongifolia and its parasite Cladhymenia oblongifoliophila.

\section{Cladhymenia oblongifoliophila Cladhymenia oblongifolia}

sp. nov.

\begin{tabular}{lll}
\hline $\begin{array}{l}\text { Thallus } \\
\text { Size }\end{array}$ & $2 \mathrm{~mm}$ in diameter \\
$\begin{array}{l}\text { Colouration } \\
\text { Female }\end{array}$ & Unpigmented & $\begin{array}{l}30 \mathrm{~cm} \text { high } \\
\text { gametophytes }\end{array}$ \\
Location & On branches & \\
$\begin{array}{l}\text { Tetrasporangia } \\
\text { Form }\end{array}$ & Tetrahedrally divided & On proliferations \\
Location & On branches & Tetrahedrally divided \\
Reference & This study & On branches \\
\hline
\end{tabular}


Appendix 3.14. Te Papa voucher specimens of Blastophyllis calliblepharoides and Blastophyllis hombroniana with the parasite Judithia parasitica from New Zealand, arranged north to south.

\begin{tabular}{|c|c|c|c|c|c|}
\hline Host species & $\begin{array}{l}\text { WELT } \\
\text { voucher } \\
\text { number }\end{array}$ & $\begin{array}{l}\text { Collection } \\
\text { date }\end{array}$ & Location & Coordinates & Collector \\
\hline $\begin{array}{l}\text { Blastophyllis } \\
\text { calliblepharoides }\end{array}$ & $\mathrm{A} 11368 \mathrm{~b} / \mathrm{c}$ & 23.12 .1976 & North side of Boat Harbour, Snares Island & $48^{\circ} 01^{\prime} \mathrm{S}, 166^{\circ} 36^{\prime} \mathrm{E}$ & C. D. Fenwick \\
\hline Blastophyllis & A1262 & & Banks Peninsula, South Island & $43^{\circ} 45^{\prime} \mathrm{S}, 72^{\circ} 55^{\prime} \mathrm{E}$ & Berggren \\
\hline \multirow[t]{14}{*}{ hombroniana } & A2833 & & Timaru, South Island & $44^{\circ} 24^{\prime} \mathrm{S}, 171^{\circ} 16^{\prime} \mathrm{E}$ & \\
\hline & A11547 & 10.02 .1981 & $\begin{array}{l}\text { Shag Point, Bay south of Boat Harbour, } \\
\text { North Otago, South Island }\end{array}$ & $45^{\circ} 28^{\prime} \mathrm{S}, 170^{\circ} 50^{\prime} \mathrm{E}$ & N. M. Adams \\
\hline & A2832 & & Dunedin, South Island & $45^{\circ} 53^{\prime} \mathrm{S}, 170^{\circ} 31^{\prime} \mathrm{E}$ & \\
\hline & A02126 & 07.1998 & Brighton, Otago, South Island & $45^{\circ} 57^{\prime} \mathrm{S}, 170^{\circ} 20^{\prime} \mathrm{E}$ & W. A. Nelson \\
\hline & A024349 & 08.12 .2008 & Brighton, Otago, South Island & $45^{\circ} 57^{\prime} \mathrm{S}, 170^{\circ} 20^{\prime} \mathrm{E}$ & R. D'Archino \\
\hline & A028700 & 12.03.1998 & Brighton, Otago, South Island & $45^{\circ} 57^{\prime} \mathrm{S}, 170^{\circ} 20^{\prime} \mathrm{E}$ & J. Broom \\
\hline & A028701 & 12.03.1998 & Brighton, Otago, South Island & $45^{\circ} 57^{\prime} \mathrm{S}, 170^{\circ} 20^{\prime} \mathrm{E}$ & J. Broom \\
\hline & A12937 & 03.03 .1982 & South end Tautuku Beach, South East & $46^{\circ} 36^{\prime} \mathrm{S}, 169^{\circ} 26^{\prime} \mathrm{E}$ & C. Hay \& \\
\hline & & & Otago, South Island & & P. Hay \\
\hline & A7530 & 22.11.1959 & Ringaringa, Stewart Island & $46^{\circ} 54^{\prime} \mathrm{S}, 168^{\circ} 8^{\prime} \mathrm{E}$ & E. A. Willa \\
\hline & A029648 & 06.10 .1994 & Ringaringa, Stewart Island & $46^{\circ} 54^{\prime} \mathrm{S}, 168^{\circ} 8^{\prime} \mathrm{E}$ & W. A. Nelson \\
\hline & A029649 & 06.10 .1994 & Ringaringa, Stewart Island & $46^{\circ} 54^{\prime} \mathrm{S}, 168^{\circ} 8^{\prime} \mathrm{E}$ & W. A. Nelson \\
\hline & A029650 & 06.10 .1994 & Ringaringa, Stewart Island & $46^{\circ} 54^{\prime} \mathrm{S}, 168^{\circ} 8^{\prime} \mathrm{E}$ & W. A. Nelson \\
\hline & A029651 & 06.10 .1994 & Ringaringa, Stewart Island & $46^{\circ} 54^{\prime} \mathrm{S}, 168^{\circ} 8^{\prime} \mathrm{E}$ & W. A. Nelson \\
\hline
\end{tabular}


A029786

A9457

06.10 .1994

01.1975

Ringaringa, Stewart Island

Sandy Beach, Enderby Island, Auckland

Islands

A16585
02.1985

Sandy

Islands $46^{\circ} 54^{\prime} \mathrm{S}, 168^{\circ} 8^{\prime} \mathrm{E}$

$50^{\circ} 30^{\prime} \mathrm{S}, 166^{\circ} 17^{\prime} \mathrm{E}$

W. A. Nelson

J. C. Yaldwyn

$50^{\circ} 30^{\prime} \mathrm{S}, 166^{\circ} 17^{\prime} \mathrm{E}$
J. C. Yaldwyn 
Appendix 3.15. Comparison of Judithia parasitica and its closest relative Judithia delicatissima.

Judithia parasitica sp. nov. Judithia delicatissima

Thallus

Size

$1 \times 1 \mathrm{~mm}$

$12-21 \times 4-10 \mathrm{~cm}$

Branching

One time

One or more times

Pigmentation

Light reddish

Light rose-red

Tetrasporangia

Form

Cruciate

Cruciate

Location

Scattered in branches

Scattered outer cortex

Size

$26 \times 13 \mu \mathrm{m}$

25-28 x 18-20 $\mu \mathrm{m}$

Reference

This study

D'Archino et al. 2016 
Freshwater, D. W. \& Rueness, J. 1994. Phylogenetic relationships of some European Gelidium (Gelidiales, Rhodophyta) species, based on $r b c \mathrm{~L}$ nucleotide sequence analysis. Phycologia 33:187-194.

Harper, J. T. \& Saunders, G. W.2001. The application of sequences of the ribosomal cistron to the systematics and classification of the florideophyte red algae (Florideophyceae, Rhodophyta). Cah. Biol. Mar. 42:25-38.

Lin, S. M. \& Nelson W. A. 2010. Systematic revision of the genus Phycodrys (Delesseriaceae, Rhodophyta) from New Zealand, with the descriptions of three new species, $P$. novaezelandiae sp. nov., P. franiae sp. nov. and P. adamsiae sp. nov. Eur. J. Phycol. 45:200214.

Kamiya, M., West, J. A. \& Hara, Y. 2011. Induction of apomixis by outcrossing between genetically divergent entities of Caloglossa leprieurii (Ceramiales, Rhodophyta) and evidence of hybrid apomicts in nature. J. Phycol. 47:753-762.

Kim, M. S., Kim, S. Y. \& Nelson, W. A. 2010. Symphyocladia lithophila sp. nov. (Rhodomelaceae, Ceramiales), a new Korean red algal species based on morphology and rbcL sequences. Bot. Mar. 53:233-241.

Nelson, W. A. 2013. New Zealand Seaweeds. Museum of New Zealand Te Papa Tongarewa, Wellington, New Zealand.

Wang, H. W., Kawaguchi, S. Horiguchi, T. \& Masuda, M. 2000. Reinstatement of Grateloupia catenata (Rhodophyta, Halymeniaceae) on the basis of morphology and $r b c \mathrm{~L}$ sequences. Phycologia 39:228-237. 
Appendix 4.1. Samples used for phylogenetic analysis.

$\operatorname{cox} 1$

Aiolocolax pulchellus Pocock

KF671160

Digenea arenahauriens C.W.Schneider, Hamzeh et G.W.Saunders

MG648076

Digenea cymatophilum (R.E.Norris) Díaz-Tapia et Maggs

HQ422981

Echinothamnion hystrix (Hook.f. et Harv.) Kylin

KU564426

Leptosiphonia schousboei (Thur.) Kylin

KF671176

Melanothamnus bajacali (Hollenb.) Díaz-Tapia et Maggs

HM573526

Melanothamnus harveyi (Bailey) Díaz-Tapia et Maggs

KJ202082

Melanothamnus japonicus (Harv.) Díaz-Tapia et Maggs

KM894048

KX265515

Melanothamnus pseudovillum (Hollenb.) Díaz-Tapia et Maggs

HM573524

Melanothamnus somalensis Bornet et Falkenb.

KU564334

Melanothamnus sphaerocarpa (Børgesen) Díaz-Tapia et Maggs

KX265541

Melanothamnus strictissima (Hook.f. et Harv.) Díaz-Tapia et Maggs

HM573534

Melanothamnus teradomariensis (Noda) Díaz-Tapia et Maggs

KX265517

Melanothamnus tongatensis (Harv. ex Kütz.) Díaz-Tapia et Maggs

HM573518

Melanothamnus upolensis (Grunow) Díaz-Tapia et Maggs

HQ422784

Polyostea arctica (J.Agardh) Savoie et G.W.Saunders

JX571980

Polysiphonia atlantica Kapraun et J.N.Norris

HM573539

Polysiphonia caespitosa (Pocock) Hollenb.

KF671181

Polysiphonia binneyi Harv.

KY656536

Polysiphonia brodiei (Dillwyn) Spreng.

KJ961047

Polysiphonia confusa Hollenb.

KR080578

Polysiphonia devoniensis Maggs et Hommers.

KF671186

Polysiphonia echinata Harv.

HM573559

Polysiphonia elongata (Huds.) Spreng.

KJ961050

Polysiphonia fibrillosa (Dillwyn) Spreng.

KJ961052

Polysiphonia havanensis Mont.

HM573522

Polysiphonia hemisphaerica Aresch.

HQ412544

Polysiphonia homoia Setch. et N.L.Gardner

HM573507

Polysiphonia morrowii Harv.

HM573540

Polysiphonia pacifica Hollenb.

KM254964

Polysiphonia paniculata Mont.

KR090577 


\begin{tabular}{|c|c|}
\hline Polysiphonia pentamera Hollenb. & HM573510 \\
\hline Polysiphonia schneideri B.Stuercke et Freshwater & HM573514 \\
\hline Polysiphonia scopulorum Harv. & HM573535 \\
\hline Polysiphonia sertularioides (Gratel.) J.Agardh & HM573519 \\
\hline Polysiphonia stricta (K.Mert ex Dillwyn) Grev. & KJ961053 \\
\hline Polysiphonia subtilissima Mont. & JX294916 \\
\hline Symphyocladia latiuscula (Harv.) Yamada & KC782862 \\
\hline Symphyocladia dendroidea (Mont.) Savoie et G.W.Saunders & KU564383 \\
\hline Tolypiocladia glomerulata (C.Agardh) F.Schmitz & HQ423106 \\
\hline \multirow[t]{4}{*}{ Vertebrata aterrima } & HM573536 \\
\hline & HM573537 \\
\hline & MH670285 \\
\hline & MH670286 \\
\hline \multirow[t]{3}{*}{ Vertebrata aterrimophila } & MH670282 \\
\hline & MH670283 \\
\hline & MH670284 \\
\hline Vertebrata byssoides (Gooden. et Woodw.) Kuntze & KJ960354 \\
\hline Vertebrata constricta (Womersley) Díaz-Tapia et Maggs & HM573542 \\
\hline Vertebrata fruticulosa (Wulfen) Kuntze & KJ960346 \\
\hline Vertebrata fucoides (Huds.) Kuntze & HM5734496 \\
\hline Vertebrata hypnoides (Welw.) Kuntze & KF671184 \\
\hline Vertebrata isogona (Harv.) Díaz-Tapia et Maggs & HM573541 \\
\hline Vertebrata lanosa (L.) T.A.Chr. & KX687880 \\
\hline Vertebrata nigra (Huds.) Díaz-Tapia et Maggs & KC130873 \\
\hline Vertebrata tripinnata (Harv.) Kuntze & KC130871 \\
\hline Vertebrata reptabunda (Suhr) Díaz-Tapia et Maggs & KF671184 \\
\hline
\end{tabular}


Appendix 4.2. Te Papa vouchers of Vertebrata aterrimophila on its host Vertebrata aterrima from New Zealand, arranged north to south.

\begin{tabular}{llll}
\hline $\begin{array}{l}\text { Te Papa } \\
\text { voucher }\end{array}$ & Collection date & Location & Collectors \\
\hline A022101 & 06.10 .1991 & Pouawa, East Coast & W. A. Nelson \\
A19890 & 05.10 .1991 & Mahia Peninsula & W. A. Nelson \\
A19887 & 05.10 .1991 & Mahia Peninsula, & W. A. Nelson \\
& & East of Aurora Point & \\
A3773a & 24.07 .1970 & Island Bay, & N. M. Adams \\
& & Wellington & \\
A025251 & 12.06 .1998 & Island Bay, & W. A. Nelson \\
& & Wellington & \\
A16028 & 19.03 .1984 & Kairākau, Hawkes & W. A. Nelson \\
& & Bay & \\
A19089 & 06.04 .1990 & Middle Trio Island, & C. Duffy \\
& & Trio Islands & \\
\hline
\end{tabular}


Appendix 5.1. Sequences and whole organelle genomes plus associated GenBank Accession numbers used for molecular analysis of parasite, host species and representatives within the Florideophytes. Sequences and whole organelle genomes newly obtained during this study are highlighted in bold.

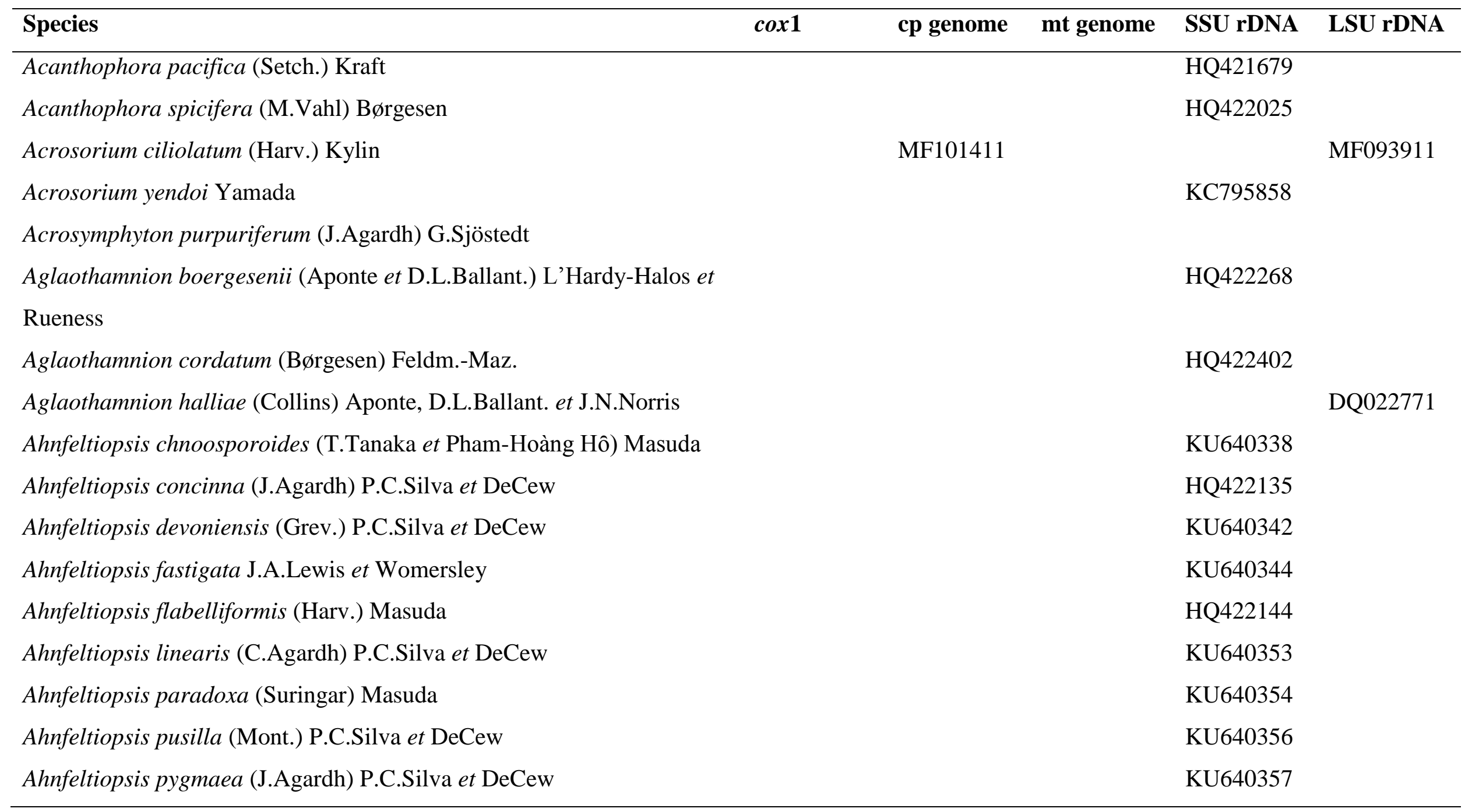


Amansia fimbrifolia (R.E.Norris) L.E.Phillips

Amansia glomerata C.Agardh

Antithamnion antillanum Børgesen

Antithamnion decipiens (J.Agardh) Athanas.

Antithamnionella spiirographidis (Schiffn.) E.M.Woll.

Antithamnion erucacladellum R.E.Norris

Antithamnion sparsum Tokida

Asparagopsis taxiformis (Delile) Trevis.

Asterfilopsis centralis M.S.Calderon et S.M.Boo

Asterfilopsis disciplinalis (Bory) M.S.Calderon et S.M.Boo

Asterfilopsis furcellata (C.Agardh) P.C.Silva et DeCew

Asterfilopsis piurana M.S.Calderon et S.M.Boo

Besa catenata (Yendo) M.S.Calderon et S.M.Boo

Besa divaricata (Holmes) M.S.Calderon et S.M.Boo

Besa leptophylla (J.Agardh) M.S.Calderon et K.A.Miller

Betaphycus gelatinus (Esper) Doty ex P.C.Silva

Bostrychia moritziana (Sond. ex Kütz.) J.Agardh

Bostrychia simpliciuscula Harv. ex J.Agardh

Bostrychia tenella (J.V.Lamour.) J.Agardh

Botryocladia occidentalis (Børgesen) Kylin
HQ422093

HQ421684

AF251512

HQ422561

HQ422454

DQ022761

HQ422565

AY168238

NC031148 KJ398158

KU640365

KU640360

KU640362

KU640363

KU749583

HQ421815

KU749585

KU640351

MF680514

MF101419

MF101421

MF101417 
Botryocladia pyriformis (Børgesen) Kylin

Botryocladia skottsbergii (Børgesen) Levring

Botryocladia spinulifera W.R.Taylor et I.A.Abbott

Botryocladia wynnei D.L.Ballant.

Bryothamnion seaforthii (Turner) Kütz.

Calliarthron tubercolosum (Postels et Rupr.) E.Y.Dawson

Callithamnion corymnosum (Sm.) Lyngb.

Caloglossa adhaerens R.J.King et Puttock

Caloglossa beccarii (Zanardini) De Toni

Caloglossa bengalensis (G.Martens) R.J.King et Puttock

Caloglossa continua (Okamura) R.J.King et Puttock

Caloglossa intermedia M.Kamiya et J.A.West

Caloglossa leprieurii (Mont.) G.Martens

Caloglossa monosticha M.Kamiya

Caloglossa ogasawaraensis Okamura

Caloglossa postiae M.Kamiya et R.J.King

Caloglossa rotundata M.Kamiya

Caloglossa saigonensis Tanaka et Pham-Hoàng Hô

Caloglossa stipitata E.Post
KT154739

HQ422497

EU670591

EU670589

NC021075

NC021075 NC027061

KC795866

AF522199

MF101422

AF522208

MF093916

AF522210

AF5522212

MF101418

MF093917

AF522204

AF522217

AF522213

MF093918

AF522239 AF251514

AF522242

AF522248

AF522244

AF522247 
Ceramium affine Setch. et N.L.Gardner

AF460859

Ceramium codii (H.Richards) Feldm.-Maz.

HQ421967

Ceramium diaphanum (Lightf.) Roth

KC795860

DQ022760

Ceramium dumosertum R.E.Norris et I.A.Abbott

HQ421685

Ceramium hyalacanthum (Kütz.) Sond.

Ceramium japonicum Okamura

HQ422526

Ceramium kondoi Yendo

NC031174 KJ398159 KC795870

KC795848

Ceramium nakamurae E.Y.Dawson

HQ421934

Ceramium sungminbooi Hughey et G.H.Boo

NC031211 KU145004

Ceramium tenerrimum (G.Martens) Okamura

KC795867

AF460867

Ceramium womersleyi R.E.Norris et I.A.Abbott

HQ422536

HQ422496

Champia harveyana D.L.Ballant. et C.Lozada-Troche

FJ212289

Champia parvula (C.Agardh) Harv.

HQ422011

Champia vieillardii Kütz.

HQ422541

FJ212290

Chiharaea bodegensis H.W.Johans.

KC157588

$\mathrm{KC} 157576$

Chondracanthus acucularis (Roth) Fredericq

HQ421761

Chondracanthus intermedius (Suringar) Hommers.

KU640368

Chondracanthus tenellus (Harv.) Hommers.

HQ422443

Chondria crassicaulis Harv.

KC795859

Chondria dangeardii E.Y.Dawson

HQ422160 
Chondria spp.

Chondrophycus cartilagineus (Yamada) Garbary et J.T.Harper

Chondrophycus dotyi (Y.Saito) K.W.Nam

Chondrophycus succisus (Cribb) K.W.Nam

Chondrophycus undulatus (Yamada) Garbary et J.T.Harper

Chondrus crispus Stackh.

Chondrus ocellatus Holmes

Chrysymenia brownii (Harv.) De Toni

$\stackrel{\circ}{\circ}$

Chrysymenia kaernbachii Grunow

Chrysymenia littleriana J.N.Norris et D.L.Ballant.

Chrysymenia nodulosa J.N.Norris et D.L.Ballant.

Chrysymenia ornata (J.Agardh) Kylin

Chrysymenia planifrons (Melvill) J.Agardh

Chrysymenia pseudoventricosa W.E.Schmidt, Gurgel et Fredericq

Chrysymenia ventricosa (J.V.Lamour.) J.Agardh

Cliftonaea pectinata (Harv.) Harv.

Coelarthrum cliftonii (Harv.) Kylin

Coeloseira compressa Hollenb.

Coelothrix irregularis (Harv.) Børgesen
MF101429

MF101431

MF101451

\begin{tabular}{|c|c|c|c|}
\hline & & HQ421772 & \\
\hline & & HQ421698 & \\
\hline & & HQ422366 & \\
\hline & & HQ421943 & \\
\hline NC020795 & NC001677 & KU640369 & DQ317002 \\
\hline & & HQ421762 & DQ316985 \\
\hline & & KT154734 & \\
\hline & & HQ422492 & \\
\hline & & KT154728 & \\
\hline & & KT154724 & \\
\hline & & KT154735 & \\
\hline & & KT154725 & \\
\hline & & KT154727 & \\
\hline & & KT154732 & \\
\hline MF101450 & & & \\
\hline & & HQ421847 & EU670595 \\
\hline NC030338 & KU053956 & & \\
\hline & & HQ422007 & FJ173068 \\
\hline
\end{tabular}


Corallina officinalis L.

Corallophila huysmansii (Weber Bosse) R.E.Norris

Cryptonemia yendoi Weber Bosse

Cubiculosporum koronicarpis Kraft

Dasya anastomosans (Weber Bosse) M.J.Wynne

Dasya binghamiae A.Millar

Dasya corymbifera J.Agardh

Dasya iridescens (Schlech) A.Millar et I.A.Abbott

Dasya kristeniae I.A.Abbott

Dasya murrayana I.A.Abbott et A.Millar

Dasya naccarioides Harv.

Dasyclonium flaccidium (Harv.) Kylin

Dictyomenia sonderi Harv.

Digenea simplex (Wulfen) C.Agardh

Diplothamnion jolyi C.Hoek

Dipterocladia arabiensis M.J.Wynne et Y.S.D.M.de Jong

Dipterosiphonia australica Womersley

Dudresnaya hawaiiensis R.K.S.Lee

Eucheuma denticulatum (Burm.f.) Collins et Herv.

Euptilocladia magruderi I.A.Abbott et R.E.Norris

Gelidiella acerosa (Forssk.) Feldmann et Hamel
KU641510

HQ421935

HQ422439

HQ421763

HQ422407

NC031161 KX247283

HQ422118

HQ422246

HQ421889

HQ422216

MF101436

MF101455

MF101455

MF101465

HQ422542

MF101408

NC035288

HQ421771

MF680515

HQ422348

GAU60342 AF296518 
Gelidiella machrisiana E.Y.Dawson

Gelidium arborescens N.L.Gardner

Gelidium crinale f. luxurians

Gelidium elegans Kütz.

Gelidium floridanum W.R.Taylor

Gelidium galapagense W.R.Taylor

Gelidium isabelae W.R.Taylor

Gelidium japonicum (Harv.) Okamura

Gelidium pacificum Okamura

Gelidium pluma Bornet ex Loomis

న

Gelidium pulchellum (Turner) Kütz.

Gelidium reediae Loomis

Gelidium sclerophyllum W.R.Taylor

Gelidium sinicola N.L.Gardner

Gelidium vagum Okamura

Gelinaria ulvoidea Sond.

Gibsmithia dotyi Kraft et R.W.Ricker

Gibsmithia hawaiiensis Doty

Gloiocladia iyoensis (Okamura) R.E.Norris

Gracilaria abbottiana M.D.Hoyle

Gracilaria chilensis C.J.Bird, McLachlan et E.C.Oliveira
HQ421741

KX427228

KX427229

NC029858 KF290995

AF296510

GFU60351

KX427230

KX427231

AF521185

AB017667

HM629871

HQ422413

AF296509

HQ421956

KX427232

KX427233

NC029859 KC875854

GQ471910

HQ421756

HQ422508

HQ422184

HQ422425 
Gracilaria chouae J.F.Zhang et B.M.Xia

Gracilaria coronopifolia J.Agardh

Gracilaira dawsonii M.D.Hoyle

Gracilaria dotyi M.D.Hoyle

Gracilaria epihippisora M.D.Hoyle

Gracilaria firma C.F.Chang et B.M.Xia

Gracilaria parvispora I.A.Abbott

Gracilaria salicornia (C.Agardh) E.Y.Dawson

Gracilaria tenuistipitata C.F.Chang et B.M.Xia

$\stackrel{+}{+}$

Gracilaria tikvahiae McLachland

Gracilaria vermiculophylla (Ohmi) Papenf.

Gracilariophila oryzoides Setch. et H.L.Wilson

Gracilariopsis andersonii (Grunow) E.Y.Dawson

Gracilariopsis chorda (Holmes) Ohmi

Gracilariopsis lemaneiformis (Bory de Saint-Vincent) E.Y.Dawson

Grateloupia angusta (Okamura) Kawag. et H.W.Wang

Grateloupia catenata Yendo

Grateloupia filicina (J.V.Lamour.) C.Agardh

Grateloupia hawaiiana E.Y.Dawson
MF351970

HQ421829

HQ422426

HQ421977

HQ422428

NC033877

KF861575

HQ422206

$\mathrm{NC} 023785$

AY673996

HQ422432 GRCEARA

KJ526626

HQ586059

HQ586060

KX284722 KC875851

NC029644 JQ071938

HQ422429 KC577234

KP330491

KC875853

HQ422450

HQ422213

HQ422300 


\begin{tabular}{|c|c|c|c|c|}
\hline Grateloupia ovata Womersley et J.A.Lewis & & & GQ471911 & \\
\hline Grateloupia phuquocensis Tanaka et Pham-Hoàng Hô & & & HQ421682 & \\
\hline Grateloupia taiwanensis Showe M.Lin et H.Y.Liang & KC894740 & KM999231 & & \\
\hline Griffithsia heteromorpha Kütz. & & & HQ422062 & \\
\hline Griffithsia schousboei Mont. & & & HQ421680 & \\
\hline Gymnogongrus crenulatus (Turner) J.Agardh & & & KU640371 & \\
\hline Gymnogongrus griffithsiae (Turner) Mart. & & & KU640372 & \\
\hline Gymnogongrus guadalupensis E.Y.Dawson & & & KU640373 & \\
\hline Gymnothamnion elegans (Schousb. ex C.Agardh) J.Agardh & & & HQ422562 & \\
\hline Halymenia maculata J.Agardh & & & GQ471913 & \\
\hline Halymenia plana Zanardini & & & GQ471914 & HPU33133 \\
\hline Halymenia pseudofloresii Collins et M.Howe & & & GQ471915 & \\
\hline Herposiphonia versicolor (Hook.f. et Harv.) Reinbold & MF101434 & & & \\
\hline Heterosiphonia crispella (C.Agardh) M.J.Wynne & & & HQ422436 & \\
\hline Heterosiphonia japonica Yendo & & & KC795855 & \\
\hline Hypnea cervicornis J.Agardh & & & HQ421782 & \\
\hline
\end{tabular}


Hypnea chordacea Kütz.

Hypnea musciformis (Wulfen) J.V.Lamour.

Hypnea nidifica J.Agardh

Hypnea pannosa J.Agardh

Hypnea spinella (C.Agardh) Kütz.

Hypnea valentiae (Turner) Mont.

Hypneocolax stellaris Børgesen

Janczewskia hawaiiana Apt

Jania sagittata (J.V.Lamour.) Blainv.

Kallymenia sessilis Okamura

Kallymenia thompsonii I.A.Abbott et McDermid

Kappaphycus alvarezii (Doty) Doty ex P.C.Silva

Kappaphycus striatus (F.Schmitz) Doty ex P.C.Silva

Kuetzingia canaliculata (Grev.) Sond.

Laurencia brachyclados Pilg.

Laurencia decumbens Kütz.

Laurencia galtsoffii M.Howe

Laurencia majuscula (Harv.) A.H.S.Lucas

Laurencia mcdermidiae I.A.Abbott

Laurencia nidifica J.Agardh

Laurencia nipponica Yamada
HQ421792

HQ421809

HQ421816

HQ421823

HQ421827

HQ421828

HQ422549

HQ422189

KC157591

KC157580

HQ421882

HQ422445

NC036637 KU885455

KF833365

MF101449

HQ422341

HQ421722

HQ421781

HQ421712

HQ421713

HQ421726

KC795864 
Laurencia obtusa (Huds.) J.V.Lamour.

Laurencia sp.

Laurencieae $s p$.

Laurencia tenera C.K.Tseng

Laurenciella marilzae (Gil-Rodríguez, Sentíes, Díaz-Larrea, Cassano et

M.T.Fujii) Gil-Rodríguez, Sentíes, Díaz-Larrea, Cassano et M.T.Fujii

Lejolisia pacifica Itono

Leveillea jungermannioides (K.Hering et G.Martens) Harv.

Lomentaria hakodatensis Yendo

Lophocladia kipukaia Schlech

Lophocladia kuetzingii (Kuntze) P.C.Silva

Martensia flabelliformis Harv. ex J.Agardh

Martensia fragilis Harv.

Mastocarpus papillatus (C.Agardh) Kütz.

Mazzaella japonica (Mikami) Hommers.

Mazaella volans (C.Agardh) Fredericq

Melaconema minimum Hollenb.

Melanothamnus ferulacea (Suhr ex J.Agardh) Díaz-Tapia et Maggs

Melanothamnus harveyi (J.W.Bailey) Díaz-Tapia et Maggs

Melanothamnus japonicus (Harv.) Díaz-Tapia et Maggs

Melanothamnus upolensis (Grunow) Díaz-Tapia et Maggs
KC795869

LN833431

MF101412

HQ422278

MF101410

HQ421689

HQ422288

HQ422104

HQ422350

MF101448

HQ421860

HQ422500

NC031167 KX525587

KU640374

HQ421873

HQ422545

HM560645

MF101437

KC795854

AB219908

HQ421932 
Membranoptera platyphylla (Setch. et N.L.Gardner) Kylin

Membranoptera tenuis Kylin

Membranoptera weeksiae Setch. et N.L.Gardner

Millerella pannosa (Feldmann) G.H.Boo et L.Le Gall

Monosporus indicus Børgesen

Neorhodomela munita (Perest.) Masuda

Neosiphonia tepida (Hollenb.) S.M.Guim. et M.T.Fujii

Ophidocladus simpliciuscula (P.Crouan et H.Crouan) Falkenb.

Osmundaria fimbriata (J.V.Lamour.) R.E.Norris

Osmundaria obtusiloba (C.Agardh) R.E.Norris

Pachymenia lusoria (Grev.) J.Agardh

Pachymenia orbicularis (Zanardini) Setch. et N.L.Gardner

Palisada crustiformans (McDermid) A.R.Sherwood, Kurihara et

K.W.Nam

Palisada parvipapillata (C.K.Tseng) K.W.Nam

Palisada sp.

Palisada yamadana (M.Howe) K.W.Nam

Peleophycus multiprocarpium I.A.Abbott

Perikladosporon percurrens (E.Y.Dawson) Athanas.

Periphykon beckeri Weber Bosse

Peyssonnelia conchicola Picc. et Grunow
NC032041

NC032399

NC032396

AF308799

HQ422554

KC795863

HQ421963

MF101440

MF101415

HQ422217

GQ471917

GQ471918

HQ421721

HQ422036

MF101453

HQ421780

HQ421875

HQ422566

MF101413 


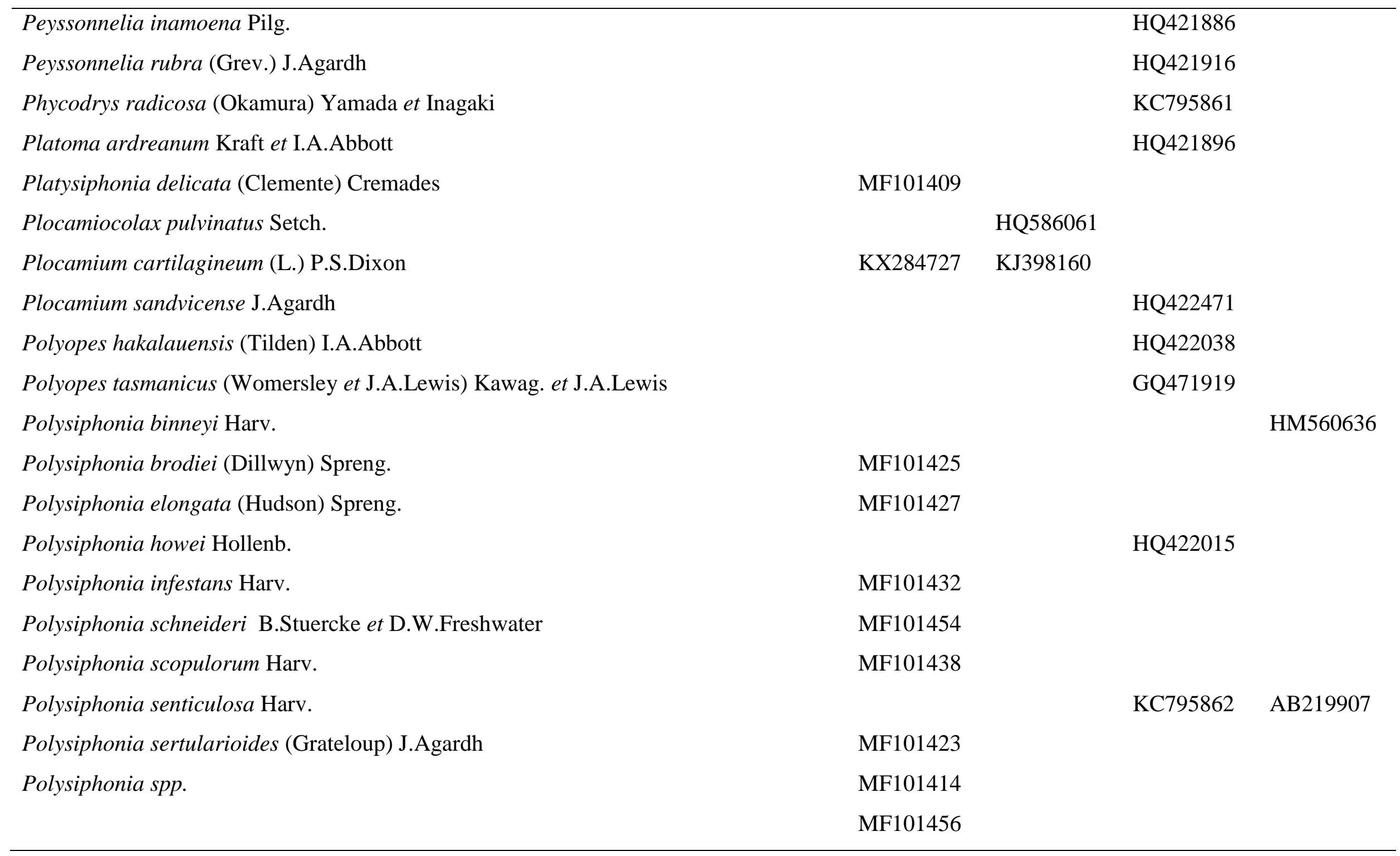


Polysiphonia stricta (Mertens ex Dillwyn) Grev.

Predaea laciniosa Kraft

Predaea weldii Kraft et I.A.Abbott

Pterocladia lucida Group I

Pterocladia lucida Group II

$\stackrel{N}{O}$

Pterocladiella bartlettii (W.R.Taylor) Santel.

Pterocladiella beachiae Freshwater

Pterocladiella caerulescens (Kütz.) Santel. Hommers.

Pterocladiella capillacea (S.G.Gmel.) Santel. et Hommers.

\section{MF101428}

HQ422487

HQ422488

XXXXXX

KT443928

KT443932

KT443933

KT443936

KT443937

XXXXXX XXXXXX

XXXXXX XXXXXX

KT443939

KT443942

KT443943

KT443946

KT443950

HM629885
AF296515

AF296514

AF296513

EF191192

AB031301

KX427235 AF308797

AB017672

Pterocladiella media (E.Y.Dawson) G.H.Boo et K.A.Miller 
Pterocladiella musciformis (W.R.Taylor) G.H.Boo et K.A.Miller

Pterocladiophila hemisphaerica

Pterothamnion yezoense (Inagaki) Athanas. et Kraft

Ptilophora diversifolia (Suhr) Papenf.

Ptilophora hildebrantii (Hauck) R.E.Norris

Ptilophora mediterranea (H.Huvé) R.E.Norris

Ptilophora pinnatifida J.Agardh

Ptilophora prolifera (Harv.) J.Agardh

Ptilophora pterocladiodes Andriam.

Ptilophora rhodoptera R.E.Norris

$\stackrel{N}{=}$

Ptilophora scalaramosa (Kraft) R.E.Norris

Ptilophora subcostata (Okamura) R.E.Norris

Rhodolachne decussata M.J.Wynne

Rhodomela confervoides (Huds.) P.C.Silva

Rhodymenia californica Kylin

Rhodymenia corallina (Bory) Grev.

Rhodymenia pseudopalmata (J.V.Lamour.) P.C.Silva

Schimmelmannia schousboei (J.Agardh) J.Agardh

Schizymenia dubyi (Chauvin ex Duby) J.Agardh

Schottera koreana M.S.Calderon, T.H.Seo et S.M.Boo

Schottera nicaeensis (J.V.Lamour. ex Duby) Guiry et Hollenb.

\section{KX427236}

XXXXXX

XXXXXX

$\mathrm{XXXXXX}$

XXXXXX

KC795865

AF521182

AF521178

AF521179

AF521180

PPU60345

AF296511

AF521181

AF521183

AF296512

EF191195

PSU60348

HQ422564

MF101424

KT154743

KT154742

KX284709 KC875852

KX284711 KJ398162

KX284712 KJ398163 


\begin{tabular}{|c|c|c|c|c|}
\hline Sebdenia flabellata (J.Agardh) P.G.Parkinson & KX284713 & KJ398164 & & \\
\hline Sonderella linearis (Harv.) F.Schmitz & MF101445 & & & \\
\hline Spirocladia barodensis Børgesen & & & HQ422437 & \\
\hline Symphyocladia dendroidea (Mont.) Savoie et G.W.Saunders & MF101420 & & & \\
\hline Symphyocladia latiuscula (Harv.) Yamada & & & KC795850 & \\
\hline Tayloriella dictyurus (J.Agardh) Kylin & & & HQ422440 & \\
\hline Thaumatella adunca (J.Agardh) M.J.Parsons et Womersley & MF101447 & & & \\
\hline Thuretia quercifolia Desne. & MF101442 & & & \\
\hline Tolypiocladia glomerulata (C.Agardh) F.Schmitz & MF101467 & & HQ422440 & MF093960 \\
\hline Vertebrata isogona (Harv.) Díaz-Tapia et Maggs & MF101433 & & & \\
\hline Vertebrata lanosa & KP308097 & NC032003 & & \\
\hline Vertebrata thuyoides (Harv.) Kuntze & MF101426 & & & \\
\hline Wrangelia elegantissima R.E.Norris & & & HQ422251 & \\
\hline
\end{tabular}


Appendix 5.2. Plastid protein coding genes, tRNA and rRNA in alphabetical order by functional group with gene length in bp and AT content in percentage in Pterocladiophila hemisphaerica and Pterocladia lucida.$-=$ missing in the plastid genome.

\section{Pterocladiophila hemisphaerica Pterocladia lucida

Length (bp) AT content Length AT content \\ $(\%) \quad(\mathrm{bp}) \quad(\%)$}

\section{Protein coding genes}

ATP synthesis coupled

proton transport

atp $\mathrm{A}$
$\operatorname{atp} \mathrm{B}$
atpD
atpE
atpF
atpG
atpH
atp $\mathrm{I}$

$1512 \quad 65.3$

$1419 \quad 64.6$

$555 \quad 74.1$

$405 \quad 67.9$

$534 \quad 68.5$

$480 \quad 69.8$

$249 \quad 59.0$

$741 \quad 68.2$

Acyl carrier protein

$\begin{array}{lllll}a c p \mathrm{P} & 258 & 79.5 & 258 & 65.1\end{array}$

Biosynthetic processes

$\begin{array}{llll}\arg \mathrm{B} & - & 855 & 70.1 \\ c a r \mathrm{~A}^{2} & - & 1173 & 71.4 \\ g l t \mathrm{~B}^{2} & - & 4596 & 66.7 \\ i l v \mathrm{~B} & - & 1770 & 66.8 \\ i l v \mathrm{H} & - & 534 & 69.7 \\ m o e \mathrm{~B} & - & 1089 & 73.9 \\ t h i \mathrm{G} & - & 819 & 66.4\end{array}$

Cell division
$f t s \mathrm{H}^{7}$
1803
74.4
$1881 \quad 64.6$

Cell redox homeostasis

bas 1

$600 \quad 69.2$

Cytochrome complex

assembly

$\operatorname{ccs} \mathrm{A}$

924

71.3 


$c c s 1$
$d s b \mathrm{D}^{3}$

1317

74.9

723

73.3

DNA replication

dna $\mathrm{B}$

1773

78.0

1803

76.2

Fatty acid biosynthesis

$\operatorname{acc} \mathrm{A}$

$\operatorname{acc} \mathrm{B}$

$a c c \mathrm{D}$

$f a b \mathrm{H}$

Glycolytic processes

odp $\mathrm{A}$

odp $\mathrm{B}$

$\operatorname{pgm}^{7}$

981

342

816

1011

996

984

1251

syh

Iron-sulfur cluster transfer

orf114

pet $\mathrm{F}$

sufB

sufC

Metabolic processes

$c l p \mathrm{C}$

$\operatorname{trp} \mathrm{G}$

$\operatorname{trx} \mathrm{A}^{8}$

Oxidation-reduction

processes

ftrB 345

297

1449

741

2466

582
70.9

972

66.7

73.7

71.4

71.8

68.7

1029

978

1536

864

1005

68.5

\author{
1536
}

$1245 \quad 72.2$

73.8

74.8

69.0

297

65.3

72.6

$1458 \quad 69.0$

75.8

753

71.0

Phenylalanyl-tRNA

amnioacylation

$$
s y f \mathrm{~B}
$$

69.2

71.1

2472

64.9

573

71.0

333

66.1

351

66.7

Photosynthetic processes

$$
\begin{aligned}
& \operatorname{apc\mathrm {A}^{1,3}} \\
& \operatorname{apc\mathrm {B}^{1,3}}
\end{aligned}
$$

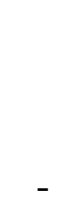




\begin{tabular}{|c|c|c|c|}
\hline$a p c \mathrm{D}^{1,3}$ & - & 486 & 68.9 \\
\hline $\operatorname{apc} \mathrm{E}^{1,3}$ & - & 2652 & 68.9 \\
\hline$a p c \mathrm{~F}$ & - & 510 & 72.2 \\
\hline chll & - & 1062 & 65.7 \\
\hline$c b b \mathrm{X}$ & - & 897 & 67.3 \\
\hline$c p c \mathrm{~A}^{1,3}$ & - & 489 & 64.0 \\
\hline$c p c \mathrm{~B}^{1,3}$ & - & 519 & 62.8 \\
\hline$c p c \mathrm{G}$ & - & 696 & 68.1 \\
\hline cpe $^{1,3}$ & - & 495 & 62.8 \\
\hline cpe $\mathrm{B}^{1,3}$ & - & 534 & 62.4 \\
\hline$p b s \mathrm{~A}^{10}$ & - & 696 & 70.5 \\
\hline $\operatorname{pet} \mathrm{A}^{3}$ & - & 957 & 70.0 \\
\hline $\operatorname{pet} \mathrm{B}^{11}$ & - & 648 & 65.6 \\
\hline pet $\mathrm{D}$ & - & 483 & 63.4 \\
\hline $\operatorname{pet} \mathrm{G}^{3}$ & - & 114 & 63.2 \\
\hline pet $\mathbf{J}$ & - & 324 & 67.3 \\
\hline $\operatorname{pet} \mathrm{L}^{3}$ & - & 96 & 75.0 \\
\hline $\operatorname{pet} \mathrm{M}^{3}$ & - & 99 & 69.7 \\
\hline $\operatorname{pet} \mathrm{N}^{3}$ & - & 90 & 58.9 \\
\hline pre $\mathrm{A}^{9}$ & - & 972 & 70.5 \\
\hline$p s a \mathrm{~A}^{1}$ & - & 2259 & 63.8 \\
\hline$p s a \mathrm{~B}^{1}$ & - & 2205 & 64.1 \\
\hline$p s a \mathrm{C}$ & - & 246 & 58.9 \\
\hline$p s a \mathrm{D}$ & - & 426 & 66.2 \\
\hline$p s a \mathrm{E}$ & - & 186 & 71.5 \\
\hline$p s a \mathrm{~F}$ & - & 558 & 66.1 \\
\hline$p s a \mathrm{I}$ & - & 111 & 68.5 \\
\hline$p s a \mathrm{~J}$ & - & 129 & 74.4 \\
\hline psaK & - & 276 & 65.9 \\
\hline$p s a \mathrm{~L}$ & - & 453 & 64.9 \\
\hline psaM & - & 93 & 73.1 \\
\hline$p s b \mathrm{~A}^{1,6}$ & - & 1083 & 62.4 \\
\hline$p s b \mathrm{~B}^{1}$ & - & 1530 & 60.8 \\
\hline$p s b C^{1}$ & - & 1449 & 61.0 \\
\hline
\end{tabular}




\begin{tabular}{|c|c|c|c|c|}
\hline$p s b \mathrm{D}^{1}$ & - & & 1056 & 61.3 \\
\hline$p s b \mathrm{E}$ & - & & 255 & 63.4 \\
\hline$p s b \mathrm{~F}$ & - & & 135 & 67.4 \\
\hline$p s b \mathrm{H}$ & - & & 204 & 69.6 \\
\hline$p s b \mathrm{I}$ & - & & 117 & 75.2 \\
\hline$p s b \mathbf{J}$ & - & & 120 & 62.5 \\
\hline$p s b \mathrm{~K}$ & - & & 138 & 66.7 \\
\hline$p s b \mathrm{~L}$ & - & & 117 & 70.9 \\
\hline$p s b \mathrm{~N}$ & - & & 132 & 70.5 \\
\hline$p s b \mathrm{~T}$ & - & & 96 & 71.9 \\
\hline$p s b \mathrm{~V}$ & - & & 486 & 67.9 \\
\hline$p s b \mathrm{~W}$ & - & & 348 & 66.7 \\
\hline$p s b \mathrm{X}$ & - & & 120 & 69.2 \\
\hline$p s b \mathrm{Y}$ & - & & 105 & 61.9 \\
\hline$p s b Z$ & - & & 192 & 70.3 \\
\hline$y c f 3$ & - & & 522 & 69.5 \\
\hline$y c f 4$ & - & & 546 & 70.9 \\
\hline$y c f 12$ & - & & 105 & 71.4 \\
\hline$y c f 54$ & - & & 312 & 73.1 \\
\hline$y c f 59^{9}$ & - & & 1050 & 70.6 \\
\hline \multicolumn{5}{|c|}{ Phycobilisome degradation } \\
\hline \multicolumn{5}{|l|}{ protein } \\
\hline$n b l \mathrm{~A}$ & - & & 156 & 77.6 \\
\hline \multicolumn{5}{|c|}{ Protein biosynthesis } \\
\hline $\inf \mathrm{B}$ & - & & 2115 & 71.8 \\
\hline tufA & 1230 & 68.9 & 1227 & 63.8 \\
\hline \multicolumn{5}{|c|}{ Protein chromophore } \\
\hline \multicolumn{5}{|l|}{ linkage } \\
\hline$y c f 17$ & - & & 144 & 66.0 \\
\hline \multicolumn{5}{|c|}{ Protein folding } \\
\hline$d n a \mathrm{~K}$ & 1848 & 70.7 & 1881 & 66.7 \\
\hline \multicolumn{5}{|c|}{ Protein-phycocyanobilin } \\
\hline \multicolumn{5}{|l|}{ linkage } \\
\hline orf149 & - & & 450 & 77.1 \\
\hline
\end{tabular}


$y c f 58$

Protein refolding

groEL

Protein transport

$$
\sec \mathrm{Y}
$$

1212

Proton transport

$\operatorname{cem} \mathrm{A}$

Reductive pentose-

phosphate cycle

$r b c \mathrm{~L}$

$r b c \mathrm{~S}$

this

Regulation of transcription

$$
\begin{aligned}
& d f r \\
& o m p \mathrm{R}^{12,13}
\end{aligned}
$$

Ribonuclease

$r n z$

RNA processing

$$
\text { rne }
$$

Translation

infC
$r p l 1$
$r p l 2$
$r p l 3$
$r p l 4$
$r p l 5$
$r p l 6$
$r p l 9$
$r p l 11$
$r p l 12$
$r p l 13$
$r p l 14$
$r p l 16$
$r p l 18$

525

597

501

504

411

375

405

369

408

315
207

80.7

1593

66.7

76.8

1236

71.0

837

71.9

$1467 \quad 63.4$

$417 \quad 65.2$

$216 \quad 75.5$

$1944 \quad 73.5$

$735 \quad 66.9$

$\begin{array}{llll}684 & 79.1 & 672 & 73.7\end{array}$

$1488 \quad 73.3$

$\begin{array}{lll}77.5 & 543 & 70.9\end{array}$

$\begin{array}{lll}- & 702 & 66.4\end{array}$

$\begin{array}{llll}822 & 67.5 & 828 & 62.8\end{array}$

$633 \quad 74.2 \quad 621 \quad 67.3$

75.9

$651 \quad 72.5$

73.7

540

71.5

72.2

$537 \quad 70.0$

$474 \quad 75.3$

74.7

426

64.8

76.0

396

68.2

76.8

441

71.2

73.2

369

65.0

71.1

405

63.2

77.5

318

70.4 


\begin{tabular}{|c|c|c|c|c|}
\hline rpl19 & 294 & 76.2 & 357 & 74.2 \\
\hline$r p l 20$ & 339 & 74.9 & 345 & 71.9 \\
\hline$r p l 21$ & 339 & 81.1 & 315 & 71.4 \\
\hline$r p l 23$ & 237 & 85.7 & 315 & 73.3 \\
\hline$r p l 24$ & - & & 255 & 74.5 \\
\hline rpl27 & 339 & 81.1 & 255 & 67.8 \\
\hline$r p l 28$ & - & & 192 & 72.9 \\
\hline rpl29 & - & & 201 & 77.6 \\
\hline$r p l 31$ & 219 & 72.6 & 210 & 67.1 \\
\hline rpl32 & 144 & 70.8 & 177 & 68.9 \\
\hline rpl33 & 186 & 80.6 & 201 & 71.1 \\
\hline rpl34 & - & & 138 & 66.7 \\
\hline rpl35 & 195 & 74.4 & 198 & 73.2 \\
\hline rpl36 & 114 & 77.2 & 114 & 67.5 \\
\hline$r p s 1$ & - & & 786 & 72.9 \\
\hline$r p s 2$ & 678 & 74.9 & 684 & 68.1 \\
\hline rps3 & 633 & 74.2 & 654 & 66.5 \\
\hline rps 4 & 615 & 74.3 & 606 & 68.5 \\
\hline$r p s 5$ & 486 & 71.6 & 522 & 67.0 \\
\hline rps 6 & 285 & 79.3 & 312 & 77.2 \\
\hline rps 7 & 462 & 75.5 & 471 & 67.9 \\
\hline$r p s 8$ & - & & 399 & 76.9 \\
\hline$r p s 9$ & 426 & 72.1 & 414 & 64.3 \\
\hline rps 10 & 333 & 77.5 & 312 & 67.0 \\
\hline rps 11 & 363 & 72.2 & 390 & 64.1 \\
\hline rps 12 & 366 & 67.5 & 375 & 64.8 \\
\hline rps 13 & 348 & 76.1 & 381 & 66.7 \\
\hline rps 14 & 294 & 73.5 & 303 & 67.0 \\
\hline rps 16 & 240 & 76.2 & 255 & 72.2 \\
\hline rps 17 & - & & 237 & 72.6 \\
\hline rps 18 & - & & 213 & 71.4 \\
\hline rps19 & 282 & 72.0 & 279 & 70.6 \\
\hline rps 20 & - & & 267 & 74.9 \\
\hline
\end{tabular}




\begin{tabular}{|c|c|c|c|c|}
\hline$y c f 65$ & - & & 300 & 70.7 \\
\hline \multicolumn{5}{|c|}{ Transcription } \\
\hline lys R & - & & 951 & 64.4 \\
\hline$n t c \mathrm{~A}$ & - & & 657 & 78.5 \\
\hline rрoА & 909 & 75.8 & 936 & 67.6 \\
\hline rрoB & 3246 & 73.4 & 3417 & 67.5 \\
\hline rpoC1 & 1785 & 71.3 & 1890 & 66.2 \\
\hline rpo 2 & 3474 & 75.8 & 3657 & 70.0 \\
\hline$y c f 29^{12}$ & - & & 657 & 70.0 \\
\hline$y c f 61$ & - & & 234 & 72.2 \\
\hline \multicolumn{5}{|l|}{ Transport } \\
\hline $\sec \mathrm{A}^{4,5}$ & 2589 & 79.6 & 2640 & 71.7 \\
\hline$y c f 38$ & 846 & 77.2 & 837 & 71.7 \\
\hline$y c f 63$ & - & & 696 & 71.1 \\
\hline \multicolumn{5}{|c|}{ tRNA 5'-leader removal } \\
\hline$r n p \mathrm{~B}$ & - & & 339 & 69.3 \\
\hline \multicolumn{5}{|c|}{ tRNA processing } \\
\hline$y c f 62$ & 963 & 79.8 & 813 & 74.5 \\
\hline \multicolumn{5}{|c|}{ Tryptophan synthase } \\
\hline $\operatorname{trp} \mathrm{A}$ & 783 & 73.9 & 795 & 70.4 \\
\hline \multicolumn{5}{|c|}{ Uncharacterized proteins } \\
\hline orf105 & - & & 318 & 77.4 \\
\hline orf110 & - & & 333 & 71.8 \\
\hline orf151 & 456 & 81.6 & - & \\
\hline orf181 & - & & 546 & 76.2 \\
\hline orf 257 & - & & 774 & 79.6 \\
\hline orf395 & - & & 1188 & 79.2 \\
\hline orf407 & 1224 & 80.8 & - & \\
\hline orf491 & - & & 1476 & 76.5 \\
\hline orf623 & - & & 1872 & 79.3 \\
\hline tat $\mathrm{C}$ & - & & 717 & 74.2 \\
\hline$t s f$ & 501 & 72.9 & 657 & 69.7 \\
\hline$y c f 19$ & 297 & 76.1 & 291 & 74.2 \\
\hline$y c f 20$ & - & & 234 & 67.5 \\
\hline
\end{tabular}




\begin{tabular}{|c|c|c|c|c|}
\hline$y c f 21$ & 528 & 77.8 & 564 & 75.9 \\
\hline$y c f 22$ & - & & 471 & 75.2 \\
\hline$y c f 23$ & - & & 801 & 71.8 \\
\hline$y c f 33$ & - & & 198 & 76.3 \\
\hline$y c f 34$ & - & & 207 & 75.8 \\
\hline$y c f 35$ & - & & 384 & 71.1 \\
\hline$y c f 36$ & - & & 495 & 73.3 \\
\hline$y c f 37$ & - & & 447 & 78.7 \\
\hline$y c f 39$ & - & & 969 & 70.9 \\
\hline$y c f 41$ & - & & 321 & 74.1 \\
\hline$y c f 45$ & - & & 1707 & 67.7 \\
\hline$y c f 46$ & - & & 1467 & 69.9 \\
\hline ycf52 & 540 & 68.7 & 540 & 64.3 \\
\hline$y c f 53$ & - & & 675 & 67.4 \\
\hline$y c f 55$ & - & & 993 & 75.5 \\
\hline$y c f 60$ & - & & 525 & 73.0 \\
\hline \multicolumn{5}{|l|}{ rRNA } \\
\hline rrn5 & - & & 118 & 54.2 \\
\hline $\mathrm{rnl}$ & 2894 & 63.8 & 2866 & 54.3 \\
\hline rns & 1535 & 62.5 & 1475 & 50.3 \\
\hline \multicolumn{5}{|l|}{ tRNA } \\
\hline Ala (TGC) & 74 & 55.4 & 73 & 41.1 \\
\hline $\operatorname{Arg}(\mathrm{ACG})$ & 75 & 57.3 & 74 & 39.2 \\
\hline $\operatorname{Arg}(\mathrm{CCG})$ & - & & 73 & 54.8 \\
\hline $\operatorname{Arg}(\mathrm{CCG})$ & - & & 95 & 42.1 \\
\hline $\operatorname{Arg}(\mathrm{TCT})$ & 75 & 65.3 & 75 & 56.0 \\
\hline Asn (GTT) & 72 & 59.7 & 74 & 48.6 \\
\hline Asp (GTC) & 74 & 60.8 & 74 & 41.9 \\
\hline Cys (GCA) & 72 & 62.5 & 73 & 52.1 \\
\hline Glu (TTC) & 75 & 54.7 & 75 & 42.7 \\
\hline Gln (TTG) & 74 & 59.5 & 74 & 41.9 \\
\hline Gly (GCC) & 73 & 56.2 & 72 & 45.8 \\
\hline Gly (TCC) & 73 & 71.2 & 73 & 50.7 \\
\hline His (GTG) & 75 & 50.7 & 74 & 45.9 \\
\hline
\end{tabular}




\begin{tabular}{|c|c|c|c|c|}
\hline Ile (GAT) & 77 & 62.7 & 74 & 47.3 \\
\hline Leu (CAA) & - & & 82 & 18.0 \\
\hline Leu (TAA) & 82 & 65.9 & 86 & 53.5 \\
\hline Leu (TAG) & 85 & 69.4 & 83 & 53.0 \\
\hline Lys (TTT) & 72 & 56.9 & 72 & 45.8 \\
\hline Met (CAT) & 74 & 47.3 & 74 & 40.5 \\
\hline Met (CAT) & 76 & 69.7 & 74 & 44.6 \\
\hline Met (CAT) & 89 & 48.3 & - & \\
\hline Phe (GAA) & 73 & 54.8 & 73 & 47.9 \\
\hline Pro (TGG) & 76 & 52.6 & 75 & 42.7 \\
\hline Ser (TGA) & 88 & 63.6 & 86 & 50.0 \\
\hline Ser (GCT) & 91 & 71.4 & 90 & 53.3 \\
\hline Thr (GGT) & - & & 74 & 60.8 \\
\hline Thr (TGT) & 75 & 66.7 & 73 & 56.2 \\
\hline $\operatorname{Trp}(\mathrm{CCA})$ & 74 & 73.0 & 75 & 56.0 \\
\hline Tyr (GTA) & 81 & 60.5 & 82 & 39.0 \\
\hline Val (GAC) & - & & 74 & 58.1 \\
\hline Val (TAC) & 74 & 67.6 & 72 & 38.9 \\
\hline
\end{tabular}

${ }^{1}$ Protein chromophore linkage, ${ }^{2}$ Metabolic processes, ${ }^{3}$ Oxidation-reduction processes, ${ }^{4}$ Protein import, ${ }^{5}$ Protein targeting, ${ }^{6}$ Reponse to herbicide, ${ }^{7}$ Catabolic processes, ${ }^{8} \mathrm{Cell}$ redox homeostasis, ${ }^{9}$ Biosynthetic processes, ${ }^{10} \mathrm{Heme}$ oxidation, ${ }^{11}$ Respiratory electron transport chain, ${ }^{12}$ Signal transduction system, ${ }^{13}$ Transcription 


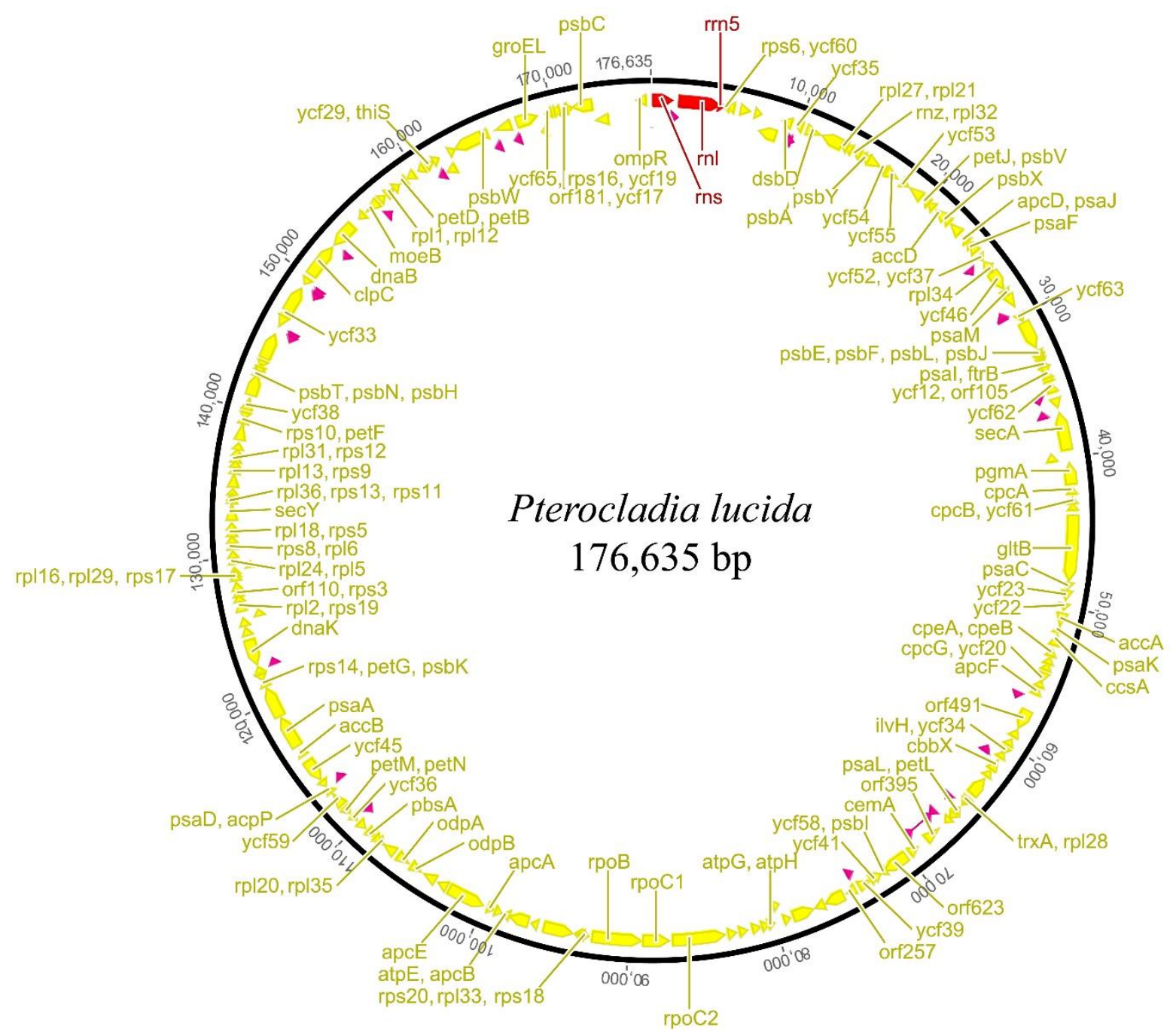

Appendix 5.3. The plastid genome of Pterocladia lucida with 200 protein coding genes (yellow), three rRNA's (red) and 30 tRNA's (pink). 


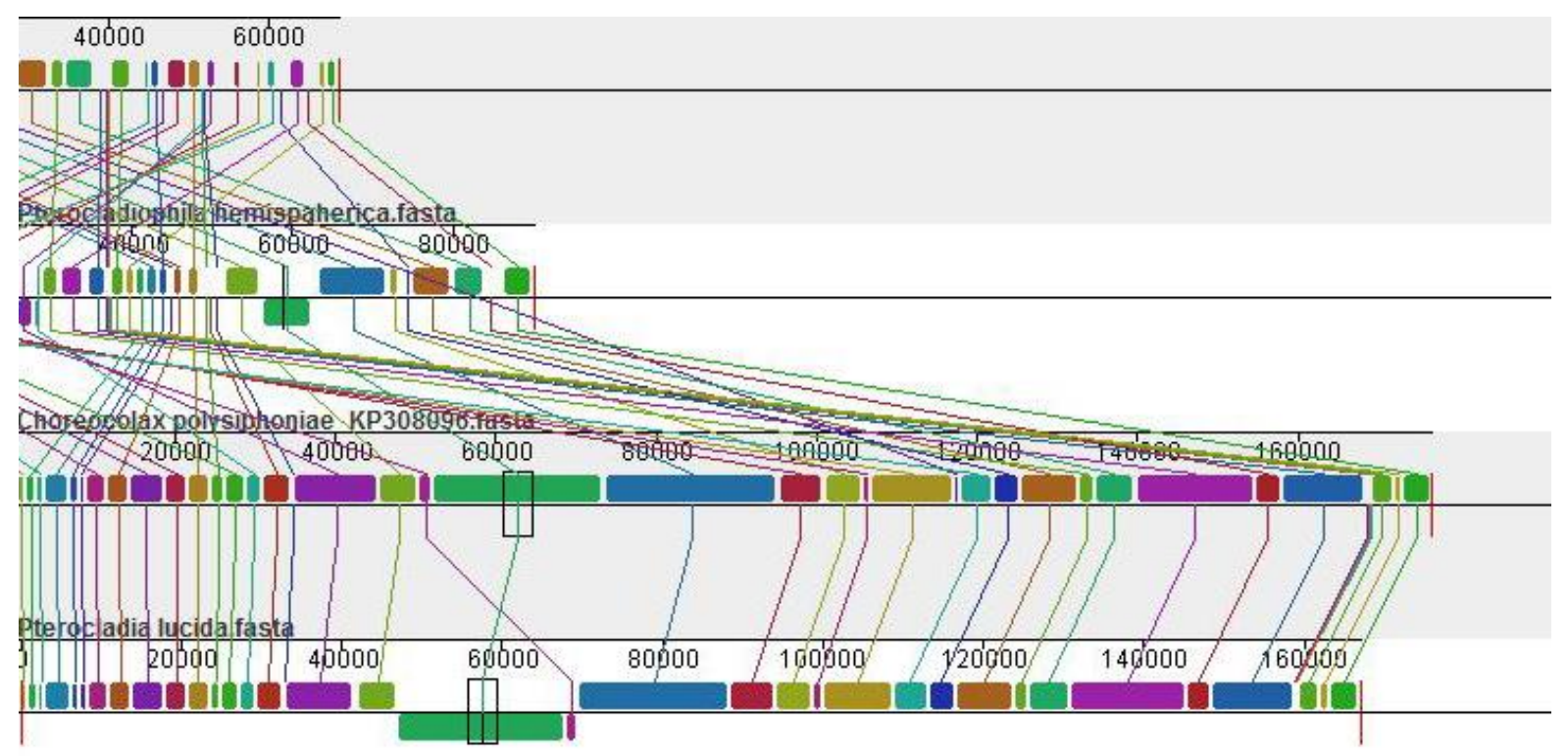

Vertebrata lanosa KP308097.fasta

Appendix 5.4. Progressive Mauve alignment of Pterocladiophila hemisphaerica, its host Pterocladia lucida, the parasite Choreocolax polysiphoniae and its host Vertebrata lanosa. The parasites show highly reduced organelle genomes. 


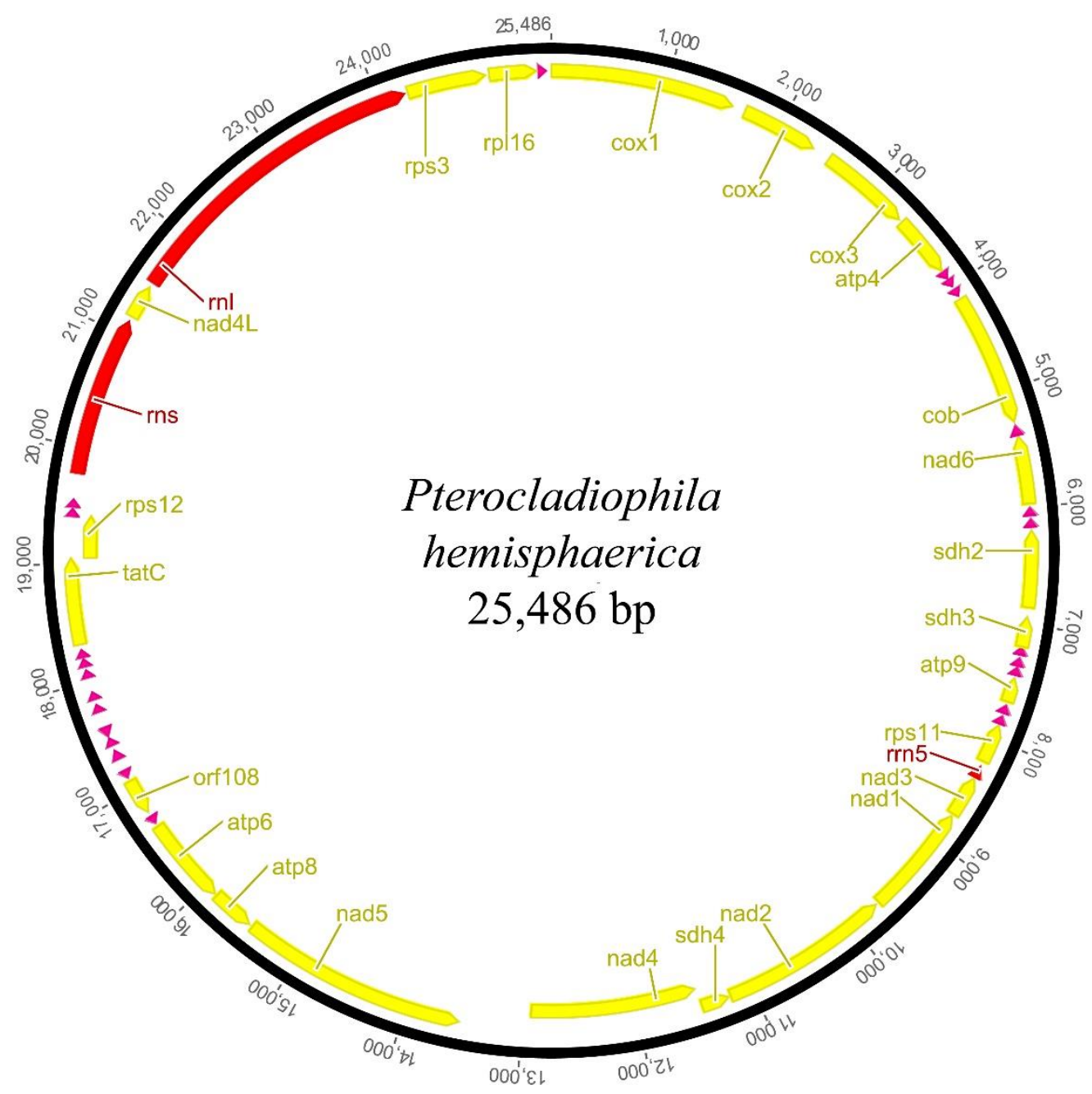

Appendix 5.5. The mitochondrial genome of the parasite Pterocladiophila hemisphaerica with 24 protein coding genes (yellow), three rRNA's (red) and 24 tRNA's (pink). 


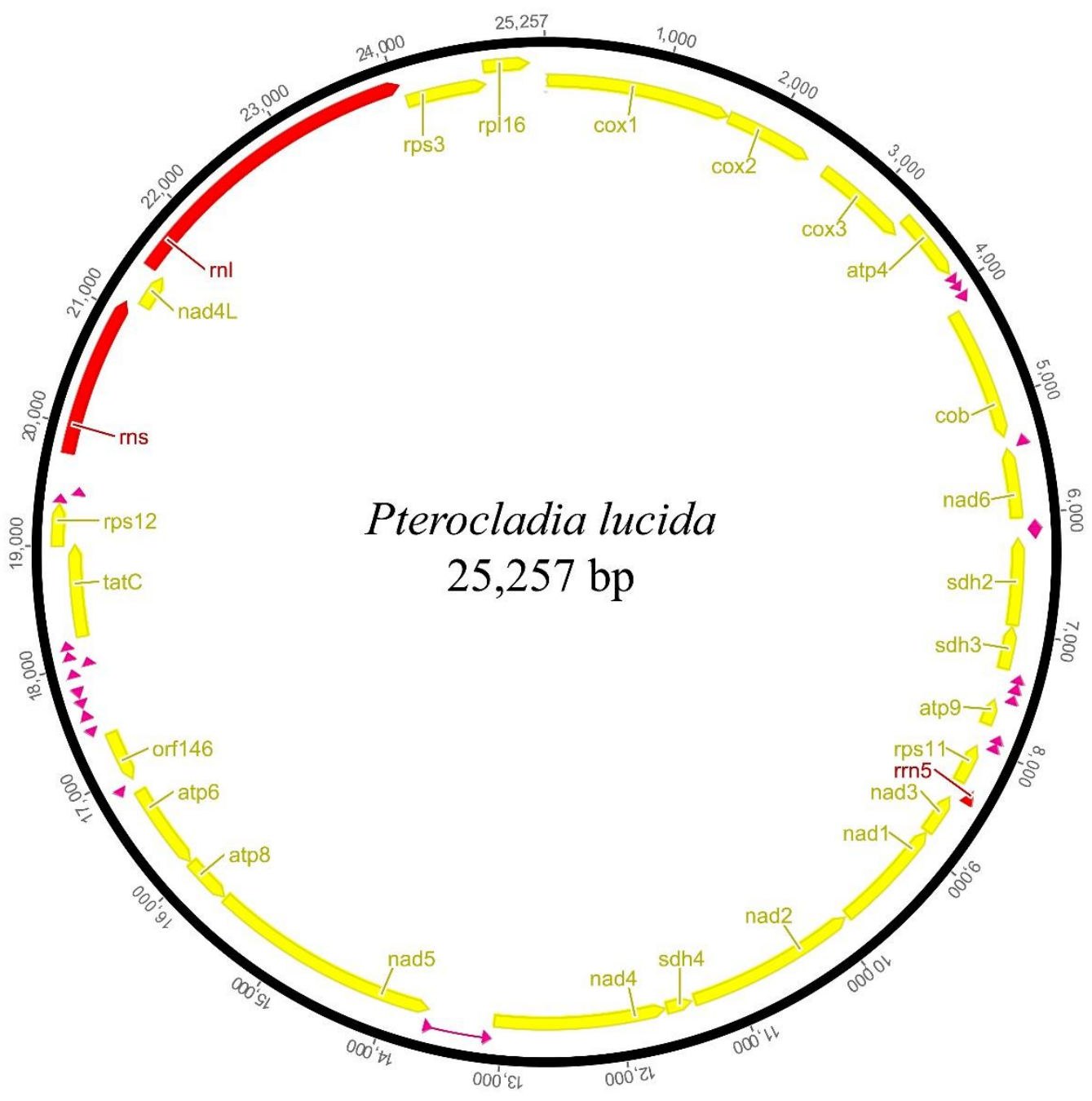

Appendix 5.6. The mitochondrial genome of Pterocladia lucida with 24 protein coding genes (yellow), three rRNA's (red) and 23 tRNA's (pink). 
Appendix 5.7. Mitochondrial protein coding genes, tRNA and rRNA in alphabetical order by functional group with gene length in bp and AT content in percentage in Pterocladiophila hemisphaerica and Pterocladia lucida.

\section{Pterocladiophila hemisphaerica Pterocladia lucida}

Length (bp) AT content Length AT content
$(\%)$
(bp)
$(\%)$

\section{Protein coding genes}

ATP synthesis coupled

proton transport

$\begin{array}{lllll}\text { atp4 } & 543 & 89.1 & 600 & 79.2 \\ \text { atp6 } & 762 & 77.6 & 759 & 70.4 \\ \text { atp8 } & 384 & 84.9 & 414 & 75.6 \\ \text { atp9 } & 1 & 68.4 & 231 & 64.9 \\ \text { nad1 } & 231 & 75.5 & 984 & 69.9 \\ \text { nad2 } & 975 & 81.8 & 1482 & 73.9 \\ \text { nad3 } & 1482 & 77.6 & 366 & 71.9 \\ \text { nad4 } & 366 & 77.9 & 1479 & 70.7 \\ \text { nad4L } & 1479 & 79.7 & 306 & 72.2 \\ \text { nad5 } & 306 & 76.7 & 1995 & 69.2 \\ \text { nad6 } & 1962 & 82.4 & 609 & 73.7\end{array}$

Electron transport chain

$\begin{array}{lllll}\operatorname{cob} & 1152 & 76.0 & 1143 & 69.5 \\ \operatorname{cox} 1^{2,3} & 1578 & 70.7 & 1599 & 65.9 \\ \operatorname{cox} 2 & 672 & 75.1 & 777 & 68.7 \\ \operatorname{cox} 3 & 810 & 75.3 & 819 & 65.5\end{array}$

Translation

$\begin{array}{lllll}\text { rpl16 } & 417 & 83.2 & 399 & 71.4 \\ r p s 3 & 693 & 82.4 & 702 & 74.1 \\ r p s 11 & 357 & 81.2 & 354 & 77.1 \\ r p s 12 & 384 & 70.8 & 366 & 70.4\end{array}$

Tricarboxylic acid cycle

$\begin{array}{lllll}s d h 2 & 675 & 77.8 & 750 & 70.9 \\ s d h 3 & 273 & 83.9 & 369 & 76.7 \\ s d h 4 & 246 & 87.0 & 243 & 77.4\end{array}$

Uncharacterized protein 


\begin{tabular}{|c|c|c|c|c|}
\hline tatC & 744 & 86.6 & 810 & 76.9 \\
\hline ORF108 & 327 & 84.1 & & \\
\hline ORF146 & - & & 441 & 76.2 \\
\hline \multicolumn{5}{|l|}{ rRNA } \\
\hline $\mathrm{rnl}$ & 2726 & 76.2 & 2591 & 70.6 \\
\hline rns & 1380 & 71.7 & 1353 & 65.0 \\
\hline $\operatorname{rrn} 5$ & 115 & 79.1 & 120 & 76.7 \\
\hline \multicolumn{5}{|l|}{ tRNA } \\
\hline Ala (TGC) & 74 & 71.6 & 76 & 67.1 \\
\hline Asn (GTT) & - & & 75 & 60.0 \\
\hline $\operatorname{Arg}(\mathrm{ACG})$ & 75 & 70.7 & 76 & 68.4 \\
\hline \multirow[t]{2}{*}{$\operatorname{Arg}(\mathrm{TCT})$} & 76 & 73.7 & 74 & 68.9 \\
\hline & 76 & 73.7 & - & \\
\hline Cys (GCA) & 73 & 71.2 & 71 & 64.8 \\
\hline Gln (TTG) & 76 & 65.8 & 72 & 58.3 \\
\hline Glu (TTC) & 74 & 68.7 & 74 & 60.8 \\
\hline Gly (GCC) & 74 & 66.2 & 75 & 60.0 \\
\hline Gly (TCC) & 77 & 71.4 & 75 & 58.7 \\
\hline His (GTG) & 75 & 64.0 & 75 & 49.3 \\
\hline Ile (GAT) & - & & 73 & 57.5 \\
\hline Leu (TAA) & 84 & 66.7 & 86 & 58.1 \\
\hline Leu (TAG) & 83 & 73.5 & 84 & 65.5 \\
\hline Lys (TTT) & 77 & 72.7 & 75 & 69.3 \\
\hline \multirow[t]{2}{*}{ Met (CAT) } & 71 & 71.8 & 75 & 61.3 \\
\hline & 74 & 70.3 & 73 & 64.4 \\
\hline Phe (GAA) & 74 & 68.9 & 73 & 54.8 \\
\hline Pro (TGG) & 74 & 64.9 & 75 & 61.3 \\
\hline $\mathrm{SeC}$ (TCA) & 76 & 64.5 & 75 & 56.0 \\
\hline Ser (TGA) & 85 & 70.6 & 84 & 64.3 \\
\hline Ser (GCT) & 90 & 64.4 & 86 & 58.1 \\
\hline \multirow[t]{2}{*}{ Tyr (GTA) } & 87 & 65.5 & 84 & 61.9 \\
\hline & 87 & 65.5 & - & \\
\hline Val (GTC) & 74 & 59.5 & - & \\
\hline Val (TAC) & 72 & 70.8 & 73 & 71.2 \\
\hline
\end{tabular}




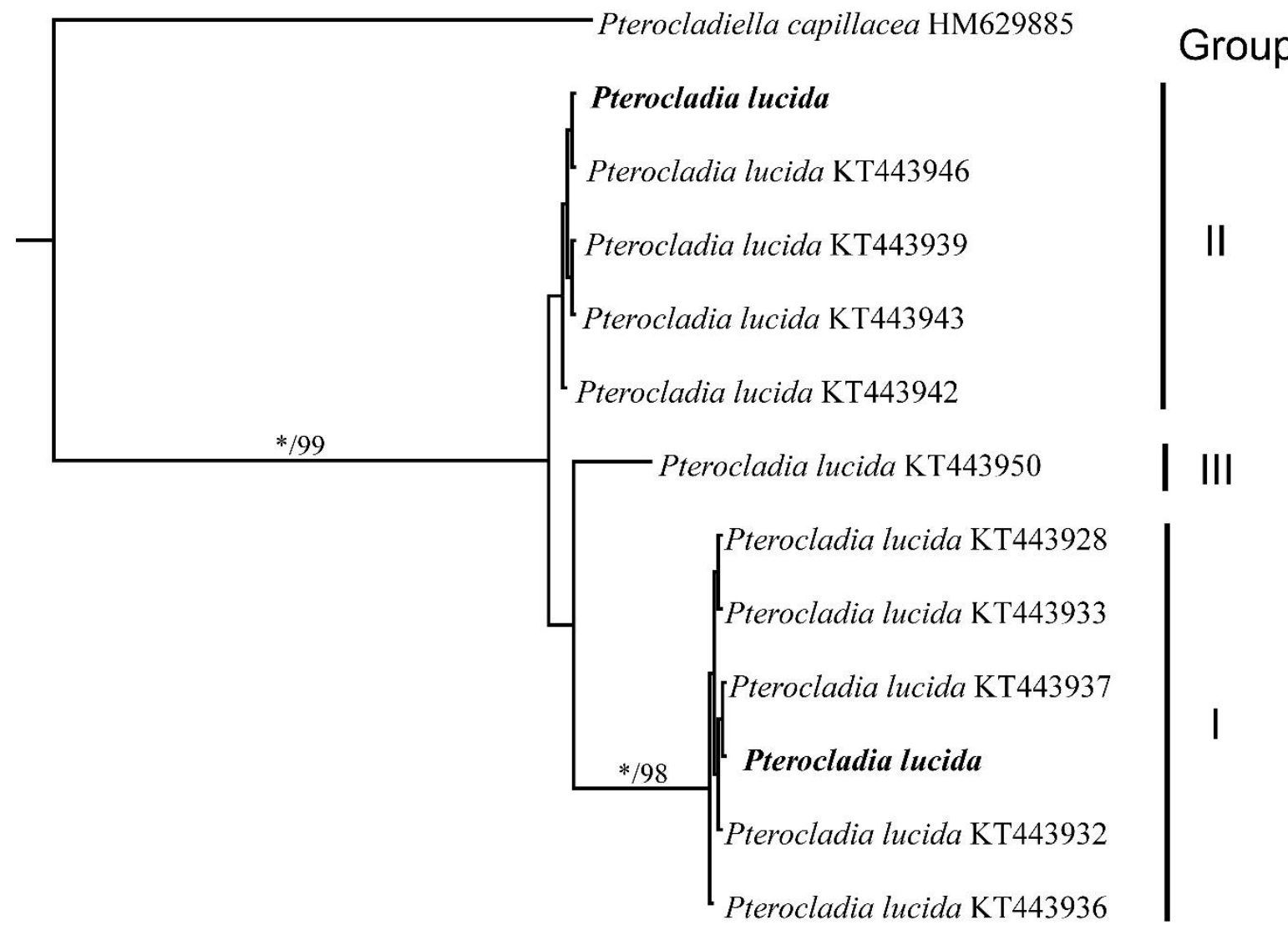

Appendix 5.8. Bayesian topology of partial cox 1 of two Pterocladia lucida samples infected with Pterocladiophila hemisphaerica, plus representatives of the three cryptic species of Pterocladia lucida and Pterocladiella capillacea with GenBank Accession numbers (Appendix 5.1). Outgroups Gelidiella acerosa and Gelidium pacificum were removed to facilitate presentation. Asterisks indicate posterior probability value of 1.00 / ultrafast bootstrap values of $100 \%$. Values $<0.85$ posterior probability and $<85 \%$ ultrafast ML bootstrap not shown. 
Appendix 6.1. Measurements of $\Delta \mathrm{F} / \mathrm{Fm}$ ' (Day 0, 0h and Day 1, 2-8h) and Fv/Fm (Day1, 0h) in three parasites (Rhodophyllis parasitica, Vertebrata aterrimophila, Pterocladiophila hemisphaerica) and their hosts (Rhodophyllis membranacea, Vertebrata aterrima, Pterocladia lucida).

\begin{tabular}{lllllll}
\hline & $\begin{array}{l}\text { Day 0 } \\
(0 \mathrm{~h})\end{array}$ & $\begin{array}{l}\text { Day 1 } \\
(0 \mathrm{~h})\end{array}$ & $\begin{array}{l}\text { Day 1 } \\
(2 \mathrm{~h})\end{array}$ & $\begin{array}{l}\text { Day 1 } \\
(4 \mathrm{~h})\end{array}$ & $\begin{array}{l}\text { Day 1 } \\
(6 \mathrm{~h})\end{array}$ & $\begin{array}{l}\text { Day 1 } \\
(8 \mathrm{~h})\end{array}$ \\
\hline Rhodophyllis & 0 & 0 & 0 & 0 & 0 & 0 \\
parasitica & 0 & 0 & 0 & 0 & 0 & 0 \\
Rhodophyllis & 0 & 0 & 0 & 0 & 0 & 0 \\
membrancaea & 0.408 & 0.173 & 0.369 & 0.258 & 0.280 & 0.314 \\
& 0.462 & 0.333 & 0.367 & 0.152 & 0.445 & 0.446 \\
Vertebrata & 0 & 0.337 & 0.344 & 0.460 & 0.429 & 0.451 \\
aterrimophila & 0 & 0 & 0 & 0 & 0 & 0 \\
& 0 & 0 & 0 & 0 & 0 & 0 \\
Vertebrata & 0.405 & 0.345 & 0.381 & 0.280 & 0.693 & 0.252 \\
aterrima & 0.413 & 0.225 & 0.255 & 0.389 & 0.328 & 0.240 \\
& 0.235 & 0.104 & 0.302 & 0.262 & 0.238 & 0.256 \\
Pterocladiophila & 0.370 & 0.308 & 0.187 & 0.212 & 0.231 & 0.247 \\
hemisphaerica & 0.350 & 0.379 & 0.359 & 0.344 & 0.354 & 0.295 \\
& 0.376 & 0.374 & 0.267 & 0.221 & 0.335 & 0.271 \\
Pterocladia & 0.462 & 0.326 & 0.321 & 0.352 & 0.152 & 0.227 \\
lucida & 0.383 & 0.332 & 0.324 & 0.262 & 0.386 & 0.272 \\
& 0.504 & 0.424 & 0.341 & 0.261 & 0.310 & 0.339 \\
\hline
\end{tabular}

